\title{
IMPACTO DEL USO E INCORPORACIÓN DE UNA WIKI EN EL APRENDIZAJE DE LA BIOLOGÍA
}

\author{
Sonia Elena Vela Vargas
}

Trabajo de grado para optar al título de:

Magister en tecnología educativa y medios innovadores para la educación

Mtra. Carmen Medina Almeida

Asesor tutor

Dr. José Antonio Rodríguez Arroyo

Asesor titular

TECNOLÓGICO DE MONTERREY

Escuela de Graduados en Educación

Monterrey, Nuevo León. México

UNIVERSIDAD AUTÓNOMA DE BUCARAMANGA

Facultad de Educación

Bucaramanga, Santander. Colombia 


\section{Dedicatorias}

A Dios, eje motor de toda esencia porque en este camino fue grande su presencia.

A la memoria de mis padres, Ana Rosa Vargas y Julio Roberto Vela, porque siempre creyeron en mí. A pesar de las dificultades colocaron en primer plano mi educación y siempre con su comprensión, amor y apoyo, me mostraron que la voluntad y perseverancia mueven montañas.

A mi compañero de vida, Jaime Ocampo, por estar a mi lado y apoyarme. A mis hermanos, Yatnet, Jaime, Jhon, Julio, Andrés y a mi tía Margarita, mis angelitos, mis guías, que junto a mis cuñadas Liliana y Estela, siempre me animaron y ayudaron en este proceso. A todos gracias por confiar en mí, por su amor y comprensión.

A mis muy queridos y amados sobrinos, Aleja, Sofía y Jaimito, que son una constante chispa de energía en este recorrido de mi vida. Espero que en un futuro, este logro se convierta en un ejemplo para ellos, de que toda lucha y sacrifico académico en pro de ser mejores seres humanos y servir de mejor manera a otros, vale la pena. 


\section{Agradecimientos}

A la Maestra Carmen Medina Almeida, asesora de esta investigación, por su incalculable aporte académico y humano. Su sabiduría, dedicación, comprensión y paciencia guiaron este proceso de aprendizaje y permitieron llevarlo a buen término.

Al Dr. José Antonio Rodríguez Arroyo, titular de la línea de investigación, por el apoyo desde su experiencia y conocimiento.

A los docentes de la Maestría en Tecnología Educativa, por compartir sus conocimientos y ser guías en todo este ciclo educativo.

A los estudiantes de octavo grado, sus docentes titulares en el área de Biología, el docente administrador de la sala de sistemas y los directivos de la Institución Educativa Belisario Peña Piñeiro, por facilitar las instalaciones y hacer posible el desarrollo de esta indagación.

A mi amiga y Maestra Marta Lucía Valderrama por sus consejos y orientaciones para el desarrollo de este proyecto. 


\section{Impacto del uso e incorporación de una wiki en el aprendizaje de la}

\section{Biología}

\section{Resumen}

El presente estudio fue desarrollado con el objetivo de conocer el impacto del uso e incorporación de una wiki en el aprendizaje de la Biología. Lo anterior, como una forma de buscar estrategias que puedan contribuir con el mejoramiento del desempeño académico de los estudiantes de octavo grado de una secundaria colombiana en el área de Biología y que a su vez, logren incentivar el interés, atención y participación de los alumnos en estas clases. El enfoque metodológico utilizado correspondió a los métodos mixtos con un diseño exploratorio secuencial en modalidad comparativa y los instrumentos empleados en la recolección de datos fueron: la observación no participante y la entrevista semiestructurada, para la fase cualitativa. La preprueba, posprueba y encuesta a los alumnos del grupo experimental se aplicaron para la fase cuantitativa. De esta manera, el análisis de la información obtenida en este estudio permitió evidenciar, que el uso e incorporación de una wiki ayudó a modificar el rol del docente y las interacciones de los alumnos, de tal forma que se logró transformar la enseñanza tradicional de las clases y promover el trabajo cooperativo, lo cual, también motivó a los aprendices a interactuar activamente entre ellos mismos, incluso con respeto, tolerancia, ayuda mutua y solidaridad. Igualmente, se detectó el agrado que sintieron al estudiar Biología con este tipo de apoyo tecnológico y el incremento en la participación e interés en las clases, además de la mejoría en su rendimiento académico, 
después del uso de la wiki. Se concluyó el estudio con propuestas para mejorar la práctica docente en el colegio colombiano. 


\section{Índice}

Resumen................................................................iv

1. Planteamiento del problema.......................................1

1.1 Antecedentes........................................................

1.2 Definición del problema de investigación................................6

1.3 Objetivos........................................................... 10

1.3.1 Objetivo general...............................................10

1.3 .2 Objetivos específicos...................................... 10

1.4 Hipótesis ............................................................ 11

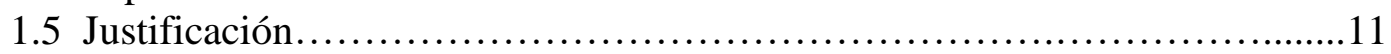

1.6 Delimitación del estudio.................................................. 13

1.7.Definición de términos............................................. 14

2. Marco teórico......................................................18

2.1. Los entornos virtuales para el aprendizaje de las ciencias naturales.........19

2.1.1. Uso de las wikis en el nivel de secundaria........................24

2.1.2. Interacción social a través de las wikis............................30

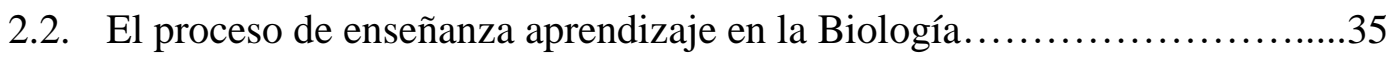

2.2.1. El aprendizaje cooperativo en alumnos de secundaria..............42

2.2.2. La autogestión del aprendizaje......................................47

2.3. Investigaciones sobre el uso de las wikis y el aprendizaje de la Biología....49

3. Método..................................................................60

3.1. Enfoque metodológico de la investigación..............................60

3.2. Población, participantes y selección de la muestra................................66

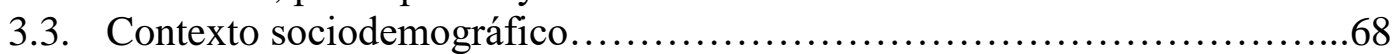

3.4. Instrumentos de recolección de datos................................72

3.5. Procedimiento para la aplicación de instrumentos.........................79

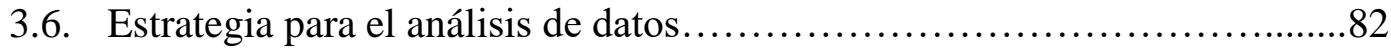

4. Análisis y discusión de resultados....................................85

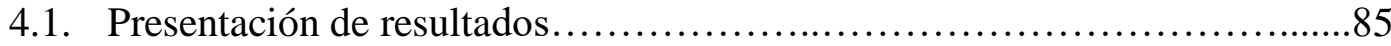

4.1.1. Fase cualitativa............................................... 87

4.1.1.1. Categorización de la observación no participante para el grupo

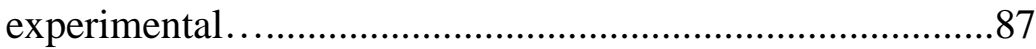

4.1.1.2. Categorización de la entrevista semiestructurada con el titular del grupo experimental...................................................93 
4.1.2. Fase cuantitativa ............................................. 101

4.1.2.1. Resultados de la preprueba para los grupos de octavo grado

4.1.2.2. Resultados de la posprueba para los grupos de octavo grado

4.1.2.3. Resultados de la encuesta aplicada a los alumnos del grupo

Experimental

4.2.Análisis e interpretación

5. Conclusiones...........................................................129

5.1. Resumen de los principales hallazgos de la investigación....................129

5.2. Sugerencias de estudios futuros..........................................134

5.3. Propuestas para mejorar la práctica docente..............................137

Referencias

Apéndices

Apéndice A: Carta de consentimiento para la institución educativa.

Apéndice B: Antecedente del bajo desempeño académico de los alumnos en la Prueba Saber - área de ciencias naturales........................152

Apéndice C: Guía de observación no participante para el grupo experimental....153

Apéndice D: Guía de entrevista semiestructurada para el titular del grupo experimental.......................................................156

Apéndice E: Encuesta para los estudiantes que utilizaron la wiki..............158

Apéndice F: Preprueba de Biología para los alumnos de octavo grado............161

Apéndice G: Posprueba de Biología para los alumnos de octavo grado.

Apéndice H: Actividades cooperativas para realizar en la wiki....................169

Apéndice I: Rúbrica para evaluar el desempeño de los alumnos con la wiki......171

Apéndice J: Libro de códigos de la encuesta para los alumnos...................173

Apéndice K: Transcripciones de las clases observadas.........................176

Apéndice L: Transcripción de la entrevista con el titular del grupo

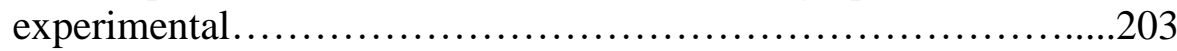

Apéndice .M: Evidencias fotográficas del trabajo de campo...................217

Apéndice N: Resultados estadísticos de la encuesta - datos aclaratorios.........221

Apéndice O: Datos aclaratorios de los resultados de la preprueba.................226

Apéndice P: Datos aclaratorios de los resultados de la posprueba................227

Apéndice Q: Datos aclaratorios de los resultados de la prueba t.................228

Apéndice R: Evidencias del trabajo realizado con la wiki.....................230 


\section{Índice de tablas}

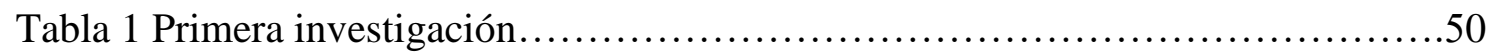

Tabla 2.Segunda investigación............................................... 51

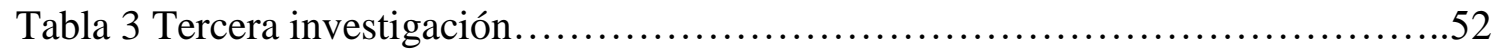

Tabla 4 Cuarta investigación........................................................53

Tabla 5 Quinta investigación..................................................54

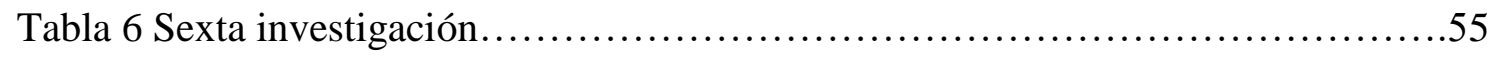

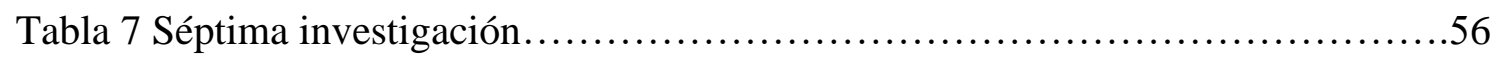

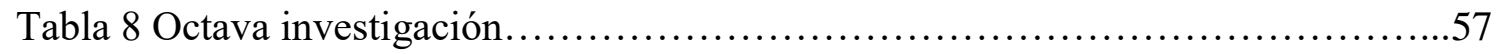

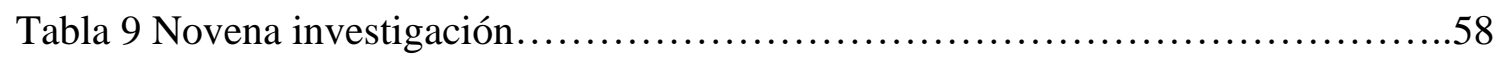

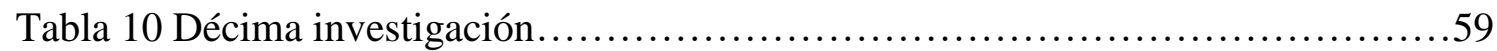

Tabla 11 Resultados comparativos de las pruebas saber para el área de ciencias naturales.............................................................. 71

Tabla 12 Categorías consideradas en la guía de observación para la recolección de

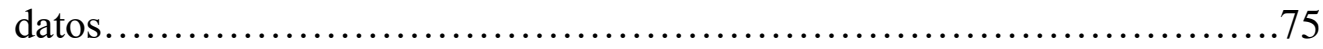

Tabla 13 Categorías emergentes derivadas de las observaciones no participantes en el grupo 8 -1 (ONP-GE) .............................................. 88

Tabla 14 Categorías emergentes de la entrevista al maestro titular del grupo

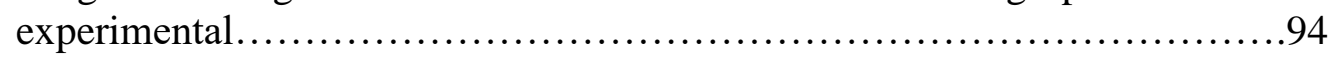

Tabla 15 Contenido temático de la preprueba y posprueba para el octavo grado........102

Tabla 16 Niveles de desempeño de la preprueba...................................103

Tabla 17 Distribución de frecuencias de la preprueba en el grupo experimental (8-1).104

Tabla 18 Distribución de frecuencias de la preprueba en el grupo de control (8-2)......104 
Tabla 19 Resultados comparativos de la preprueba en el grupo experimental y de control........................................................105

Tabla 20 Niveles de desempeño de la posprueba..............................106

Tabla 21 Distribución de frecuencias de la posprueba en el grupo experimental.......107

Tabla 22 Distribución de frecuencias de la posprueba en el grupo de control...........107

Tabla 23 Resultados comparativos de la posprueba en el grupo experimental y de control............................................................ 108

Tabla 24 Distribución de frecuencias correspondiente a la encuesta aplicada al grupo experimental.....................................................110

Tabla 25 Resultados comparativos (prueba $t$ ) de la posprueba en el grupo experimental y de control....................................................... 127 


\section{Planteamiento del problema}

En este capítulo se presentan los argumentos que sustentan el origen y justificación de la problemática objeto de esta indagación, donde se consideró el uso e incorporación de un Ambiente Virtual de Aprendizaje, como estrategia para mejorar el aprendizaje de la Biología. Asimismo, en este capítulo se mencionan algunos aportes empíricos previos y relacionados con el objeto de estudio; se define el planteamiento del problema a través de una pregunta general de investigación, además de las interrogantes derivadas de la misma. También se incluyen las hipótesis que guiaron el desarrollo del estudio, así como sus alcances y la delimitación del proyecto desarrollado en una secundaria pública colombiana.

\subsection{Antecedentes}

Debido a que los sistemas biológicos son tan complejos y diversos, no es de extrañar las dificultades que tienen los estudiantes para comprenderlos y asimilarlos, máxime cuando es común encontrar disparidades en la definición y conceptualización de algunos términos por parte de las comunidades académico-científicas. Ejemplo de esto es la división de criterios que pueden estudiarse con respecto al concepto de especie y población, entre otras (Mayr, 2006).

De esta manera, los procesos de enseñanza aprendizaje en la Biología enfrentan el reto de superar estas barreras, de conocer y razonar de manera crítica sobre aquellos avances que surgen continuamente en el mundo moderno, a través de los grandes 
descubrimientos de la ciencia en campos como la Medicina, la Genética, la Biología molecular, que traspasan la capacidad de asombro. Esto exige dinamizar o enriquecer los procesos educativos, para dar mayor protagonismo a los estudiantes e incrementar la posibilidad de interacción con los docentes, con el fin de lograr un desarrollo integral y una construcción social del conocimiento (López, 2013). No obstante, se debe recordar que las tecnologías, como mediadores del aprendizaje tienen repercusiones en las prácticas educativas y según su uso e incorporación en el aula pueden o no, llegar a favorecerlas. Finalmente, puede afirmarse que no se trata de una moda, su uso debe considerar la orientación particular de la materia, así como el perfil de los alumnos.

En este sentido, Sardá y Sanmartí (2000) indican que generar actividades cooperativas a partir de un Ambiente Virtual de Aprendizaje (en adelante AVA) como una wiki, contribuye al aprendizaje de las ciencias de manera agradable y significativa, porque los estudiantes hablan y escriben ciencia de una forma diferente a la tradicional. De lo anterior, puede inferirse que una forma que tienen los docentes de secundaria para innovar en la didáctica de las ciencias, es a partir de la planificación e implementación de metodologías colaborativas, con apoyo de recursos tecnológicos; lo que además, puede favorecer el éxito escolar.

Al respecto, Manzano (2011) realiza un estudio de tipo cualitativo acerca de la utilización de las wikis en tareas educativas a nivel de secundaria. Considera este recurso como un instrumento de mediación didáctica que tiene un gran valor educativo, porque permite la construcción social del conocimiento además plantea nuevas formas de trabajar y aprender en el aula. Señala que es uno de los desarrollos tecnológicos que mejor simboliza la cultura en línea y la pedagogía interactiva, que conduce a una 
filosofía de la acción participativa. Puede afirmarse que la interacción entre los alumnos y con el docente, así como con el apoyo tecnológico, constituye la base del aprendizaje, pues ninguna persona aprende bajo una condición de aislamiento.

Por otra parte, la investigación mixta de Chu, Siu, Liang, Capio, y Wendy (2013), aborda las experiencias y percepciones de los estudiantes de educación superior, sobre el uso de dos wikis para el aprendizaje colaborativo y la gestión del conocimiento. Indicaron que ambas wikis, fueron vistas como instrumentos adecuados para desarrollar trabajos de equipo, que mejoraron la colaboración y la calidad del mismo. Esto le permitió al investigador, sugerir que las wikis podrían ser usadas en cualquier nivel educativo y para cualquier área del conocimiento, con buenas perspectivas para favorecer el aprendizaje en los alumnos. Sin embargo, en el estudio fue difícil determinar qué tipo de wiki debe ser implementada, o los usos específicos más beneficiosos para los alumnos.

Asimismo, el trabajo de Villarroel (2007) explica una experiencia didáctica en la que se recurre a una wiki como apoyo tecnológico para mejorar la predisposición de los alumnos frente al concepto de energía, en la asignatura de Física. En general el alumnado respondió con interés y agrado hacia la propuesta de uso e incorporación del AVA, a pesar de que el contenido temático abordado, habitualmente era el de mayor dificultad. El autor también observó que la actividad realizada en la wiki le otorgó significatividad a los conceptos o contenidos teóricos, que de otra manera resultaban incomprensibles.

A partir del estudio de Suárez (2010), basado en el paradigma cualitativo, donde se buscó profundizar el conocimiento de la interacción cooperativa en equipos de 
aprendizaje bajo condiciones tecnológicas de mediación asíncrona escrita, y también según Becerra (2010), que estudió interacciones en línea y su relación con la construcción del conocimiento, puede afirmarse que los alumnos aprenden debido al intercambio de ideas y al apoyo que reciben por parte de los compañeros y la retroalimentación del docente. Lo anterior, ocurre gracias al diálogo y comunicación que se genera entorno a la interacción social en espacios de aprendizaje virtual. Acorde con todo lo señalado, puede afirmarse que la interacción social que se promueve a través de las wikis, favorece el desarrollo de las siguientes competencias específicas en Biología, exigidas por el Ministerio de Educación Nacional de Colombia:

- Comunicar, considerada como la capacidad para escuchar, plantear puntos de vista y compartir conocimiento.

- Trabajo en equipo, entendida como la capacidad para interactuar productivamente asumiendo compromisos.

- Disposición para reconocer la dimensión social del conocimiento y para asumirla responsablemente (Becerra, 2010; Suárez, 2010).

De igual manera, DeWitt, Siraj y Alias (2014), consideran en su investigación de carácter cualitativo que en la educación secundaria, la instrucción debe centrarse en técnicas y procedimientos diseñados, a partir de las interacciones sociales, para que los estudiantes de ciencias naturales, sean capaces de comunicarse socialmente sobre aspectos relacionados con la ciencia, en este caso particular compartir conocimientos sobre un tema tratado en la clase de Biología, como la nutrición De esta manera, lograr que se apropien del vocabulario y la estructura del lenguaje científico a través de las 
interacciones con los contenidos del curso y también con sus compañeros, mediante actividades cooperativas. Bajo estas circunstancias, estos últimos son considerados como andamios para la construcción social del conocimiento. Lo anteriormente expuesto, refuerza la idea de que el aprendizaje cooperativo y las interacciones a través de una wiki, promueven el desarrollo del pensamiento crítico y mejoran la disposición para aceptar, la naturaleza abierta, parcial y cambiante del conocimiento. Competencias específicas de las ciencias naturales, como la Biología que es objeto de este estudio.

Los estudios anteriores, muestran las nuevas posibilidades a nivel didáctico que ofrecen los AVA como apoyos tecnológicos, orientados a mejorar la actitud de los estudiantes hacia las asignaturas científicas y también para facilitar el aprendizaje y mejorar el desempeño académico. Esta cuestión, puede convertirse en una alternativa para favorecer los actuales procesos de enseñanza aprendizaje desarrollados en una básica secundaria ubicada en el Municipio de Roldanillo en el Departamento del Valle del Cauca en Colombia, donde es frecuente observar el bajo rendimiento académico de los alumnos en el área de ciencias naturales y particularmente, en la enseñanza de la Biología. También podría ayudar con su falta de interés en los contenidos teóricos de las clases magistrales y con la dificultad en la comprensión y aprehensión de los conceptos científicos.

Por otra parte, se advierte que las ideas preconcebidas sobre los fenómenos naturales y las actitudes que los alumnos asumen hacia el aprendizaje de estos, sumado a las problemáticas sociales (narcotráfico, drogadicción, violencia intrafamiliar, delincuencia) propias de la región, cada vez tienen mayor impacto sobre la comunidad educativa, lo que implica que los docentes deben incrementar los esfuerzos por cambiar 
las prácticas tradicionalistas y buscar nuevas estrategias que les permitan desarrollar las competencias básicas o disciplinares, vinculadas a las ciencias naturales de una forma agradable y motivadora para los estudiantes. Es importante cambiar la concepción de recurrir a técnicas de enseñanza que solo se orientan hacia la aprobación de una materia, la memorización de conceptos, sin importar el dominio de los mismos, comprensión y aplicación de los conceptos, así como el logro de aprendizajes significativos.

Igualmente, no se puede olvidar que la concepción acerca de la imagen de las ciencias concebida por los estudiantes, está definida no sólo por la forma en que el docente aborda los conocimientos teóricos, sino también por cómo implementa las estrategias de enseñanza-aprendizaje. Asimismo, de gran importancia es el componente afectivo y comunicacional que se desarrolla en el aula de clase. De allí, que los AVA resulten buenos mediadores para la generación de interacciones sociales, enriquecidas, constantes y sin barreras geográficas, ni limitaciones de tiempo.

\subsection{Definición del problema de investigación}

La actual sociedad del conocimiento, exige que los procesos de enseñanza aprendizaje de las diferentes instituciones educativas de básica secundaria y nivel medio, se aproximen cada vez más a la idea del aprendizaje como una acción que se desarrolla durante toda la vida y donde el estudiante debe ser capaz de manipular el conocimiento, de comprender lo que aprende, transformarlo y adaptarlo a diferentes situaciones o contextos, para poder elegir lo que es adecuado para él (Fernández, 2005). En este sentido, el Ministerio de Educación Nacional de Colombia (en adelante MEN), ha establecido unos lineamientos y estándares de competencias, como referentes para 
evaluar los niveles de desempeño que deben alcanzar los estudiantes durante cada grado escolar y en las diferentes áreas del saber, con el fin de desarrollar habilidades, aptitudes y valores para usar el conocimiento que se construye de forma individual y colectiva, en situaciones diferentes a aquellas donde fueron aprendidas, es decir, en su futuro desempeño profesional.

Lo anterior, no se desvincula de los contenidos temáticos, propios de cada asignatura, debido a que para el ejercicio de cada competencia es necesario su dominio o calidad de experto, conforme a un determinado nivel de desempeño. De tal manera que en la enseñanza de la Biología, se puede encontrar una diversidad de temas que tienen una estructura específica y que establecen exigencias teóricas y conceptuales para los estudiantes, pero que también contribuyen al desarrollo de las competencias instrumentales, interpersonales, o relacionales (López, 2013). Asimismo, puede afirmarse que estas competencias son la base para el desarrollo de las competencias específicas o propias de las ciencias, tales como, el desarrollo de proyectos investigación, la comunicación verbal y escrita, el pensamiento crítico, la búsqueda y selección de información, la gestión de proyectos, la valoración de temas ambientales, el trabajo en equipo, así como la interacción en ambientes multiculturales.

Asimismo, se precisa que para el trabajo de los aprendices en la enseñanza aprendizaje de la Biología, no sólo se debe procurar el desarrollo de las capacidades individuales, sino sociales de los estudiantes y promover con estas últimas, el trabajo cooperativo o entre pares, para que se vislumbre la posibilidad de constituir pequeñas comunidades científicas, donde los estudiantes asuman compromisos individuales y colectivos en beneficio del grupo y de su contexto (MEN, 2006). Todo ello, con una sola 
meta: desarrollar habilidades y valores útiles para toda la vida. Por ejemplo: empatía, respeto mutuo y tolerancia.

Por esta razón resulta preocupante el bajo nivel que han presentado los estudiantes de la secundaria pública colombiana de la Institución Educativa Belisario Peña Piñeiro, ubicada en el Municipio de Roldanillo, al norte del Departamento del Valle del Cauca, tanto en los resultados de las dos últimas pruebas censales practicadas por el Instituto Colombiano de Educación Superior (en adelante ICFES) a nivel nacional, como en el resultado de su desempeño académico durante los diferentes períodos anuales, donde se aprecia, un descendimiento paulatino en el rendimiento académico. Los resultados muestran que los estudiantes tienen dificultades en lo siguiente: el manejo de los conocimientos propios de las ciencias naturales, donde está incluida la Biología, es decir, el uso de habilidades científicas, además de la búsqueda y selección de información; la interpretación de resultados datos relevantes que permitan dar respuesta a preguntas de corte científico; la construcción y comprensión de argumentos; la lectura crítica y el análisis de representaciones o modelos que dan razón de un fenómeno. Lo anterior, también ha generado una actitud negativa hacia los contenidos abordados en la Biología.

Particularmente en el octavo grado de la secundaria, se presenta, una marcada apatía por el desarrollo de trabajo en equipo o cooperativo, influenciado desde los hogares, lo que implica para los estudiantes, trabajar de manera individual, debido a las condiciones geográficas, sociales y de convivencia propias de la zona. Al respecto, es pertinente aclarar que las familias de la mayor parte de los estudiantes, viven en zonas de difícil acceso, alejadas de la parte urbana y donde se presentan conflictos constantes 
debido a la intolerancia, delincuencia, falta de comunicación al interior del núcleo familiar y escasos recursos económicos. Toda la región se ha caracterizado por la influencia del narcotráfico y de grupos que viven al margen de la ley, lo que incide de manera negativa en el desarrollo de las actividades compartidas, que procuran establecer mediaciones entre los estudiantes y que se conciben desde la perspectiva del aprendizaje como una construcción social propia de la formación humana (Tobón, Pimienta y García-Fraile, 2010, citados por López, 2013).

Aunado a lo anterior, no se han logrado desarrollar en la clase de Biología del octavo grado, ambientes participativos apoyados en las Tecnologías de la Información y la Comunicación (en adelante TIC) que permitan el intercambio de experiencias entre los profesores y los estudiantes, para dinamizar la práctica educativa e incrementar, en estos últimos su protagonismo, como aspectos de integralidad que deben ser manejados desde la formación por competencias (Sangrá, 2001 y López, 2013). Sin embargo, se percibe de manera general que a los alumnos les llama la atención el poder estar en la sala de sistemas y sólo acceder a redes sociales como Facebook. Esto no significa, que conozcan los AVA, al contrario, no han tenido la oportunidad de trabajar con este tipo de apoyos tecnológicos y aún existen estudiantes que desconocen la manera de acceder a información a través de Internet. Obviamente, tampoco saben cómo buscar y seleccionar fuentes de alta calidad.

Esto despertó el interés de la autora, por buscar nuevas estrategias o apoyos tecnológicos, que puedan influir positivamente en el aprendizaje de la Biología, respecto a los estudiantes del octavo grado de básica secundaria. Consecuentemente, se pretendió responder la siguiente pregunta general de investigación: ¿cuál es el impacto de uso e 
incorporación de una wiki en el aprendizaje de la Biología, por parte de los alumnos de una secundaria colombiana?

De la anterior pregunta principal, derivaron las siguientes interrogantes:

- ¿Cuáles son los beneficios del uso e incorporación de una wiki en el trabajo cooperativo de la clase de Biología?

- ¿Cómo se desarrolla la interacción en la wiki, durante la realización de actividades cooperativas, por parte de los alumnos?

- ¿Cuál es la actitud de los alumnos respecto al uso e incorporación de una wiki en la clase de Biología?

- ¿Cuáles son las diferencias entre el rendimiento académico de los alumnos que utilizaron una wiki, respecto a los que no la usaron?

\subsection{Objetivos}

\subsubsection{Objetivo general}

Conocer el impacto del uso e incorporación de una wiki en el aprendizaje de la Biología.

\subsubsection{Objetivos específicos}

- Determinar los beneficios del uso e incorporación de una wiki en el trabajo cooperativo de la clase de Biología.

- Describir cómo se desarrolla la interacción en la wiki durante la realización de actividades cooperativas, por parte de los alumnos. 
- Conocer la actitud de los alumnos respecto al uso e incorporación de una wiki en la clase de Biología

- Analizar las diferencias entre el rendimiento académico de los alumnos que utilizaron una wiki, respecto a los que no lo hicieron.

\subsection{Hipótesis}

A continuación, se presentan las hipótesis que guiaron el desarrollo de la indagación:

Hi: El uso e incorporación de una wiki facilita el aprendizaje de la Biología, en los alumnos de octavo grado.

Hi: Existen diferencias significativas en el rendimiento académico de los alumnos que usaron la wiki, respecto a los que no lo hicieron.

De igual manera, las hipótesis nulas fueron:

Ho: El uso e incorporación de una wiki no facilita el aprendizaje de la Biología, en los alumnos de octavo grado.

Ho: No existen diferencias significativas en el rendimiento académico de los alumnos que usaron la wiki, respecto a los que no lo hicieron.

\subsection{Justificación}

La enseñanza de la Biología se caracteriza por la diversidad de conceptos que se manejan, así como por terminología científica actualmente empleada para representar los diferentes fenómenos, esto hace que muchos estudiantes tengan ideas poco precisas al respecto, lo que dificulta su aprendizaje y genera apatía por los contenidos abordados en 
la asignatura. Implementar estrategias novedosas que involucren el uso de un AVA, como una wiki, favoreció el enriquecimiento del proceso de enseñanza aprendizaje en el octavo grado y permitió comenzar a cambiar la percepción de los estudiantes respecto a la enseñanza tradicional en la asignatura de Biología, pues no todo puede limitarse a la lectura individual de documentos proporcionados por el docente, o a la memorización de conceptos. La wiki también ayudó a la construcción colectiva del conocimiento, basada en diversas actividades promotoras de nuevos aprendizajes, entre los que destacan: la interacción, la cooperación y el compromiso grupal. Todo ello, redundará en un mayor interés de los alumnos hacia la materia y consecuentemente, en un mejor rendimiento académico por parte de los aprendices.

Por otro lado, realizar actividades cooperativas en la enseñanza de la Biología a través de una wiki, puede contribuir a que los estudiantes comprendan, lean, apliquen y visualicen la ciencia de forma más agradable y significativa para ellos, además de hacerlo de forma argumentada. Esto implica que deben aprender a utilizar habilidades cognitivas y lingüísticas propias del pensamiento crítico, requerido en el ámbito de las ciencias (Sarda-Jorge y Sanmartí, 2000). Además, derivado de las interacciones positivas durante las actividades en el entorno virtual, surgió la posibilidad de comenzar a disminuir la percepción negativa de los padres hacia el trabajo en equipo, lo cual también redundará en mejores ambientes de aprendizaje y beneficiará el clima del aula. Finalmente, a partir de los resultados obtenidos, se hicieron propuestas para mejorar la práctica docente, con base en el uso de una wiki en futuros cursos de Biología que se impartan en la secundaria pública colombiana, que fue el escenario educativo de este estudio. 


\subsection{Delimitación del estudio}

Los obstáculos que restringieron el desarrollo de esta investigación, se detallan a continuación:

- La velocidad de conexión a Internet, tanto de la institución educativa como la suministrada por las empresas prestadoras del servicio y a la que acceden los estudiantes que integraron la muestra, pues en ocasiones fue lenta e inestable.

- La dificultad que presentaron los docentes de ciencias naturales en el manejo de los apoyos tecnológicos, debido a su poca familiarización con ellos.

- En general, la comunidad educativa no tiene adecuadas habilidades en el uso de las TIC, ni está familiarizada con entornos virtuales de aprendizaje. También hay cierta predisposición negativa hacia su uso.

- La apatía que presentaron ciertos alumnos para desarrollar las actividades propuestas en la wiki.

En cuanto al contexto o delimitación geográfica, el presente estudio se realizó en una secundaria pública colombiana, ubicada en el Municipio de Roldanillo, situado al norte del Departamento del Valle de Cauca en Colombia. El estudio se enfocó en los estudiantes de octavo grado, pues así lo indicó la rectora del colegio. Respecto a la delimitación metodológica, para enriquecer el estudio se implementó un diseño mixto, que contempló observaciones no participantes para describir la interacción con el apoyo tecnológico, una entrevista semiestructurada con el titular del grupo experimental, la aplicación de una preprueba y posprueba para ambos grupos considerados en el estudio, 
así como un cuestionario autoadministrado con escala Likert para los alumnos que usaron la wiki. Todo ello, permitió dar riqueza a los datos recolectados.

\subsection{Definición de términos}

A continuación se presentan, los principales conceptos usados en la investigación:

- Ambiente virtual de aprendizaje (AVA): es un sitio web que contiene una serie de herramientas y ayudas de navegación, para que los materiales educativos puedan ser colocados en línea de manera clara, organizada y estructurada (Cleary y MarcusQuinn, 2008). Puede considerarse, como la principal estrategia en la organización e implementación de cursos en línea, donde el aprendizaje de los alumnos se fortalece a través de la relación y comunicación que se genera entre el docente y los participantes de la clase. En los AVA, se distinguen seis tipos de componentes o herramientas: herramientas de administración, herramientas de comunicación, herramientas de información, herramientas de publicación, herramientas de colaboración, herramientas de autor (López, 2013).

- Competencias: son procesos generales contextualizados, referidos al desempeño de la persona dentro de una determinada área del desarrollo humano. Son la orientación del desempeño humano hacia la idoneidad en la realización de actividades y resolución de problemas. Se basan en indicadores de desempeño y estos corresponden a los indicadores de logro como una manera de establecer la formación en etapas (criterios de desempeño y evidencias requeridas). Las competencias indican las metas 
por alcanzar en procesos pedagógicos asumidos en su integralidad, mientras que los estándares se refieren a las metas específicas por lograr durante las fases de dicho proceso. Por ende los estándares se establecen según la orientación de las competencias De acuerdo con el Instituto Colombiano para el Fomento a la Educación Superior, las competencias, están concebidas como la capacidad de actuar e interactuar en un contexto material y social (ICFES, 2007).

- Ministerio de Educación Nacional: entidad gubernamental de Colombia, encargada de definir las políticas planes y programas del sector educativo, así como la operación del sistema de aseguramiento de la calidad de la educación, la pertinencia de los programas, la evaluación permanente y sistemática, la eficiencia y transparencia de la gestión para facilitar la modernización de las instituciones, implementar un modelo administrativo por resultados y la asignación de recursos con racionalidad (MEN, 2006).

- Trabajo cooperativo: implica interacciones basadas en la división de tareas y se pretende que el alumno alcance su objetivo, siempre y cuando sus compañeros alcancen sus metas; por consiguiente, los aprendices cooperarán entre sí para conseguir sus respectivos objetivos (Deutsch, 1962, citado por López, 2013). Por lo tanto el aprendizaje debe garantizar, para que sea cooperativo, la igualdad de cada individuo en el proceso de aprendizaje, la realización de experiencias mutuas en el aula entre los diferentes compañeros de tal forma que haya una bidireccionalidad en 
el proceso de enseñanza aprendizaje (unos aprenden de los otros) y mediante la distribución de responsabilidades y el intercambio de roles que deben ser planificados y supervisados por el profesor (Díaz Barriga, 1999 citada por López, 2013).

- Wiki: es un Ambiente Virtual de Aprendizaje donde se favorece la mediación entre docentes y estudiantes; se ha convertido en una manera de reconceptualizar el aprendizaje como autoría, es decir son formas dinámicas y sencillas de acceder o crear contenido en un espacio caracterizado por la interacción, la comunicación y el intercambio de ideas. Las wikis son similares a bibliotecas de proyectos, repositorios de contenidos o productoras de contenidos abiertos disponibles para que cualquier persona los reutilice, edite, o inspeccione (López, 2013).

- Competencias instrumentales: son competencias genéricas, que involucran conocimientos transferibles, generales y específicos de una disciplina. Se relacionan con el saber conocer y comprender. También se asocian con el dominio de métodos y técnicas. Incluyen funciones cognitivas, metodológicas, tecnológicas y lingüísticas. Entre ellas, destacan: la resolución de problemas, gestionar la información, el uso de las TIC, la comunicación verbal y escrita, etcétera. Constituyen parte del dominio que el estudiante debe tener sobre el conjunto de conocimientos teóricos que sustentan una materia (López, 2013). 
- Competencias interpersonales: se refieren a la capacidad de mantener una óptima relación social y están vinculadas con la colaboración y la cooperación para desarrollar un trabajo, proyecto común o de autoconocimiento. Se clasifican en individuales y sociales (Tobón, 2006). Al respecto, sobresale el trabajo en equipo, el manejo de conflictos, la negociación, el trabajo interdisciplinario, la automotivación, la adaptación al entorno y el sentido ético, entre otras competencias. También son consideradas como el saber ser (López, 2013).

Para finalizar este capítulo, es oportuno enfatizar la necesidad de innovar en las prácticas pedagógicas, como un camino para el mejoramiento de las dificultades que presentan algunos estudiantes colombianos entorno al aprendizaje de la Biología, a nivel de secundaria y particularmente, en el escenario educativo seleccionado para este estudio. Dichas dificultades podrán ser atendidas de mejor manera, una vez se conozcan los resultados y análisis derivados de este estudio y conforme al planteamiento del problema detallado en este capítulo. Cabe anotar, que un componente interesante que se maneja alrededor de las wikis es la importancia de la interacción social en la construcción de conocimientos y en el favorecimiento del aprendizaje cooperativo. Al respecto, en el marco teórico, se abordarán los fundamentos que sustentaron la presente indagación, así como los antecedentes empíricos que sirvieron de guía para la realización de la misma. 


\section{Marco teórico}

Este capítulo presenta conceptualizaciones, teorías y fundamentos relacionados con las variables de esta investigación, sustentadas principalmente en publicaciones de divulgación científica, que serán tratadas en tres secciones o temáticas principales. En la primera, referente a los entornos virtuales para el aprendizaje, se describe el significado de estos nuevos escenarios educativos, teniendo como base los objetivos de esta investigación, además de su contribución al mejoramiento de los procesos de enseñanzaaprendizaje de las ciencias naturales a nivel secundaria (área del saber considerada en este estudio). Para ello, se incluyen dos subtemas: el uso de las wikis en el grado educativo ya mencionado y la interacción social a través de las mismas.

El segundo subtema, sobre el proceso de enseñanza-aprendizaje de la Biología, contempla las posibilidades que ofrecen las wikis como apoyo tecnológico en el desarrollo de competencias propias del entorno científico, donde es necesario fomentar el trabajo cooperativo y la autogestión del aprendizaje. Finalmente, se concluye con la descripción de algunas investigaciones empíricas sobre el uso de las wikis en los procesos de enseñanza-aprendizaje de las ciencias, donde se contempla la Biología. Todo ello, con el objeto de presentar el sustento teórico de esta investigación y situarla en el contexto específico de los conceptos abordados en la misma (Hernández, Fernández y Baptista, 2010). 


\subsection{Los entornos virtuales para el aprendizaje de las ciencias naturales}

Los entornos o ambientes virtuales de aprendizaje surgieron según López (2013) debido a la utilización que se le ha dado desde finales del siglo XX a las TIC y a su rápido crecimiento. Son considerados como espacios de formación, establecidos en el Internet, a partir de páginas web; compuestos por herramientas informáticas que posibilitan la interacción didáctica y la constitución de comunidades virtuales. Lo que sirve de apoyo en actividades educativas presenciales y como recurso para estructurar e implementar cursos en línea (Aborisade, 2009; López, 2013). Por lo anterior, puede señalarse que este tipo de recursos deberían ser utilizados e incluidos como apoyos tecnológicos para fomentar el desarrollo de competencias cognitivas, de comunicación, tecnológicas, lingüísticas y científicas, entre otras. Particularmente, en el área de ciencias naturales prevista en los diferentes grados escolares del nivel de básica secundaria, en Colombia.

La diferencia que existe entre la educación presencial y la que se efectúa a través de la red, o virtual reside en el cambio de medio y las posibilidades educativas que se generan debido a la manera de usar e interactuar con estos nuevos entornos. A pesar de que se busque una misma finalidad educativa, no es conveniente, ni posible, replicar los modelos tradicionales en los espacios virtuales; siempre habrá que hacer una adaptación, para aprovechar los recursos que cada medio ofrece y poder alcanzar los objetivos trazados en una determinada acción educativa. De esta forma, se aprovechará el potencial creativo que ofrece la virtualidad para mejorar y variar los procesos y acciones didácticas, al tiempo que se benefician los sistemas virtuales con el trabajo educativo y comunicativo desarrollado (Sangrá, 2001). 
Estos espacios de interacción social, son salones sin paredes, distales, multicrónicos que funcionan a partir de redes electrónicas conectadas en diversos lugares (Aborisade, 2009; Bello, 2005). Con una utilidad, tendiente a ser más reconocida, debido a la flexibilidad en tiempo y espacio que brinda a los alumnos la posibilidad de estudiar en el momento que lo requieran y desde cualquier lugar, siempre y cuando tengan acceso a un computador provisto de Internet. Esto contribuye con la disminución de las barreras geográficas que obstaculizan los procesos de enseñanzaaprendizaje y promueve la alfabetización digital, en especial en zonas rurales apartadas. Sin embargo, tampoco garantizan por sí solos la adquisición de conocimientos, por parte de los estudiantes y el desarrollo de un pensamiento analítico y crítico, requerido en el estudio de las ciencias naturales. No obstante, si ofrecen diferentes servicios e instrumentos que propician la construcción de conocimiento, la cooperación y la interacción entre pares y con los docentes como acciones que permiten el aprendizaje de esta ciencia (Bautista, Borges y Flores, 2006; Salinas, 1997; Salinas, 2011).

De acuerdo con lo anterior, puede afirmarse que en los AVA los docentes dedicados a la enseñanza de la Biología pueden establecer elementos a partir de los cuales, los estudiantes desarrollan procesos mentales que permiten la construcción del conocimiento y adquieren habilidades para convertirse en protagonistas de su aprendizaje. Asimismo, los alumnos pueden contar con otras herramientas tecnológicas y aplicaciones que facilitan la interacción colectiva, de tal manera que se posibilitan las actividades de grupo en donde los estudiantes aprenden juntos, ajustan la forma, el momento y el lugar donde realizarán las tareas o actividades propuestas por sus maestros y que pretenden contribuir al desarrollo de competencias sociales y sistémicas, con las 
cuales pueden obtener mayor información entorno a los fenómenos naturales y de la vida, para poder organizarla, intercambiar sus pensamientos y demostrar sus conocimientos (Bustos y Coll, 2010). No obstante, es pertinente referir que debido al carácter volitivo del estudiante, su aprendizaje también está sujeto a la responsabilidad, gestión y compromiso con la que enfrenta las metas de aprendizaje propuestas en estos escenarios de trabajo. En este sentido, de gran importancia es el acompañamiento del tutor o maestro, a fin de facilitar todos esos procesos.

De igual manera, los AVA se basan en representaciones visuales, que históricamente se han relacionado con la cultura científica, debido al uso y construcción de modelos para manejar y comprender conceptos abstractos, describir y explicar fenómenos, utilizar teorías que permiten acercarse a la comprensión de los entornos naturales y complejos de la vida y hacerlos más asequibles a la razón. En consecuencia, puede concluirse que la implementación de estos nuevos recursos en el aprendizaje de las ciencias naturales influye de manera positiva en la promoción de las representaciones externas como vía de acceso a los procesos de razonamiento y modelamiento interno, es decir, como instrumentos de construcción del conocimiento en la Biología y para fomentar el pensamiento crítico y la autogestión del aprendizaje.

Sin embargo, no puede ignorarse que en caso de minimizar la función del docente, la selección adecuada de contenidos, recursos o fuentes, además de la planeación, debido a la facilidad aparente que ofrecen estos ambientes de trabajo, se podrían afectar ostensiblemente los procesos de enseñanza aprendizaje de las ciencias. Por ello, se debe asegurar su aprovechamiento y el dominio de los aspectos metodológicos que distinguen 
a la enseñanza en ambientes virtuales, a fin de facilitar el aprendizaje en los alumnos y también para incrementar su accesibilidad, manejo y cobertura.

Un aspecto muy importante que debe tener en cuenta el docente de ciencias, como diseñador y administrador del AVA, es el conocimiento tanto de los saberes o conocimientos previos del alumno, así como de las exigencias que implica la adaptación al nuevo entorno de aprendizaje. También debe considerarse el adecuado diseño instruccional y la planeación didáctica que considere los nuevos saberes que se pretende desarrollar en los alumnos, además del seguimiento y retroalimentación que demandan estos ambientes, lo cual implica una variedad de recursos multimedia, comunicación e interacción constante a través de ese mundo virtual (Ramos 2003). Lo anteriormente señalado, aporta a la innovación didáctica y favorece la motivación del alumno hacia el aprendizaje de la Biología, debido a que se plantea un acercamiento a los conocimientos de manera diferente y más próxima a la forma como actualmente se comunican los jóvenes en los niveles de secundaria y en general, en la sociedad del conocimiento.

Para incorporar el uso de un AVA en el aula, es necesario tener un conocimiento básico sobre las configuraciones requeridas en cuanto a los recursos tecnológicos, como computadoras, sistemas de interconexión, redes, soporte y formato de la información, además de sistemas de administración de contenidos y/o de aprendizaje, entre otros. Asimismo comprender su complejidad debida a la variedad de las aplicaciones que se encuentran en Internet, su uso y la posibilidad de combinar variedad de recursos, a través de simulaciones, materiales multimedia, o herramientas de administración, comunicación, información, publicación, colaboración y de autoría; lo que se traduce en una interacción enriquecida, ya sea sincrónica o asincrónica. Todo ello, sin perder de 
vista, las finalidades y objetivos de aprendizaje del curso o asignatura en cuestión, además del sustento pedagógico basado en el perfil del alumno. De lo anterior, se desprende que los recursos tecnológicos pueden ser configurados con aplicaciones en red para:

- apoyar cursos tradicionales en modalidades presenciales o a distancia, basados en la interconexión entre grupos de instituciones diversas para compartir o intercambiar información o recursos.

- estructurar aulas o campus virtuales como apoyo para el desarrollo de variedad de actividades en procesos de enseñanza aprendizaje;

- interconectar y estructurar redes de conocimiento (knowledge networks) donde se promueva la adquisición de información y la construcción de conocimiento entre diversas comunidades de práctica (Harasim, Hiltz, Teles y Turoff, 2000).

En virtud de todo lo señalado, puede concluirse que para lograr que un estudiante adquiera las habilidades para construir conocimientos, se requiere de instrumentos de mediación, sean estos materiales o simbólicos; considerados estos últimos, como herramientas que apoyan los procesos del pensamiento y permiten o facilitan la transmisión de la cultura porque remiten acercarse a otras realidades a través de signos o símbolos utilizados a partir del lenguaje y que logran modificaciones en la persona y en su actuación con el entorno (Bentolila y Clavijo, 2001). Los AVA pueden constituir un apoyo excelente para generar el interés de los estudiantes en el tema de los seres vivos y sus interacciones, de tal manera que pueda llevarlos a comprender sus procesos internos y sus relaciones con los medios físicos y bióticos, a través de los cuales puedan 
reflexionar sobre cómo los conocimientos y competencias en ciencias se aplican a situaciones de la cotidianidad en beneficio individual y colectivo, además de adquirir la capacidad para interpretar logros y problemas de los avances científicos y tecnológicos en términos de sus efectos sociales y naturales, asociados a los intereses económicos y sociales que los promueven (MEN, 2006). Puede concluirse que esta dinamización y enriquecimiento del proceso de enseñanza y aprendizaje de la Biología a través del uso AVA, podría contribuir a mejorar sus desempeños académicos durante el año escolar y también los ayudaría a enfrentar de mejor manera la Prueba Saber (evaluación a nivel nacional en Colombia), debido a que no dependerían de la memorización de conceptos; los aplicarían y antes de ello, habría un proceso profundo de comprensión y reflexión de los mismos.

2.1.1. Uso de las wikis en el nivel de secundaria. Diversos estudios (González, Calderón, Galache y Torrico, 2006; López, 2013; Rodríguez, 2009), explican que la palabra wiki, es de origen hawaiano y significa rápido o informal. Una wiki-web o simplemente wiki, es la base de datos en línea más simple que pueda funcionar, e implica un tipo de sistema de gestión de contenidos o Content Management System, que provee las herramientas indispensables para su administración: creación, gestión, presentación, mantenimiento y actualización, en donde una colección de páginas web se encuentran enlazadas entre sí y pueden ser visitadas y editadas por cualquier persona. Esto la convierte en un AVA idóneo para situar actividades de aprendizaje de tipo cooperativo y colaborativo basadas en el desarrollo de contenido. También constituye una manera de reconceptualizar el aprendizaje como autoría. A pesar de la variedad de 
proyectos wiki propuestos actualmente, es posible hacer una generalización de las etapas utilizadas para la creación de sus contenidos desde una acción participativa, que también involucre a los alumnos participantes en el curso, donde se pretende incorporar el AVA. Al respecto, sobresalen las siguientes:

- planificación, búsqueda y selección de la información.

- intercambio, negociación y consenso.

- transformación, adaptación y deliberación.

- construcción y creación (González, Calderón, Galache y Torrico, 2006; López, 2013; Rodríguez, 2009).

De acuerdo con lo anteriormente señalado, en el campo de la educación, la wiki, es un espacio de mediación entre estudiantes y docentes de secundaria, quienes pueden crear, escribir, revisar, modificar el contenido de una página web, compartir información y conocimiento sobre una asignatura en particular, e incluso borrar algún artículo, dentro de un espacio digital compartido, de forma interactiva, fácil y rápida. Esto sugiere la realización de trabajo individual y en equipo, con el fin de desarrollar actividades que estimulen, tanto la búsqueda, como la selección y evaluación crítica de la información consultada; esto favorece la creatividad e innovación y la realización de actividades de aprendizaje cooperativo, que propicien la motivación del alumno y un mejor rendimiento académico en la enseñanza de las ciencias naturales (Onrubia, Colomina y Engel, 2008; López, 2013).

Según Lamb (2004), las wikis se caracterizan por los siguientes aspectos: 
- normalmente permiten los aportes e intervenciones de cualquier estudiante que desee participar, esto ocurre de forma rápida debido a que los procesos de lectura y edición son similares.

- utilizan marcas hipertextuales simplificadas, por lo tanto no se necesita conocer el lenguaje de programación en que están hechas las páginas web, o utilizar editores de páginas web para poder colaborar en una wiki.

- son apoyos tecnológicos muy flexibles debido a que no requieren de una estructura predefinida a la que deban acomodarse los docentes y los estudiantes; cualquiera de ellos puede crear nuevas páginas y vincularlas a otras páginas existentes.

- a pesar de que el anonimato es una costumbre en este AVA, en las wikis educativas y en especial las destinadas al trabajo en el nivel de secundaria, es importante reconocer quiénes participan y de qué manera lo hacen, con el objeto de retroalimentar los aportes realizados (Lamb, 2004).

Por lo anterior, puede afirmarse que la creación de contenidos en la wiki, no deberá considerarse como definitiva o terminada, pues siempre existirá la posibilidad de enriquecerla con la participación, el conocimiento y las ideas de otros estudiantes en nuevos cursos o niveles educativos, porque tal y como lo plantea Adell (2007), las wikis se parecen a las ideas y a los conocimientos, pueden evolucionar, cambiar y avanzar.

Al respecto, Villaroel (2000); Parker y Chao (2007), indican que una wiki es compatible con un enfoque de aprendizaje cooperativo y colaborativo, enmarcados en la psicología educativa y en el paradigma constructivista, los cuales promueven el 
aprendizaje significativo de los estudiantes y el análisis crítico, en dimensiones sociales, a través de las interacciones que involucran al estudiante en su aprendizaje y le permite ser más activo: Por medio de las wikis, los alumnos pueden integrar nuevas ideas, aprender a partir de la reflexión, monitorear su progreso a través de actividades auténticas y retadoras, que facilitan la comprensión y la transferencia del aprendizaje a situaciones nuevas y fuera del aula. Todo lo anterior, contribuye a que el estudiante de secundaria, comparta ideas, busque ayuda, negocie en situaciones específicas y discuta soluciones, en un ambiente de respeto y tolerancia hacia las ideas de otros. Puede afirmarse, que se trata de habilidades y valores que mejorarán su desempeño académico en el aprendizaje de la Biología.

Por otro lado, López (2013) y Lott (2005 citado por Adell, 2007) han propuesto una lista de usos típicos de las wikis en la educación:

- espacio de comunicación de la clase.

- espacio de cooperación y colaboración de la clase/base de conocimientos.

- archivo de textos en proceso de elaboración.

- manual de la clase/autoría colaborativa.

Todo esto, contribuye a la elaboración conjunta de artículos, bitácoras, casos, debates, ensayos, entrevistas, informes, investigaciones, monografías, portafolios, mapas conceptuales, prácticas, problemas, proyectos, reportes, entre otros. Actividades que ayudan en el desarrollo de los procesos del pensamiento cognitivo como la comprensión, el análisis y el uso del conocimiento (López, 2013; Lott, 2005 citado por Adell, 2007). 
De igual manera, a través de las wikis, los contenidos del curso de Biología en el nivel de secundaria como la estructura celular, la reproducción, entre otros, pueden ser manejados en forma consecutiva o seriada, es decir, primero abordar uno para luego tratar el otro y de esta manera poder abordar otros temas como las poblaciones. Todos ellos, pueden ser organizados en formatos web, como un respaldo a la enseñanza presencial de esta asignatura: La actualización e interactividad de los AVA, modifica el control de la comunicación, centrada tradicionalmente en el docente y se enfoca en los estudiantes, lo que favorece el aprendizaje. Sin embargo, es necesario que el docente tenga amplio conocimiento sobre la asignatura y sobre el manejo de los espacios para el aprendizaje virtual. Asimismo, los sistemas educativos deben plantear modelos pedagógicos que apoyen la inclusión de los AVA en los procesos de enseñanza aprendizaje para promover la educación sin barreras geográficas ni temporales, con el objeto de formar y retroalimentar permanentemente al estudiante (Acosta, Quintero y Riveros, 2013).

En la investigación de carácter mixto, realizada por Jofré, Bunster, Martínez y Márquez (2014), destaca el uso de una wiki en la asignatura de Bioquímica, para la generación de artículos sobre ciencia y tecnología destinados a la comunidad chilena, redactados por estudiantes de primer semestre de la Universidad de Concepción, en un lenguaje y nivel apropiado. Confirman la utilidad de este AVA, en la generación de ambientes contemporáneos que se aproximaron a las expectativas y necesidades de los estudiantes del mundo actual. Además, consideran que a través del entorno virtual se incentivó la autonomía e interactividad entre pares y se logró, por parte de los estudiantes, la diferenciación entre el conocimiento conceptual y el pensamiento crítico 
entorno a la Bioquímica, así como la responsabilidad de comunicar temas de ciencia y tecnología a la sociedad. Por otro lado, se incrementó el compromiso y el aprendizaje autónomo, debido a que los estudiantes eran conscientes de la existencia de una audiencia al crear el contenido, que contribuyó a la evaluación crítica de la información, la creatividad y el trabajo independiente.

A pesar del evidente potencial de las wikis, en los niveles de secundaria, en países como Colombia, su utilización aún es incipiente. No es de extrañar, que su uso continuado requiera de mayor investigación y análisis de las interacciones entre los alumnos, así como de la comprensión de los posibles errores que se cometan al tratar de incorporarlos en el aula y del rechazo inicial a su utilización por parte de docentes y estudiantes, debido a que no existe una cultura educativa digital y son claras las dificultades en el manejo de las TIC. Sin embargo, esto no quiere decir que los estudiantes no participen de la tendencia mundial del uso del Internet y de los móviles inteligentes, o que también destinen gran parte de su tiempo a comunicarse por las redes sociales como una actividad de ocio e interés por interactuar con nuevas personas y comunicarse constantemente con sus amigos para tratar asuntos que nada tienen que ver con la educación. Por tal motivo, debe existir una mayor guía en el proceso de enseñanza aprendizaje desarrollado a través de estos AVA. Finalmente, puede afirmarse que no se trata de una moda, la selección de estos apoyos tecnológicos debe basarse en un adecuado fundamento pedagógico, considerar el perfil de los alumnos y la orientación de la materia en la que se incorporarán.

Por otro lado, debido a que es característico de las wikis, el manejo de los procesos discursivos, la edición y eliminación de contenidos, resulta necesario, sensibilizar a los 
estudiantes sobre estas situaciones e incorporar sesiones sobre redacción y comunicación efectiva en entornos virtuales, así como sesiones con expertos para establecer criterios claros sobre el manejo de la información editada por todos los alumnos participantes en el AVA, para evitar cualquier afectación a los derechos de autor. Algunas destrezas y habilidades sociales como la persuasión, el liderazgo o la capacidad negociadora desempeñan un papel relevante en este tipo de tareas (García, 2011)

En virtud de todo lo anteriormente señalado, puede afirmarse que para implementar nuevos modelos pedagógicos acordes con el desarrollo de estrategias didácticas apoyadas en tecnología y lograr la innovación en los procesos de enseñanza aprendizaje, es necesario que las instituciones educativas municipales en Colombia, se preocupen por gestionar y proporcionar una infraestructura tecnológica adecuada, así como invertir en un servicio de Internet con un ancho de banda adecuado, que pueda respaldar el intercambio de datos que acontece al interior de las instituciones educativas y que tiende a incrementarse con la incorporación de los AVA en las aulas. Por otra parte, es importante que los directivos apoyen los intentos de los docentes por mejorar sus prácticas y se estimule su participación en proyectos que involucren el uso de las TIC como herramientas que pueden motivar al estudiante de secundaria en su aprendizaje, además de proveerles capacitación y apoyo constante con el fin de mejorar los procesos educativos mediados por las TIC.

2.1.2 Interacción social a través de las wikis. De acuerdo con García del Dujo y Suárez (2012), la tecnología genera un nuevo escenario en el que confluyen diferentes formas de interacción social, es decir, la virtualidad. La educación se ha visto 
influenciada por esta condición para evolucionar y lograr responder a los cambios generados en esta sociedad. De esta manera, la wiki como AVA se encuentran inmersa en esta relación entre tecnología y construcción de procesos sociales desarrollados a partir de una nueva dinámica comunicativa, que obliga a reestructurar los espacios, los tiempos y los modos de relación académica entre los actores de una comunidad educativa, así como a promover el manejo de habilidades sociales que aseguren una comunicación asertiva.

En este sentido, las características de estas nuevas formas de interacción en la virtualidad (que la diferencian de la interacción presencial), son las siguientes:

- la interacción se realiza entre personas a través de aparatos electrónicos.

- la comunicación se produce a partir de interacciones que no requieren de la presencia física de las personas.

- se facilita la posibilidad de llegar a audiencias que serían difíciles de abarcar, en forma presencial.

- se fortalece la comunicación a través de la comunicación escrita.

- es necesario conocer la utilización del medio a través del cual se desarrolla la interacción.

- la interacción favorece el desarrollo de habilidades vinculadas con el uso de las TIC.

- la interacción se da a través de un conjunto de textos escritos, imágenes y sonidos que permiten realizar simulaciones. 
- interacción pluri-modal, pues puede incluir múltiples modalidades de comunicación y tipos de contenidos (Gávez y Tirado, 2006 citados por Cabero y Llorente, 2007; Van Dijk, 2005 y Hillman et al., 1994, citados por Castaño, 2011).

Debido a que las interacciones virtuales son acciones comunicativas que demandan una gran capacidad lecto-escritura, obligan a los estudiantes a llevar a cabo procesos de discriminación, que les permite reconsiderar, reformular y replantear lo que desean trasmitir, a partir de la comprensión de la información que comparten. De esta manera, se favorece la organización de la estructura cognitiva, debido a que es más frecuente debatir con los compañeros y enseñarle a un par, en lugar de aprender el material de manera individual o en forma aislada (Serrano, Piñuel, Gracia y Arias, 1982). Sin embargo, en el caso particular de este estudio también se generó un obstáculo en este tipo de comunicación asíncrona, debido a que muchos de los estudiantes de la zona urbana de la institución donde se llevó a cabo esta investigación, presentaron dificultades en el manejo de sus habilidades orales y escritas, especialmente cuando se trató de comprender información específica en el campo de la Biología, y para debatir una idea o buscar información y ejercer su pensamiento crítico respecto de lo leído.

Se considera que las interacciones sociales entre los alumnos, con el docente, así como con los apoyos tecnológicos, son un elemento fundamental en los procesos de enseñanza-aprendizaje. Asimismo, se ha demostrado que la interacción en las wikis, también se ha incrementado por la facilidad para obtener ayuda y la efectividad que genera en los procesos didácticos, debido a la reestructuración de los conocimientos a partir de la comprensión y el análisis originado en el debate con los pares o integrantes de equipo, lo que también propicia la interpretación de los contenidos y no su 
memorización. De igual manera, se refiere que se favorecen los procesos psicológicos superiores, gracias a las relaciones que se establecen con diferentes personas como mediadoras del conocimiento (Coll y Sánchez, 2008).

Según Ovejero (1993), a través de la interacción social, los estudiantes aprenden a desarrollar las aptitudes, destrezas y habilidades necesarias para adaptarse a la sociedad. Se puede observar la incidencia que ejerce, en la forma cómo se perciben los estudiantes y la manera de interactuar con los contenidos del curso, la motivación y la autorregulación de su aprendizaje, como factores determinantes del éxito escolar. Por lo tanto, puede afirmarse que el uso de las wikis resulta una alternativa óptima para promover las interacciones sociales de manera asincrónica entre los estudiantes, en actividades de aprendizaje, propias de las ciencias naturales y con alumnos de secundaria.

Por otra parte, Carretero (1997) considera que el hecho de que exista un desequilibrio ocasionado por la variedad de información que provee el medio, le exige al estudiante, equilibrar sus esquemas cognitivos y por lo tanto, aprender. Esto es posible, por las relaciones que se propician entre el estudiante y su contexto social, lo que indica que hay una relación directa del constructivismo con estas situaciones de aprendizaje y por lo tanto con el aprendizaje significativo. Lo anteriormente señalado permite afirmar que la construcción de conocimientos a partir del análisis, la reflexión crítica y compartida por parte de los estudiantes, se puede promover a partir de un AVA como las wikis.

Debido a que las interacciones entre iguales son tan importantes para el trabajo en red y el aprendizaje en AVA, es requisito que los estudiantes se concienticen de la 
interdependencia que existe entre los integrantes de un grupo, que puede lograr sus metas, solo si cada uno de sus miembros consigue alcanzar las suyas. De tal manera, que los grupos que interaccionan de manera cooperativa o colaborativa alcanzan mayor nivel o aprovechamiento académico, respecto a los que trabajan de forma individualista, puesto que buscan resultados beneficiosos para sí mismos, sin importar lo que suceda con sus compañeros (Coll, y Sánchez, 2008).

De igual manera, las habilidades sociales se forman en torno a las ideas, creencias, sentimientos, valores de los estudiantes y están ligadas con el autoconcepto y la autoestima. Esto exige, que los docentes como guías, al implementar las actividades que deben realizar los estudiantes en línea, orienten el desarrollo de estas habilidades y proporcionen recursos e indicaciones para que logren relacionarse de mejor forma con sus pares al momento de intercambiar ideas, experiencias, opiniones, y con ello, abordar los contenidos temáticos, y lograr la comprensión y posterior reflexión durante el proceso de aprendizaje de la Biología.

Resulta importante enfatizar que la interacción grupal requiere que el clima de aula sea favorable y que el grupo esté mínimamente cohesionado, así como una actitud de madurez, responsabilidad, compromiso y respeto entre pares y con el docente, ante las diferentes situaciones que puedan presentarse en torno a las actividades grupales o de carácter participativo, como los desacuerdos de opinión, o durante el manejo de la información, así como en la forma de expresar una idea. Consecuentemente, es indispensable la guía, el seguimiento y la atención de los docentes en el desarrollo de estas conductas y en el diseño instruccional de las actividades de aprendizaje, para que 
siempre se busque el favorecimiento de la comunicación continua y la gestión de la heterogeneidad (Pujolás, 2008).

En este sentido, el docente puede programar actividades pertinentes, que ayuden a la integración del grupo, igualmente acordar junto con los estudiantes algunas normas para enriquecer y facilitar la interacción, como:

- evitar ofender o ridiculizar a un compañero por tratar de defender una idea;

- evitar las expresiones agresivas y promover la cordialidad en la comunicación;

- tratar de mediar en situaciones de dificultad;

- expresar de manera abierta y clara las opiniones, sin olvidarse del respeto hacia los demás.

Para concluir, hay que tener en cuenta que la heterogeneidad como lo afirma Pujolás (2008), es algo inherente a la naturaleza humana y es imposible eliminarla o reducirla. Resulta más benéfico buscar formas de manejarla que considerar una homogeneidad inexistente.

\subsection{El proceso de enseñanza-aprendizaje en la Biología}

De acuerdo con los lineamientos del Ministerio de Educación Colombiano, los procesos de enseñanza aprendizaje en Biología deben orientarse hacia la apropiación de conceptos científicos que se aproximen de forma explicativa a los procesos de la naturaleza, así como a un modo de proceder en relación con el entorno y la vida misma, marcada por la observación, la sistematicidad en las acciones y la argumentación franca y honesta. La enseñanza de las ciencias tiene un papel fundamental, pues favorece la 
formación de seres humanos solidarios, capaces de pensar de manera autónoma, de actuar de manera propositiva y responsable en los diferentes contextos en los que se encuentren (MEN, 2006). No obstante, puede afirmarse que los procesos de enseñanza aprendizaje siguen muy asociados al paradigma tradicionalista, que desconoce el protagonismo de los estudiantes en la construcción de su propio conocimiento; factor que influye negativamente en la tarea de aprender de forma significativa y por lo tanto, en la tarea de alcanzar las directrices definidas por el Estado. Todo ello, reafirma la necesidad de innovar a través del uso e incorporación de las wikis, en el aula.

De esta manera, es considerada la Biología como una disciplina científica, constituida por un cuerpo de conocimientos que deben desarrollarse en el marco de las teorías que dirigen la investigación y a través de la cual pueden promoverse competencias específicas en los estudiantes. Además, en su estudio, se intenta no solo hacer descripciones de sucesos de la realidad o predecir acontecimientos bajo ciertas condiciones, sino comprender lo que ocurre en el mundo, la complejidad de las relaciones existentes entre diversos elementos, la interrelación entre los hechos y las razones de la ocurrencia de los eventos, así como lo que se oculta detrás de ellos; aspectos fundamentales en esta ciencia (MEN, 2006). Por esta razón. es importante comprender que la ciencia se ha convertido en una práctica social, que debe tener un manejo adecuado en los contextos escolares, donde se debe asumir como una práctica humana que puede verse limitada por las expectativas de los estudiantes y por las condiciones de vida en las que se desenvuelven.

Por otra parte, para la formación en ciencias naturales en la educación básica y media, el Estado se ha propuesto que a través de la educación en ciencias se promueva el 
pensamiento científico y en consecuencia, se fomente la capacidad de pensar analítica y críticamente, de tal manera que las nuevas generaciones tengan la capacidad de evaluar la información a la que se accede en términos de fuentes y metodologías. De esta manera, los docentes deben diseñar metodologías para llevarlas a la vida diaria, explicar el mundo en que se vive y con ello permitir que los estudiantes realicen actuaciones como lo hacen los científicos. Para lograrlo, el MEN colombiano ha definido los Estándares Básicos de Competencias en el área de ciencias naturales, donde se señala lo que todos los estudiantes del país deben conocer y saber hacer una vez finalizado su paso por un conjunto de grados $\left(1^{\circ}\right.$ a $\left.11^{\circ}\right)$, independientemente de la región donde se encuentren. Lo anteriormente señalado, permite afirmar que a través de la wiki se puede dinamizar el desarrollo del pensamiento crítico porque permite la interacción constante de los estudiantes, el intercambio de información, conocimientos y reflexiones respecto a una situación o problema planteado.

De acuerdo con lo anterior, las siete competencias específicas definidas para el área de ciencias naturales, que deben desarrollarse en todos los grados de la educación colombiana y que permiten a los estudiantes avanzar progresivamente en el conocimiento del mundo, desde la observación de los fenómenos y para responder las interrogantes propias de esta área del saber, son:

- discernir: entendida como la capacidad para reconocer y diferenciar fenómenos, representaciones y preguntas pertinentes sobre estos fenómenos. 
- indagar: capacidad para plantear preguntas y procedimientos adecuados y para buscar, seleccionar, organizar e interpretar información relevante para dar respuesta a esas preguntas.

- explicar: capacidad para construir y comprender argumentos representaciones o modelos que den razón de fenómenos.

- comunicar, considerada como la capacidad para escuchar, plantear puntos de vista y compartir conocimiento.

- trabajar en equipo, entendida como la capacidad para interactuar productivamente asumiendo compromisos.

- disposición para aceptar la naturaleza abierta, parcial y cambiante del conocimiento.

- disposición para reconocer la dimensión social del conocimiento y para asumirla responsablemente (MEN, 2006).

Lo anterior, es el referente para la construcción y realización de las Pruebas SABER, entendidas como el medio para lograr una apreciación sobre la calidad de la educación que se imparte en los planteles escolares en Colombia. Es así, como el ICFES a partir de los Estándares Básicos definidos por el MEN colombiano, expresan los conocimientos básicos comunes de la formación en un contexto multicultural y pluriétnico en el que se sientan las bases para la unidad nacional a través del respeto a las diferencias. De esta manera, en el contexto de la prueba SABER, en el área de ciencias naturales, específicamente para Biología se definen tres componentes denominados: celular, organísmico y ecosistémico. Un componente se considera como un elemento integrador de un sistema de representaciones que permite abordar el estudio 
de lo vivo, a partir de las interrelaciones de los organismos con el medio. Además se evalúan solo tres competencias específicas de las siete definidas por el MEN, identificar, indagar y explicar, las otras deben desarrollarse en el aula como parte de la formación de los estudiantes en ciencias, a pesar de que no puedan ser objeto de evaluación externa.

De acuerdo con los planteamientos de Tobón (2006), en el enfoque de formación basada en competencias es indispensable que los docentes comprendan que más allá de dirigir su atención en la forma en que desarrollarán una clase y la organización de los recursos didácticos para presentarla, es indispensable establecer los aprendizajes con que llegan los estudiantes a las aulas de clase, sus expectativas, lo que realmente han aprendido, lo que falta por aprender, los estilos de aprendizaje y la forma de involucrarlos de forma activa en su aprendizaje. Con estos referentes deben orientarse las metas, la evaluación y las estrategias didácticas, para orientar la formación hacia un desempeño adecuado en los diversos contextos en que se desenvuelve el alumno.

Lo anterior, también implica que el estudiante asuma un papel protagónico en su proceso de aprendizaje, a través del desarrollo y fortalecimiento de las habilidades cognitivas y metacognitivas, el conocimiento y regulación de sus procesos afectivos y motivacionales. De acuerdo con lo señalado anteriormente, puede concluirse que los estudiantes competentes, tienen niveles de desempeño adecuados y contextualizados, acordes al mundo donde viven y que la adquisición de estas habilidades responde a procesos de enseñanza aprendizaje coherentes con las exigencias de la sociedad.

Sin embargo, un panorama diferente es el que se encuentra al interior de las aulas de los colegios ubicados en los municipios de Colombia y en los sectores tanto urbanos como rurales de los mismos. La educación que se imparte sigue la versión de una ciencia 
completamente descubierta y explicada, donde lo común es transmitir conocimientos elaborados y consignados en los libros determinados para tal fin. Normalmente se ignora los sucesos que dieron origen a diversas teorías y creencias científicas y la manera en que evolución de estos pensamientos, ha permitido los avances tecnológicos actuales. Mucho menos se reconocen las ideas previas de los estudiantes, ni los contextos de donde provienen. La proposición de ideas, la experimentación y la reflexión crítica se ha dejado para los científicos.

Predomina la pedagogía tradicional, donde la trasmisión de información y la memorización se han convertido en el referente para medir los aprendizajes de los estudiantes. Si bien es cierto, en los planes de estudio se definen unas competencias a desarrollar, que tratan de responder a los estándares, en la práctica, la didáctica empleada se aleja de la consecución de estas metas de aprendizaje. Hay una ruptura entre lo que plantea el MEN, lo que se dice, lo que se planifica y lo que realmente se hace.

Lo cierto es que cada vez, se percibe una mayor desmotivación por parte de los estudiantes en el aprendizaje de las ciencias naturales y el éxito académico decae en las asignaturas afines, como son la Biología, la Química y la Física. Esto exige por parte de los docentes planteamientos diferentes en los procesos educativos y mayor atención a los aprendizajes fundamentados en teorías constructivistas de la enseñanza, donde el aprendizaje, es un proceso activo de construcción por parte del sujeto y la enseñanza, es el apoyo de dicha construcción; la esencia de todo eso, es el constructivismo (Acosta, Quintero y Riveros, 2013; Castañeda y Adell, 2013).

Resulta entonces interesante, implementar las TIC en el aula, en este caso una wiki, como una innovación didáctica generadora de una oportunidad para mejorar tanto 
las habilidades, como las metodologías de enseñanza implementadas. Un cambio que posiblemente será gradual, que implica esfuerzos, investigación y estudio, pero que puede convertirse en un apoyo tecnológico favorable para el aprendizaje (Valzacchi, 1998, citado por Quse, Masullo y Occelli, 2011). De lo anteriormente señalado, puede concluirse que a pesar de que los estudiantes no tengan contacto continuo con un AVA, pueden adaptarse rápidamente a ellos, debido a su capacidad innata para manejar equipos digitales y al entusiasmo que muestran al navegar por Internet. Esa actitud positiva también puede aprovecharse para favorecer los aprendizajes significativos en la Biología.

Por otro lado, al utilizar un AVA se motiva al estudiante para aprender de una forma diferente, es decir, a través de la incorporación de metodologías didácticas más centradas en el alumno, más abiertas. Se ofrece la posibilidad de ampliar conocimientos y estimular la investigación y autonomía. De esta manera, también se potencian la interacción y el aprendizaje social (Salinas, 2004b, citado por Castañeda y Adell, 2013). Sin embargo, el docente debe verificar el manejo de los conceptos que enseña, por parte de los estudiantes, debido a que su incomprensión puede conducir a posteriores obstáculos en el aprendizaje. Por esta razón, se deben tener presentes los aprendizajes previos para ser reafirmados o transformados.

Para finalizar, puede concluirse que es importante que el docente comprenda que la implementación de un apoyo tecnológico le exige la construcción de los materiales didácticos que va a utilizar en el proceso de enseñanza aprendizaje. Imágenes, textos, videos, deben ser adecuados a los estudiantes, de acuerdo con el nivel de formación y con el contexto en el cual se desenvuelven; así, el espacio de trabajo será la virtualidad. 
Por otra parte, es necesario que cuestione constantemente sus prácticas pedagógicas y reflexione acerca de la efectividad de los apoyos tecnológicos que decida implementar para el mejoramiento de los aprendizajes de los estudiantes en torno a la Biología.

2.2.1. El aprendizaje cooperativo en alumnos de secundaria. De acuerdo con Duart y Sangrá (2000), el trabajo cooperativo es una técnica de intervención escolar que establece una relación mutua entre un conjunto de personas que tienen la capacidad de contrastar sus pensamientos con la finalidad de generar un proceso de construcción social de conocimiento. Esto conduce a la negociación y contrastación de posturas, así como a la capacidad de resolver algún tipo de diferencia, con el objetivo de lograr una meta común. Por tal razón, en los procesos formativos en el área de ciencias naturales a nivel de secundaria, debería considerarse como una meta el facilitar las oportunidades y recursos para promover el aprendizaje cooperativo.

Para González y García (2007), el aprendizaje cooperativo hace referencia a una forma diferente de ordenar los procesos cognitivos promovidos en un proceso de enseñanza aprendizaje tanto al interior como fuera del aula. Se trata de superar determinados vacíos dejados por la implementación exclusiva de las técnicas tradicionales de aprendizaje grupal, que le ha otorgado mayor importancia a los resultados, a las responsabilidades grupales, a los líderes únicos que a los aprendizajes y responsabilidades individuales, a los grupos heterogéneos, a los liderazgos mutuos.

Consideran al igual que Johnson y Johnson (1985, 1989, citados por González y García, 2007) que a través del aprendizaje cooperativo, los estudiantes deben lograr interdependencia positiva, interacción asertiva, responsabilidad individual, habilidades 
sociales y el procesamiento grupal autónomo. Por lo anterior, se sugiere la necesidad, de que todos los estudiantes desarrollen estos elementos o capacidades, para garantizar que las interacciones que se desarrollen a través de la wiki, procuren la comunicación asertiva y el respeto por las ideas de los pares, para que éstas sean significativas.

Por otra parte, D’ Angelo (2002) considera que el aprendizaje cooperativo es un aprendizaje social que involucra tanto la conformación de espacios de diálogo y elaboración, sobre la base de las nociones de interacción social, desarrollo potencial y aprendizaje grupal crítico-reflexivo y creativo, como la asimilación e intercambio de comportamientos relacionados con la afectividad, las motivaciones y los valores que conforman el modelo ideal y la actuación real de una persona en un contexto específico. Según este autor, en estos espacios de interacción colectiva se puede experimentar el diálogo permanente, el contraste de ideas en la búsqueda de consenso y la capacidad de disentir responsablemente mediante la argumentación. Finalmente, puede afirmarse que a través de la cooperación se fortalecen las normas de convivencia pacífica, donde debe primar el respeto por el otro y la solidaridad, de tal manera que las ideas individuales se vuelven significativas para el grupo y pueden ser mejoradas a través de las interacciones al interior del mismo.

Al respecto, López (2013), afirma que cooperar significa ayuda, apoyo mutuo, interés de una persona por la otra, por tanto, en el trabajo cooperativo se persigue una doble finalidad, cooperar para aprender y aprender para cooperar. De esta manera, se logra un mayor rendimiento académico y productividad, respecto del trabajo individual o competitivo debido a que las metas son distribuidas. Por lo tanto, el aprendizaje cooperativo conforma el medio adecuado para fortalecer la educación para el diálogo y 
para vivir en comunidad. Sin embargo, es importante darle sentido a las interacciones de los estudiantes para lograr un acercamiento a la comprensión sobre cómo logran la construcción del conocimiento con sus pares.

De la misma manera, para Suárez (2010) la cooperación virtual implica el debate virtual y la visualización de una meta conjunta, donde, el volumen textual del debate no equivale necesariamente al volumen de cooperación. La meta de equipo, no solo es el elemento que configura el debate virtual en la acción cooperativa, sino el motivo de esta acción. El concepto de equipo señala una unidad de interacción desde donde se puede comprender, proponer y analizar la interacción cooperativa entre alumnos en la formación virtual, de tal forma que se ejecuta una ética de cooperación que señala que relegar a un miembro del aprendizaje es postergar la oportunidad de todos. La evaluación interna del equipo, es una dimensión de la acción cooperativa poco desarrollada por los equipos de aprendizaje virtual, entendiéndose ésta como una verificación del cumplimiento de la meta de trabajo conjunto y como un ejercicio reflexivo sobre la propia dinámica grupal. Sin embargo, aún, está muy ligada a la búsqueda de una calificación más que a una práctica metacognitiva como equipo. En virtud de todo lo señalado, puede concluirse que el aprendizaje cooperativo mejora la reflexión individual e influye positivamente en el incremento de la autoconfianza, la autocomprensión y la sensibilidad grupal, como aspectos de integralidad del ser humano en formación.

A pesar de todo lo anteriormente mencionado, en los estudios de Becerril (2011), se presentan diversas investigaciones (Johnson y Johnson, 1990; Bearison, Magzamen y Filardo, 1986, citados por Becerril, 2011), donde se determina que el hecho de que 
exista controversia, no significa que ésta por sí sola garantice el aprendizaje debido a que pueden presentarse otros factores y variables influyentes, como por ejemplo, la frecuencia con la que se producen los conflictos y el grado de dificultad de resolución de la controversia. Fernández y Melero (1995, citado por Becerril, 2011) consideran que los aspectos cognitivos y relacionales son un tipo de regulación del conflicto y que este último es un factor decisivo en la efectividad de los conflictos en el aprendizaje. Consecuentemente, puede afirmarse que los consensos y disensos producto de argumentaciones y debidamente respaldados por el adecuado acompañamiento del profesor, también puede redundar en aprendizajes significativos.

Por otra parte, según los estudios realizados por León del Barco (2006), en el aprendizaje cooperativo no basta con dejar que los alumnos se pongan a trabajar en grupo o con promover la interacción entre ellos para obtener, de manera inmediata, unos efectos favorables sobre el desarrollo, la socialización y el aprendizaje; lo más importante es la calidad y los efectos de estas interacciones. Asimismo, considera que la cohesión, el clima y la madurez del grupo, son factores determinantes de un ambiente grupal positivo que se consiguen tras un periodo largo de trabajo en común, de éxitos y fracasos y de un conocimiento mutuo de los integrantes del grupo. De lo anterior, se deduce que planificar trabajo cooperativo en el estudio de la Biología a nivel secundaria, así como conocer la opinión y destreza de los estudiantes en el trabajo grupal y entrenarlos previamente para interactuar en este tipo de dinámica, permite promover de mejor manera las habilidades sociales y asegurar experiencias exitosas en las situaciones de aprendizaje cooperativo. 
En este sentido, Sanz, Madoz, Zangara, y Albanesi (2008), mencionan que la cooperación es una metodología didáctica de interacción diseñada para facilitar el cumplimiento de un producto final o meta. La autoridad queda en manos del instructor, quien continúa siendo el dueño de la tarea, que involucra un problema que puede tener una solución determinada, o incluso varias alternativas de solución, ya que el docente es quien conoce o puede predecir la respuesta (Sanz, Madoz, Zangara, y Albanesi, 2008). Por tal razón, el grado de apertura que tiene la tarea es un determinante en la comunicación y cooperación entre los participantes. Pueden planificarse tareas abiertas que faciliten la comunicación y cooperación y tareas cerradas con lineamientos específicos, en las cuales la comunicación y la colaboración se vean reducidas. La tarea más abierta, de promoción al aprendizaje cooperativo, es aquella donde se plantea una situación de discusión. Las tareas de aprendizaje de conceptos y solución de problemas son las tareas más estructuradas, que dan menos opciones a manifestar conductas interpersonales aprendidas mediante un entrenamiento en dinámicas de grupo (Palincsar, Stevens y Gavelek 1989, citado por León del Barco, 2006

De esta manera, el papel del profesor no debe limitarse a la observación del trabajo de los grupos, sino a constatar, el proceso de construcción del conocimiento, así como las interacciones de los miembros de los distintos grupos. Es entonces, un mediador en la generación del conocimiento y del desarrollo de las habilidades sociales de los alumnos. Esto lo obliga a asegurarse que los grupos tengan muy claros los objetivos de la tarea a realizar para asegurar la participación, propiciar el intercambio de ideas, así como la rotación de las funciones de cada uno de los miembros del grupo. En definitiva, este tipo de trabajo promueve el aprendizaje de los alumnos a través de la 
instrucción del maestro y de las decisiones que se toman en el transcurso de la tarea. Es por ello que aprender en cooperación con otros, es de gran ayuda para mejorar la capacidad de resolver problemas, tomar iniciativas, adecuar los objetivos e intereses propios a los del resto del grupo, proponer normas, respetarlas, comportarse de acuerdo a los valores y normas que rigen las relaciones entre las personas (Almazán, 2010). Por lo anterior, puede señalarse que la enseñanza para el aprendizaje cooperativo, favorece la capacidad de pensar, tomar decisiones, relacionarse positivamente con los demás, y de cooperar con la comunidad educativa. El desarrollo de esas habilidades y valores en la educación secundaria, trascenderá positivamente en la vida adulta.

2.2.2 La autogestión del aprendizaje. En sus estudios (Bandura, 1997; Zimmerman, 1989 citados por Góngora, 2005), consideran que la autogestión del aprendizaje, es la situación en la cual el estudiante se apropia de su aprendizaje, le da seguimiento a sus objetivos académicos y motivacionales, activa y sostiene cogniciones, conductas y afectos que están orientados sistemáticamente hacia el cumplimiento de los objetivos académicos. Por consiguiente, la planificación, ejecución y autoevaluación en el proceso de aprendizaje son elementos muy importantes, porque le permiten al estudiante reflexionar sobre su nivel de aprendizaje y reorientarlo en caso de necesitarlo. De esa manera, se autogestionan los procesos de aprendizaje.

De acuerdo con las investigaciones de Ardura y Zamora (2014), una de las posibilidades que ofrecen los AVA es la facilidad para que los estudiantes autoevalúen sus trabajos y los de sus compañeros mediante pruebas diseñadas por el docente que les permiten conocer sus errores (áreas de oportunidad) y consecuentemente, abordar su 
corrección. Esto, resulta ser un factor preponderante en el aprendizaje de los estudiantes ya que de acuerdo con trabajos desarrollados por estos autores en años previos, se presentaban dificultades al momento que los estudiantes trataban de identificar y describir sus propios errores.

Por otra parte, consideran que el uso de un AVA, ayuda a los estudiantes a tomar conciencia sobre aquello que aprenden, en la medida que favorece la autorreflexión, aumenta la motivación, el compromiso y la responsabilidad por su propio aprendizaje. En los análisis, encuentran que el $80 \%$ de los estudiantes, piensa que un AVA constituye una buena herramienta para facilitar el estudio. Asimismo, la mayoría de los estudiantes indicaron que la experiencia les ha llevado a ser más conscientes de su proceso de aprendizaje cuando utilizan el apoyo tecnológico, en contraste con los métodos más tradicionales, aunque no se percibe una influencia significativa en su motivación.

Según la encuesta de evaluación de las actividades realizadas, el trabajo con el apoyo tecnológico ayudó a los estudiantes en la autorregulación de su aprendizaje a través del uso Hot Potatoes, un sistema utilizado para crear ejercicios educativos y en este caso, una herramienta que sirvió para construir una autoevaluación. Además, las pruebas de evaluación facilitaron la monitorización de su rendimiento de manera continua a lo largo de la experiencia con el nuevo entorno de trabajo (Ardura y Zamora, 2014). Por lo tanto, tal como refiere López (2013) la autogestión, también se vincula con la autodeterminación, con habilidades de proyección y previsión, así como con el aprendizaje autónomo. 


\subsection{Investigaciones sobre el uso de las wikis y el aprendizaje de la Biología}

Waldeg (2012) considera que una de las principales ventajas de la integración de las wikis en los procesos de enseñanza y aprendizaje de las ciencias naturales, en especial de la Biología, es que su uso e incorporación pretende recapturar el mundo real de una forma diferente y enriquecida, para reabrirlo al estudiante en el interior del aula. Comenta que quienes propugnan por su integración para el aprendizaje de las ciencias afirman que con este AVA, existe la posibilidad de presentar los contenidos y materiales de apoyo, a través de múltiples formas, medios y canales, además de motivar e involucrar a los estudiantes en actividades de aprendizaje significativas, proporcionar representaciones gráficas de conceptos y modelos abstractos, mejorar el pensamiento crítico y la comunicación escrita, así como favorecer la búsqueda y selección de información para resolver problemas y explicar fenómenos del entorno a través del acceso a documentos de corte científico, bases de datos y mediante el contacto con expertos. De igual manera, los maestros y estudiantes cuentan con un espacio donde pueden interactuar y comunicarse con colegas de lugares distantes, para intercambiar experiencias, desarrollar investigaciones y establecer comunidades de práctica, sin límites de espacio o de tiempo.

En consecuencia, es importante presentar las investigaciones y consultas obtenidas para el desarrollo de la perspectiva teórica de esta investigación. La información recolectada tiene relación con el tema de estudio y ha sido útil para los propósitos del mismo. Cada uno de estos estudios empíricos constituyó una guía para el desarrollo de esta indagación. A continuación, se presentan diversas tablas, donde se describen los artículos de investigación con sus principales datos. 
Tabla 1

Primera investigación

\begin{tabular}{|c|c|}
\hline Autores: & Jofré, C. B., Bunster, M., Martínez, J. y Márquez, C. \\
\hline Título del artículo: & $\begin{array}{l}\text { Utilizar la wiki para promover autoaprendizaje y responsabilidad social en } \\
\text { futuros científicos. }\end{array}$ \\
\hline Revista científica: & Educación Médica Superior. \\
\hline $\begin{array}{l}\text { Objetivos de } \\
\text { investigación: }\end{array}$ & $\begin{array}{l}\text { General: conocer el impacto de uso de una wiki como metodología de } \\
\text { enseñanza-aprendizaje en Bioquímica. } \\
\text { Específico: promover la motivación en el aprendizaje de la disciplina y en la } \\
\text { responsabilidad de comunicar temas de ciencia y tecnología a la sociedad. }\end{array}$ \\
\hline $\begin{array}{l}\text { Instrumentos de } \\
\text { medición: }\end{array}$ & $\begin{array}{l}\text { Se realizaron entrevistas con comentarios libres y se analizaron los artículos } \\
\text { publicados por los estudiantes. Los artículos se calificaron grupalmente } \\
\text { utilizando una rúbrica global de desempeño. Se estimó la apreciación del } \\
\text { estudiante mediante una lista de cotejo. }\end{array}$ \\
\hline $\begin{array}{l}\text { Principales } \\
\text { hallazgos: }\end{array}$ & 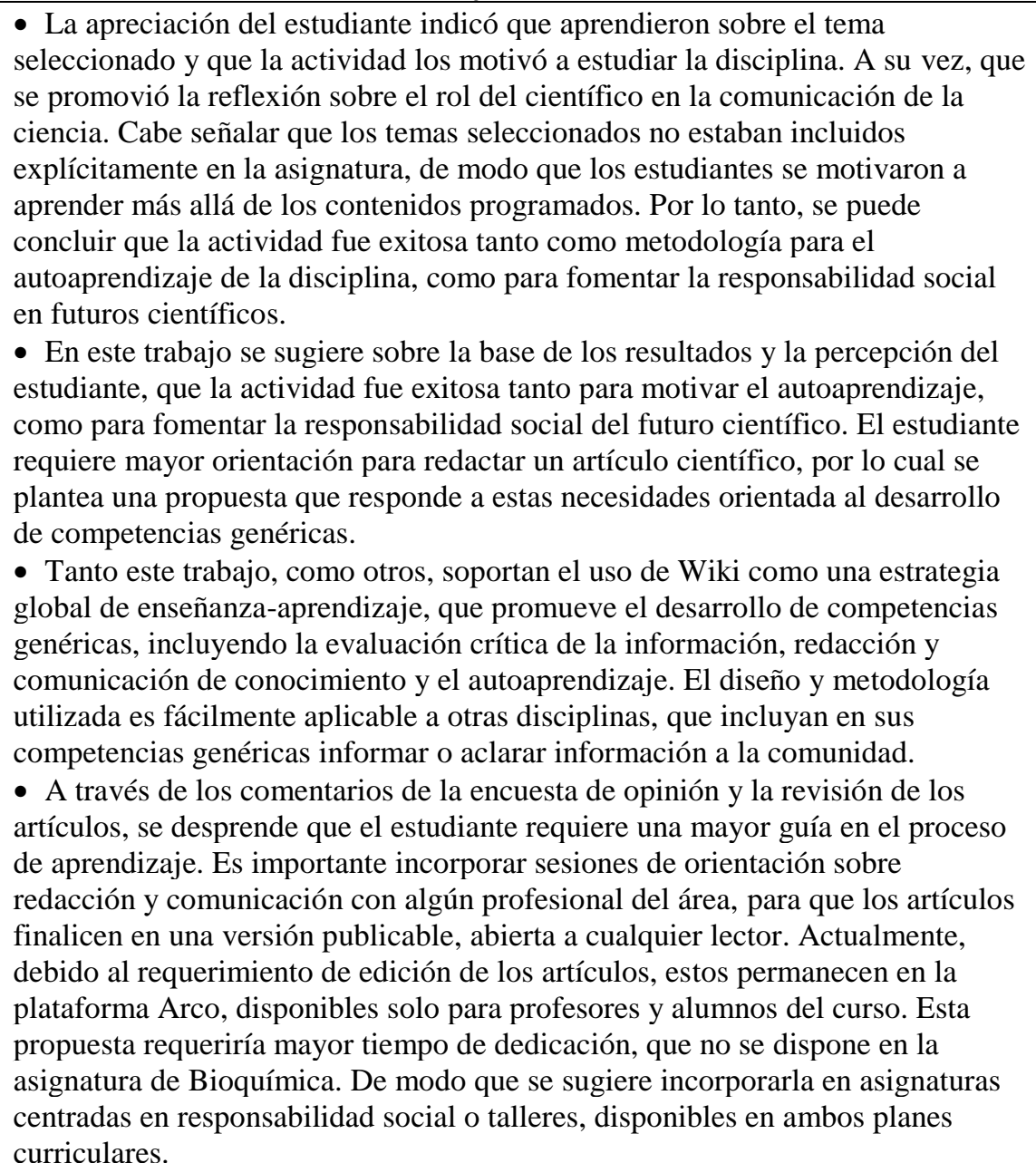 \\
\hline
\end{tabular}


Tabla 2

Segunda investigación

\begin{tabular}{lll}
\hline Autores & Villalustre, L. y Del Moral, M.E. & \multicolumn{1}{c}{ Año: 2011 } \\
\hline Título del artículo: & $\begin{array}{l}\text { Webquest y wikis: búsqueda de información en red y desarrollo de competencias en } \\
\text { colaboración. }\end{array}$ \\
\hline Revista científica: & $\begin{array}{l}\text { Teoría de la Educación. Educación y Cultura en } \\
\text { la Sociedad de la Información. }\end{array}$ & Tipo de estudio: Cualitativo \\
\hline Objetivos de & General: conocer el tipo de competencias desarrolladas por los estudiantes a partir del \\
investigación: & $\begin{array}{l}\text { trabajo planteado en una actividad en colaboración basada en la filosofía de las } \\
\text { webquest y apoyada con el uso de las wikis. }\end{array}$ \\
& $\begin{array}{l}\text { Específicos: determinar las competencias genéricas que se desarrollan; conocer el } \\
\text { nivel de satisfacción de los estudiantes en relación con las actividades propuestas; } \\
\text { conocer la percepción acerca de la dificultad y utilidad de las actividades propuestas } \\
\text { en la wiki. }\end{array}$ \\
\hline Instrumentos de & $\begin{array}{l}\text { La información se obtuvo a partir de una guía de entrevista que integraba los datos de } \\
\text { medición: }\end{array}$ & $\begin{array}{l}\text { identificación de la muestra, los datos específicos sobre el nivel de satisfacción de los } \\
\text { estudiantes en relación a las actividades desarrolladas y los datos sobre las } \\
\text { competencias genéricas que manifiestan los discentes haber desarrollado y/o } \\
\text { consolidado con las prácticas formativas propuestas. }\end{array}$ \\
\hline
\end{tabular}

Principales

- La adopción de una metodología didáctica flexible basada en la realización de hallazgos: proyectos colaborativos y cooperativos a través de webquest, y apoyados en el uso de los recursos que ofrece la red Internet y diferentes herramientas digitales, tales como las wikis, posibilita a los estudiantes adquirir nuevos aprendizajes de manera significativa y colaborativa, que propician el desarrollo de competencias y habilidades más específicas, vinculadas al futuro desempeño de una actividad profesional.

- La ejecución de trabajo grupal y el diseño de actividades en línea apoyadas con el uso de wikis, donde se usen contenidos propios y adecuados de una materia, acompañados de materiales elaborados como manuales de consulta junto con otros recursos pedagógicos complementarios, como artículos de revista, periódicos, aportaciones de congresos, enlaces web, entre otros, permiten que los estudiantes adquieran conocimientos básicos sobre dicha disciplina y manejen algunos conceptos específicos.

- Actividades en colaboración basadas en la filosofía de las webquest y apoyada con el uso de las wikis contribuyen además al desarrollo de competencias instrumentales como la comunicación escrita, las habilidades para el uso de herramientas informáticas necesarias para desarrollar el trabajo colaborativo.

- En relación a las competencias interpersonales que los discentes manifiestan haber desarrollado con el proyecto, un alto porcentaje establece que han puesto en práctica habilidades para el trabajo en equipo puesto que, el desarrollo de las actividades debían efectuarse necesariamente de forma colaborativa.

- Dentro de las competencias sistémicas que los discentes declaran haber desarrollado, en mayor medida, se encuentran las habilidades para diseñar y gestionar proyectos, y su capacidad para aportar ideas innovadoras y creativas. Evidentemente, necesarias para crear una iniciativa novedosa y con ciertas garantías de éxito que favorezca el desarrollo de una población rural desfavorecida. En este sentido, un $46 \%$ de los estudiantes establece que con el diseño del proyecto han incrementado su espíritu emprendedor. 


\section{Tabla 3}

Tercera investigación

\begin{tabular}{|c|c|}
\hline Autores: & Año: 2010 \\
\hline Título del artículo: & $\begin{array}{l}\text { Las wikis en mi experiencia docente. Del diccionario, de la asignatura, al diario de } \\
\text { clase. }\end{array}$ \\
\hline Revista científica: & $\begin{array}{l}\text { Teoría de la Educación. Educación y Cultura en la } \\
\text { Sociedad de la Información. }\end{array}$ \\
\hline $\begin{array}{l}\text { Objetivos de } \\
\text { investigación: }\end{array}$ & $\begin{array}{l}\text { General: ofrecer una visión general de las posibilidades educativas de las wikis. } \\
\text { Específicos: describir algunos ejemplos del uso de las wikis en el contexto de un } \\
\text { aula virtual de una asignatura montada bajo la plataforma Moodle; dar a conocer a } \\
\text { los estudiantes la herramienta digital wiki y que experimenten el potencial que } \\
\text { tiene. }\end{array}$ \\
\hline $\begin{array}{l}\text { Instrumentos de } \\
\text { medición: }\end{array}$ & Se utiliza la observación directa en la plataforma. \\
\hline $\begin{array}{l}\text { Principales } \\
\text { hallazgos: }\end{array}$ & $\begin{array}{l}\text { - Desde la perspectiva del aprendizaje de los estudiantes, las wikis son recursos } \\
\text { útiles para el desarrollo de proyectos de investigación en una perspectiva socio } \\
\text { constructivista del conocimiento, porque permite que un equipo de alumnos } \\
\text { redacten, escriban y reconstruyan información y conocimiento que van elaborando } \\
\text { en torno a un determinado tópico, problema o caso planteado de forma colectiva. } \\
\text { - Las wikis tienen una importante potencialidad evaluativa ya que al registrarse la } \\
\text { historia de construcción de un documento, los docentes obtienen información } \\
\text { altamente valiosa para realizar el seguimiento del proceso de aprendizaje tanto } \\
\text { individual como grupal de los estudiantes, a partir del desarrollo de cualquier tarea } \\
\text { o producto. } \\
\text { - Las wikis son altamente versátiles porque además de servir como plataforma } \\
\text { para el desarrollo de cualquier tarea intelectual que requiera el empleo del lenguaje } \\
\text { escrito puede ser adaptada tanto para el trabajo colaborativo en grupo como para el } \\
\text { trabajo individual. } \\
\text { - Las wikis son recursos útiles para la enseñanza y el aprendizaje por cuanto } \\
\text { facilitan el trabajo cooperativo y colaborativo entre estudiantes a través de entornos } \\
\text { virtuales, posibilitan la publicación y difusión en internet de los trabajos elaborados } \\
\text { por un grupo o equipo de alumnos, además, de que estimulan la motivación e } \\
\text { implicación de los estudiantes en actividades que requieren procesos de búsqueda, } \\
\text { análisis y reconstrucción del conocimiento. }\end{array}$ \\
\hline
\end{tabular}




\section{Tabla 4}

Cuarta investigación

\begin{tabular}{|c|c|}
\hline Autores: & Kimmerle, J., Moskaliuk., J. y Cress, U. \\
\hline Título del artículo: & $\begin{array}{l}\text { Using wikis for learning and knowledge building: Results of an experimental } \\
\text { study. }\end{array}$ \\
\hline Revista científica: & Journal of Educational Technology \& Society. \\
\hline $\begin{array}{l}\text { Objetivos de } \\
\text { investigación: }\end{array}$ & $\begin{array}{l}\text { General: examinar procesos de aprendizaje y construcción de conocimiento } \\
\text { mediante el trabajo en wiki. } \\
\text { Específico: esbozar algunas teorías sobre la interacción entre los procesos de } \\
\text { aprendizaje individual y en colaboración. }\end{array}$ \\
\hline $\begin{array}{l}\text { Instrumentos de } \\
\text { medición: }\end{array}$ & $\begin{array}{l}\text { Se realizó un estudio experimental controlando condiciones y con observación } \\
\text { directa a través de la wiki. Se aplicaron algunos cuestionarios. }\end{array}$ \\
\hline $\begin{array}{l}\text { Principales } \\
\text { hallazgos: }\end{array}$ & $\begin{array}{l}\text { - Sobre la base de esta investigación y los enfoques teóricos tenidos en cuenta se } \\
\text { puede señalar que también debe centrarse la atención, en el proceso de aprendizaje } \\
\text { del grupo o comunidad y en sus procesos de construcción de conocimientos sobre } \\
\text { el otro. } \\
\text { - Un factor que desencadena el aprendizaje y la construcción del conocimiento es } \\
\text { la interacción entre los conocimientos de un individuo y la nueva información que } \\
\text { obtiene del entorno. Un catalizador central en este estudio es el conflicto cognitivo } \\
\text { percibido, que puede conducir a la acomodación y asimilación. Así que los } \\
\text { educadores deben proporcionar entornos educativos virtuales en los que puedan } \\
\text { crearse tales conflictos y ser activamente resueltos por los alumnos. Un wiki vacío } \\
\text { desactiva la posibilidad de vincular los propios conocimientos de contenido } \\
\text { disponible, y una wiki con toda la información relevante puede desmotivar a los } \\
\text { estudiantes a participar. Una wiki parcialmente llena, pero todavía incompleta } \\
\text { ofrece la oportunidad de considerar la nueva información, añadir los propios } \\
\text { conocimientos, resolver las controversias, e integrar diferentes posiciones. En todos } \\
\text { los casos, los educadores tienen que especificar las metas de aprendizaje. } \\
\text { - Trabajar con una wiki parece tener un menor impacto en el desarrollo del } \\
\text { conocimiento de los hechos y la construcción del conocimiento de asimilación que } \\
\text { en el desarrollo de conceptos y la construcción de conocimiento de acomodación. } \\
\text { - Las wikis representan un punto de vista constructivista en el aprendizaje, que } \\
\text { define la construcción del conocimiento como un proceso socio-cognitivo entre los } \\
\text { individuos y los grupos. }\end{array}$ \\
\hline
\end{tabular}




\section{Tabla 5}

\section{Quinta investigación}

\begin{tabular}{|c|c|}
\hline Autores: & Montenegro, M. y Pujol, J. \\
\hline Título del artículo: & $\begin{array}{l}\text { Evaluación de la wiki como herramienta de trabajo colaborativo en la docencia } \\
\text { universitaria. }\end{array}$ \\
\hline Revista científica: & Revista de Educación a Distancia. \\
\hline $\begin{array}{l}\text { Objetivos de } \\
\text { investigación: }\end{array}$ & $\begin{array}{l}\text { General: Describir el proceso seguido en la implementación de una wiki en } \\
\text { algunas asignaturas de la Licenciatura de Psicología de la Universidad Autónoma } \\
\text { de Barcelona (se coloca como ejemplo el seguimiento en solo una asignatura). } \\
\text { - Específicos: analizar el desarrollo de trabajo y tareas durante el semestre; } \\
\text { reflexionar sobre las implicaciones de uso para los procesos de enseñanza } \\
\text { aprendizaje realizado. }\end{array}$ \\
\hline $\begin{array}{l}\text { Instrumentos de } \\
\text { medición: }\end{array}$ & $\begin{array}{l}\text { Se realiza un cuestionario y debates (grupos de enfoque) para discutir los distintos } \\
\text { aspectos y profundizar en las cuestiones expresadas en el cuestionario. } \\
\text { Se observan las interacciones a través de la wiki. }\end{array}$ \\
\hline $\begin{array}{l}\text { Principales } \\
\text { hallazgos: }\end{array}$ & $\begin{array}{l}\text { - La wiki es de utilidad para favorecer las competencias de trabajo en equipo. La } \\
\text { necesidad de negociación al interior de los grupos de trabajo en relación con los } \\
\text { contenidos y el reconocimiento del trabajo de los otros compañeros hace que se } \\
\text { trabajen competencias encaminadas al desarrollo de procesos colectivos. } \\
\text { Favorece la capacidad de expresión escrita, la de análisis, la de síntesis, la } \\
\text { capacidad de gestión de la información y del tiempo dedicado al estudio, } \\
\text { mediante el uso continuado y el seguimiento del desarrollo del trabajo. } \\
\text { - A pesar que la wiki es considerada como una herramienta potente para los } \\
\text { procesos de docencia, es importante no perder de vista que su uso debe estar } \\
\text { acompañado de otros métodos de enseñanza (tutorías presenciales, reuniones de } \\
\text { grupo, ejercicios al aula, etc.). Se debe tener cuidado de no evaluar la } \\
\text { contribución de los estudiantes sólo a partir de lo que se refleja en la wiki } \\
\text { (historial), puesto que también se desarrolla trabajo en equipo presencialmente y } \\
\text { se corre el peligro de no tomar en cuenta el trabajo de aquellas personas con } \\
\text { menos acceso o competencia en el uso de las herramientas virtuales. }\end{array}$ \\
\hline
\end{tabular}




\section{Tabla 6}

\section{Sexta investigación}

\begin{tabular}{llc}
\hline Autores: & Anguita, R., García S., Villagrá, S. y Jorrín, I.M. & Año: 2010 \\
\hline $\begin{array}{l}\text { Título del } \\
\text { artículo: }\end{array}$ & $\begin{array}{l}\text { Wikis y aprendizaje colaborativo: lecciones aprendidas (y por aprender) en la facultad } \\
\text { de educación. }\end{array}$ & \\
\hline $\begin{array}{l}\text { Revista } \\
\text { científica: }\end{array}$ & Revista de Educación a Distancia. & Tipo de estudio: Cualitativo \\
\hline
\end{tabular}

Objetivos de General: analizar cómo desde una asignatura soportada por tecnología wiki y orientada

investigación: $\quad$ sobre los principios del aprendizaje por indagación (IBL) se puede ayudar a promover el trabajo colaborativo y el pensamiento crítico entre los estudiantes desde la apertura de posibilidades didácticas y docentes.

Específico: mostrar las distintas experiencias de innovación docente que desde el curso 2003 hasta la actualidad, han dado lugar a sucesivas modificaciones, tanto en el diseño educativo inicial como en los recursos empleados por los docentes que hasta el momento han impartido

\begin{tabular}{ll}
\hline $\begin{array}{l}\text { Instrumentos } \\
\text { de medición: }\end{array}$ & Se utiliza la observación directa (participante) en la plataforma. \\
\hline Principales & $\bullet \quad$ Los entornos de aprendizaje colaborativo buscan propiciar espacios en los cuales
\end{tabular}

Principales hallazgos: se promueva el desarrollo de habilidades individuales y grupales a partir de la discusión entre los estudiantes en el momento de explorar nuevos conceptos, donde cada persona debe ser responsable de su propio aprendizaje. Se busca que estos ambientes educativos sean ricos en posibilidades y, más que organizadores de la información, propicien el crecimiento del grupo.

- La gran ventaja de una wiki respecto a otras tecnologías web, es que permite crear y mejorar las páginas de forma instantánea, permitiendo dar gran libertad al usuario. A su vez, el trabajo colaborativo se desarrolla de forma muy abierta y flexible y todo ello en una interfaz muy sencilla. No obstante, el profesorado consideró también necesario disponer de un entorno privado y accesible para que el alumnado matriculado organice y comparta información "sensible" generada durante el curso. Por ello, algunos espacios de la wiki deben ser manejados en entornos cerrados gestionados dentro de Synergeia, para este caso particular.

- La confluencia de estas tecnologías permitió la creación de un espacio de trabajo único que aglutinó el diseño completo del aprendizaje y facilitó lo que se ha denominado colaboración en wiki o co-wiki (Jorrín et al., 2007, citado por Anguita, García, Villagrá, y Jorrín, 2010). La unión de tecnologías permite que el soporte ofrezca una respuesta mejor adaptada a las peculiaridades y necesidades de un proceso educativo basado en la colaboración mediada por tecnología.

- Un aspecto relevante a destacar relacionado con las pretensiones de la asignatura para fomentar aprendizajes contextualizados, se encuentra en el hecho de que el alumnado siempre tiene como punto de referencia un caso de estudio que le permite generar progresivamente diferentes recursos educativos. Respecto de las tareas que se realizan en la asignatura, se estructuran en tres grandes bloques, las que tienen que ver con el desarrollo más teórico de la asignatura, las de perfil teórico práctico que se relacionan con el análisis de diferentes medios y las que tienen por finalidad la creación de un recurso didáctico original y multimedia para llevarlo al aula. - Hay elementos de dificultad que hacen reflexionar sobre la situación real del alumnado, no tanto relacionados con la wiki sino con el acceso en general a la tecnología (existe un número menor pero significativo de estudiantes que no tienen acceso a la misma desde su residencia habitual durante el curso) y la conexión a internet y con el aprendizaje para desarrollar un trabajo colaborativo (ponerse de acuerdo, llevar el trabajo al ritmo del grupo, aportar a todos los temas). 
Tabla 7

Séptima investigación

\begin{tabular}{|c|c|}
\hline Autores: & Quiterio, A. \\
\hline Título del artículo: & $\begin{array}{l}\text { El uso de la wiki como herramienta didáctica para fomentar la competencia del } \\
\text { trabajo colaborativo: una experiencia en el ITESM, CEM. }\end{array}$ \\
\hline Revista científica: & $\begin{array}{l}\text { Teoría de la Educación. Educación y Cultura en } \\
\text { la Sociedad de la Información. }\end{array}$ \\
\hline $\begin{array}{l}\text { Objetivos de } \\
\text { investigación: }\end{array}$ & $\begin{array}{l}\text { General: conocer la percepción de los alumnos, respecto a si la wiki favorece la } \\
\text { competencia del trabajo colaborativo en la asignatura Formación en el } \\
\text { Pensamiento Crítico que se imparte en nivel medio superior del ITESM, CEM. }\end{array}$ \\
\hline $\begin{array}{l}\text { Instrumentos de } \\
\text { medición: }\end{array}$ & $\begin{array}{l}\text { Se trata de un pre experimento del tipo estudio de caso con una sola medición, la } \\
\text { cual consiste en administrar un estímulo o tratamiento a un grupo y después } \\
\text { aplicar una medición de una o más variables para observar cuál es el nivel del } \\
\text { grupo en esas variables. }\end{array}$ \\
\hline $\begin{array}{l}\text { Principales } \\
\text { hallazgos: }\end{array}$ & $\begin{array}{l}\text { - Desde la perspectiva del aprendizaje de los estudiantes, las wikis son recursos } \\
\text { útiles para el desarrollo de proyectos de investigación en una perspectiva socio } \\
\text { constructivista del conocimiento, porque permiten que un equipo de alumnos } \\
\text { redacten, escriban y reconstruyan información y conocimiento que van } \\
\text { elaborando en torno a un determinado tópico, problema o caso planteado de } \\
\text { forma colectiva. } \\
\text { - Las wikis tienen una importante potencialidad evaluativa ya que al registrarse } \\
\text { la historia de construcción de un documento, los docentes obtienen información } \\
\text { altamente valiosa para realizar el seguimiento del proceso de aprendizaje tanto } \\
\text { individual como grupal de los estudiantes, a partir del desarrollo de cualquier } \\
\text { tarea o producto. } \\
\text { - Las wikis son altamente versátiles porque además de servir como plataforma } \\
\text { para el desarrollo de cualquier tarea intelectual que requiera el empleo del } \\
\text { lenguaje escrito puede ser adaptada tanto para el trabajo colaborativo, como para } \\
\text { el trabajo individual. } \\
\text { - Las wikis son recursos útiles para la enseñanza y el aprendizaje por cuanto } \\
\text { facilitan el trabajo colaborativo entre estudiantes a través de entornos virtuales, } \\
\text { posibilitan la publicación y difusión en Internet de los trabajos elaborados por un } \\
\text { grupo o equipo de alumnos, además de que estimulan la motivación e implicación } \\
\text { de los estudiantes en actividades que requieren procesos de búsqueda, análisis y } \\
\text { reconstrucción del conocimiento. }\end{array}$ \\
\hline
\end{tabular}




\section{Tabla 8}

\section{Octava investigación}

\begin{tabular}{|c|c|}
\hline Autores: & Brack, C. y Van Damme, M-P. \\
\hline $\begin{array}{l}\text { Título del } \\
\text { artículo: }\end{array}$ & The wiki factor: Scaffolding online learning in groups. \\
\hline $\begin{array}{l}\text { Revista } \\
\text { científica: }\end{array}$ & $\begin{array}{l}\text { In 27th Ascilite Conference (memories), Curriculum, } \\
\text { Technology and Transformation for an Unknown } \\
\text { Future. }\end{array}$ \\
\hline $\begin{array}{l}\text { Objetivos de } \\
\text { investigación: }\end{array}$ & $\begin{array}{l}\text { General: presentar la evaluación de un diseño educativo con un entorno en línea y la } \\
\text { pedagogía que subyace del trabajo en grupo en línea y del andamiaje del aprendizaje } \\
\text { colaborativo. } \\
\text { Específicos: describir el uso de la tecnología en el andamiaje del aprendizaje } \\
\text { colaborativo y considerar los efectos sobre la actividad de los estudiantes; facilitar tanto } \\
\text { el proceso como el producto de la colaboración en línea. }\end{array}$ \\
\hline $\begin{array}{l}\text { Instrumentos } \\
\text { de medición: }\end{array}$ & $\begin{array}{l}\text { Se consideró: la observación cuantitativa en la plataforma, en ella se tuvo en cuenta, el } \\
\text { número de participantes, cantidad de participaciones, porcentaje de participantes unidos } \\
\text { al foro, número y duración de las páginas; -la observación cualitativa, que se utilizó para } \\
\text { analizar la naturaleza y calidad de las contribuciones de los estudiantes; -la entrevista } \\
\text { semiestructurada a una muestra de alumnos para conocer sus percepciones frente al } \\
\text { trabajo realizado. }\end{array}$ \\
\hline $\begin{array}{l}\text { Principales } \\
\text { hallazgos: }\end{array}$ & 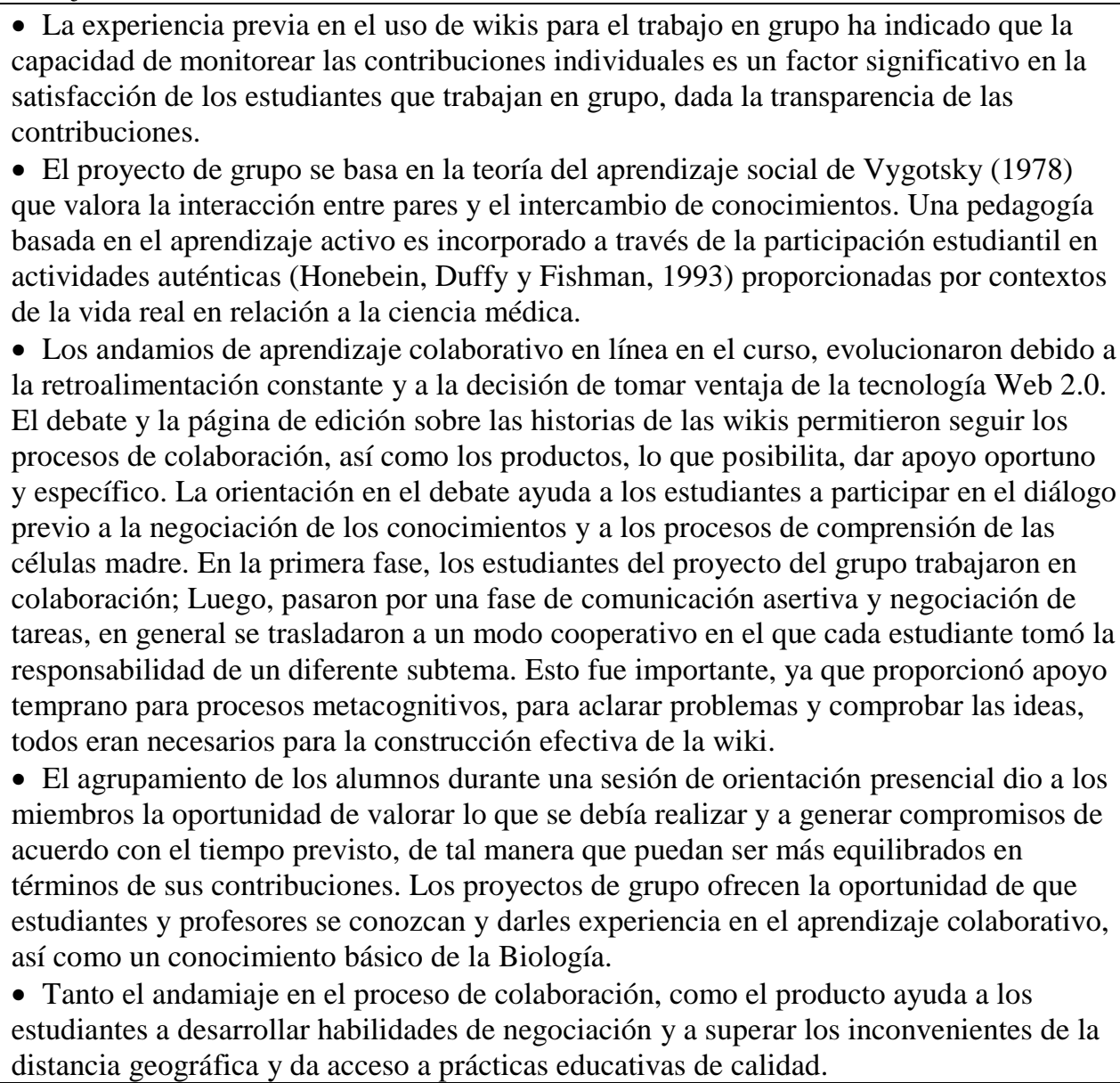 \\
\hline
\end{tabular}




\section{Tabla 9}

\section{Novena investigación}

\begin{tabular}{|c|c|}
\hline Autores: & Perea, G.P., Estrada, B. y Campos, M \\
\hline Título del artículo: & $\begin{array}{l}\text { El blog y wiki como herramienta docente para el trabajo colaborativo, el } \\
\text { aprendizaje autónomo, activo y reflexivo. }\end{array}$ \\
\hline Revista científica: & $\begin{array}{l}\text { Revista Iberoamericana para la Investigación y el } \\
\text { Desarrollo Educativo. }\end{array}$ \\
\hline $\begin{array}{l}\text { Objetivos de } \\
\text { investigación: }\end{array}$ & $\begin{array}{l}\text { General: mostrar los escenarios que permiten transformar el entorno tradicional } \\
\text { del salón de clases, por el aprendizaje colaborativo en el ámbito educativo, y las } \\
\text { posibilidades en mejora de la calidad, la comunicación, el desempeño y la } \\
\text { participación de los estudiantes. } \\
\text { Específico: implementar el uso de la tecnología específicamente el blog y wiki } \\
\text { como apoyo en la docencia. }\end{array}$ \\
\hline $\begin{array}{l}\text { Instrumentos de } \\
\text { medición: }\end{array}$ & La entrevista semiestructurada. \\
\hline $\begin{array}{l}\text { Principales } \\
\text { hallazgos: }\end{array}$ & $\begin{array}{l}\text { - La incorporación de las tecnologías a la educación resulta eficaz si se } \\
\text { conciben y se aplican con el propósito expreso de fomentar el aprendizaje } \\
\text { autónomo, activo y reflexivo y el desarrollo del trabajo colaborativo. } \\
\text { - Para que el docente mantenga un control del trabajo, puede realizar un } \\
\text { portafolio de evidencias y así evaluar el comportamiento y participación de cada } \\
\text { estudiante, por lo que cada subgrupo abre un wiki que permite observar quien } \\
\text { participa, contenido, aporte y número de veces que participó. Por este medio se } \\
\text { presenta el grado de desarrollo para el uso de los blogs educativos y wikis, a } \\
\text { través de su aplicación en el aula para participar en el salón de clase, así como } \\
\text { para la realización de tareas grupales colaborativas. } \\
\text { - En comparación con los estudiantes del período agosto-diciembre } 2011 \text {, } \\
\text { donde no se había hecho uso de las TIC (blog y wiki), la participación de los } \\
\text { alumnos en clase fue solo durante sus presentaciones sin distinción alguna, con la } \\
\text { desventaja que algunos no colaboraron con la actividad y sus compañeros de } \\
\text { grupo no lo comunicaron. Por esta razón hay que sensibilizar a los estudiantes en } \\
\text { este sentido. } \\
\text { - El aprendizaje significativo para los estudiantes en } 2012 \text { correspondió al } 98 \% \text {, } \\
\text { se dio el } 100 \% \text { del trabajo colaborativo, lo que permitió la participación activa y } \\
\text { reflexiva en un } 93 \% \text {, por consiguiente los estudiantes desarrollaron sus } \\
\text { habilidades en un 95\% lo que al unir los rubros anteriores, permitió que se } \\
\text { generara aprendizaje significativo. }\end{array}$ \\
\hline
\end{tabular}


Tabla 10

Décima investigación

\begin{tabular}{|c|c|}
\hline Autores: & Aborisade, $\mathrm{P}$. \\
\hline Título del artículo: & $\begin{array}{l}\text { Investigating a Nigerian XXL-cohort wiki-learning experience: Observation, } \\
\text { feedback and reflection }\end{array}$ \\
\hline Revista científica: & Electronic Journal of e-Learning \\
\hline $\begin{array}{l}\text { Objetivos de } \\
\text { investigación: }\end{array}$ & $\begin{array}{l}\text { General: socializar la experiencia de uso de una wiki como herramienta para el } \\
\text { aprendizaje colaborativo y la interacción social en un proyecto de mejoramiento } \\
\text { del idioma. } \\
\text { Específicos: conocer la percepción de los estudiantes frente a su aprendizaje y a la } \\
\text { realización de las actividades y saber si hay alguna diferencia de aprendizaje antes } \\
\text { y después del apoyo tecnológico; vivenciar las ventajas (si las hay) de una wiki } \\
\text { para el aprendizaje mixto en aulas extra grandes. }\end{array}$ \\
\hline $\begin{array}{l}\text { Instrumentos de } \\
\text { medición: }\end{array}$ & $\begin{array}{l}\text { El cuestionario y los formularios de evaluación para la parte cuantitativa. La } \\
\text { observación, y los registros de colaboración en las actividades, retroalimentación, } \\
\text { reflexiones y comentarios a través de la wiki, para la parte cualitativa. }\end{array}$ \\
\hline $\begin{array}{l}\text { Principales } \\
\text { hallazgos: }\end{array}$ & $\begin{array}{l}\text { - Las grandes ventajas del módulo con apoyo de tecnología para aulas de clase } \\
\text { extra grandes, reside en la posibilidad de extender el aula más allá de las paredes } \\
\text { (en línea), que requiere de la colaboración y de la interacción de los estudiantes } \\
\text { en proyectos de trabajo en grupo. Esto mejora en los estudiantes el uso del } \\
\text { computador no solo como herramienta para enviar y recibir correos electrónicos } \\
\text { o hacer compras en línea, sino que es utilizado con fines académicos para la } \\
\text { edición de material y construcción de conocimiento. } \\
\text { - Debido a que el aprendizaje apoyado o mediado por tecnología requiere } \\
\text { conocimientos de la pedagogía apropiada, es necesario un plan de acción por } \\
\text { parte de la institución, para que mejore o innove los cursos con base en esa nueva } \\
\text { pedagogía. Asociado a esto, se encuentran los métodos de evaluación. Si los } \\
\text { procesos de enseñanza aprendizaje cambian, es necesario que la metodología de } \\
\text { evaluación también cambie. } \\
\text { - En países del tercer mundo, donde los entornos tecnológicos a nivel escolar son } \\
\text { pobres, se puede hacer mucho por mejorar las experiencias de aprendizaje de los } \\
\text { jóvenes, debido a que los alumnos se sienten más a gusto con las nuevas } \\
\text { tecnologías. }\end{array}$ \\
\hline
\end{tabular}




\section{Método}

El propósito de este capítulo, es presentar la estrategia que se utilizó para obtener los datos que permitieron dar respuesta a las preguntas de investigación formuladas en el planteamiento del problema. De esta manera, se presenta el enfoque metodológico y el diseño mixto que se implementó, así como las características de la muestra, el contexto sociodemográfico, los instrumentos de recolección de datos, los procedimientos para su aplicación y finalmente, las estrategias para el análisis de los datos recolectados, mismos que derivaron de la observación no participante al grupo que usó la wiki (grupo experimental) y la entrevista semiestructurada para el maestro titular de ese mismo grupo, en lo concerniente a la fase cualitativa del estudio. Asimismo, también sobresalió la encuesta para los alumnos del grupo experimental, además de la preprueba y posprueba aplicadas tanto a los estudiantes que utilizaron el apoyo tecnológico, como a

los que no lo hicieron (grupo de control); esos instrumentos fueron considerados para la fase cuantitativa.

\subsection{Enfoque metodológico de la investigación}

De acuerdo con el planteamiento de Giroux y Tremblay (2004) sobre la importancia de la investigación, la recolección y el análisis de los datos, es importante señalar que para la selección del enfoque de este estudio, se tuvo como referente la utilización de diversos instrumentos o técnicas de recolección que contribuyeron a enriquecer la perspectiva de la investigadora y proporcionaron mayor información 
respecto al fenómeno indagado. En este caso, se pretendió conocer el impacto del uso e incorporación de una wiki en el aprendizaje de la Biología y comprobar las hipótesis referidas en el capítulo 1, sobre la facilidad que proporcionó la wiki para el aprendizaje de la Biología, así como la diferencia en el rendimiento académico, entre un grupo intervenido con el apoyo tecnológico y otro grupo que no fue sometido a dicha intervención. Consecuentemente, en virtud de que se buscó dar riqueza a la recolección de datos, el enfoque metodológico correspondiente a los métodos mixtos resultó ser el más apropiado y benéfico para este estudio.

Al respecto Hernández, Fernández y Baptista (2010) señalan que la investigación mixta utiliza las fortalezas de la investigación cualitativa y de la investigación cuantitativa, que al integrarse sistemáticamente permitieron al investigador tener una visión más amplia de otros aspectos relevantes del fenómeno como: los beneficios de la wiki en el trabajo cooperativo de los estudiantes en la clase de Biología, las interacciones que se desarrollaron y la actitud asumida por los estudiantes en ese espacio virtual de trabajo. Todo, como parte de los objetivos de la indagación y cuyo cumplimiento se fortaleció con las técnicas de recolección propias, de los enfoques cualitativos y cuantitativos.

Por otra parte, la discusión generada una vez obtenidos los datos de ambas etapas, tanto la cualitativa como la cuantitativa, permitieron hacer deducciones importantes, gracias a toda la información recolectada (metainferencias) y lograr un mayor entendimiento del fenómeno estudiado. De esa manera y a través de la triangulación con los fundamentos teóricos, se respondieron las preguntas de investigación. Asimismo, esta información constituyó una representación genuina y confiable sobre cómo 
aprendieron los alumnos al usar una wiki en la clase de Biología (Hernández, Sampieri y Mendoza, 2008; Todd y Lobeck, 2004 citados por Hernández et al 2010).

De igual manera, a través de la integración de las diferentes técnicas de recolección de datos, utilizadas en el enfoque mixto de investigación se logró incluir tanto la lógica deductiva como la inductiva. Esto ayudó a ampliar los horizontes de la investigación cualitativa y con ello se comprendieron mejor los análisis estadísticos y la categorización de datos (Teddlie y Taschakkori, 2012).

En resumen, con el método mixto se consiguió amplitud y profundidad en la perspectiva del fenómeno estudiado; se clarificó el problema investigado, debido a la riqueza y variedad de los datos obtenidos a partir de las diferentes fuentes y en distintos espacios escolares (virtual y presencial), producto de la implementación de los instrumentos de recolección cuantitativos y cualitativos (guía de observación no participante, entrevista semiestructurada para el maestro titular del grupo experimental, la encuesta para los alumnos, entre otros), además se enriquecieron los análisis teóricos y prácticos, debido al manejo riguroso, crítico y reflexivo de los datos. Todo lo anterior fue posible, gracias a que los métodos mixtos se fundamentan en el pragmatismo y por lo tanto, permitieron la inclusión de diversas premisas teoréticas y metodologías (Hernández et al 2010; Teddlie y Taschakkori, 2012).

En cuanto al diseño, se tomó en cuenta el breve tiempo de la indagación y por lo tanto se decidió trabajar con un diseño exploratorio secuencial y en modalidad comparativa (en adelante DEXPLOS), donde se reunieron y analizaron los datos cualitativos, en una primera fase y en una segunda etapa se recolectaron y analizaron los 
datos del método cuantitativo, con una muestra no probabilística (Hernández et al. 2010).

En la fase cualitativa, se recurrió a la observación no participante de la interacción de los estudiantes en la wiki (sólo con los alumnos del grupo experimental) y a la entrevista semiestructurada con el maestro titular de ese grupo (ver Apéndices C y D). Para la fase cuantitativa, se aplicó una encuesta a los alumnos del grupo experimental (Grupo 8-1; ver Apéndice E), así como dos exámenes, una preprueba y una posprueba (ver Apéndices F y G), con el estilo de la evaluación censal aplicada en Colombia (prueba SABER -área de ciencias naturales), a fin de medir el impacto del uso de la wiki (intervención tecnológica) en el aprendizaje de la Biología, por parte de los alumnos del octavo grado. Cabe señalar, que el uso de la wiki fue la variable independiente y el aprendizaje de la biología, constituyó la variable dependiente de este estudio mixto. Finalmente, para ello se contempló un grupo de control que no utilizó la wiki (Grupo 82) y otro experimental que sí usó la wiki (Grupo 8-1).

Por lo anterior, puede señalarse, que la observación no participante para el grupo experimental y la entrevista semiestructurada para el maestro titular del grupo experimental (ver Apéndices C y D), permitieron profundizar y reflexionar sobre las interacciones ocurridas entre los estudiantes, así como sobre las que se efectuaron entre el maestro y los alumnos, además del trabajo cooperativo realizado por los estudiantes a través de la wiki, lo que produjo una valoración permanente acerca del impacto de este apoyo tecnológico en el aprendizaje de la Biología y particularmente, en el desempeño académico de los alumnos. Igualmente con la observación no participante del grupo experimental, fue posible describir el nuevo ambiente de aprendizaje desarrollado, 
comprender los procesos y patrones que marcaron esta experiencia educativa, tanto en los maestros como en los alumnos (ver Apéndice K). La entrevista semiestructurada al titular del grupo experimental (ver Apéndice L), generó mayor comunicación con el docente y se obtuvo más información para la elaboración y comprensión conjunta de significados relacionados con las interacciones y las actividades desarrolladas (Hernández et al. 2010).

Es pertinente señalar que para la fase cuantitativa, también se consideró un diseño cuasiexperimental con preprueba y posprueba (Hernández et al. 2010; Valenzuela y Flores, 2012), así como con un grupo de control (Grupo 8-2) y otro experimental (Grupo 8-1). Cabe destacar, que se consideraron los grupos de alumnos que ya estaban previamente conformados (no hubo selección aleatoria), es decir, eran grupos intactos basados en las necesidades de la institución educativa. El grupo experimental fue intervenido con el apoyo tecnológico, es decir, el uso de la wiki y posteriormente ambos grupos fueron sometidos a la posprueba, para determinar el impacto en la variable dependiente (aprendizaje de la Biología). Todo ello, a fin de contrastar las diferencias entre ambos grupos y evaluar el posible mejoramiento en el rendimiento académico de los alumnos después del uso del AVA (Creswell, 2009 citado por Hernández et al. 2010). Finalmente, se aplicó una encuesta (ver Apéndice E) a los estudiantes del grupo experimental que trabajaron con la wiki, con el objetivo de conocer su actitud respecto al uso de la wiki en la clase de Biología.

Por otra parte, la modalidad del diseño DEXPLOS de la presente indagación fue comparativa, debido a que la fase cuantitativa no se construyó sobre la base cualitativa; sólo se tomó en cuenta la información relevante de los resultados iniciales. 
Posteriormente, los hallazgos de ambas fases se compararon e integraron en el análisis y discusión final, donde se hizo una triangulación con los fundamentos detallados en el capítulo 2. De esa forma se dio respuesta al problema planteado, es decir, a través de metainferencias (Hernández et al. 2010).

De acuerdo con Creswell (2009 citado por Hernández et al. 2010), un diseño DEXPLOS, es útil para quien busca explorar el fenómeno. Como ya se ha mencionado, este estudio constó de dos fases: una cualitativa (CUAL) y otra cuantitativa (CUAN). En cada una de ellas, fue necesario tomar en cuenta los procesos que guiaron la investigación y que estuvieron relacionados con cada una de las etapas de la indagación (muestreo, recolección de datos y análisis de los mismos), tal y como se presenta en la Figura 1. Con ello, se generaron un conjunto de datos que se compararon e integraron en la discusión final (capítulo 4), así como en las conclusiones de la investigación. La ventaja de todo lo anterior, radicó en su fácil implementación, porque las etapas fueron claras y diferenciadas, lo que facilitó dar respuesta a las preguntas de investigación (Hernández et al.2010).

A continuación, en la Figura 1, se presentan las principales etapas de la indagación, conforme al diseño DEXPLOS implementado. 


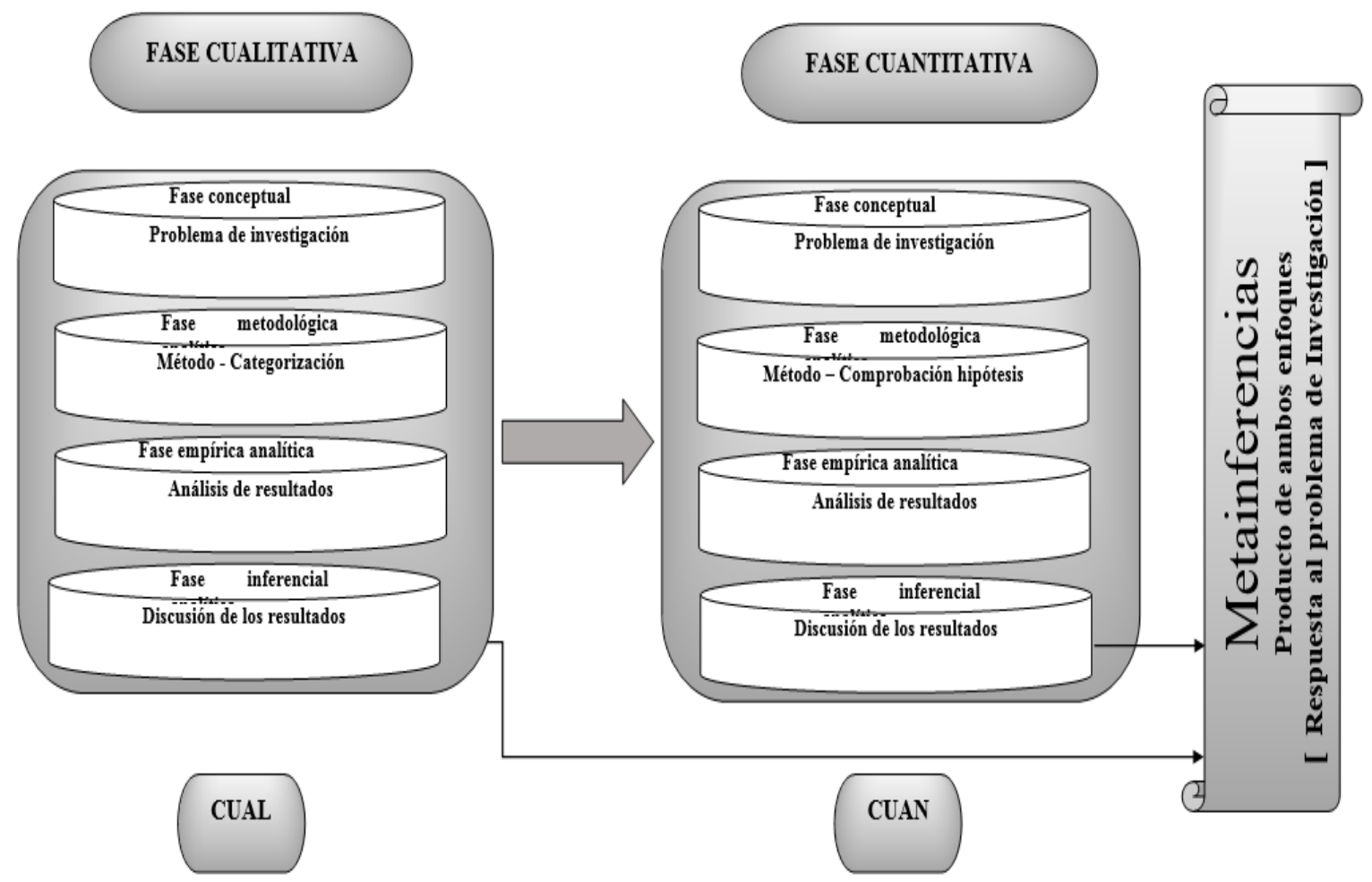

Figura 1. Etapas del proceso mixto (adaptado de Hernández, Fernández y Baptista, 2010).

\subsection{Población, participantes y selección de la muestra}

En este apartado fue necesario precisar la unidad de análisis y para ello, se tuvo en cuenta que la población o universo, estuvo constituida por la totalidad de los estudiantes de octavo grado de secundaria que pertenecían a una institución educativa pública colombiana, ubicada al norte del Departamento del Valle, en el Municipio de Roldanillo. De esta manera, 119 alumnos conformaron dicha población, es decir jóvenes con edades que oscilaron entre los 13 y 17 años, según documentos institucionales.

En concordancia con lo anterior, el tipo de muestra fue no probabilística porque el procedimiento para su selección fue informal y obedeció a que se pretendió conocer el impacto del uso e incorporación de un apoyo tecnológico en el aprendizaje de la 
Biología, con el objeto de buscar, no sólo estrategias para mejorar el desempeño académico de estos alumnos, sino también contribuir a su preparación para la presentación de la prueba censal que realizarán en noveno grado. Esto, debido a que en octavo, se abordan los conceptos que deberán ser dominados en dicha prueba. En este sentido la muestra no se consideró representativa del universo de alumnos, pero sí contó con casos típicos o estudiantes seleccionados conforme a los fines de la indagación y como lo afirman Colás y Buendía (1992), en las investigaciones educativas, las situaciones y realidades humanas son diversas, difíciles de controlar y medir, por tal razón no se pretendió hacer generalizaciones. No obstante, la muestra no probabilística fue conveniente para los fines del estudio, porque coincidió con los objetivos del problema planteado (Hernández et al. 2010).

Asimismo, la población se encontró dividida por grupos de alumnos, ubicados en sus aulas de clase respectiva, es decir, grupos previamente conformados o denominados intactos, por Hernández et al. (2010). En total hubo cuatro grupos, de los cuales dos se localizaron en la zona urbana y dos en la zona rural. De esta manera, para la selección de la muestra no probabilística se consideraron sólo los grupos de secundaria de la zona urbana. Por lo tanto, el tamaño de la muestra estuvo constituida sólo por 79 estudiantes, de los cuales, 41 alumnos, usaron el apoyo tecnológico, como parte del grupo experimental (Grupo 8-1). En la fase cuantitativa, también se consideró al grupo de control (Grupo 8-2), con los 38 estudiantes restantes, a fin de hacer las respectivas comparaciones sobre el desempeño académico de los estudiantes que usaron la wiki (grupo experimental), respecto de aquellos que no lo hicieron. 
De acuerdo con el procedimiento descrito, y con los planteamientos de Teddie y Yu (2007 citados por Hernández et al. 2010), donde se admite que no existen estrategias únicas para la selección de los sujetos participantes en los métodos mixtos, es importante indicar, que se tuvo en consideración el requerimiento de las directivas de la institución, respecto a la selección de alumnos regulares y con su matrícula legalizada (inscritos) hasta ese momento. Este tipo de muestra también conocida como dirigida, fue conveniente para el investigador, porque favoreció la recolección y análisis de datos. Asimismo, el muestreo coincidió con los objetivos de la investigación y no dependió de que todos los sujetos participantes tuvieran la misma probabilidad para ser elegidos (Hernández et al. 2010).

\subsection{Contexto sociodemográfico}

La Institución Educativa Belisario Peña Piñeiro se encuentra situada en el Municipio de Roldanillo, ubicado al Norte del Departamento del Valle del Cauca, sobre la vertiente oriental de la cordillera occidental de Colombia. Es una entidad educativa de carácter oficial (pública) que ha ofrecido sus servicios educativos en los niveles de preescolar, básica primaria, básica secundaria y media técnica. Lleva su nombre en honor del ilustre pedagogo Don Belisario Peña Piñeiro. Actualmente, beneficia con su labor educativa a una población de aproximadamente 1690 estudiantes, que en su mayoría pertenecen al nivel socio económico bajo, seguido del nivel medio y categorizados de acuerdo con el sistema de identificación de potenciales beneficiarios de los programas sociales a nivel nacional (SISBEN) en nivel 1, 2 y 3. De las actividades laborales que se desarrollan en la región destacan la agricultura, la ganadería, los 
empleos estatales, el turismo y el comercio en general. La región se ha caracterizado por la influencia del narcotráfico.

La Institución fue fundada por Ordenanza de la Honorable Asamblea Departamental № 45 del 22 de Junio de 1939 como colegio de segunda enseñanza y el Ministerio de Educación Nacional en 1960, aprobó los estudios correspondientes a la educación secundaria. En el año 2002, el colegio se fusionó con varios establecimientos educativos oficiales, conformándose un total de 13 sedes ubicadas tanto en la zona rural como en la zona urbana.

La infraestructura física de la sede principal, donde se realizó este estudio, cuenta con zonas verdes, 20 aulas de clase, aula máxima, sala de profesores, 3 oficinas administrativas, laboratorios de física y química, biblioteca, un salón religioso, salas de audiovisuales, 2 video beam (proyector), un equipo de sonido, restaurante escolar, baterías sanitarias, cancha de futbol, 3 salas de cómputo, con aproximadamente 15 equipos cada una, en dos de las salas hay conexión a Internet con servidores independientes, aire acondicionado, sin embargo las velocidades de navegación son bajas. Asimismo, de una de ellas se genera una conexión de Internet para la tercera sala, esto hace, que el acceso a Internet en esta última sala, sea aún más deficiente, sumado a las constantes fallas en los equipos de cómputo, ya que ésta no cuenta con aire acondicionado.

La misión de la institución educativa está orientada a ofrecer un servicio educativo a niños, niñas, jóvenes y adultos en los niveles educativos ya referidos, en jornadas diurna y nocturna, con especialidad en auxiliar administrativo, auxiliar contable, auxiliar en mantenimiento de hardware y software, auxiliar en gestión y procesamiento de 
imágenes gráficas, donde se potencializa el talento humano de la comunidad educativa y para lograr la formación holística de los estudiantes, se proponen metas de calidad académicas y formativas, mediante el desarrollo de competencias básicas, ciudadanas y laborales generales y específicas. Además, proyecta para el 2015, convertirse en una de las mejores organizaciones educativas en el ámbito local y regional, comprometido con las metas de calidad e identidad institucional, y con propiciar procesos de humanización para insertarse en el siglo XXI exitosamente en el sector laboral.

En este sentido, es importante señalar la influencia que tiene el factor socio familiar de los alumnos en el desempeño de las pruebas censales y en su rendimiento académico, esto debido a múltiples razones, una de ellas es que algunos padres de familia no le otorgan importancia a la prueba, porque están más interesados en que sus hijos simplemente permanezcan en el sistema educativo con el ánimo de recibir los subsidios que proporciona el Estado, en ocasiones, cuando los obtienen simplemente retiran a sus hijos de la institución; otra, son las condiciones económicas tan precarias que se viven al interior de las familias, lo que conduce al maltrato, microtráfico (narcomenudeo) o expendio de sustancias psicoactivas e ilegales, así como el consumo de las mismas; problemáticas, que inciden de manera negativa en el rendimiento de los estudiantes. A pesar de lo anteriormente mencionado y acorde con las exigencias del Estado, la institución educativa debe hacerse responsable de la presentación de todos sus estudiantes a dicha prueba, que es de carácter nacional como mecanismo de seguimiento y control a la calidad de la educación colombiana.

Ese examen estandarizado, es aplicado a los estudiantes de $3^{\circ}, 5^{\circ}$ y $9^{\circ}$ grado, donde se culmina la secundaria. Anteriormente, era aplicado cada 4 años, sin embargo a 
partir de la vigencia 2012 el Ministerio de Educación Nacional, decidió que fuera anual y los resultados han sido entregados un año o dos años, después de presentada la prueba. Los últimos exámenes aplicados para el área de ciencias naturales (objeto de este estudio) corresponden a los años 2009, 2012 y 2014, sin embargo, hasta el año 2014 para el área de ciencias naturales no se conocían los resultados obtenidos en el año 2012. A finales de marzo de 2015 fue publicada la información tanto de la prueba 2014, como la de años anteriores (ver Apéndice B).

En este orden de ideas, en el año 2009, 168 estudiantes de la institución presentaron dicha prueba; en el año 2012, 70 estudiantes y en el 2014, 94 estudiantes. Su ubicación en los diferentes niveles de desempeño se presenta en la Tabla 11.

Tabla 11

Resultados comparativos de las pruebas SABER para el área de ciencias naturales

\begin{tabular}{lcccccc}
\hline & \multicolumn{2}{c}{ Año 2009 } & \multicolumn{2}{c}{ Año 2012 } & \multicolumn{2}{c}{ Año 2014 } \\
\hline & No. Estud. & $\%$ & No. Estud. & \% & No. Estud & \% \\
\hline Insuficiente & 36 & $(21,42)$ & 4 & $(6)$ & 21 & $(22)$ \\
\hline Mínimo & 106 & $(63,09)$ & 28 & $(40)$ & 47 & $(50)$ \\
\hline Satisfactorio & 23 & $(13,67)$ & 27 & $(38)$ & 24 & $(26)$ \\
\hline Avanzado & 3 & $(1,8)$ & 11 & $(16)$ & 2 & $(2)$ \\
\hline
\end{tabular}

Al respecto, puede observarse que un porcentaje considerable de los estudiantes se ubica en los niveles de insuficiente y mínimo. Debido a esta situación, la institución ha tratado de reformar el plan de estudios, de tal forma que los conceptos y temas abordados para la prueba de Biología, sean manejados y afianzados entre octavo y noveno grado. En los siguientes grados, décimo y onceavo, que comprenden el último 
nivel de escolaridad, se hace énfasis en los conceptos químicos y físicos de la materia. Consecuentemente, los conocimientos que un estudiante adquiere en octavo grado son los fundamentos de noveno. De allí, que se busquen estrategias para mejorar los procesos didácticos en el área de ciencias naturales y en general de todas las asignaturas del plan de estudios. Esta cuestión también forma parte de la justificación de este estudio mixto, donde se pretendió contribuir al enriquecimiento del proceso de enseñanzaaprendizaje, a través del uso e incorporación de una wiki en la clase de Biología del octavo grado.

\subsection{Instrumentos de recolección de datos}

Las técnicas que se emplearon, para la obtención de los datos requeridos en este estudio, con el fin de dar respuesta a todas las interrogantes que se formularon en el planteamiento del problema, fueron de diferentes tipos y para diferentes propósitos, entre ellos reunir variedad de datos (cualitativos y cuantitativos) complejos de medir, como los comportamientos y situaciones de enseñanza aprendizaje vivenciados en el salón de clase con el apoyo tecnológico, así como el desempeño académico y las actividades específicas que se desarrollaron en el entorno virtual y el aula presencial. Todos estos datos se recolectaron cuando se observó, escuchó y evalúo a los alumnos participantes en esta investigación (Valenzuela y Flores, 2012).

A continuación, se describen los instrumentos que se aplicaron en el estudio, conforme a las fases del diseño DEXPLOS: 
Fase cualitativa: En cuanto a las herramientas de recolección de datos, para la fase cualitativa, se utilizó la guía de observación no participante para el grupo experimental (Grupo 8-1), respecto a la interacción de los alumnos con el apoyo tecnológico, además de la guía de entrevista semiestructurada para el titular del mismo grupo (ver Apéndices C y D). Es importante precisar que la observación es una técnica que permite la anotación y registro de eventos, comportamientos y artefactos de manera sistemática en el contexto social seleccionado para el estudio (Marshall y Rosman, 1999, citados por Valenzuela y Flores, 2012).

Particularmente se trató de un tipo de observación no participante, debido a que el observador no se involucró con las personas, ni fue intrusivo durante las actividades estudiadas. En este caso, la autora de la investigación sólo se limitó a observar la interacción de los alumnos en la wiki, a través del acompañamiento y retroalimentación constante del maestro titular del Grupo 8-1 (grupo experimental), a través de una guía que contenía cuatro categorías principales: la interacción de los alumnos con el docente, la interacción de los alumnos con la wiki, el desarrollo del trabajo cooperativo en la clase de Biología y la facilidad para aprender la misma (ver Apéndice C).

La primera sección o categoría, con sus respectivos indicadores, permitió abordar la interacción del maestro con los alumnos a partir de los comportamientos presentados al inicio de la sesión de clase, como fueron el establecimiento de los objetivos de la sesión, la familiarización con el apoyo tecnológico, las instrucciones que se impartieron para la realización de actividades cooperativas en la wiki, además de la retroalimentación de dudas y resolución de problemas técnicos. La segunda categoría proporcionó información sobre las interacciones de los alumnos con el apoyo 
tecnológico y con sus compañeros, el agrado o rechazo mostrado por el trabajo con la wiki, el seguimiento a las instrucciones, la participación, el progreso en las actividades y el cumplimiento de compromisos individuales y grupales. La tercera categoría brindó información respecto al cierre de la sesión, con un breve resumen sobre los principales aspectos abordados en la clase, el énfasis en las dudas aclaradas, así como los logros de aprendizaje y la conclusión exitosa de la sesión (ver Apéndice C).

Los aspectos anteriormente señalados, fueron indicadores de las principales categorías consideradas en la guía de observación no participante para el octavo grado, las cuales se detallan más adelante (ver Tabla 12). Además es conveniente señalar que la guía de observación también contempló otro tipo de aspectos, como aquellos eventos o comportamientos positivos reflejados en la sesión de clase y los que eran susceptibles de mejorarse.

Cabe señalar, que durante el proceso de observación, la investigadora presenció cuatro sesiones de clase que tenían como base las actividades cooperativas diseñadas para que los alumnos las realizaran en la wiki (ver Apéndice H). Particularmente, estas actividades consistieron en la solución a preguntas detonadoras, definición del concepto de reproducción, elaboración del cuadro comparativo o mapa conceptual y construcción de un documento final con toda la información contenida y alojada en la página creada por cada equipo de trabajo dentro de la wiki (ver Apéndice H) 
Tabla 12.

Categorías consideradas en la guía de observación para la recolección de datos

\begin{tabular}{cl}
\hline Categorías & \multicolumn{1}{c}{ Indicadores } \\
\hline & --Establecimiento de objetivos \\
& --Familiarización con el apoyo tecnológico \\
& --Instrucciones impartidas por el docente para trabajar en la \\
Interacción del profesor con los & wiki \\
alumnos & --Actitud del docente \\
& --Explicación de la forma de evaluar las actividades en la wiki \\
& --Retroalimentación de dudas \\
& --Resolución de problemas técnicos en la wiki. \\
\hline Interacción de los alumnos con & --Agrado o rechazo mostrado por los alumnos al usar la wiki \\
la wiki & --Comentarios verbales expresados por los estudiantes al usar \\
& --Dificultades en la interacción \\
\hline Desarrollo del trabajo & --Interacciones respetuosas y tolerantes \\
Biología & --Cumplimiento de compromisos \\
& --Participación activa en la wiki \\
\hline Biología & --Seguimiento de las instrucciones del profesor para \\
& interactuar con la wiki \\
\hline Facilidad para aprender & --Resumen de los principales aspectos abordados. \\
\hline & --Éxito en la terminación de la sesión \\
\hline & --Principales logros en el aprendizaje de la Biología \\
\hline
\end{tabular}

Por otra parte y de acuerdo con Valenzuela y Flores (2012), la entrevista se considera una técnica de recolección de datos que es utilizada en todas las investigaciones de corte cualitativo y que puede ser estructurada de diferentes maneras. Implica una construcción de significados entre el investigador y el participante y permite al investigador recabar datos que no pueden ser obtenidos por medio de la observación. En esta investigación se optó por la entrevista semiestructurada por ser más abierta y menos estructurada, de esta manera se logró que el entrevistado manifestara sus perspectivas sobre las situaciones de aprendizaje e interacciones con el apoyo tecnológico, acorde con las vivencias presenciales y virtuales (ver Apéndice D). En concordancia con lo anterior, la guía de entrevista semiestructurada incluyó un total de 15 preguntas abiertas sobre temáticas relacionadas con el aprendizaje de la Biología, las 
interacciones en la wiki, los beneficios de utilizar el AVA para enseñar la ciencia, entre otros (ver Apéndice D). Estas interrogantes fueron formuladas al docente titular del grupo experimental, dentro de las instalaciones de la institución educativa, una vez concluidas las sesiones de clase previstas con el apoyo tecnológico. Su orden quedó a criterio del entrevistador quien pudo añadir alguna pregunta o modificarla según lo consideró conveniente (Valenzuela y Flores, 2012).

En cuanto a la validez de los instrumentos cualitativos, los criterios tenidos en cuenta fueron la credibilidad y la dependencia cualitativas (Hernández et al. 2010). En búsqueda de la consistencia de los resultados, para la dependencia cualitativa, la investigadora consideró todos los datos recabados y a todos los sujetos que integraron la muestra, especificó el contexto donde realizó el trabajo de campo y la forma cómo accedió a los datos recolectados. Sistematizó las interpretaciones de los mismos, sin considerar sus creencias y opiniones subjetivas con el propósito de no afectar su coherencia. Asimismo, no generó conclusiones sin que hubiese culminado el análisis de los datos. Por otra parte, la autora especificó y fundamentó tanto la perspectiva teórica como el diseño metodológico que utilizó, así como los criterios usados para seleccionar a los participantes y técnicas de recolección de datos (Hernández et al. 2010).

Con relación a la credibilidad cualitativa, además de privilegiar o considerar a todos los participantes y dar importancia a ese cúmulo de datos, se realizó la triangulación de los mismos a partir de diferentes fuentes o técnicas de recolección cualitativas y cuantitativas. Para ello, se trianguló la información obtenida por la observación no participante en el grupo experimental, con los datos derivados de la entrevista semiestructurada al maestro titular de ese grupo (Hernández et al. 2010). 
Al respecto, cabe señalar que para Valenzuela y Flores (2012), la triangulación, de fuentes, técnicas de recolección y datos, con los fundamentos teóricos del capítulo 2, también constituye un elemento que fortalece la validez o credibilidad de la indagación.

Fase cuantitativa. En cuanto a las herramientas de recolección de datos para esta etapa, se recurrió a una preprueba y posprueba sobre Biología, es decir, una prueba antes y después del uso de la wiki, tanto en el grupo de control, como en el grupo experimental (ver Apéndices F y G), así como a la encuesta que fue aplicada a todos los alumnos que usaron el AVA (ver Apéndice E). Dichos instrumentos incluyeron preguntas cerradas cuyas respuestas fueron codificadas y sometidas a un posterior análisis de estadística descriptiva e inferencial. Cabe destacar, que además fueron contestados en formatos impresos (cuestionarios autoadministrados), con lápiz y de manera presencial (Valenzuela y Flores, 2012).

En este caso, se aplicó la encuesta sólo a los estudiantes del curso de Biología que trabajaron con el apoyo tecnológico, considerado como experimental (Grupo 8-1) y en ella se abordaron aspectos relacionados con su experiencia de aprendizaje a través de la wiki en la asignatura ya mencionada, es decir, el trabajo cooperativo, el interés y motivación que despertó en los estudiantes el uso del AVA, así como su actitud respecto a su uso e incorporación en el aula. Además, contaba con un total de 25 ítems o preguntas cerradas donde se utilizó escala Likert (ver Apéndice E). Al respecto, la escala fue la siguiente: $4=$ totalmente de acuerdo; $3=$ de acuerdo; $2=$ en desacuerdo; $1=$ totalmente en desacuerdo. 
Por otro lado, tal como refieren Valenzuela y Flores (2012), las pruebas de aptitudes en educación (en este estudio, preprueba y posprueba), son instrumentos de medición que permiten predecir situaciones específicas de un fenómeno educativo, en este caso, el desempeño académico en el área de Biología, antes y después del uso de la wiki. Dichas pruebas se pueden contestar a través de formatos físicos o impresos, utilizando lápiz, o incluso de manera virtual. Para este estudio, se aplicó una preprueba a los alumnos del grupo de control y experimental, antes del uso del apoyo tecnológico, con el fin de medir las condiciones previas a la intervención y también se consideró una posprueba a estos mismos grupos, para medir su rendimiento académico, es decir, el efecto de la wiki sobre la variable dependiente (aprendizaje de la Biología), después de la intervención con el AVA. De esta manera, se pretendió comparar el rendimiento académico de ambos grupos, el de control y el experimental.

Por lo tanto, en cada preprueba y posprueba se incluyeron un total de 15 preguntas cerradas cada una con un valor de dos puntos, que relacionaron aspectos vistos en las diferentes sesiones de clase, como el concepto de reproducción, la reproducción celular y la reproducción asexual (ver Apéndices F y G). Asimismo, en su diseño se tuvo en cuenta el estilo utilizado en la prueba censal colombiana Saber, que considera diferentes opciones de respuesta con una sola opción correcta. De igual manera, se diseñó una rúbrica con escala mixta para que el titular del grupo experimental evaluara el desempeño de los estudiantes en la wiki (ver Apéndice I). Las categorías o dimensiones que se consideraron fueron: realización de actividades en la wiki, calidad de las aportaciones al trabajo cooperativo, calidad de la información presentada, organización de la misma, desarrollo del trabajo cooperativo y manejo del tiempo. La escala de 
calificación fue mixta y se consideró de la siguiente forma: 5=Superior, 4=Alto, 3.=Básico y 2=Bajo (López, 2013).

En cuanto a la validez de los instrumentos cuantitativos, se consideró la validez del contenido, del criterio y del constructo, tal como lo establecen Hernández et al. (2010). Asimismo, se recurrió a la validez de expertos con grado de maestría y doctorado respectivamente, quienes avalaron el contenido de los mismos en virtud de su experiencia y perfil profesional. De dicha revisión, derivaron algunos ajustes al contenido de los instrumentos.

\subsection{Procedimientos para la aplicación de instrumentos}

Para dar inicio al proceso de aplicación de los instrumentos, primero fue necesario contar con la debida aprobación de la directora de la institución educativa y para tal efecto, se entregó una carta de solicitud de autorización para realizar la indagación en las instalaciones del colegio (ver Apéndice A). Para la fase cualitativa, el procedimiento de aplicación de instrumentos fue el siguiente:

- Observación en el aula: una vez obtenido el permiso, se estableció por parte de la investigadora una actitud amable y respetuosa al momento de su ingreso al salón de clase con el objetivo de lograr la confianza, comprensión y empatía de los participantes. Durante la observación, la autora consideró las recomendaciones de Valenzuela y Flores (2012) y mantuvo un comportamiento discreto, además de haber estado alerta a los gestos, posturas, actitudes, comentarios y tonos de voz que utilizaron los alumnos y el docente. La guía de observación no participante (ver Apéndice C), permitió que la autora se adentrara paulatinamente al escenario 
educativo, de esta manera logró comprender la dinámica del grupo experimental y tuvo mayor claridad sobre los principales aspectos que acontecieron, los detalló y analizó las situaciones más específicas según las categorías e indicadores del instrumento; esto contribuyó al descubrimiento de eventos repetitivos e importantes para su estudio. Todo ello, permitió recolectar los datos relativos al uso de la wiki, por parte de los alumnos y las interacciones que se generaron para el aprendizaje de la Biología. (ver Apéndice C) (Valenzuela y Flores, 2012). Consecuentemente, la investigadora realizó el registro escrito de lo que observó, durante 4 sesiones de clase (cada una de 1 hora y 30 minutos) y también consignó la hora de inicio y finalización de la clase, la fecha de la observación, el nombre del titular de la clase y todos los detalles observados en el aula (ver Apéndice K), además se realizaron registros fotográficos para evidenciar el trabajo de campo (ver Apéndice M).

- Entrevista semiestructurada al titular del grupo experimental (8-1): consideradas las recomendaciones de Valenzuela y Flores (2012), se programó una cita previa con el docente, quien fue entrevistado después de que concluyeron las sesiones de clase donde se utilizó la wiki. Para ello, se recurrió a la guía de entrevista, previamente descrita (ver Apéndice D) y las temáticas abordadas se organizaron en una lista clara de preguntas abiertas. Sin embargo, tal como lo sugieren Valenzuela y Flores (2012), la autora de la investigación fue flexible en términos del orden en que fueron consideradas las preguntas y permitió que el entrevistado desarrollara sus ideas y ampliara los temas abordados. Previamente, la autora se presentó y dio a conocer al maestro el propósito de la entrevista; también solicitó algunos datos relativos a su perfil profesional y la entrevista fue grabada en su totalidad. Cabe señalar, que se 
aseguró la confidencialidad de los datos y la utilidad de los mismos en la investigación. La autora de este estudio trató de establecer el rapport, que consistió en generar un clima de confianza y empatía con el docente entrevistado (Valenzuela y Flores, 2012). La entrevista realizada se transcribió en su totalidad (ver Apéndice L). Finalmente, cabe destacar que para la recolección de los datos cualitativos, también se recurrió al diario de campo para realizar anotaciones y reflexiones adicionales, además de haberse tomado algunas fotografías como evidencia de la labor realizada (ver Apéndice M).

Para la fase cuantitativa, el procedimiento de aplicación de instrumentos fue el siguiente:

- Preprueba: se aplicó antes de usar la wiki, conforme a las actividades cooperativas diseñadas para ello (ver Apéndice H). Se entregaron los exámenes impresos a los docentes titulares de los Grupos 8-1 y 8-2 (experimental y de control, respectivamente) en el momento exacto de su aplicación; los alumnos tuvieron 45 minutos para responder a los cuestionamientos planteados y sólo utilizaron lápiz para responder la prueba aplicada en forma presencial. El investigador tomó algunas fotos que permiten mostrar este proceso (ver Apéndice M).

- Posprueba: se aplicó después de la conclusión del trabajo desarrollado por los alumnos en la wiki, es decir, fue posterior a la intervención con el AVA. Se entregaron las pruebas impresas a los docentes titulares de los grados en el momento de su aplicación, los alumnos tuvieron 45 minutos para responder a los cuestionamientos planteados y sólo utilizaron lápiz. Cabe destacar que la preprueba y 
posprueba fueron aplicadas durante horas libres de clase. Sin embargo, en todo momento se contó con la presencia de los docentes titulares de los Grupos 8-1 y 8-2. La investigadora nuevamente registró evidencias fotográficas (ver Apéndice M).

- Encuesta para los alumnos que utilizaron la wiki (sólo grupo experimental): fue aplicada a través de un cuestionario autoadministrado durante una sesión de clase y fue respondido por los alumnos en un tiempo aproximado de 35 minutos; sólo usaron lápiz y en caso de requerirlo, un borrador. De esa manera, se facilitó la aplicación del instrumento (su practicidad) y realmente no se requirió ayuda directa de la encuestadora y autora del estudio.

\subsection{Estrategia para el análisis de datos}

La fase cualitativa de este estudio se fundamentó tanto en la triangulación metodológica (consistente en contrastar múltiples fuentes de datos) como en la dependencia y credibilidad cualitativas, tal como ya se refirió antes (como elementos de validez). Por esta razón para el análisis de los datos, éstos se trascribieron, codificaron y se hizo un análisis preliminar a fin de obtener un sentido de todo el cúmulo de datos, antes de segmentarlo por tendencias y patrones (Valenzuela y Flores, 2012).

Posteriormente, se clasificaron y etiquetaron, asignándoles códigos representativos; se examinaron nuevamente y se segmentaron en temas más amplios que derivaron en categorías exhaustivas, a fin de generar una codificación axial (Creswell, 2005, citado por Valenzuela y Flores, 2012). Con esta codificación de los datos cualitativos, se concretó la construcción de categorías que respondieron a los fines del estudio en forma congruente. De esta forma, se logró definir las tendencias y patrones que se convirtieron 
en los temas o abstracciones derivadas de los datos y que a su vez, permitieron dar respuesta al problema de investigación. En este sentido, también sobresalió la bitácora de análisis o diario reflexivo donde se registraron variedad de datos que también complementaron aquellos que fueron recolectados con los instrumentos diseñados exclusivamente para este estudio. Todo ello, a través del método comparativo constante (Lincoln y Guba, 1985, citados por Valenzuela y Flores, 2012).

Por otro lado, respecto a la fase cuantitativa la objetividad de los datos cuantitativos permitió codificarlos en una matriz de Excel, previo uso del libro de códigos de la encuesta (ver Apéndice J), para su posterior análisis a través del programa de cómputo Minitab 17, a fin de presentar los datos mediante distribuciones de frecuencias (absolutas y relativas) y realizar los correspondientes análisis de estadística descriptiva e inferencial, es decir, con medidas de dispersión y de variabilidad, así como la prueba t para probar la hipótesis de diferencia de grupos (Hernández et al. 2010; Valenzuela y Flores, 2012).

Finalmente, tal como refieren Teddlie y Tashakkori (2008, citados por Hernández et al. 2010), a fin de dar respuesta a las preguntas de investigación formuladas en el capítulo 1, se hicieron metainferencias derivadas de los hallazgos obtenidos en cada fase de este estudio mixto (inferencias cualitativas y cuantitativas). Todo eso se triángulo con los fundamentos teóricos del capítulo 2. En ese sentido, es aplicable el comentario de Valenzuela y Flores, 2012), respecto a la triangulación de fuentes, métodos y sustentos teóricos, que da validez al estudio. Por otro lado, en el siguiente capítulo se presentarán los resultados derivados de los instrumentos aplicados en esta indagación, conforme a 
cada etapa de la misma y también se dará respuesta a las preguntas de investigación, a través de una discusión final, donde se retomarán las bases teóricas del capítulo 2 . 


\section{Análisis y discusión de resultados}

El propósito del presente capítulo, es presentar los resultados obtenidos a través de los instrumentos de recolección diseñados para tal fin, además de su análisis y discusión, con el objetivo de dar respuesta al problema planteado en el capítulo 1. Para ello, el capítulo se ha dividido en dos partes: la primera, en la que se presentan los resultados más relevantes recolectados durante la fase cualitativa y cuantitativa, conforme al diseño mixto (DEXPLOS) implementado. Asimismo, en una segunda parte, se analizan, interpretan y triangulan los hallazgos más significativos, con los fundamentos teóricos presentados en el capítulo 2, a fin de dar respuesta a las preguntas de investigación.

\subsection{Presentación de resultados}

Debido a que el diseño de esta investigación fue DEXPLOS, los datos fueron recabados en dos fases de indagación. En la primera fase, correspondiente a la aproximación cualitativa, se aplicó una guía de observación no participante (ver

Apéndice C) respecto a la interacción de los alumnos con la wiki en la clase de Biología y también una guía de entrevista semiestructurada para el maestro titular del Grupo 8-1 (grupo experimental de la fase cuantitativa - ver Apéndice D). Posteriormente, se transcribieron y organizaron los datos; se analizaron las frases y patrones de respuesta o de conductas derivadas de la observación (segmentos de texto más relevantes). 
Finalmente, se buscaron las frases con sentido (unidades de análisis), se categorizaron y codificaron, identificándose los temas que le dieron sentido a los datos.

Consecuentemente, tal como refieren Valenzuela y Flores (2012), para el análisis de los datos cualitativos, se recurrió al método comparativo constante, mediante notas sintéticas y en extenso, a través de la bitácora de análisis, lo que se complementó con el diario de campo, donde también se registraron las experiencias, ideas y reflexiones de la investigadora, durante todo el análisis del contenido. Todo ello, permitió contar con el análisis taxonómico que fue la base de la triangulación, donde se respondieron las preguntas de investigación.

En cuanto a la segunda fase de la indagación, es decir, la aproximación cuantitativa, los datos derivaron de la preprueba y posprueba (ver Apéndices F y G), correspondientes a la intervención con la wiki, así como de la aplicación de una encuesta para los alumnos del grupo experimental (ver Apéndice E). Dichos datos fueron organizados y codificados mediante tablas y matrices en Excel, lo que permitió hacer análisis de estadística descriptiva e inferencial, con de medidas de tendencia central y de dispersión, presentadas mediante distribuciones de frecuencias absolutas y relativas. Asimismo, cabe señalar que para el análisis de los datos derivados de la encuesta, también se recurrió al uso del libro de códigos (ver Apéndice J).

Por lo tanto, en esta primera sección del capítulo se presentan los resultados, a partir de las etapas del diseño mix to implementado (DEXPLOS) y según los instrumentos aplicados en cada fase del estudio (primero la cualitativa y posteriormente la cuantitativa). Con la información obtenida en este proceso y según lo que se aborda en 
las siguientes páginas, se logró dar cumplimiento al objetivo general de este estudio que fue: conocer el impacto del uso de una wiki en el aprendizaje de Biología.

4.1.1. Fase cualitativa. Tal como ya se refirió previamente, durante esta etapa de la investigación los instrumentos aplicados para recolectar los datos fueron: la guía de observación no participante y la guía de entrevista semiestructurada (ver Apéndices C y E).

\subsubsection{Categorización de la observación no participante para el grupo}

experimenta (8-l). En esta sección se presentan las situaciones más relevantes que fueron observadas y que guardaron estrecha relación con el impacto del uso de una wiki en el aprendizaje de la Biología, particularmente en el grupo experimental del estudio (Grupo 8-1). Para ello, se desarrolló una tabla con todas las categorías derivadas del análisis taxonómico, junto con sus códigos respectivos; posteriormente, se resumió lo sucedido a lo largo de las sesiones observadas (incidentes), acorde con las categorías enlistadas y definidas. Cabe destacar, que el uso de la wiki se observó durante cuatro clases y conforme a las actividades diseñadas para tal efecto, como parte de esta indagación (ver Apéndices H y K).

Asimismo, cada clase observada tuvo una duración aproximada de 1 hora y 30 minutos, misma que se realizaron a lo largo de casi cuatro semanas, debido a la disponibilidad del maestro titular del grupo experimental. Dicho lapso de tiempo fue adecuado y permitió que los estudiantes del octavo grado (Grupo 8-1) tuvieran la oportunidad de familiarizarse con una herramienta desconocida hasta ese momento para ellos. Las clases se desarrollaron en el aula de sistemas, espacio donde la autora registró 
sus observaciones a través de una guía de observación no participante (ver Apéndice C).

De esta manera fue posible registrar los detalles de cada sesión en forma separada (ver Apéndices $\mathrm{C}$ y K), es decir, cada clase observada fue transcrita en su totalidad. Por consiguiente, resulta conveniente indicar que la observación no participante tuvo como finalidad, explorar el escenario educativo donde se usó e incorporó el AVA, así como conocer el desarrollo de la interacción de los alumnos con la wiki.

Particularmente, las categorías y códigos que se establecieron para agrupar los incidentes observados en las clases de Biología fueron las siguientes: interacción del profesor con los alumnos (IP-CA), interacción de los alumnos en la wiki (IA-CW), desarrollo del trabajo cooperativo en la clase de Biología (TC-CB), facilidad para aprender Biología (FAB-CW) y recursos e infraestructura escolar para usar la wiki $(R I E-U W)$. Lo anterior, se encuentra descrito en la Tabla 13. De igual manera, para identificar el registro de las observaciones no participantes en el grupo experimental se utilizó el código: $O N P-G E$.

Tabla 13

Categorias emergentes derivadas de las observaciones no participantes en el Grupo 8-1 $(O N P-G E)$

\begin{tabular}{cl}
\hline Categorías & \multicolumn{1}{c}{ Indicadores } \\
\hline $\begin{array}{c}\text { Interacción del profesor } \\
\text { con los alumnos (IP-CA) }\end{array}$ & $\begin{array}{l}\text { En esta categoría se agruparon las situaciones relacionadas (incidentes) con } \\
\text { el desempeño del docente durante las sesiones de clase trabajadas con la } \\
\text { wiki, considerando la interacción de los alumnos con el maestro. }\end{array}$ \\
\hline $\begin{array}{c}\text { Interacción de los alumnos } \\
\text { con la wiki } \\
\text { (IA-CW) }\end{array}$ & $\begin{array}{l}\text { En esta categoría se agruparon las situaciones relacionadas con el } \\
\text { desempeño de los alumnos durante las clases mediadas por la wiki; } \\
\text { particularmente, su interacción con el AVA. }\end{array}$ \\
\hline $\begin{array}{c}\text { Desarrollo del trabajo } \\
\text { cooperativo en la clase de } \\
\text { Biología (TC-CB) }\end{array}$ & $\begin{array}{l}\text { En esta categoría se agruparon los incidentes relacionados con las } \\
\text { actividades cooperativas desarrolladas por los alumnos, en la wiki. }\end{array}$ \\
\hline $\begin{array}{c}\text { Facilidad para aprender la } \\
\text { Biología (FAB-CW) }\end{array}$ & $\begin{array}{l}\text { En esta categoría se agruparon las situaciones relacionadas (incidentes) con } \\
\text { los logros obtenidos en el aprendizaje de la Biología con apoyo de la wiki. }\end{array}$ \\
\hline $\begin{array}{c}\text { Recursos e infraestructura } \\
\text { escolar para usar la wiki } \\
\text { (RIE-UW) }\end{array}$ & $\begin{array}{l}\text { En esta categoría se agruparon las situaciones relacionadas (incidentes) con } \\
\text { los aspectos materiales que obstaculizan el uso de la wiki. }\end{array}$ \\
\hline
\end{tabular}


A continuación, se presenta un resumen de los principales hechos observados en cada categoría (ver Apéndice K):

\section{Interacción del profesor con los alumnos (IP-CA). En las observaciones no} participantes realizadas en las sesiones de clase de Biología apoyadas con la wiki (sólo con el grupo experimental), fue notorio el rol activo del docente para familiarizar a los estudiantes con el AVA, e incentivarlos a interactuar con sus compañeros. En cada sesión de clase, el docente siempre indicó los objetivos de la clase y la forma de realizar las actividades diseñadas para tal efecto (ver Apéndice H). El maestro manifestó en todo momento una actitud cordial y respetuosa lo cual ayudó a que los estudiantes compartieran constantemente sus dudas y participaran en los foros virtuales de la wiki. El maestro siempre estuvo atento a resolver las dificultades que se presentaron en el salón de clase, fueran éstas de carácter tecnológico, o incluso sobre la logística de las actividades en la wiki. También hizo seguimiento a las participaciones virtuales de los estudiantes y las retroalimentó. Fue un guía que ofreció indicaciones precisas tanto de forma verbal como escrita, esta última a través de la wiki. Finalmente, se le observó dispuesto a apoyar a sus estudiantes, a escucharlos en todo momento, sin dejar de ser riguroso y formal (ver Apéndice K; ONP-GE).

2. Interacción de los alumnos con la wiki $(\mathbf{I A}-\mathrm{CW})$. De manera general, se analizó que la interacción entre los alumnos en un principio se desarrolló de forma paulatina o progresiva, es decir, poco a poco lograron comprender la forma de trabajar en la wiki, debido a que los estudiantes no estaban acostumbrados a este tipo de apoyo tecnológico y menos en asignaturas diferentes a las relacionadas con la Informática. Sin embargo, pudo apreciarse que después de la segunda sesión observada, los estudiantes se 
mostraron más activos y participativos, con una actitud diferente frente al proceso de enseñanza aprendizaje mediado por la wiki. Fue notorio el entusiasmo con el que cinco equipos de alumnos llegaban a la clase y la motivación con la que desarrollaron las actividades cooperativas, además del ánimo que dieron a otros compañeros para que trabajaran con la wiki. Las siguientes expresiones escuchadas durante la observación de la tercera y cuarta sesión de clase, por parte de los diferentes integrantes de los equipos de trabajo reflejaron esta situación: "Hágale que trabajar con la wiki es fácil venga le muestro"; "reunámonos para definir el concepto que va a dejar el grupo”; “me está quedando chévere mi aportación" (ver sesiones observadas 3 y 4 - Apéndice K). También se evidenció que en general, los estudiantes buscaron el apoyo de sus docentes cuando tuvieron dudas, así como la ayuda de sus compañeros, estuvieran o no, en el mismo equipo de trabajo. Se comunicaron a través de los foros, respondieron las preguntas planteadas y cuestionaron lo que escribían. La búsqueda de información fue un proceso que les agradó mucho, porque tuvieron la oportunidad de observar diversos vídeos e imágenes, a fin de completar las actividades en la wiki (ver Apéndice H). Igualmente, al observar las aportaciones que realizaron en las dos últimas sesiones de clase dentro de la wiki logró percibirse el avance en las actividades, la participación en las actividades cooperativas y se evidenció la producción conjunta (ver Apéndice K; ONP-GE).

\section{Desarrollo del trabajo cooperativo en la clase de Biología (TC-CB). En este}

aspecto, se notó, que la mayor parte de los equipos trabajaron muy bien de forma cooperativa, sus integrantes se mostraron activos y motivados, hicieron discusiones enriquecedoras, se apoyaron unos a otros, compartieron información, interactuaron 
constantemente de manera respetuosa y armónica, reconocieron las habilidades de sus compañeros y aceptaron sus debilidades, esto les permitió consensuar y dinamizar el trabajo cooperativo. En contraposición, se presentaron dificultades con la minoría de los equipos (no todos), porque en ellos, se observaron casos de estudiantes con poca disposición e interés para trabajar. El docente siempre intervino en estas situaciones y guió a los equipos en la realización de las aportaciones y participaciones para la ejecución conjunta de las actividades. Un aspecto interesante de la comunicación en la wiki, fue el respeto y tolerancia mostrada por los alumnos para discutir en sus foros, fueron cuidadosos para decirle a sus compañeros sobre una idea escrita o un aporte erróneo en la edición de las actividades (ver Apéndice K; ONP-GE).

4. Facilidad para aprender la Biología $(F A B-C W)$. En esta categoría, se observó que las nuevas formas de interacción social entre los estudiantes jugaron un papel importante para el aprendizaje cooperativo y el cumplimiento de las actividades sobre el concepto de reproducción (en general), reproducción asexual y celular realizadas en la wiki (ver Apéndice H). Aquellos estudiantes que se concientizaron sobre la responsabilidad de cumplir con sus aportaciones, de interactuar constantemente, negociar y aprender a valorar lo que escribieron sus compañeros, fueron capaces de alcanzar los objetivos de aprendizaje (ONP-GE; ver Apéndice K).

En estos equipos se percibieron progresos significativos relacionados con el aprendizaje cooperativo, porque las interacciones eran más frecuentes y enriquecidas, se ayudaron mutuamente, las tareas fueron distribuidas, se vio el compromiso de los integrantes, se explicaban unos a otros, llegaron a consensos y a discusiones que se escuchaban interesantes, se divertían a la vez que construían sus páginas de trabajo, 
todas estas actitudes y habilidades contribuyeron al aprendizaje de las temáticas trabajadas en la clase de Biología y al desarrollo de las competencias requeridas en esta área del saber, como, la comunicación, el discernimiento, el trabajo en equipo, entre otras (ONP-GE; ver Apéndice K) .

5. Recursos e infraestructura escolar para usar la wiki (RIE-UW). En este sentido, desafortunadamente también fueron evidentes los problemas presentados en todas las sesiones de clase con la señal de Internet (intermitencia, lentitud y a veces la ausencia del servicio). Esto afectó tanto el desarrollo normal de las clases, como la distribución del tiempo que había considerado el docente para cada actividad en la wiki, lo que también impactó en la motivación de algunos estudiantes. Por tal razón, es importante que maestros y administrativos busquen soporte y asesoría técnica para minimizar las fallas durante las clases y evitar que se perturbe o incluso detenga el trabajo de los estudiantes. Además es necesaria la comprensión por parte de los directivos de este tipo de situaciones, para garantizar: la renovación con equipos de cómputo modernos, con todos sus accesorios y periféricos, la dotación de salas de cómputo con las condiciones óptimas para que los estudiantes y docentes de otras áreas diferentes a tecnología e informática puedan usarlas sin inconvenientes (ONP-GE; ver Apéndice K).

Asimismo, es indispensable que los equipos de cómputo sean previamente revisados por el titular del grupo, a fin de garantizar que todos funcionen de manera óptima en las diferentes actividades diseñadas y que además sean previstas las posibles fallas técnicas para que se contemplen actividades alternas de trabajo que puedan ser realizadas en el momento que se presenten este tipo de incidentes. Otra constante observada fue la actitud negativa de algunos estudiantes hacia el estudio. Dichos jóvenes 
no realizaron las actividades (no todos) y el docente no pudo convencer a ese grupo minoritario de alumnos para que completara las actividades en la wiki dentro de los tiempos establecidos. Puede afirmarse que si se considera el desempeño de esos alumnos durante todo el curso (como una conducta permanente), esa situación requerirá de un mayor acompañamiento, a fin de sensibilizarlos sobre la importancia que tiene la materia para su desarrollo académico y también para su futuro. En ese sentido, será necesario fortalecer valores como la responsabilidad, la perseverancia, la solidaridad, la honestidad. Lo anterior, también contribuirá a crear una cultura del uso de los AVA en la comunidad educativa y mejorará las interacciones entre alumnos y docentes (ONPGE; ver Apéndice K).

\subsubsection{Categorización de la entrevista semiestructurada con el titular del grupo} experimental (8-1). En este apartado se describen los datos derivados de la entrevista con el maestro titular del Grupo 8-1 (experimental), la cual permitió conocer su perspectiva sobre el impacto del uso e incorporación de una wiki en la enseñanzaaprendizaje de la Biología. Para tal fin y conforme a lo que se describió en el capítulo 3, en el instrumento se incluyeron 15 preguntas abiertas sobre aspectos relacionados con los beneficios de la wiki para enriquecer y facilitar el aprendizaje de la Biología, a través del trabajo cooperativo. Asimismo, se consideraron las dificultades enfrentadas por el docente y los estudiantes con el uso del AVA, su utilidad para modificar los modelos tradicionales de enseñanza y su conveniencia en la realización de actividades cooperativas para favorecer la construcción del conocimiento, entre otros. El instrumento se aplicó mediante una guía de entrevista semiestructurada (ver Apéndice D). 
La duración máxima de la entrevista fue de 35 minutos y el registro de los datos se logró con el uso de una videograbadora. Posteriormente, las respuestas fueron transcritas en su totalidad (ver Apéndice L). Consecuentemente, se identificaron las unidades de análisis y segmentos más sobresalientes que permitieron establecer los temas y principales patrones de respuesta, así como las categorías y códigos respectivos (ver Tabla 14).

Tabla 14

Categorías emergentes de la entrevista con el maestro titular del grupo experimental

\begin{tabular}{|c|c|}
\hline Categorías & Indicadores \\
\hline $\begin{array}{l}\text { Interacción del profesor con los } \\
\text { alumnos (IP-CA) }\end{array}$ & $\begin{array}{l}\text { En esta categoría se agruparon las opiniones (segmentos) } \\
\text { del maestro sobre el uso de la wiki, durante la interacción } \\
\text { con los alumnos. }\end{array}$ \\
\hline $\begin{array}{l}\text { Interacción de los alumnos con la } \\
\text { wiki (IA-CW) }\end{array}$ & $\begin{array}{l}\text { En esta categoría se agruparon segmentos, respecto a las } \\
\text { actitudes y situaciones enfrentadas por los estudiantes } \\
\text { durante el trabajo con la wiki. }\end{array}$ \\
\hline $\begin{array}{c}\text { Desarrollo del trabajo cooperativo en } \\
\text { la clase de Biología (TC-CB) }\end{array}$ & $\begin{array}{l}\text { En esta categoría se agruparon los segmentos, relacionados } \\
\text { con las actividades cooperativas desarrolladas en la wiki. }\end{array}$ \\
\hline $\begin{array}{c}\text { Facilidad para aprender Biología con } \\
\text { la wiki } \\
(\text { FAB-CW) }\end{array}$ & $\begin{array}{l}\text { En esta categoría se agruparon los segmentos relativos a los } \\
\text { beneficios del uso de la wiki para el aprendizaje de la } \\
\text { Biología, en los alumnos del octavo grado. }\end{array}$ \\
\hline $\begin{array}{l}\text { Recursos e infraestructura escolar } \\
\text { para usar la wiki } \\
\text { (RIE-UW) }\end{array}$ & $\begin{array}{l}\text { En esta categoría se agruparon los segmentos relacionados } \\
\text { con los recursos materiales y humanos necesarios para } \\
\text { facilitar el uso e incorporación de la wiki en las clases de } \\
\text { secundaria. }\end{array}$ \\
\hline
\end{tabular}

A continuación, se resumen los principales hallazgos con base en las unidades de análisis o principales segmentos (respuestas) del maestro titular del grupo experimental, correspondiente a cada una de las categorías emergentes previamente detalladas. Para citar las opiniones textuales del maestro entrevistado, se utilizó el código: EMT-GE, que significa: entrevista al maestro titular del grupo experimental.

1. Interacción del profesor con los alumnos (IP-CA). El docente expresó claramente que el uso de la wiki permite modificar la enseñanza tradicional de las clases de Biología 
y cambiar su rol en el proceso de enseñanza aprendizaje, pues le otorgó mayor protagonismo al estudiante y posibilitó enriquecer su interacción con él (maestroalumno). Entre las razones que mencionó se encuentran: "se incorpora la parte dinámica, la parte de vídeos, la parte de los conceptos y permite mayor interacción con el docente y entre los estudiantes y también con la misma fuente digamos de consulta" (EMT-GE; ver Apéndice L). Advirtió que el uso de la wiki ayuda a reforzar y complementar la clase presencial, así como a cambiar la forma de presentar los contenidos, la información y los momentos de interacción, esto le permite al estudiante, buscar y seleccionar información de diferente procedencia y en diversos formatos, en el momento que lo necesita, lo que también enriquece el intercambio de ideas, porque: "no se trata solamente de una fuente de información que es el docente y el concepto que él emite, sino que permite al estudiante interactuar con diferentes fuentes y de diferente forma, ya no sólo sincrónicamente sino también asincrónicamente, no sólo verbal, sino en forma escrita; con la wiki se comparte conocimiento e información de manera diferente y rápida y esto es de gran agrado para aquellos estudiantes, para quienes quizás es mucho más fácil que solamente [presentar] texto" (EMT-GE; ver Apéndice L). Al respecto, puede afirmarse que la innovación que representó el nuevo apoyo tecnológico, despertó el interés de la mayoría de los alumnos por utilizar la wiki, a pesar de ciertas dificultades en la infraestructura tecnológica de la escuela, que fueron subsanadas con el acompañamiento del maestro titular del grupo.

Por otro lado, el docente expresó que los profesores en general, tienen la gran responsabilidad de diseñar actividades que se ajusten a las nuevas dinámicas y concepciones pedagógicas de los apoyos tecnológicos. Al respecto, el maestro titular 
señaló las siguientes razones: “de no contemplar ciertas estrategias pedagógicas que dinamicen el trabajo en ella [la wiki], se podría entorpecer el buen desarrollo de las actividades y caerse nuevamente en el tradicionalismo. De hecho los maestros debemos manejar bien estos apoyos tecnológicos, pero éstos deben estar mediados [contemplados] en el currículo [en casi todas las materias de la secundaria]" (EMTGE; ver Apéndice L).

2. Interacción de los alumnos con la wiki $(\mathbf{I A}-\mathrm{CW})$. El maestro consideró que al usar la wiki, se incrementaron las interacciones entre los alumnos (como parte de las actividades cooperativas) y la posibilidad de alcanzar los objetivos establecidos en ellas, porque los alumnos intercambiaron información, se ayudaron entre sí y destacaron las aportaciones relevantes de sus compañeros, o las que consideraron como interesantes (ya publicadas o susceptibles de ser subidas en la wiki). La siguiente afirmación del maestro, confirma lo mencionado: "Debido a que algunos estudiantes interactúan constantemente, logran construir conjuntamente páginas llamativas y presentar ideas que captan el interés de otros, las interacciones mejoran, se incrementan, además de que así, poco a poco van tomando protagonismo y esto les ayuda a alcanzar las metas, mejorar sus conocimientos, y a disfrutar al compartirlo” (EMT-GE; ver Apéndice L).

De igual forma, refirió que la mayoría de los estudiantes manifestaron actitudes tanto de agrado, pero también hubo un grupo minoritario de alumnos que manifestaron cierto rechazo frente al uso de la wiki y sólo se debió a cuestiones relacionadas con la parte física del aula, algunos aspectos de la infraestructura tecnológica, la imposibilidad de usar una computadora después de los horarios de clase, además de las dificultades que representó comenzar a familiarizarse con el AVA. 


\section{Desarrollo del trabajo cooperativo en la clase de Biología (TC-CB). El maestro}

consideró que el uso de la wiki dinamizó las actividades cooperativas porque los estudiantes asumieron un rol diferente, lo que es reflejado en esta afirmación: “La wiki estimula las actividades cooperativas, ya que de alguna manera hace que recobre importancia el papel activo que deben tener los estudiantes, los motiva.'. Manifestó además, que la wiki ayudó a que los estudiantes expresaran sin temor sus ideas previas respecto a un concepto, esto generó un diálogo que les permitió de manera conjunta organizar sus esquemas mentales debido a que: "ellos van formando y reformulando las ideas que ellos tienen para construir un concepto un poco más aproximado a lo científico, porque pueden discutir en cualquier momento con sus compañeros y docente. Así, los integrantes de cada equipo se ayudan mutuamente, se evalúan, respetan los aportes de todos y tratan de mejorar sus producciones. Claro está cuando hay responsabilidad y entendimiento entre los grupos de trabajo”.

También, destacó el hecho de que el trabajo cooperativo requiere un componente muy importante y complejo por parte de los estudiantes y es la voluntad. Consideró, que la actitud positiva mostrada por la mayoría de los estudiantes promovió el apoyo y trabajo mutuo y mejoró los procesos de aprendizaje. Sin embargo, expresó, que en el caso contrario (la actitud negativa de algunos estudiantes) podría entorpecer el desarrollo grupal de las actividades cooperativas. Esto se vio reflejado en los siguientes comentarios: "Cuando en los grupos no se presentan tantas diferencias y logran empatía entre sus integrantes, digamos que la wiki les posibilita trabajar cuando ellos así lo quieren o pueden, tanto de forma presencial como virtual, se apoyan mutuamente en las actividades cooperativas, tienen definidos claramente sus roles y los hacen 
cumplir, se nota una interacción más frecuente y productiva, comparten no sólo conocimientos, sino que aprenden y socializan experiencias personales, que los sensibiliza y les ayuda a ser más amigables y respetuosos entre ellos”.

El maestro expresó que los procesos de aprendizaje cooperativo requieren de tiempo y de una continua revisión del trabajo desarrollado por cada integrante de un equipo; en el momento que estos integrantes lograron adaptarse, hubo mayores interacciones y más avances en las actividades y se pudo lograr una mejor comprensión y construcción de los conceptos, además de un mayor acercamiento al pensamiento crítico. Esto se puede constatar cuando el maestro afirmó: "Por otro lado pienso que el aprendizaje cooperativo no se logra de un momento a otro, el tiempo ayuda a que los grupos se vayan ajustando y sus integrantes digamos aprendan a conocerse, a reconocerse, y así las interacciones y producciones cada vez sean mejores" (EMT-GE; ver Apéndice L).

4. Facilidad para aprender Biología con la wiki $(\boldsymbol{F A B}-\mathrm{CW})$. El docente argumentó que el uso de la wiki facilitó a los estudiantes aprender Biología, no sólo porque permitió que él los guiara y apoyara, sino porque se pudieron establecer interacciones constantes a partir de las actividades cooperativas que fueron diseñadas con instrucciones claras. Estas ideas se manifestaron en las siguientes expresiones: “como esta wiki está incorporada a un manejo de un trabajo en equipo con actividades cooperativas, va a permitir también intercambiar ideas y conceptos; pienso que el hecho de que los equipos y sus integrantes aprendan a apoyarse mutuamente y a interactuar y compartir sus ideas y elaboraciones de manera responsable y crítica, les ayuda positivamente para la construcción del conocimiento” (EMT-GE; ver Apéndice L). 
El docente también expresó que la participación activa es un factor muy importante en el aprendizaje de la Biología, porque ayuda al enriquecimiento de las interacciones y de las concepciones y construcciones que hacen los estudiantes. Indicó que la wiki ayuda al maestro a organizar información, plantear diversas actividades y se convierte en un guía de trabajo para los estudiantes, en la que es posible poner a su disposición diferentes recursos y brindarles múltiples opciones para acceder al conocimiento de la Biología, es decir, desarrollar la competencia de búsqueda y selección de información. Asimismo, el docente consideró valioso el hecho que en la wiki también se pudiese dejar establecida la rúbrica de evaluación de las actividades, porque esto ayudó a que los alumnos conocieran la forma en qué serían evaluados y que además podían consultarla en cualquier momento, esto facilitó el aprendizaje de la Biología y dio certidumbre a sus actividades. Las opiniones anteriormente mencionadas, se manifiestan en las respuestas del profesor: "pienso que la participación en las clases de Biología se ve favorecida por el uso de la wiki y en la medida que haya más participación, hay más interacción, se incrementan las posibilidades de que se aclaren dudas se consigan mejores desempeños porque unos ayudan a los otros y se comprometen con su propio aprendizaje, hay autogestión y con ello más garantías de aprender Biología de manera conjunta. El uso de rúbricas de evaluación es un aspecto muy importante que no es utilizado en la institución, y que las veo como instrumentos de seguimiento a favor del estudiante, porque tiene la posibilidad de conocer de antemano cómo va a ser valorado, los aspectos relevantes que deberá tener en cuenta al momento de desarrollar las actividades, aprenderá a reconocer la importancia de sus 
aportaciones y del trabajo cooperativo que se desarrolla en los equipos, así como de los aprendizajes que se espera que debe alcanzar" (EMT-GE; ver Apéndice L).

El docente señaló además, que con el uso de la wiki se desarrollan paulatinamente tanto valores como habilidades y esto se puede constatar cuando dijo: "los principales valores que considero se desarrollan a través del uso de la wiki, es la responsabilidad enfocada tanto en el buen uso de esas ayudas tecnológicas como en el cumplimiento de los compromisos que se adquieren en todo el proceso de realización de las actividades; de hacer bien las cosas [realizar adecuadamente las actividades]adquieren unas habilidades tecnológicas, para poder manejar el apoyo de forma adecuada y rápida, también veo que se mejora paulatinamente la búsqueda, organización y análisis de la información sobre la Biología” (EMT-GE; ver Apéndice L).

\section{Recursos e infraestructura escolar para usar la wiki (RIE-UW): De manera} general el docente advirtió que las dificultades, en cuanto a interacción, relaciones interpersonales, desarrollo de actividades y manejo del tiempo, se ocasionan por la necesidad de mejorar la infraestructura del colegio y por el inadecuado aprovechamiento de los actuales recursos, así como, la falta de cultura, conocimientos y habilidades por parte de la comunidad académica acerca del uso de los AVA. Anotó la complejidad que significa para el docente, manejar el tiempo requerido en el diseño y organización de la wiki con actividades apropiadas y acordes a las nuevas tendencias pedagógicas, así como la necesidad de desarrollar habilidades docentes para el manejo de la información, es decir, la búsqueda y selección de fuentes de calidad. Lo anterior derivó de expresiones como: "requiere de tiempo, y de habilidades, el poder organizar la información y tratar de que sea atractiva para los estudiantes, el manejo de volúmenes 
de participaciones; el maestro tiene que manejar bien la herramienta y saber qué habilidades busca realmente que sus estudiantes desarrollen a partir de la wiki, para que guíe adecuadamente y en el tiempo preciso las participaciones a los estudiantes. Desafortunadamente, en la institución no hay suficientes recursos físicos ni tecnológicos, para llevar a cabo la clase con este tipo de apoyos tecnológicos [de manera permanente]. En nuestra institución no estamos digamos a la vanguardia, algunos equipos de cómputo necesitan ser actualizados. No hay una logística apropiada de uso [en la organización de horarios para acceder a las salas y a los equipos, no se tienen en cuenta las necesidades de los maestros de áreas diferentes a informática y tecnología] para los equipos más modernos" (EMT-GE; ver Apéndice L).

4.1.2. Fase cuantitativa. Los instrumentos aplicados en esta fase fueron la encuesta y dos pruebas escritas sobre Biología, la primera fue aplicada antes de la intervención con el apoyo tecnológico (preprueba) y la otra, después del uso de la wiki (posprueba). Para ello, se consideró un grupo experimental, es decir, el Grupo 8-1 que usó la wiki y otro de control, con la ausencia de esa variable independiente (Grupo 8-2). La medición implicó, la comparación del desempeño académico del grupo experimental, con otro grupo de octavo grado, que no fue intervenido con el apoyo tecnológico, es decir, el de control. Ambas pruebas, versaron sobre las mismas temáticas y se aplicaron en condiciones similares (ver Apéndices D y E).

Debido a que ambos grupos (el experimental y de control), en las diferentes sesiones de clase realizaron actividades que abordaron temáticas relacionadas con el concepto de reproducción (ver Apéndice H), en la preprueba y posprueba también se 
evaluó esa temática y los subtemas relacionados con la misma (formas de reproducción, reproducción asexual-tipos y división celular). Particularmente, en ambas pruebas se consideraron competencias como: discernimiento, adquisición y análisis de datos e información (ver Apéndices F y G). En la Tabla 15, se especifican los contenidos y las competencias contempladas en las pruebas.

Tabla 15

Contenido temático de la preprueba y posprueba para el octavo grado

\begin{tabular}{|c|c|c|c|c|}
\hline $\begin{array}{c}\text { Temas } \\
\text { abordados }\end{array}$ & $\begin{array}{c}\text { Competencias } \\
\text { evaluadas }\end{array}$ & $\begin{array}{c}\text { No. de preguntas } \\
\text { por temática } \\
\text { evaluada en la } \\
\text { preprueba }\end{array}$ & $\begin{array}{l}\text { No. de preguntas } \\
\text { por temática } \\
\text { evaluada en la } \\
\text { posprueba }\end{array}$ & $\begin{array}{l}\text { Total de } \\
\text { aciertos } \\
\text { de cada } \\
\text { prueba }\end{array}$ \\
\hline $\begin{array}{l}\text { Reproducción } \\
\text { y tipos }\end{array}$ & $\begin{array}{c}\text { Discernimiento } \\
\text { Adquisición y análisis } \\
\text { de datos e información }\end{array}$ & 6 & 7 & \\
\hline $\begin{array}{l}\text { Formas de } \\
\text { reproducción } \\
\text { asexual } \\
\end{array}$ & $\begin{array}{c}\text { Discernimiento } \\
\text { Adquisición y análisis } \\
\text { de datos e información }\end{array}$ & 5 & 4 & 30 \\
\hline $\begin{array}{l}\text { Proceso de } \\
\text { División } \\
\text { celular }\end{array}$ & $\begin{array}{c}\text { Discernimiento } \\
\text { Adquisición y análisis } \\
\text { de datos e información }\end{array}$ & 4 & 4 & \\
\hline
\end{tabular}

Cabe señalar, que en la preprueba y posprueba sólo incluyeron 15 ítems o preguntas cerradas, cada una con un valor de 2 puntos, de esta manera el total de aciertos fue de 30 puntos y se usó un escalamiento similar al de la prueba censal colombiana (Prueba Saber). Asimismo, ambas pruebas fueron contestadas con lápiz (en forma autoadministrada) y a través de una hoja de respuestas específica. Ambas pruebas tuvieron una duración de 45min. Los criterios de valoración del desempeño académico fueron los correspondientes a los definidos por el colegio en su sistema institucional de evaluación: bajo, básico, alto y superior. 
A continuación, se presentan los resultados de esas pruebas a través de distribuciones de frecuencias y para ello también se consideraron medidas de tendencia central y de dispersión así como la prueba t, para comparar las diferencias en el rendimiento de los grupos (ver Apéndices O-Q); todo ello, calculado mediante el programa estadístico Minitab 17.

\subsubsection{Resultados de la preprueba aplicada a los alumnos de octavo grado.}

Es importante precisar que esta prueba escrita de Biología, fue un indicador general del desempeño académico de los alumnos del grupo experimental y del grupo de control, antes del uso de la wiki. Se consideró una escala que comprendió los niveles: bajo, básico, alto y superior, conforme al número de aciertos obtenido por cada estudiante y cuyos detalles pueden observarse en la Tabla 16. La medición permitió la comparación del desempeño entre ambos grupos.

Tabla 16

Niveles de desempeño de la preprueba

\begin{tabular}{lc}
\hline Nivel de desempeño & $\begin{array}{c}\text { Rangos de aciertos de la } \\
\text { prueba } \\
\text { (total 30) }\end{array}$ \\
\hline Bajo & $0-16$ \\
Básico & $17-23$ \\
Alto & $24-26$ \\
Superior & $27-30$ \\
\hline
\end{tabular}

De esta manera, los resultados obtenidos por el grupo experimental (en adelante GE) en la preprueba evidenciaron que el $95 \%$ de los alumnos se encontraba en un nivel de desempeño bajo y sólo el 5\%, equivalente a 2 estudiantes, alcanzaron el nivel básico. En los niveles alto y superior no se ubicaron estudiantes (ver Tabla 17 y Apéndice O). 
Tabla 17

Distribución de frecuencias de la preprueba en el grupo experimental (8-1)

\begin{tabular}{lcc}
\hline Nivel de desempeño & $\begin{array}{c}\text { Número de estudiantes en } \\
\text { cada nivel (frecuencias } \\
\text { absolutas) }\end{array}$ & $\begin{array}{c}\text { Frecuencias relativas } \\
\text { (porcentajes) }\end{array}$ \\
\hline Bajo & 39 & $95 \%$ \\
Básico & 2 & $5 \%$ \\
Alto & 0 & $0 \%$ \\
Superior & 0 & $0 \%$ \\
Total & 41 & $100 \%$ \\
\hline
\end{tabular}

Asimismo, los resultados obtenidos en el grupo de control (en adelante GC)

mostraron que el $94.7 \%$ de los alumnos que respondió la preprueba, se ubicó en un nivel de bajo desempeño y sólo el 5.3\%, equivalente a 2 estudiantes, alcanzó el nivel básico de desempeño. Al igual que para el GE, en los niveles alto y superior, no se ubicó ningún estudiante (ver Tabla 18 y Apéndice O).

Tabla 18

Distribución de frecuencias de la preprueba en el grupo de control (8-2)

\begin{tabular}{lcc}
\hline Nivel de desempeño & $\begin{array}{c}\text { Número de estudiantes en } \\
\text { cada nivel (frecuencias } \\
\text { absolutas) }\end{array}$ & $\begin{array}{c}\text { Frecuencias relativas } \\
\text { (porcentajes) }\end{array}$ \\
\hline Bajo & 36 & $94.7 \%$ \\
Básico & 2 & $5.3 \%$ \\
Alto & 0 & $0 \%$ \\
Superior & 0 & $0 \%$ \\
Total & 38 & $100 \%$ \\
\hline
\end{tabular}

De acuerdo con los resultados previos (ver Tablas 17 y 18, Apéndice O) y según las medidas de tendencia central y de dispersión (ver Tabla 19), es evidente que tanto el 
GE como el GC, presentaron dificultades académicas en el área de Biología, antes del uso de la wiki.

Tabla 19

Resultados comparativos de la preprueba en el grupo experimental y de control

\begin{tabular}{lcc}
\hline Medidas estadísticas & $\begin{array}{c}\text { Grupo 8-1 } \\
\text { Experimental } \\
\text { (41 estudiantes) }\end{array}$ & $\begin{array}{c}\text { Grupo 8-2 } \\
\text { De control } \\
\text { (38 estudiantes) }\end{array}$ \\
\hline Media & 9.951 & 9.526 \\
Desviación Estándar & 3.507 & 4.397 \\
Calificación Mínima & 4 & 4 \\
Calificación Máxima & 20 & 20 \\
Rango & 16 & 16 \\
Mediana & 10 & 10 \\
Moda & 8 & 4 \\
Varianza & 12.298 & 19.337 \\
Asimetría & 0.65 & 0.38 \\
\hline
\end{tabular}

Se puede observar en la Tabla 19 que la diferencia en el promedio de calificación de los grupos experimental y de control fue de 0.425 , sin embargo el valor más alto lo obtuvo el GE con 9.951 y el promedio más bajo el GC con 9.526. El 50\% de los alumnos del GE y del GC alcanzaron una calificación mayor a 10 puntos, la otra mitad de los alumnos no obtuvieron los 10 puntos. Se puede observar que la calificación mínima tanto en el GE como en el GC fue de 4puntos y la calificación máxima fue de 20 puntos. Para el GE las calificaciones se desviaron de la media 3.507 puntos de la escala, mientras que para el GC se desviaron 4.397, esto, además indica que hay una notable dispersión de los datos, lo que se reafirma con el valor de 16 obtenido para el rango en ambos grupos (como diferencia entre la puntuación mayor y la puntuación menor). La generalidad de los resultados anteriores, refleja que no hubo diferencias sobresalientes 
en cuanto al bajo desempeño académico que se presentaron en ambos grupos, antes del uso de la wiki (GE y GC).

\subsubsection{Resultados de la posprueba aplicada a los alumnos de octavo grado.}

Al igual que la preprueba, la posprueba fue un indicador general del desempeño académico de los alumnos del GE y del GC, que sirvió de referente para medir el impacto del uso de la wiki en el rendimiento de los estudiantes. En la Tabla 20, se presentan los niveles de desempeño con los respectivos rangos de aciertos para la posprueba, aplicada después del uso del AVA.

Tabla 20

Niveles de desempeño de la posprueba

\begin{tabular}{lc}
\hline Nivel de desempeño & $\begin{array}{c}\text { Rangos de aciertos de la } \\
\text { prueba } \\
\text { (total 30) }\end{array}$ \\
\hline Bajo & $0-16$ \\
Básico & $17-23$ \\
Alto & $24-26$ \\
Superior & $27-30$ \\
\hline
\end{tabular}

Los resultados obtenidos por el GE en la posprueba, una vez terminada la intervención con la wiki, mostraron algunos cambios positivos en el desempeño académico de los alumnos. Aproximadamente, el 46.3\% de los estudiantes logró aprobar la posprueba, a diferencia del 5\% inicial que aprobó la preprueba. De esta manera, al analizar los resultados de la posprueba, se observa que el $4.9 \%$ de los estudiantes se ubicaron en un nivel de desempeño alto y el $2.4 \%$ correspondió al nivel superior (niveles no alcanzados en la preprueba - ver Tablas 17 y 21). Asimismo, el 39\% se ubicó en el básico y el 53.7 correspondió al nivel bajo (ver Tabla 23 y Apéndice P). 
Tabla 21

Distribución de frecuencias de la posprueba en el grupo experimental (8-1)

\begin{tabular}{lcc}
\hline Nivel de desempeño & $\begin{array}{c}\text { Número de estudiantes en } \\
\text { cada nivel (frecuencias } \\
\text { absolutas) }\end{array}$ & $\begin{array}{c}\text { Frecuencias relativas } \\
\text { (porcentajes) }\end{array}$ \\
\hline Bajo & 22 & $53.7 \%$ \\
Básico & 16 & $39.0 \%$ \\
Alto & 2 & $4.9 \%$ \\
Superior & 1 & $2.4 \%$ \\
Total & 41 & $100 \%$ \\
\hline
\end{tabular}

Por otro lado, los resultados obtenidos por el GC en la posprueba mostraron cierta mejoría en el aprendizaje del grupo con respecto a la preprueba, sin embargo no fue tan significativa como la observada en el GE (ver Tabla 21 y Apéndice P). En el GC (en la posprueba), desafortunadamente no se ubicaron estudiantes en los niveles de desempeño alto y superior, a diferencia de los alumnos del GE en la posprueba. De tal forma que solo el $21 \%$ de los estudiantes del grupo de control aprobaron la posprueba con un nivel de desempeño básico y el $79 \%$ de los alumnos la reprobaron, ubicándose en un nivel bajo (ver Tabla 22 y Apéndice P). Cabe destacar, que en la preprueba reprobó el 94.7\%, equivalente a una diferencia del 15.7\%, respecto a la posprueba (ver Tabla 20).

Tabla 22

Distribución de frecuencias de la posprueba en el grupo de control (8-2)

\begin{tabular}{lcc}
\hline Nivel de desempeño & $\begin{array}{c}\text { Número de estudiantes en } \\
\text { cada nivel (frecuencias } \\
\text { absolutas) }\end{array}$ & $\begin{array}{c}\text { Frecuencias relativas } \\
\text { (porcentajes) }\end{array}$ \\
\hline Bajo & 30 & $79 \%$ \\
Básico & 8 & $21 \%$ \\
Alto & 0 & $0 \%$ \\
Superior & 0 & $0 \%$ \\
Total & 41 & $100 \%$ \\
\hline
\end{tabular}


Todo lo anteriormente mencionado, puede corroborarse con los resultados comparativos presentados en la Tabla 23, donde destaca que el promedio de calificación del GE fue de 15.561 un valor más alto, del obtenido por el GC que fue de 12.789, y mucho mayor que el obtenido en la preprueba (9.959-GE). El 50\% de los alumnos del GE alcanzaron una calificación mayor a 14 puntos, mientras que el 50\% de los estudiantes del GC obtuvieron una calificación mayor a 12 puntos. Se puede observar que la calificación máxima para GE fue de 28 puntos y para el GC fue de 22 puntos. La calificación mínima para el GE fue de 8 puntos y para el GC de 6 puntos. Para el GE las calificaciones se desviaron de la media 29.702 puntos de la escala mientras que para el GC se desviaron 22.171 respectivamente, esto, además indica que hay una notable dispersión de los datos, lo que se reafirma con el valor de 20 y 16 puntos obtenidos respectivamente para el rango en ambos grupos (como diferencia entre la puntuación mayor y menor de la posprueba. La generalidad de los resultados anteriores, refleja los efectos positivos del uso de la wiki en el desempeño académico de los estudiantes del GE, respecto a los estudiantes del GC (ver Tabla 23).

Tabla 23

Resultados comparativos de la posprueba en el grupo experimental y de control

\begin{tabular}{lcc}
\hline Medidas estadísticas & $\begin{array}{c}\text { Grupo 8-1 } \\
\text { experimental } \\
\text { (41 estudiantes) }\end{array}$ & $\begin{array}{c}\text { Grupo 8-2 } \\
\text { de control } \\
\text { (38 estudiantes) }\end{array}$ \\
\hline Media & 15.561 & 12.789 \\
Desviación Estándar & 5.450 & 4.709 \\
Mínimo de puntos obtenidos & 8 & 6 \\
Máximo de puntos obtenidos & 28 & 22 \\
Rango & 20 & 16 \\
Mediana & 14 & 12 \\
Moda & 18 & 10 \\
Varianza & 29.702 & 22.170 \\
Asimetría & 0.30 & 0.49 \\
\hline
\end{tabular}




\subsubsection{Resultados de la encuesta aplicada a los alumnos del grupo}

experimental (8-1). El instrumento consistió de un total de 25 preguntas cerradas

presentadas a los estudiantes mediante afirmaciones y se solicitó emitir su opinión a

partir de la siguiente escala Likert: $1=$ totalmente en desacuerdo, $2=$ en desacuerdo, $3=$ de acuerdo, $4=$ totalmente de acuerdo.

Con ese escalamiento se pretendió medir la actitud de los estudiantes sobre el uso de la wiki para facilitar el aprendizaje de la Biología. Este cuestionario se aplicó en forma autoadministrada y de manera presencial, sólo al GE (ver Apéndice E). Una vez recolectados los datos, se procedió a su codificación a través de una matriz de Excel. Los resultados de la encuesta aplicada a los alumnos del grupo que usó la wiki, se presentan a través de una distribución de frecuencias absolutas y relativas (ver Tabla 24) y mediante una segunda distribución (como datos aclaratorios), se incluyen los resultados de las medidas de tendencia central y de dispersiones aplicadas (ver Apéndice N). 
Tabla 24

Distribución de frecuencias correspondientes a la encuesta aplicada al grupo experimental (Datos recabados por el autor).

\begin{tabular}{|c|c|c|c|}
\hline Ítems (frases representativas) & Alternativas de respuesta & $\begin{array}{c}\text { Frecuencia } \\
\text { absoluta }\end{array}$ & $\begin{array}{l}\text { Frecuencia } \\
\text { relativa }(\%)\end{array}$ \\
\hline \multirow{4}{*}{$\begin{array}{l}\text { 1. Facilidad para aprender Biología } \\
\text { con la wiki. }\end{array}$} & Totalmente de acuerdo & 23 & $56.10 \%$ \\
\hline & De acuerdo & 11 & $26.83 \%$ \\
\hline & En desacuerdo & 3 & $7.32 \%$ \\
\hline & Totalmente en desacuerdo & 4 & $9.76 \%$ \\
\hline \multirow{4}{*}{$\begin{array}{l}\text { 2. Mayor aprendizaje de Biología } \\
\text { con la wiki. }\end{array}$} & Totalmente de acuerdo & 16 & $39.02 \%$ \\
\hline & De acuerdo & 17 & $41.46 \%$ \\
\hline & En desacuerdo & 7 & $17.07 \%$ \\
\hline & Totalmente en desacuerdo & 1 & $2.44 \%$ \\
\hline \multirow{4}{*}{$\begin{array}{l}\text { 3. Contenidos de la wiki agradables } \\
\text { y fáciles de comprender. }\end{array}$} & Totalmente de acuerdo & 18 & $43.90 \%$ \\
\hline & De acuerdo & 17 & $41.46 \%$ \\
\hline & En desacuerdo & 6 & $14.63 \%$ \\
\hline & Totalmente en desacuerdo & & $0.00 \%$ \\
\hline \multirow{4}{*}{$\begin{array}{l}\text { 4. Mejores resultados al trabajar } \\
\text { cooperativamente. }\end{array}$} & Totalmente de acuerdo & 19 & $46.34 \%$ \\
\hline & De acuerdo & 16 & $39.02 \%$ \\
\hline & En desacuerdo & 6 & $14.63 \%$ \\
\hline & Totalmente en desacuerdo & & $0.00 \%$ \\
\hline \multirow{4}{*}{$\begin{array}{l}\text { 5. La comunicación cordial y } \\
\text { respetuosa a través de la wiki. }\end{array}$} & Totalmente de acuerdo & 18 & $43.90 \%$ \\
\hline & De acuerdo & 20 & $48.78 \%$ \\
\hline & En desacuerdo & 3 & $7.32 \%$ \\
\hline & Totalmente en desacuerdo & & $0.00 \%$ \\
\hline \multirow{4}{*}{$\begin{array}{l}\text { 6. Apoyo del maestro para resolver } \\
\text { conflictos en la wiki. }\end{array}$} & Totalmente de acuerdo & 24 & $58.54 \%$ \\
\hline & De acuerdo & 11 & $26.83 \%$ \\
\hline & En desacuerdo & 5 & $12.20 \%$ \\
\hline & Totalmente en desacuerdo & 1 & $2.44 \%$ \\
\hline \multirow{4}{*}{$\begin{array}{l}\text { 7. La guía del maestro facilita la } \\
\text { realización de actividades en la wiki. }\end{array}$} & Totalmente de acuerdo & 20 & $48.78 \%$ \\
\hline & De acuerdo & 18 & $43.90 \%$ \\
\hline & En desacuerdo & 1 & $2.44 \%$ \\
\hline & Totalmente en desacuerdo & 2 & $4.88 \%$ \\
\hline \multirow{4}{*}{$\begin{array}{l}\text { 8. La wiki incrementa el interés por } \\
\text { desarrollar las actividades de } \\
\text { Biología. }\end{array}$} & Totalmente de acuerdo & 20 & $48.78 \%$ \\
\hline & De acuerdo & 13 & $31.71 \%$ \\
\hline & En desacuerdo & 7 & $17.07 \%$ \\
\hline & Totalmente en desacuerdo & 1 & $2,44 \%$ \\
\hline \multirow{4}{*}{$\begin{array}{l}\text { 9. La wiki genera mayor } \\
\text { participación en clase de Biología. }\end{array}$} & Totalmente de acuerdo & 19 & $46.34 \%$ \\
\hline & De acuerdo & 14 & $34.15 \%$ \\
\hline & En desacuerdo & 6 & $14.63 \%$ \\
\hline & Totalmente en desacuerdo & 2 & $4.88 \%$ \\
\hline
\end{tabular}




\section{Continuación Tabla 24}

\begin{tabular}{|c|c|c|c|}
\hline Ítems (frases representativas) & Alternativas de respuesta & $\begin{array}{c}\text { Frecuencia } \\
\text { absoluta }\end{array}$ & $\begin{array}{c}\text { Frecuencia } \\
\text { relativa }(\%)\end{array}$ \\
\hline \multirow{4}{*}{$\begin{array}{l}\text { 10. Mejor comprensión de conceptos } \\
\text { por las aportaciones de los } \\
\text { compañeros en la wiki. }\end{array}$} & Totalmente de acuerdo & 21 & $51.22 \%$ \\
\hline & De acuerdo & 14 & $34.15 \%$ \\
\hline & En desacuerdo & 5 & $12.20 \%$ \\
\hline & Totalmente en desacuerdo & 1 & $2.44 \%$ \\
\hline \multirow{4}{*}{$\begin{array}{l}\text { 11. Actividades en la wiki, claras e } \\
\text { interesantes. }\end{array}$} & Totalmente de acuerdo & 22 & $53.66 \%$ \\
\hline & De acuerdo & 13 & $31.71 \%$ \\
\hline & En desacuerdo & 4 & $9.76 \%$ \\
\hline & Totalmente en desacuerdo & 2 & $4.88 \%$ \\
\hline \multirow{4}{*}{$\begin{array}{l}\text { 12. Conflictos del trabajo en equipo } \\
\text { resueltos con tolerancia y respeto. }\end{array}$} & Totalmente de acuerdo & 19 & $46.34 \%$ \\
\hline & De acuerdo & 18 & $43.90 \%$ \\
\hline & En desacuerdo & 4 & $9.76 \%$ \\
\hline & Totalmente en desacuerdo & & $0.00 \%$ \\
\hline \multirow{4}{*}{$\begin{array}{l}\text { 13. Generación de acuerdos } \\
\text { individuales y grupales al trabajar en } \\
\text { la wiki. }\end{array}$} & Totalmente de acuerdo & 10 & $24.39 \%$ \\
\hline & De acuerdo & 18 & $43.90 \%$ \\
\hline & En desacuerdo & 10 & $24.39 \%$ \\
\hline & Totalmente en desacuerdo & 3 & $7.32 \%$ \\
\hline \multirow{4}{*}{$\begin{array}{l}\text { 14. La wiki aumento el interés por } \\
\text { aprender Biología. }\end{array}$} & Totalmente de acuerdo & 19 & $46.34 \%$ \\
\hline & De acuerdo & 17 & $41.46 \%$ \\
\hline & En desacuerdo & 1 & $2.44 \%$ \\
\hline & Totalmente en desacuerdo & 4 & $9.76 \%$ \\
\hline \multirow{4}{*}{$\begin{array}{l}\text { 15. La wiki mejora la } \\
\text { responsabilidad del trabajo en } \\
\text { equipo. }\end{array}$} & Totalmente de acuerdo & 14 & $34.15 \%$ \\
\hline & De acuerdo & 17 & $41.46 \%$ \\
\hline & En desacuerdo & 3 & $7.32 \%$ \\
\hline & Totalmente en desacuerdo & 7 & $17.07 \%$ \\
\hline \multirow{4}{*}{$\begin{array}{l}\text { 16. Es aburrido estudiar Biología } \\
\text { cuando uso la wiki. }\end{array}$} & Totalmente de acuerdo & 3 & $7.32 \%$ \\
\hline & De acuerdo & 1 & $2.44 \%$ \\
\hline & En desacuerdo & 17 & $41.46 \%$ \\
\hline & Totalmente en desacuerdo & 20 & $48.78 \%$ \\
\hline \multirow{4}{*}{$\begin{array}{l}\text { 17. Con la wiki me preparo para la } \\
\text { prueba SABER. }\end{array}$} & Totalmente de acuerdo & 6 & $14.63 \%$ \\
\hline & De acuerdo & 22 & $53.66 \%$ \\
\hline & En desacuerdo & 9 & $21.95 \%$ \\
\hline & Totalmente en desacuerdo & 4 & $9.76 \%$ \\
\hline \multirow{4}{*}{$\begin{array}{l}\text { 18. La wiki debe utilizarse en otras } \\
\text { asignaturas. }\end{array}$} & Totalmente de acuerdo & 20 & $48.78 \%$ \\
\hline & De acuerdo & 13 & $31.71 \%$ \\
\hline & En desacuerdo & 3 & $7.32 \%$ \\
\hline & Totalmente en desacuerdo & 5 & $12.20 \%$ \\
\hline \multirow{4}{*}{$\begin{array}{l}\text { 19. Con la wiki se hacen } \\
\text { aportaciones importantes para las } \\
\text { actividades. }\end{array}$} & Totalmente de acuerdo & 17 & $41.46 \%$ \\
\hline & De acuerdo & 20 & $48.78 \%$ \\
\hline & En desacuerdo & 4 & $9.76 \%$ \\
\hline & Totalmente en desacuerdo & & $0.00 \%$ \\
\hline
\end{tabular}




\section{Continuación Tabla 24}

\begin{tabular}{|c|c|c|c|}
\hline Ítems (frases representativas) & Alternativas de respuesta & $\begin{array}{c}\text { Frecuencia } \\
\text { absoluta }\end{array}$ & $\begin{array}{c}\text { Frecuencia } \\
\text { relativa }(\%)\end{array}$ \\
\hline \multirow{4}{*}{$\begin{array}{l}\text { 20. Las actividades en la wiki se } \\
\text { evalúan adecuadamente. }\end{array}$} & Totalmente de acuerdo & 15 & $36.59 \%$ \\
\hline & De acuerdo & 24 & $58.54 \%$ \\
\hline & En desacuerdo & 2 & $4.88 \%$ \\
\hline & Totalmente en desacuerdo & & $0.00 \%$ \\
\hline \multirow{4}{*}{$\begin{array}{l}\text { 21. Cumplimiento en tiempo y } \\
\text { forma, de las aportaciones } \\
\text { individuales, por parte de los } \\
\text { integrantes de los equipos. }\end{array}$} & Totalmente de acuerdo & 9 & $21.95 \%$ \\
\hline & De acuerdo & 12 & $29.27 \%$ \\
\hline & En desacuerdo & 16 & $39.02 \%$ \\
\hline & Totalmente en desacuerdo & 4 & $9.76 \%$ \\
\hline \multirow{4}{*}{$\begin{array}{l}\text { 22. Las clases presenciales de } \\
\text { Biología se refuerzan y } \\
\text { complementan con la wiki. }\end{array}$} & Totalmente de acuerdo & 16 & $39.02 \%$ \\
\hline & De acuerdo & 19 & $46.34 \%$ \\
\hline & En desacuerdo & 4 & $9.76 \%$ \\
\hline & Totalmente en desacuerdo & 2 & $4.88 \%$ \\
\hline \multirow{4}{*}{$\begin{array}{l}\text { 23. Cada integrante de mi equipo } \\
\text { asumió su rol. }\end{array}$} & Totalmente de acuerdo & 16 & $39.02 \%$ \\
\hline & De acuerdo & 8 & $19.51 \%$ \\
\hline & En desacuerdo & 14 & $34.15 \%$ \\
\hline & Totalmente en desacuerdo & 3 & $7.32 \%$ \\
\hline \multirow{4}{*}{$\begin{array}{l}\text { 24. La wiki facilita el trabajo en } \\
\text { equipo. }\end{array}$} & Totalmente de acuerdo & 17 & $41.46 \%$ \\
\hline & De acuerdo & 17 & $41.46 \%$ \\
\hline & En desacuerdo & 4 & $9.76 \%$ \\
\hline & Totalmente en desacuerdo & 3 & $7.32 \%$ \\
\hline \multirow{4}{*}{$\begin{array}{l}\text { 25. Adecuada infraestructura } \\
\text { tecnológica del colegio para realizar } \\
\text { actividades en Internet. }\end{array}$} & Totalmente de acuerdo & 4 & $9.76 \%$ \\
\hline & De acuerdo & 6 & $14.63 \%$ \\
\hline & En desacuerdo & 22 & $53.66 \%$ \\
\hline & Totalmente en desacuerdo & 9 & $21.95 \%$ \\
\hline
\end{tabular}

A continuación, se describen de manera general, los principales resultados

obtenidos en la aplicación de la encuesta a los alumnos del GE que utilizaron la wiki

(ver Apéndice E):

- En cuanto a la facilidad para aprender biología con la wiki, con un porcentaje acumulado, el $82.93 \%$ de los alumnos consideró estar de acuerdo en que el uso del AVA facilitó su aprendizaje y sólo un $17.07 \%$ indicó estar en desacuerdo con ello. Asimismo, también sobresalió una tendencia favorable hacia el uso de la wiki, pues el 80.4\% coincidió que aprendió más sobre Biología, al usar la wiki. 
- El 80.48\% de los alumnos consideró que hay mayor aprendizaje de Biología con la wiki. Asimismo, expresaron que la wiki incrementó su interés por desarrollar las actividades de Biología y que generó mayor participación en la clase, frente a un $19.52 \%$ que indicó estar en desacuerdo con estas percepciones.

- Referente a la guía del maestro, el $92.68 \%$ de los alumnos reconoció que ésta facilitó la realización de las actividades en la wiki. Respecto a trabajar cooperativamente en la wiki, el $85.36 \%$ de los alumnos estimó que de esta forma, consiguieron mejores resultados y comprensión de conceptos por las aportaciones de los compañeros en la wiki. Igualmente, con un mismo porcentaje destacó que las clases presenciales de Biología se reforzaron y complementaron con la wiki, salvo un $14.64 \%$ de los estudiantes señaló estar en desacuerdo con estas apreciaciones.

- Se encontró que el $90.24 \%$ de los alumnos consideró que es más agradable estudiar Biología cuando se utiliza la wiki y que los conflictos del trabajo en equipo fueron resueltos con tolerancia y respeto; únicamente un 9.76\% expresó estar en desacuerdo con estas impresiones.

- En cuanto a la generación de acuerdos individuales y grupales, el 68.29\% de los estudiantes estuvieron de acuerdo, que éstos se lograron más fácilmente al trabajar en la wiki, respecto al $31.71 \%$, que señaló estar en desacuerdo con ello. En este mismo sentido, el $75.31 \%$ de los alumnos consideró que la wiki mejoró la responsabilidad del trabajo en equipo, mientras que el $7.32 \%$ indicó estar en desacuerdo y el $17.07 \%$ estar totalmente en desacuerdo. 
- Asimismo, el 87.5\% de los alumnos opinó que la wiki aumentó el interés por aprender Biología y sólo el 12.2\% indicó estar en desacuerdo. Consecuente con esta percepción, el $80.49 \%$ de los alumnos consideró que la wiki debe utilizarse en otras asignaturas, frente a un $19.51 \%$ que estuvo en desacuerdo.

- El 82.92\% de los alumnos opinó que la wiki facilitó el trabajo en equipo; únicamente el $17.08 \%$ estuvo en desacuerdo. Sin embargo, sólo el 58.53\% de los estudiantes estuvo de acuerdo con el rol que asumió cada integrante del equipo, frente a un 41.47\% que no lo favoreció.

- Respecto a la infraestructura tecnológica del colegio para realizar actividades en Internet, el $75.61 \%$ de los alumnos consideró que no fue adecuada y sólo el 24.39\% indicó lo contrario.

Finalmente, todo lo anterior se complementa y coincide con los resultados de estadística descriptiva incluidos en el Apéndice N (datos aclaratorios con medidas de tendencia central y de dispersión), mismos que respaldan la actitud positiva de los estudiantes respecto al uso de la wiki para el aprendizaje de la Biología.

\subsection{Análisis e interpretación}

En esta sección se realiza la discusión de los resultados más significativos, a partir de la triangulación de los mismos con los fundamentos teóricos del capítulo 2, a fin de dar respuesta a las preguntas de investigación formuladas en el planteamiento del problema. A continuación, se incluyen las preguntas (parafraseadas) y sus respectivas respuestas. Cabe señalar, que primero se presenta la respuesta de la pregunta general de 
investigación y posteriormente, se responden las interrogantes derivadas de la misma, tal como se formularon en el capítulo 1:

¿Cuál es el impacto de uso e incorporación de una wiki en el aprendizaje de la Biología, por parte de los alumnos de una secundaria colombiana? De acuerdo con la entrevista al maestro titular del GE el uso e incorporación de una wiki, permite modificar el rol del docente y las interacciones entre él y los alumnos; con ello, se transforma la enseñanza tradicional de las clases de Biología. Entre las razones mencionadas se encuentran: “otorga mayor protagonismo y cierta autonomía a los estudiantes, autonomía que considero en un principio debe ser guiada por el docente; veo muy interesante el trabajo en la wiki, porque en ella se incorpora la parte dinámica, la parte de videos, la parte de los conceptos y permite mayor interacción con el docente y entre los estudiantes y también con la misma fuente digamos de consulta" (EMT-GE; ver Apéndice L). Esto coincidió con el 100\% de las observaciones no participantes en las que se estableció claramente el rol activo del docente para familiarizar a los estudiantes con el AVA, e incentivarlos a interactuar con sus compañeros (ONP-GE; ver Apéndice K), así como, con las opiniones del 90.24\% de los alumnos que consideraron que fue muy agradable estudiar Biología cuando usaron la wiki y del $80.49 \%$ para quienes la wiki generó mayor participación en la clase de Biología (ver Tabla 24).

Lo anterior, resulta coherente con lo expresado por Villaroel (2007); Parker y Chao (2007), quienes en sus estudios, consideran que la wiki está enmarcada en la psicología educativa y en el paradigma constructivista, los cuales promueven el aprendizaje significativo de los estudiantes en dimensiones sociales, a través de las interacciones que involucran al estudiante y le permite ser más activo. Por lo tanto, 
implica, que los sistemas educativos incorporen modelos pedagógicos que apoyen la inclusión de los AVA en los procesos de enseñanza aprendizaje (Acosta, Quintero, y Riveros, 2013).

De igual manera, las observaciones no participantes indicaron que el uso de la wiki contribuyó al establecimiento de nuevas formas de interacción social entre los estudiantes, favoreció el aprendizaje cooperativo y el cumplimiento de los objetivos de aprendizaje, porque se generaron discusiones productivas, los alumnos aprendieron a negociar, se concientizaron sobre la responsabilidad de cumplir con sus aportaciones y aprendieron a valorar lo que hacían los compañeros, todo ello, mediante una comunicación cordial y respetuosa (ONP-GE; ver Apéndice K). Esto reafirma lo expresado por el docente: "Debido a que algunos estudiantes interactúan constantemente, logran construir conjuntamente páginas llamativas y presentar ideas que captan el interés de otros, las interacciones mejoran, se incrementan, además de que así, poco a poco van tomando protagonismo y esto les ayuda a alcanzar las metas, mejorar sus conocimientos y a disfrutar compartirlo” (EMT-GE; ver Apéndice L).

Una situación coincidente con este hecho, es la referida por García del Dujo y Suárez (2012), para quienes la tecnología genera un nuevo escenario en el que confluyen diferentes formas de interacción social a partir de una nueva dinámica comunicativa y de construcción de conocimientos. De esta manera, el establecimiento de relaciones con diferentes personas como mediadoras del conocimiento, de acuerdo con Coll y Sánchez (2008) favorecen los procesos psicológicos superiores.

Por otra parte, el $85.37 \%$ de los alumnos encuestados consideró que los contenidos de Biología que se encuentran en la wiki son más agradables y fáciles de aprender, las 
actividades son claras e interesantes, lo que refuerza y complementa las clases presenciales (ver Tabla 24). Estas opiniones fueron similares a las del docente, quien también señaló que el uso de la wiki cambia la forma de presentar los contenidos, la información y los momentos de interacción, esto permite al estudiante, acceder a diversa información en el momento en que la necesita, lo que enriquece el intercambio de ideas. Una de sus explicaciones fue: "con la wiki se comparte conocimiento e información de manera diferente y rápida y esto es de gran agrado para aquellos estudiantes para quienes quizás es mucho más fácil que solamente texto” (EMT-GE; ver Apéndice L).

Lo señalado, se asemeja a los estudios de Waldeg (2012) que considera como una ventaja la integración de las wikis a los procesos de enseñanza aprendizaje de la Biología, el recapturar el mundo real de una forma diferente y enriquecida para reabrirlo al estudiante en el interior del aula, a partir de la presentación de contenidos y materiales de apoyo, agradables y comprensibles entregados de múltiples formas, medios y canales. El poder ofrecer la posibilidad de ampliar conocimientos y estimular la investigación y autonomía, de acuerdo con Salinas (2004b, citado por Castañeda y Adell 2013), potencian la interacción y el aprendizaje social.

Asimismo, los resultados de la prueba t(descrita más adelante) aplicada a la preprueba y posprueba presentada por el GE, (ver Apéndice Q) confirmaron para este caso, que el uso e incorporación de una wiki facilita y mejora el aprendizaje de la Biología. Lo que se vincula con la percepción del $82.93 \%$ de los estudiantes encuestados (ver Tabla 24) y con la opinión del maestro quien consideró, que la wiki facilita que los estudiantes aprendan Biología, no sólo porque permite que el maestro los guíe y apoye, sino porque se pueden establecer interacciones constantes a partir de las actividades 
cooperativas planteadas de forma clara (EMT-GE). Una justificación es: “debido a que la wiki está incorporada a un manejo de un trabajo en equipo con actividades cooperativas va a permitir también intercambiar ideas y conceptos digamos previos que ellos tienen, o ideas previas, ayudarse, esto facilita el aprendizaje y les va a permitir avanzar" (EMT-GE; ver Apéndice L). De igual manera, el 87.5\% de los alumnos, opinó que la wiki aumento el interés por aprender Biología (ver Tabla 24).

El hallazgo descrito es similar al obtenido en la investigación de Ardura y Zamora (2014), donde se indica que el $80 \%$ de los estudiantes piensan que un AVA constituye una buena herramienta para facilitar el estudio. Igualmente los autores consideran, que su uso ayuda a los estudiantes a tomar conciencia sobre aquello que aprenden, en la medida que favorece la autorreflexión, aumenta la motivación, el compromiso y la responsabilidad por su propio aprendizaje. Las wikis se presentan como instrumentos para fomentar y facilitar los procesos de aprendizaje, así lo refieren Kimmerle, Moskaliuk y Cress (2011), en sus estudios.

Como fue evidenciado en las observaciones no participantes, el aprendizaje cooperativo logrado de forma progresiva con el uso de la wiki, contribuye al aprendizaje de las temáticas abordadas en la clase de Biología y al desarrollo de las competencias requeridas en esta área del saber, como la comunicación, el discernimiento, pensamiento crítico, argumentación y el trabajo en equipo, entre otras (ONP-GE; ver Apéndice K). Lo cual resulta congruente con lo expresado por el maestro, al considerar que a través de la wiki, los estudiantes manifiestan sin temor sus ideas previas respecto a un concepto, y esto genera un diálogo que les permite de manera conjunta organizar y reconstruir sus esquemas mentales. Una razón que él señaló, fue la siguiente: “ellos [los alumnos] van 
formando y reformulando las ideas que ellos tienen para construir un concepto un poco más aproximado a lo científico, porque pueden discutir en cualquier momento con sus compañeros y docente. Así los integrantes de cada equipo se ayudan mutuamente, se evalúan, respetan las aportaciones de todos y tratan de mejorar sus producciones" (EMT-GE; ver Apéndice L).

Las percepciones anteriores, se asemejan a las de Villalustre y Del Moral (2011), e indican que la ejecución del trabajo grupal y el diseño de actividades cooperativas en línea apoyadas en las wikis, donde se usan contenidos propios y pertenecientes a cierta materia, permiten que los estudiantes adquieran conocimientos básicos sobre dicha disciplina y manejen algunos conceptos específicos que propician el desarrollo de competencias y habilidades específicas. De acuerdo con Johnson y Johnson (1989 citados por González y García, 2007) a través del aprendizaje cooperativo los estudiantes deben lograr interdependencia positiva, interacción asertiva, responsabilidad individual, habilidades sociales y procesamiento grupal autónomo. Puede afirmarse que dichos aspectos fueron corroborados a través del trabajo de campo previamente descrito.

\section{Pregunta subordinada: ¿cuáles son los beneficios del uso e incorporación de} una wiki en el trabajo cooperativo de la clase de Biología? De acuerdo con el maestro titular del GE, el uso de la wiki dinamiza, enriquece y facilita el trabajo cooperativo, hace que los estudiantes tengan un papel más activo como integrantes de un equipo de trabajo. Esta situación destacó en la observación del GE, donde los integrantes de aquellos grupos que lograron trabajar adecuadamente, fueron activos y estuvieron motivados, se apoyaron unos a otros, compartieron información, interactuaron de manera respetuosa y armónica. Asimismo, reconocieron las habilidades de sus 
compañeros, aceptaron sus debilidades, de tal forma que fueron evidentes los consensos y el logro del aprendizaje cooperativo.

Al respecto, la investigación de Montenegro y Pujol (2010) arrojó resultados similares, puesto que describen como una utilidad de la wiki el favorecimiento del trabajo encaminado al desarrollo de procesos colectivos que requieren de la negociación al interior de grupos de trabajo, en relación con los contenidos y el reconocimiento del trabajo de los otros compañeros. La interacción cooperativa rescata el concepto de unidad y ejecuta según Suárez (2010), una ética de cooperación y señala que relegar a un miembro del aprendizaje, es postergar la oportunidad de todos.

Por otra parte, la entrevista al maestro titular del grupo experimental pone de manifiesto que la wiki, contribuye a que los estudiantes en sus respectivos espacios grupales, expresen sin temor sus ideas previas respecto a un concepto y se genere un diálogo que les permite de manera conjunta organizar sus esquemas mentales, pues "los estudiantes aprenden a comunicarse sin pelear y a entender que no todo lo que escriben y piensan es correcto o aceptado por sus compañeros” (EMT-GE; ver Apéndice L). En este sentido, en la observación no participante, destacó como un aspecto interesante acontecido al interior de los equipos de trabajo, la comunicación respetuosa y tolerante sostenida en la wiki, respecto de las discusiones en los foros y el cuidado de los estudiantes para decirle a sus compañeros sobre una idea o aportación en la edición, que según ellos fuera errónea, lo que favoreció el trabajo cooperativo y el avance en las actividades. Esto es respaldado por la opinión del 92.68\% de los estudiantes encuestados, quienes consideraron que la comunicación en la wiki fue cordial y 
respetuosa y un 90.24\% señaló que los conflictos del trabajo en equipo fueron resueltos con tolerancia y respeto (ver Tabla 24).

Sobre ello, Brack, y Van Damme (2010) señalan que en su investigación, los estudiantes pasaron por una fase de comunicación asertiva y negociación de tareas y en general, se trasladaron a un modo cooperativo en el que cada estudiante tomó la responsabilidad de un diferente subtema. La estructura y diseño de una wiki según Hoffmann (2008), permite albergar la curiosidad y satisfacción de un conjunto de personas que se esfuerzan mutuamente e intercambian ideas, como características humanas sobresalientes; elementos esenciales de un científico que comparte hallazgos y que tiene el privilegio de ser reconocido por las innovaciones que publica.

Asimismo, el $85.37 \%$ de los estudiantes consideraron que la comprensión de los conceptos abordados en la clase de Biología, mejoró por las aportaciones de los compañeros en la wiki, así como el trabajo cooperativo; también las clases presenciales se reforzaron y complementaron. De acuerdo con el maestro, la razón fue la siguiente: "el hecho de que los equipos y sus integrantes aprenden a apoyarse mutuamente, a interactuar y compartir sus ideas y elaboraciones de manera responsable y crítica, lo cual ayuda positivamente para la construcción del conocimiento" (EMT-GE; ver Apéndice L).

Lo anteriormente referido, resulta similar a lo encontrado en la investigación de Area (2010), donde se expresa, que las wikis son recursos útiles para la enseñanza y el aprendizaje porque facilitan el trabajo cooperativo y colaborativo de los alumnos, además de que estimulan la motivación e implicación de los estudiantes en actividades que requieren procesos de búsqueda, análisis y reconstrucción del conocimiento. El 
proyecto de grupo, se basa en la teoría del aprendizaje social de Vygotzky que valora la interacción entre pares y el intercambio de conocimientos (Brack y Van Damme, 2010).

Sin embargo, en la entrevista al maestro titular del GE destacó el hecho de que el trabajo cooperativo requiere un componente muy importante y complejo por parte de los estudiantes y es la voluntad. Una actitud negativa por parte de los alumnos, entorpece las actividades cooperativas en la wiki y el caso contrario, promueve el apoyo, trabajo mutuo y mejora los procesos de enseñanza aprendizaje. En este sentido, la observación no participante evidenció las dificultades presentadas con algunos estudiantes, debido a la falta de disposición e interés para trabajar (ONP-GE; ver Apéndice K). "Digamos que si un estudiante no tiene la voluntad de trabajar, de estudiar y buscar información y la responsabilidad para hacerlo, resulta muy complicado generar ese trabajo cooperativo y esto puede llegar a generar un desánimo en los equipos de trabajo, al observar que sus compañeros no aportan, ni editan nada, como sucedió con algunos alumnos en nuestro caso particular" (EMT-GE; ver Apéndice L). Igualmente, el 31.71\% de los estudiantes consideró que hubo ciertas dificultades en la generación de acuerdos individuales y grupales al trabajar en la wiki.

Al respecto, los estudios de Pere (2009) enfatizan que la interacción grupal requiere que el clima de aula sea favorable y que el grupo esté mínimamente cohesionado y que por esta razón, es importante programar actividades anteriores al trabajo cooperativo con el fin de tener las condiciones apropiadas. Por lo tanto, resulta útil buscar la forma de administrar la heterogeneidad, y no, una homogeneidad imposible (Pere, 2009). 
Sin embargo, como se evidencia en las observaciones de clase no participante y en la entrevista con el maestro titular del grupo experimental, es requisito indispensable para usar e incorporar las wiki como apoyo a los procesos de enseñanza aprendizaje, contar con infraestructura y tecnología apropiada. Igualmente, es necesario garantizar que los docentes y los alumnos dispongan de unas habilidades mínimas para el manejo de estas herramientas y de acceso constante a la tecnología.

Consideraciones semejantes destacan en los estudios de Anguita, Villagrá y Jorrín (2010). Señalan que debe reflexionarse sobre la situación real del alumnado, no tanto con la wiki, sino con el acceso general a la tecnología y la conexión a Internet. También sobre las habilidades del profesor y la disposición de derechos para administrar completamente el espacio de la wiki. Dentro de los entornos virtuales, según Ramos (2003), los maestros deben estimar el adecuado diseño instruccional, la planeación didáctica, el seguimiento y retroalimentación, que demandan estos ambientes y su relación con el manejo de variedad de recursos multimedia.

Pregunta subordinada: ¿cómo se desarrolla la interacción en la wiki, durante la realización de actividades cooperativas, por parte de los alumnos? De manera general y conforme a lo ya he referido en las observaciones no participantes se evidenció que la interacción entre los alumnos mejoró paulatinamente, debido a que los estudiantes no estaban acostumbrados a trabajar con este tipo de apoyos tecnológicos y menos en asignaturas diferentes a las relacionadas con la de Informática (ONP-GE; ver Apéndice K). Además, porque de acuerdo con la entrevista al maestro titular del GE, los alumnos deben lograr empatía con los integrantes de sus grupos de trabajo: "El tiempo ayuda a que los grupos se vayan ajustando y sus integrantes digamos aprendan a conocerse, a 
reconocerse, y así las interacciones y producciones cada vez sean mejores" (EMT-GE; ver Apéndice L).

Congruente con esta situación es la referida por Valzacchi (1998 citado por Quse, Masullo y Ocelli, 2011), quien indica que implementar apoyos tecnológicos en el aula, genera un cambio gradual, que implica esfuerzos, investigación y estudio, sin embargo se convierten en recursos convenientes para el aprendizaje. Promover la interacción de acuerdo con León del Barco (2006) no garantiza unos efectos favorables en la socialización y el aprendizaje, lo más importante es la calidad y los efectos de la misma.

De acuerdo con las observaciones no participantes, las interacciones de los alumnos en la wiki se desarrollaron porque en cada sesión de clase el docente indicó los objetivos de la clase y la forma de realizar las actividades cooperativas diseñadas para tal efecto (ONP-GE; ver Apéndice K). De manera cordial y respetuosa guió a los estudiantes para que compartieran sus dudas e ideas a través de los espacios que se destinaron en la wiki, hizo seguimiento a las participaciones virtuales de los estudiantes y las retroalimentó (ONP-GE, ver Apéndice K). De esta forma, "los estudiantes se comunican e interaccionan a través de los foros, responden las preguntas planteadas, debaten, editan en sus páginas y cuestionan lo que escriben. La búsqueda de información se convierte en un proceso agradable para ellos porque tienen la oportunidad de observar y compartir diversos vídeos e imágenes, a fin de completar las actividades en la wiki” (EMT-GE; ver Apéndice L). Asimismo, el 75.31\% consideró que la wiki mejoró la responsabilidad del trabajo en equipo. El 82.92\% opinó que el AVA lo facilitó (ver Tabla 24). 
En este sentido, para Aborisade (2009) los proyectos de trabajo en grupo permiten las interacciones de los estudiantes y posibilitan extender el aula más allá del espacio habitual de clase, porque pueden generarse encuentros, tanto sincrónicos como asincrónicos y esto gracias a las grandes ventajas de un AVA. Para Serrano, Piñuel, Gracia y Arias (1982) las interacciones virtuales demandan una gran capacidad de lectoescritura y esto favorece la estructura cognitiva, debido a que se crean debates escritos, entre los compañeros, asimismo surgen explicaciones entre los pares, esto resulta más favorable que aprender de manera individual o en forma aislada.

\section{Pregunta subordinada: ¿cuál es la actitud de los alumnos respecto al uso e} incorporación de una wiki en la clase de Biología? Los resultados obtenidos en la aplicación de la encuesta a los alumnos del GE (ver Tabla 24), evidenciaron una actitud positiva ante el uso de ese AVA. Por lo tanto, para el 90.24\% de los alumnos resultó ser más agradable estudiar Biología con la wiki, igualmente que los conflictos del trabajo en equipo, fueron resueltos con tolerancia y respeto. Asimismo, el 87.5\% de los alumnos opinó que la wiki aumentó su interés por aprender Biología y consecuente con esta percepción, el 80.49\% de los estudiantes expresó que la wiki debe utilizarse en otras asignaturas. Por otra parte, con un porcentaje acumulado del $82.93 \%$, los alumnos estimaron que el uso del AVA facilitó el aprendizaje de Biología y el trabajo en equipo. Asimismo, el 80.4\% coincidió en que aprendió más sobre Biología al usar la wiki.

Específicamente, la investigación realizada por Jofre, Bunster, Martínez y Márquez (2014) confirma la utilidad de las wikis en la generación de ambientes contemporáneos que se aproximan a las expectativas y necesidades del mundo actual. De acuerdo con Aborisade (2009), se puede hacer mucho por mejorar las experiencias 
de aprendizaje de los jóvenes, debido a que los alumnos se sienten más a gusto con las nuevas tecnologías. Al respecto, en cuanto al escenario educativo donde se hizo el estudio sobresalió la necesidad de mayor capacitación docente sobre el uso e incorporación de AVA en clases de ciencias y mejorar la infraestructura tecnológica del colegio.

\section{Pregunta subordinada: ¿cuáles son las diferencias entre el rendimiento} académico de los alumnos que utilizaron una wiki, respecto a los que no la usaron?

Las diferencias entre el rendimiento académico de los alumnos que utilizaron la wiki (GE), respecto a los que no la usaron (GC), derivaron de la prueba t, que permitió evaluar y comparar el desempeño de los alumnos del GE y el GC, en la preprueba y posprueba (antes y después de la intervención), a partir de las medias respectivas. Por lo tanto, para probar las hipótesis fue necesario hallar los grados de libertad, mediante la fórmula: $g l=n l+n l-2$ y determinar si el valor de $t$ era significativo, es decir, hallar los valores críticos de $t$ (tabla de distribución $t$ de student, según Hernández et al. 2010) en un nivel de significancia de 0.05 . Este valor fue asumido con el fin de tener el mínimo error y un valor significativo de los resultados, por lo que existió una probabilidad del 95\% de que los promedios de los grupos realmente difirieran entre sí (debido al tratamiento) y un 5\% de posibilidad de error, o de que la diferencia de promedios no fuera significativa o importante (Hernández et al. 2010). Consecuentemente, para el cálculo del valor de $t$ se obtuvieron los resultados incluidos en la Tabla 25 . 
Tabla 25

Resultados comparativos (prueba t) de la posprueba en el grupo experimental y de control

\begin{tabular}{lcc}
\hline & $\begin{array}{c}\text { Grupo 8-1 } \\
\text { Experimental }\end{array}$ & $\begin{array}{c}\text { Grupo 8-2 } \\
\text { De control }\end{array}$ \\
\hline Media & 15.56151221 & 12.78947368 \\
Varianza & 29.70260976 & 22.17069701 \\
Observaciones & 41 & 38 \\
Diferencia hipotética de las medias & 0 & \\
Grados de libertad & 77 & \\
Estadístico t & $\mathbf{2 . 1 5 9 9 0 9 3 6 4}$ & \\
$\mathrm{P}(\mathrm{T}<=\mathrm{t})$ una cola & 0.016945717 & \\
Valor crítico de $t$ (una cola) & 1.664884537 & \\
$\mathrm{P}(\mathrm{T}<=\mathrm{t})$ dos colas & 0.033891434 & \\
Valor crítico de $\mathrm{t}$ (dos colas) & 1.991254395 & \\
\hline
\end{tabular}

Como puede apreciarse en la Tabla 25 el valor calculado de $t$ fue: 2.159909364 y resulta superior al valor de la tabla o valor crítico en un nivel de confianza de 0.05 (2.159909364 > 1.991254395), lo que significó que la hipótesis de investigación (Hi), relativa a la existencia de diferencias significativas en el rendimiento académico de los alumnos que usaron la wiki, respecto a los que no lo hicieron, fue aceptada y consecuentemente se rechazó la hipótesis nula (Ho). Esto significó que los estudiantes que utilizaron la wiki sí tuvieron un mejor desempeño académico, que aquellos estudiantes que no la usaron. Asimismo, sobresalió que el $80.48 \%$ de los alumnos consideró que tuvieron un mayor aprendizaje de la Biología, al usar la wiki (ver Tabla 24).

Los resultados anteriores son consecuentes con lo expresado por Onrubia, Colomina y Engel (2006); López (2013), en el sentido de que el desarrollo de actividades que estimulan tanto la búsqueda, como la selección y evaluación crítica de 
información (actividades realizadas en la wiki), favorecen la creatividad e innovación y la realización de actividades cooperativas. Lo que a su vez propicia la motivación del estudiante y un mejor rendimiento académico en la enseñanza de las ciencias naturales, en este caso, la Biología.

Finalmente, en este capítulo se dio respuesta a las preguntas de investigación, mediante los resultados derivados de los instrumentos que se aplicaron en el trabajo de campo, a partir de las dos fases del estudio y para ello, también se hizo la triangulación con los fundamentos del marco teórico. Por lo tanto, en el siguiente capítulo se presentarán las conclusiones, resumiéndose los principales hallazgos, conforme a los objetivos de la indagación, así como las propuestas de estudios futuros y algunas recomendaciones orientadas a mejorar la práctica docente en el colegio donde se realizó este proyecto. 


\section{Conclusiones}

En este capítulo, se resumen los principales hallazgos de esta investigación, después de llevar a cabo el análisis de los datos derivados del trabajo de campo, que involucró la aplicación de observaciones no participantes y una encuesta, a un grupo experimental de estudiantes de octavo grado de una secundaria colombiana que realizaron actividades con una wiki, así como la entrevista al maestro titular de dicho grupo. De igual manera, se aplicó una preprueba y posprueba tanto al grupo experimental, como al grupo de control. Todo ello, con el fin de dar respuesta a la pregunta general de investigación y cumplir con los objetivos planteados en el capítulo 1. Finalmente, en este último capítulo se presentan sugerencias de estudios futuros con posibles interrogantes derivadas de los hallazgos, las cuales podrían ayudar a proyectar y mejorar el futuro uso de las wikis en el proceso de enseñanza aprendizaje de la Biología. Asimismo, se plantean de manera breve y concreta propuestas de mejora sobre aplicaciones prácticas que podrán ser desarrolladas al interior de la institución educativa y que surgen de la información obtenida en este estudio.

\subsection{Resumen de los principales hallazgos de la investigación}

El presente estudio fue desarrollado con el objetivo de conocer el impacto del uso e incorporación de una wiki en el aprendizaje de la Biología. Lo anterior, como una forma de buscar estrategias que puedan contribuir al mejoramiento del desempeño académico de los estudiantes de octavo grado de una secundaria colombiana en el área 
de Biología y que a su vez, ayuden a incentivar su interés, atención y participación en estas clases. En este sentido, el análisis de la información obtenida en este estudio permitió evidenciar que el uso e incorporación de una wiki, ayudó a modificar el rol del docente y las interacciones de los alumnos, de tal forma que se logró transformar la enseñanza tradicional de las clases, lo cual también motivó a los aprendices a interactuar activamente entre ellos mismos, incluso con respeto, tolerancia, ayuda mutua y solidaridad. Igualmente, se detectó el agrado que sintieron al estudiar Biología con este tipo de apoyo tecnológico y el incremento en la participación e interés en las clases (ver Tabla 24). Tal como ya se señaló en el capítulo anterior, todo ello derivó de las observaciones no participantes, de la entrevista con el maestro titular del grupo experimental, así como de la encuesta a los alumnos (ONP-GE y EMT-GE).

Asimismo, se pudo corroborar que el uso de la wiki favoreció tanto el trabajo cooperativo y el cumplimiento de los objetivos de aprendizaje relacionados con las temáticas abordadas en la clase de Biología, como el desarrollo de las competencias requeridas en esta área del saber: comunicación, discernimiento, pensamiento crítico, argumentación y el trabajo en equipo, entre otras, porque se generaron discusiones productivas, los estudiantes aprendieron a negociar, se concientizaron sobre la responsabilidad de cumplir con sus aportaciones (individuales y grupales) y valoraron lo que hacían los compañeros. Todo eso, a través una comunicación cordial y respetuosa (ONP-GE y EMT-GE; ver Tabla 24 y Apéndices K-L).

Por otra parte, el $85.36 \%$ de los alumnos consideró que los contenidos de Biología subidos en la wiki fueron más agradables y fáciles de aprender, que incluyeron el diseño de actividades claras e interesantes $(85.37 \%)$, lo que reforzó y complementó las clases 
presenciales (ver Tabla 24). Esto fue consecuente con lo señalado por el docente, quien estimó, que el uso de la wiki obligó a cambiar la forma de presentar los contenidos, facilitó el acceso a la información y mejoró la interacción con los alumnos. Por lo tanto, los estudiantes, accedieron a diversidad de información en el momento en que lo necesitaron, lo cual enriqueció el intercambio de ideas (EMT-GE; ver Apéndice L).

De igual manera, los resultados de la prueba $t$ aplicada a la preprueba y posprueba del GE y GC, (ver Apéndice Q) confirmaron que el uso e incorporación de una wiki facilitó y mejoró el aprendizaje de la Biología, respecto a los alumnos que usaron el apoyo tecnológico (GE). Lo que se confirmó con la actitud del $82.93 \%$ de los estudiantes encuestados (ver Tabla 24) y con la opinión del maestro titular del GE, quien compartió dicha perspectiva, no sólo porque la wiki le permitió guiar y apoyar a los alumnos, sino porque se logró el establecimiento de interacciones constantes a partir de las actividades cooperativas planteadas de forma clara (EMT-GE; ver Apéndice L).

Lo anteriormente mencionado, indica que en el desarrollo de esta investigación fue posible alcanzar el objetivo general propuesto en el capítulo 1 , referido al inicio de esta sección. Asimismo, es importante señalar que a partir de este objetivo general, se consideraron cuatro aspectos adicionales y relevantes para esta investigación, es decir, otros objetivos específicos que también fueron alcanzados, según se detalla a continuación. El primero de ellos, se enfocó en determinar los beneficios de la wiki en el trabajo cooperativo en la clase de Biología, el segundo pretendió describir la forma en que se desarrolló la interacción en la wiki durante la realización de las actividades cooperativas; el tercero, buscó conocer la actitud de los alumnos respecto al uso e incorporación de una wiki en dicha clase y el cuarto, pretendió analizar las diferencias 
entre el rendimiento académico de los alumnos que utilizaron la wiki, respecto a los que no la usaron.

En referencia al primer objetivo, correspondiente a los beneficios de la wiki en el trabajo cooperativo de la clase de Biología, se evidenció que el uso de este apoyo tecnológico, dinamizó, enriqueció y facilitó el trabajo cooperativo debido a que los estudiantes tuvieron un rol más activo como integrantes de un equipo de trabajo, estuvieron motivados, se apoyaron unos a otros, compartieron información, e interactuaron de manera respetuosa y armónica. También reconocieron las habilidades de sus compañeros, aceptaron sus debilidades o áreas de oportunidad, de tal forma que destacaron los consensos y el aprendizaje cooperativo. Igualmente, la virtualidad de la wiki, contribuyó a que los estudiantes en sus respectivos espacios grupales, expresaran sin temor sus ideas previas respecto a los conceptos, lo cual generó un diálogo que ayudó a la organización conjunta de sus esquemas mentales (ONP-GE y EMT-GE). De esta manera, los estudiantes consideraron que la comprensión de las temáticas abordadas en la clase de Biología, mejoró por las aportaciones de los compañeros en la wiki (85.37\%), así como la realización del trabajo cooperativo (85.92\%) diseñado para tal efecto (Tabla 24 y Apéndices H, K y L).

Por otra parte, destacó el hecho de que el trabajo cooperativo requiere un componente muy importante y complejo por parte de los estudiantes, que es la voluntad. Una actitud negativa por parte de los alumnos, entorpece las actividades cooperativas en la wiki y el caso contrario, promueve el apoyo, el trabajo mutuo y mejora los procesos de enseñanza aprendizaje (ONP-GE y EMT-GE). 
En cuanto al segundo objetivo, sobre la descripción de la forma en que se desarrolló la interacción en la wiki durante la realización de las actividades cooperativas, se pudo apreciar en las observaciones no participantes, que la interacción entre los alumnos se logró de forma paulatina, debido a que los estudiantes no estaban acostumbrados a trabajar con este tipo de apoyos tecnológicos y menos en asignaturas diferentes a las relacionadas con la asignatura de Informática, además porque fue necesario que lograran empatía con los integrantes de sus grupos de trabajo (ONP-GE y EMT-GE; ver Apéndices K y L).

Asimismo, es importante mencionar que las interacciones de los alumnos en la wiki se desarrollaron gracias a que en cada sesión de clase, el docente indicó los objetivos de la misma y la forma de realizar las actividades cooperativas diseñadas para tal efecto; hizo seguimiento a las participaciones virtuales de los estudiantes y las retroalimentó. Esto, lo realizó de manera cordial y respetuosa e incentivó a los estudiantes para que compartieran sus dudas e ideas a través de los espacios que se destinaron en la wiki (ONP-GE y EMT-GE).

Respecto al tercer objetivo, en el que se pretendió conocer la actitud de los alumnos respecto al uso e incorporación de una wiki en la clase de Biología, puede indicarse que fue positiva, ya que para los alumnos encuestados (ver Tabla 24), resultó ser más agradable estudiar Biología con este apoyo tecnológico (90.24\%) y tuvieron la sensación de que los conflictos del trabajo en equipo, fueron resueltos con tolerancia y respeto, por lo cual consideraron que la wiki debe utilizarse en otras asignaturas (80.49\%), además de que el AVA el aumentó su interés por la Biología (87.5\%). 
Sobre el cuarto y último objetivo específico, encaminado al análisis de las diferencias entre el rendimiento académico de los alumnos que utilizaron la wiki, respecto a los que no la usaron, se corroboró con la prueba $t$, que los estudiantes que utilizaron la wiki tuvieron un mejor desempeño académico, que aquellos que no lo hicieron, e incluso en la posprueba del GC, no se ubicaron alumnos en el nivel de alto desempeño, a diferencia del GE, con un 4.9\% (ver Tabla 25). Asimismo, el 80.48\% de los alumnos encuestados, consideró tener un mayor aprendizaje de la Biología, al usar la wiki (ver Tablas 21 y 24).

Para finalizar, es necesario señalar como requisito indispensable para usar e incorporar las wiki como apoyo a los procesos de enseñanza aprendizaje de la Biología, contar con infraestructura y tecnología apropiadas, así como garantizar que tanto los docentes como los alumnos desarrollen las habilidades mínimas para el manejo de estas herramientas, además del acceso constante y adecuado a las TIC (ONP-GE y EMT-GE; ver Apéndices K, L y Tabla 24). Lo anterior, con el fin de aprovechar las ventajas de este recurso para la formación de los estudiantes, ya que posibilita la interacción y contribuye a mejorar o perfeccionar la comunicación, tanto sincrónica como asincrónica a través del medio informático (Cabero y Llorente, 2007).

\subsection{Sugerencias de estudios futuros}

En el desarrollo de esta investigación, especialmente después del trabajo de campo y con la identificación y descripción de los hallazgos más relevantes, se generaron nuevas ideas respecto al uso de las wikis en los procesos de enseñanza aprendizaje, así como en la selección y organización de los contenidos a desarrollar en las mismas. En 
cuanto a su utilización en la clase de Biología y de otras asignaturas, se propone profundizar su uso en el desarrollo del trabajo colaborativo (como técnica didáctica), con lo cual, se puedan realizar ajustes complejos que conlleven a mejorar las prácticas pedagógicas y lograr que los estudiantes de las secundarias ubicadas en los municipios colombianos que se encuentran alejados de las capitales, sean más autónomos y tengan un rol protagónico, de tal manera que mejoren su desempeño académico y social.

Respecto a la selección del apoyo tecnológico, es importante recordar que las wikis no son el único tipo de AVA, ya que existen muchos otros que podrían ser utilizados por estudiantes y docentes a nivel de secundaria; especialmente, en asignaturas vinculadas a las ciencias naturales. Sin embargo, en el contexto de esta investigación, la wiki fue favorable en el proceso de enseñanza aprendizaje de la Biología, por lo tanto se sugiere que se indague sobre las posibilidades que ofrecen las wikis en la construcción de las diferentes formas de representación utilizados por la ciencia para explicar sus fenómenos. En consecuencia, se enlistan algunas interrogantes que podrían servir para futuras investigaciones: ¿cómo facilitan las wikis los procesos de enseñanza aprendizaje de las representaciones gráficas cartesianas en Biología?, ¿de qué manera las wikis promueven el desarrollo de pensamiento crítico, a través de la colaboración en estudiantes de secundaria?

Frente a los contenidos y actividades a desarrollar con este tipo de apoyos tecnológicos, deberá tenerse en consideración para su diseño instruccional, la creatividad, el uso de elementos multimedia, la actitud de los estudiantes frente a la asignatura, su perfil, estilo de aprendizaje y la orientación particular de la materia, entre otros aspectos. Esto favorecerá la producción e innovación de materiales exclusivos, 
coherentes y adecuados para cada área científica abordada en la secundaria. Por lo tanto, las interrogantes que surgieron alrededor de este aspecto fueron: ¿cómo diseñar materiales didácticos creativos que ayuden a mejorar los procesos de enseñanza aprendizaje basados en el uso de las wikis?, es decir, que fomenten el autoaprendizaje de los alumnos, el pensamiento crítico, la búsqueda y selección de información, así como la resolución de problemas. Otra posible pregunta será: ¿cómo debe el docente implementar las herramientas de comunicación y las diferentes metodologías didácticas para diseñar entornos virtuales, donde se logre una interacción más afectiva, con cercanía a los alumnos y de calidad? En este sentido, también será interesante enfocar los estudios futuros no sólo en el uso de la wiki, sino también relacionar su incorporación en el aula, con el desarrollo de otras competencias, como las referidas previamente. Consecuentemente, también será enriquecedor recurrir a otras técnicas de recolección de datos, como los grupos de enfoque o las entrevistas a profundidad, con un mayor número de grupos, maestros y alumnos.

Adicional a lo anteriormente enunciado y acorde con la metodología utilizada en este estudio, será adecuado incluir alumnos de diferentes grados y otras instituciones, donde quizás sea posible hacer una selección aleatoria para conformar los grupos de estudiantes. Esto podrá dar una mejor representación de la población de estudiantes a nivel de secundaria en el aprendizaje de la Biología, o quizás en otra asignatura relacionada con las ciencias naturales, además de que eso enriquecerá la recolección y análisis de los datos y especialmente, habría la posibilidad de generalizar los resultados.

Asimismo, será pertinente que las investigaciones puedan desarrollarse en un lapso de tiempo que comprenda más de un año académico y que coincida con el inicio del 
mismo, en caso de presentarse situaciones inesperadas con la infraestructura y el servicio de Internet, que en este estudio, en varias ocasiones imposibilitó el desarrollo normal de las clases con la wiki, o al menos contar con seis meses para realizar el trabajo de campo. Además, será adecuado observar el comportamiento de los alumnos cuando se expongan a una interacción prolongada con este tipo de apoyos tecnológicos (mínimo de tres meses), a fin de analizar con mayor profundidad su impacto en el proceso educativo y particularmente, en su aprendizaje, lo cual permitirá conocer otros mecanismos de mejoramiento más efectivos.

\subsection{Propuestas para mejorar la práctica docente}

De acuerdo con los hallazgos encontrados y sustentados en el capítulo 4, es pertinente señalar que un aspecto relevante para mejorar la práctica docente en la secundaria que fue el escenario educativo de este estudio, es el compromiso que debe adquirir la institución educativa desde el estamento directivo, a favor del desarrollo de una política que estructure y garantice el uso e incorporación de las TIC en las diferentes asignaturas impartidas, no sólo las relativas a la enseñanza de las ciencias. Por lo tanto, también debe contemplarse un mejor acondicionamiento de los espacios de trabajo del colegio, así como la actualización de los equipos de cómputo y la adquisición de más recursos tecnológicos (periféricos).

Por otra parte, tal y como lo ha promulgado el MEN colombiano, es necesario trabajar más al interior de las entidades educativas, para que las TIC sean consideradas desde el currículo y los planes didácticos de cada área del saber. De tal forma que se genere la cultura de uso de las TIC y los alumnos y docentes desarrollen las habilidades 
necesarias para su implementación y uso cotidiano. Consecuentemente, las escuelas y particularmente el colegio que fue escenario de esta indagación, podrían aprovechar las posibilidades que brindan las herramientas Web 2.0 para complementar, reforzar e innovar en las clases presenciales y medir su impacto en los procesos de enseñanza aprendizaje. En este sentido, también podrían considerarse otros AVA, como Moodle, redes sociales, $b \log s$, aplicaciones gratuitas de aprendizaje móvil, etcétera.

Lo anterior, implica que los docentes de la Institución Belisario Peña Piñeiro realmente se concienticen de la necesidad de capacitarse en el manejo de las competencias tecnológicas básicas y trabajen en la discusión y posterior construcción de nuevas propuestas didácticas que impacten de manera positiva la forma de enseñar. En dicho colegio son muy pocos los docentes que han desarrollado estas competencias, lo cual hace que los esfuerzos por implementar estos recursos se hagan de forma aislada y casi sin ningún tipo de apoyo institucional, de tal forma que sólo constituyen pequeños intentos por incorporar estos apoyos tecnológicos en el aula. Por lo tanto, es oportuno preguntarse si los docentes que llevan mucho tiempo en el ejercicio y que nunca han trabajo con las TIC, están realmente interesados en actualizarse y determinar si están conscientes de la necesidad de crear nuevos ambientes de aprendizaje mediados por la tecnología. Todo ello, en beneficio del aprendizaje de sus alumnos.

Por otro lado, los docentes deben tener en cuenta que si los alumnos usan las tecnologías, tampoco significa que forzosamente las utilicen adecuadamente. Es un hecho que los estudiantes tienen la capacidad de aprender a usarlas muy rápido, sin embargo, esto no garantiza que realmente desarrollen las competencias tecnológicas y que tengan la capacidad de comunicarse e interactuar correctamente y mucho menos 
producir contenidos multimedia, o lo más importante: poder aprender con ellas. Consecuentemente, el maestro siempre deberá buscar estrategias que permitan a sus estudiantes aprender más, a través de apoyos atractivos y eficaces. Sólo de esa manera, realmente se constituirá en un verdadero facilitador del aprendizaje.

En este sentido, es importante que los docentes se atrevan a innovar en el aula, traten de encontrar cómo motivar a sus alumnos, aprendan a escuchar lo que ellos proponen o les interesa, a su vez y de forma paulatina, que los sepan guiar en la autogestión de sus aprendizajes. Para ello, resulta conveniente que los docentes de la institución logren vislumbrar el potencial de las estructuras cooperativas y colaborativas y cómo a través de éstas, se pueden lograr mejores resultados en cuanto al aprendizaje, los intercambios verbales, la comunicación escrita, la interacción entre los individuos, respecto al trabajo competitivo que caracteriza el actual entorno laboral.

Para finalizar, en este capítulo se describieron los principales hallazgos originados en el transcurso de la investigación, se propusieron sugerencias respecto a estudios futuros y para mejorar la práctica docente en la institución donde se llevó a cabo este proyecto. Asimismo, se evidenció que en este trabajo también se dio cumplimiento tanto al objetivo general, como a los objetivos específicos formulados en el capítulo 1. 


\section{Referencias}

Aborisade, P. (2009). Investigating a Nigerian XXL-Cohort Wiki-Learning Experience: Observation, Feedback and Reflection. Electronic Journal of e-Learning, 7(3), 191-202. Recuperado de http://files.eric.ed.gov/fulltext/EJ872404.pdf

Acosta, R., Quintero, H. y Riveros, V. (2013). La infoestructura de las tecnologías de la información y la comunicación como mediadoras en el aprendizaje de la Biología. Revista Quórum Académico, 10(1), 130-152. Recuperado de http://www.redalyc.org/articulo.oa?id=199026737009

Adell, J. (2007). Wikis en educación. En J. Cabero y J. Barroso (Eds.), Posibilidades de la teleformación en el espacio europeo de educación superior (pp. 323-333). Granada, España: Octaedro Andalucía.

Algieri, R. D., Ferrante, M. S. y Mazzoglio y Nabar, M. Javier. (2011). Implementación de Tecnologías de la Información y la Comunicación en la enseñanza universitaria de la anatomía del hígado: aspectos neurobiológicos y psicopedagógicos. International Journal of Morphology, 29(4), 1130-1135.

Almazán, D. T. (2010). Aprendizaje cooperativo. Revista E-Formadores, 1(1), 1-10. Recuperado de http://red.ilce.edu.mx/sitios/revista/e_formadores_pri_10/articulos/doris_torres_fe b2010.pdf

Altarejos, F y Naval, C. (2011). Filosofía de la Educación (e-book). Navarra, España: EUNSA.

Anguita, R., García S., Villagrá, S. y Jorrín, I.M. (2010). Wikis y aprendizaje colaborativo: Lecciones aprendidas (y por aprender) en la facultad de educación. Revista de Educación a Distancia, 1(12), 2-19. Recuperado de http://www.redalyc.org/articuloBasic.oa?id=54714042007 
Ardura, D. y Zamora, A. (2014). ¿Son útiles los entornos virtuales de aprendizaje en la enseñanza de las ciencias en una secundaria? Evaluación de una experiencia en la enseñanza y el aprendizaje de la Relatividad. Revista Eureka sobre Enseñanza y Divulgación de las Ciencias, 11(1), 83-93. Recuperado de http://www.redalyc.org/articulo.oa?id=92029560008

Area, M. (2010). Las wikis en mi experiencia docente. Del diccionario, de la asignatura, al diario de clase. Revista de Educación a Distancia, 1(12), 1-. Recuperado de http://www.redalyc.org/articulo.oa?id=54714042001

Augar, N., Raitman, R., \& Zhou, W. (2004, January). Teaching and learning online with wikis. Trabajo presentado en la ASCILITE Conference, Perth, Australia.

Bautista, G., Borges, F. y Flores, A. (2006). Didáctica Universitaria en entornos virtuales de enseñanza-aprendizaje. Madrid, España: NARCEA S.A.

Becerra, A. (2006). Interacciones y construcción social del conocimiento en educación en línea. Revista de Educación Superior, 35(1), 65-77. Recuperado de http://www.redalyc.org/articulo.oa?id=60413804

Becerril, L. (2011). Procesos psicoeducativos en el aprendizaje cooperativo. Dimensiones para el análisis en un escenario educativo presencial con Tecnología. (Disertación Doctoral). De la base de datos Journal IN3 Working Paper Series. (UOC DWP10-001).

Bello, R. (2005). Educación virtual: aulas sin paredes (Monografía). Recuperado de http://www.educar.org/articulos/educacionvirtual.asp

Bentolila, S. y Clavijo, P. (2001). La computadora como mediador simbólico de aprendizajes escolares. Análisis y reflexiones desde una lectura vigotskiana del problema. Fundamentos de humanidades, 2(3). 77-101. Recuperado de http://www.redalyc.org/pdf/184/18400304.pdf

Bisquerra, R. (2000). Métodos de investigación educativa. Guía práctica. Barcelona, España: CEAC. 
Brack, C. y Van Damme, M-P. (2010, December). Curriculum, Technology and Transformation for an Unknown Future. Trabajo presentado en la ASCILITE Conference, Nueva York, EE.UU.

Bruna Jofré, C., Bunster Balocchi, M., Martínez Oyanedel, J. y Márquez, C. (2014). Utilizar la wiki para promover autoaprendizaje y responsabilidad social en futuros científicos. Educación Médica Superior, 28(2), 229-242.

Bustos, A. y Coll, C. (2010). Los entornos virtuales como espacios de enseñanzaaprendizaje. Una perspectiva para su caracterización y análisis. Revista Mexicana de Investigación Educativa, 15(44), 163-184. Recuperado de http://www.scielo.org.mx/scielo.php?script=sci_arttext\&pid=S140566662010000100009

Cabero, J. y Llorente, M. (2007). La interacción en el aprendizaje en red: uso de herramientas, elementos de análisis y posibilidades educativas. Revista Iberoamericana de Educación a Distancia, 10 (2), 97-123. Recuperado de http://www.biblioteca.org.ar/libros/142140.pdf.

Castañeda, L. y Adell, J. (Eds.). (2013). Entornos Personales de Aprendizaje: claves para el ecosistema educativo en red. Alcoy, España: Marfil.

Castaño, J. (2011). El uso de Internet para la interacción en el aprendizaje: un análisis de la eficacia y la igualdad en el sistema universitario catalán. (Disertación Doctoral). De la base de datos del repositorio de la Universitat Oberta de Catalunya.

Carretero, M. (1997). Construir y enseñar las ciencias experimentales. Buenos aires, Argentina: Aique S.A.

Cleary, Y. y Marcus-Quinn, A. (2008). Using a virtual learning environment to manage group projects: a case study. International Journal on Elearning, 7 (4), 603-622. Recuperado de http://0search.proquest.com.millenium.itesm.mx/docview/210366369?accountid=1 1643 
Colás, M. y Buendia, L. (1992). Investigación Educativa. Sevilla, España: Alfar.

Coll, C. y Sánchez, E. (2008). El análisis de la interacción alumno- profesor: líneas de investigación. Revista de Educación 1 (346), 15-32.

Creswell, J. W. y Plano Clark, V. L. (2011). Designing and conducting Mixed Method Research. Thousand Oaks, CA, EE.UU.: Sage Publications.

Chu, S. K. W., Siu, F., Liang, M., Capio, C. M., \& Wendy W.Y. Wu. (2013). User's experiences and perceptions on using two wiki platforms for collaborative learning and knowledge management. Online Information Review, 37(2), 304-325. doi:http://dx.doi.org/10.1108/OIR-03-2011-0043.

D’ Angelo, O. (2002). La acción grupal como base para los aprendizajes reflexivos Creativos. Revista Cubana de Psicología, 19(1), 84-90. Recuperado de http://0web.a.ebscohost.com.millenium.itesm.mx/ehost/pdfviewer/pdfviewer?sid=edec6a $\underline{\text { 51-e352-442e-b6c5-361cae685b9c\%40sessionmgr4004\&vid=23\&hid=4114 }}$

DeWitt, D., Siraj, S., \& Alias, N. (2014). Collaborative m-Learning: A module for learning secondary school science. Journal of Educational Technology and Society, 17(1), 89-101. Recuperado de http://search.proquest.com/docview/1502989096?accountid=150554

Domingo, J., Almajano, M., Martínez, H. y Segura, J. (2010). El aprendizaje cooperativo 2.0. Trabajo presentado en la $10^{\mathrm{a}}$ Jornada sobre Aprendizaje Cooperativo e Innovación docente, Barcelona, España. Recuperado de http://giac.upc.es/JAC10/10/13\%20Comunicaci\%F3n\%20AC2.0\%20JDom.pdf

Duart, J. M. y Sangrá, A. (2001). Aprender en la virtualidad. Barcelona. Educar, 1 (28), 117-131. Recuperado de file:///C:/Users/practicas/Downloads/20746-20670-1PB.pdf

Escámez, A. M. (2005). Enseñar Biología hoy en los niveles obligatorios o el reto de una enseñanza motivadora para un aprendizaje significativo en los tiempos que corren. Encuentros en la Biología, (100), 2-6. 
Fernández, A. (2005) Nuevas metodologías docentes. Recuperado de http://roble.pntic.mec.es/jprp0006/tesis/metodologia/nuevas_metodologias docentes_de\%20fernandez_march.pdf.

Ferreiro, R. y Calderón, M. (2001). El ABC del aprendizaje cooperativo. México: Editorial Trillas.

Fundación Universitaria Católica del Norte. (2005). Educación virtual reflexiones y experiencias. Medellín, Colombia: Fundación universitaria. Recuperado de file:///C:/Users/practicas/Downloads/youblisher.com-672676REFLEXIONES_Y_EXPERIENCIAS_DE_LA_EDUCACI_N_VIRTUAL.pdf

García, A. (2011). Blogs y wikis en tareas educativas. Aplicaciones de la web 2.0 en secundaria y bachillerato. Teoría de la Educación y Cultura en la Sociedad de la Información, 12(1), 430-432. Recuperado de http://hdl.handle.net/10366/83223

García del Dujo, A y Suárez, C. (2012). Interacción virtual y aprendizaje cooperativo. Un estudio cualitativo. Revista de Educación, 1(354), 381-429.

Giroux, S. y Tremblay, J. (2004). Metodología de las Ciencias Humanas: La Investigación en Acción. Distrito Federal, México: Fondo de Cultura Económica.

Góngora, J. J. (2005). La autogestión del aprendizaje en ambientes educativos centrados en el alumno. Boletín del Modelo Educativo, Tecnologico de Monterrey. Recuperado de http://www.sistema. itesm. mx/va/dide/botetin_9/pag, 3

González, N., y García, M. (2007). El aprendizaje cooperativo como estrategia de enseñanza-aprendizaje en Psicopedagogía (Universidad de Cantabria): repercusiones y valoraciones de los estudiantes. Revista Iberoamericana de Educación, 1(42), 1-13.

González, A.; Calderón, S.; Galache, T. y Torrico, A. (2006, septiembre). Uso de wikis para la realización de trabajos colaborativos en el aula. Trabajo presentado en La XIV Jornada ASEPUMA y II Encuentro Internacional, Badajoz, España. 
Harasim, 1., Hiltz, S. R., Teles, L. y Turoff, M. (2000). Redes de Aprendizaje: Guía para la enseñanza y el aprendizaje en Red. Barcelona, España: Gedisa.

Hernández, R., Fernández, C. y Baptista, P. (2010). Metodología de la investigación (5a. ed.). Distrito Federal, México: Mc Graw Hill.

Hoffmann, R. (2008). A wiki for the life sciences where authorship matters. Nature genetic, 1(40), 1047-1051. Recuperado de http://www.nature.com/ng/journal/v40/n9/pdf/ng.f.217.pdf

Jiménez, G. y Llitjós, A. (2006). Cooperación en entornos telemáticos y la enseñanza de la química. Revista Eureka Enseñanza y Divulgación Científica, 3(1), 115-133. Recuperado de http://0web.a.ebscohost.com.millenium.itesm.mx/ehost/pdfviewer/pdfviewer?vid=11\&sid =edec6a51-e352-442e-b6c5-361cae685b9c\%40sessionmgr4004\&hid=4114

Kimmerle, J., Moskaliuk, J. y Cress, U. (2011). Using wikis for learning and knowledge Building: Results of an Experimental Study. Educational Technology and Society, 14 (4), 138-148.

Lamb, B. (2004). Wide Open Spaces: Wikis, ready or not. EDUCAUSE, 39(5), 36-48. Recuperado de http://www.educause.edu/ir/library/pdf/erm0452.pdf

León del Barco, B. (2006). Elementos mediadores en la eficacia del aprendizaje cooperativo: entrenamiento previo en habilidades sociales y dinámica de grupos. Revista Anales de Psicología, 22(1), 105-112. Recuperado de http://redalyc.org/articulo.oa?id=16722114

López, M. A. (2013). Aprendizajes, competencias y TIC. Aprendizaje Basado en Competencias. Naucalpan de Juárez, México: Pearson Educación.

Manzano, A. (2011). Blogs y wikis en tareas educativas. Aplicaciones de la web 2.0 en secundaria y bachillerato. Teoría de la Educación. Educación y Cultura en la Sociedad de la Información, 12(1), 430-432.

Mayr, E. (2006). Por qué es única la Biología. Buenos Aires, Argentina: Katz. 
Mazzitelli, C. y León, J.A. (2001). Las estrategias de aprendizaje en un programahipermedia: Implicaciones para la enseñanza y aprendizaje de las Ciencias Naturales. Psicología Educativa, 7(2), 1-25. Recuperado de http://0web.a.ebscohost.com.millenium.itesm.mx/ehost/pdfviewer/pdfviewer?sid=edec6a 51-e352-442e-b6c5-361 cae685b9c\%40sessionmgr4004\&vid=6\&hid=4114

Montenegro, M. y Pujol, J. (2010). Evaluación de la wiki como herramienta de trabajo colaborativo en la docencia universitaria. Revista de Educación a Distancia, 1(11), 1-15. Recuperado de http://www.redalyc.org/articulo.oa?id=54714024005

Onrubia, J., Colomina, R. y Engel, A. (2008). Los entornos virtuales de aprendizaje basado en trabajo de grupo y el aprendizaje colaborativo. En C. Coll (Ed), Psicología de la educación virtual: aprender y enseñar con las tecnologías (pp 233-250). Madrid, España: Ediciones Morata.

Ovejero, A. (1993). Aprendizaje Cooperativo: Una eficaz aportación de la psicología social a la educación del Siglo XXI. Psicothema, 5, (1). 373-391.

Parker, K. y Chao, J. (2007). Wiki as a teaching tool. Interdisciplinary Journal of e-learning and Learning Objects, 3(1), 57-72. Recuperado de http://www.editlib.org/p/44798/

Perea, G., Estrada, B. y Campos, M. (2013). El blog y wiki como herramienta docente para el trabajo colaborativo, el aprendizaje autónomo, activo y reflexivo. Revista Iberoamericana para la Investigación y el Desarrollo Educativo, 3(6), 98-109. Recuperado de file:///C:/Users/practicas/Downloads/65-391-1-PB.pdf.

Pujolás, P. (2008). 9 ideas clave. El aprendizaje cooperativo. Barcelona, España: Graó.

Quse, L., Masullo, M. y Occelli, M. (2011). Enseñar y aprender educación en Biología con la plataforma Moodle. Innovación y experiencias, 1(3), 63-78.

Quiterio, A. (2001). El uso del wiki como herramienta didáctica para fomentar la competencia del trabajo colaborativo: Una experiencia en el ITESM, CEM (Tesis de maestría) De la base de datos del Tecnológico de Monterrey. 
Ramos, C. (2003). Realidad virtual.Entér@te en línea.2(24). Recuperado de http://www.enterate.unam.mx/Articulos/2003/noviembre/realivirt.htm

Rodríguez, J. M. (2009). Cambios metodológicos relacionados con el aprendizaje de las Ciencias. Revista Educación, 33(1), 61-73. Recuperado de http://www.redalyc.org/pdf/440/44015082005.pdf

Salinas, J. (1997). Nuevos ambientes de aprendizaje para una sociedad de la información. Revista pensamiento educativo, 20(1), 81-104.

Salinas, M. (2011, Abril). Entornos de aprendizaje en la escuela:tipos, modelo didáctico y rol del docente. Trabajo presentado en la semana de la educación del programa de servicios educativos del departamento de educación de la Universidad Católica Argentina, Buenos Aires, Argentina.

Sangrá, A. (2001). Enseñar y aprender en la virtualidad. Educar, 1(28), 117-131. Recuperado de http://ddd.uab.cat/record/1103.

Sanz, C. V., Madoz, M. C., Zangara, A. y Albanesi, B. (2008, Septiembre). El trabajo colaborativo y cooperativo mediado por TICs. Trabajo presentado en el XIV Congreso Argentino de Ciencias de la Computación, Buenos Aires, Argentina.

Sardá Jorge, A y Sanmartí Puig, N. (2000). Enseñar a argumentar científicamente: un reto de las clases de ciencias. Enseñanza de las ciencias, 18(3), 405-422. Recuperado de http://ddd.uab.cat/pub/edlc/02124521v18n3p405.pdf

Serrano, M., Piñuel, J. L., Gracia, J. y Arias, M. A. (1982). Teoría de la comunicación epistemología y análisis de la referencia. Madrid, España: A. Corazón.

Stake, R. E. (2007). Investigación con estudio de casos (eBook). Madrid, España: Ediciones Morata S. L.

Suárez, C. (2010). Aprendizaje cooperativo e interacción asincrónica textual en contextos educativos virtuales. Pixel-Bit. Revista de Medios y Educación, 1

(36), 53-67. Recuperado de http://www.redalyc.org/articulo.oa?id=36815128004 
Suárez, P.A. (2001). Metodología de la investigación. Diseños y técnicas. Bogotá, Colombia: Orión Editores Ltda.

Teddlie, C. y Taschakkori, A. (2009). Foundations of mixed methods research. Integrating quantitative and qualitative approaches in the social and behavioral Sciences. Thousand Oaks, CA, EE.UU. Sage Publications.

Tobón, S. (2006). Aspectos básicos de la formación basada en competencias. Trabajo presentado en el proyecto MESESUP, Talca, Chile.

Tornese, E. B., Dogliotti, C. G., Mazzoglio y Nabar, M. J., Algieri, R. D., Gazzotti, A., Jiménez Villarruel, H. N., Rey, L. M. \& Gómez, A. (2011). Entorno virtual de enseñanza y aprendizaje aplicado como recurso instruccional complementario en la enseñanza de Neuroanatomía: aspectos poblacionales, didácticos y psicopedagógicos. International Journal of Morphology, 29(4), 1130-1135.

Recuperado de http://www.scielo.cl/scielo.php?script=sci_arttext\&pid=S0717$\underline{95022011000400010}$

Valenzuela, J. R. y Flores, M. (2012). Fundamentos de investigación educativa (eBook). Monterrey, México: Editorial Digital del Tecnológico de Monterrey.

Vidal, M., Llanusa, S., Diego, F. y Vialart, N. (2008). Entornos virtuales de enseñanza aprendizaje. Educación Médica Superior, 22(1). 1-9.

Villalustre, L. y Del Moral, M.E. (2011). Webquest y wikis: búsqueda de información en red y desarrollo de competencias en colaboración. Teoría de la Educación. Educación y Cultura en la Sociedad de la Información, 15(1), 190-208.

Recuperado de

file:///C:/Users/practicas/Downloads/WEBQUEST\%20Y\%20WIKIS\%20B\%C3\%9ASQUEDA\%20DE\%20INFORMACI\%C3\%93N\%20EN\%20RED

$\% 20 \mathrm{Y} \% 20 \mathrm{DESARROLLO} \% 20 \mathrm{DE} \% 20 \mathrm{COMPETENCIAS} \% 20 \mathrm{EN} \% 20 \mathrm{COLABO}$

RACI\%C3\%93N.pdf.

Villarroel, J. (2007). Usos del wiki en educación secundaria. E-Revista de Didáctica, 1(1), 1-7. Recuperado de file:///C:/Users/practicas/Downloads/wiki\%20(2).pdf 
Waldegg, G. (2002). El uso de la las nuevas tecnologías para la enseñanza y el aprendizaje de las ciencias. Revista Electrónica de Investigación Educativa, 4(1), 95-116. Recuperado de http://www.redalyc.org/articulo.oa?id=15504106

Webb, N. M. (1982). Student interaction and learning in small groups. Review of Educational Research, 52(3), 421-445. 


\section{Apéndice A: Carta consentimiento de la institución educativa}

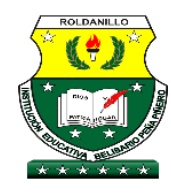

\section{INSTITUCIÓN EDUCATIVA BELISARIO PEÑA PIÑEIRO Nit. 891900829-3}

Calle 11 No.6-55 Telefax (2) 2299262

Correo Electrónico: belisario@sedvalledelcauca.gov.co

Roldanillo-Valle del Cauca-Colombia

\section{Roldanillo, Valle del Cauca, Colombia, a 13 de Febrero de 2015.}

\section{A quien corresponda:}

La que suscribe, Lic. Myriam Aydee Benítez Cano, Rectora de la Institución Educativa Belisario Peña Piñeiro, ubicada en Roldanillo, Valle del Cauca, manifiesta lo siguiente:

1) Se autoriza a la Ing. Sonia Elena Vela Vargas a realizar la investigación educativa relacionada con los estudios de maestría que cursa en el Tecnológico de Monterrey de México y cuyos objetivos comprenden la colaboración y participación de los estudiantes de octavo grado de nivel secundaria, específicamente los Grupos 8-1 y 8-2 en el primer período del año lectivo 2015.

2) Es pertinente señalar que la indagación de corte mixto, tiene como objetivo: conocer el impacto del uso e incorporación de una wiki en el aprendizaje de la Biología, respecto a los alumnos de los grupos referidos.

3) Asimismo, entre otras técnicas de recolección de datos se considerará la observación no participante, la aplicación de encuestas y la realización de entrevistas semiestructuradas a los maestros titulares de los grupos participantes en la indagación. 
4) En relación a las fotografías y videograbaciones realizadas en las sesiones de clase, éstas se utilizarán exclusivamente como evidencia del desarrollo de la presente investigación.

5) También se toma en cuenta la confidencialidad de la información proporcionada por los sujetos participantes, además de que no existirá riesgo alguno para los estudiantes, durante la realización de esta indagación.

6) En relación a lo anterior, tampoco habrá algún beneficio directo para los sujetos participantes. No obstante, su colaboración con el proyecto permitirá hacer propuestas de mejora a la práctica docente en la institución, basadas en el uso e incorporación de wikis en futuros cursos de Biología. Todo ello, con base en actividades cooperativas.

7) Consecuentemente, la Ing. Sonia Elena Vela Vargas quien cuenta con nueve años de antigüedad en el Colegio Belisario Peña Piñeiro, manifiesta -por este medio- su intención de realizar el estudio mixto y contribuir a la investigación de la práctica docente en la institución educativa, además de pretender enriquecer el proceso de enseñanza-aprendizaje de laßBiología.

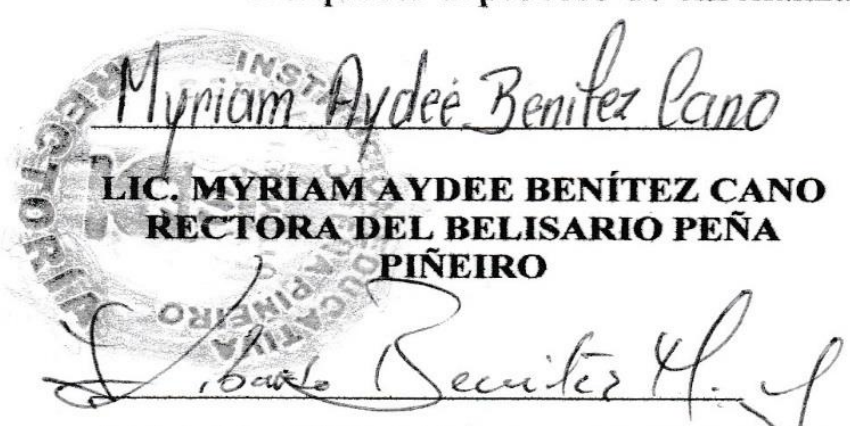

LIC. LIBARDO BENIITEZ MONDRAGÓN TITULAR DEL GRUPO 8-2 y 8-3

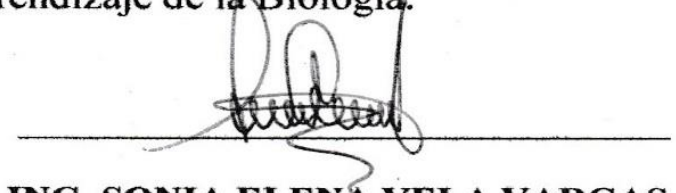

ING. SONIA ELENA VELA VARGAS AUTORA DE LA INVESTIGACIÓN

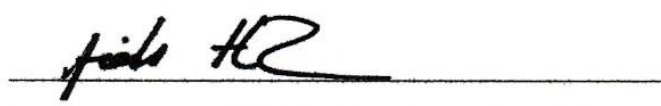

LIC. NIELS HORACIO LOZANO TITULAR DEL GRUPO 8-1 


\title{
Apéndice B. Antecedentes del bajo desempeño académico de los
}

\author{
alumnos en la Prueba Saber-área de ciencias naturales
}

Comparativo 2009, 2012, 2013 y 2014

Seleccione el grado y luego la opción que desea consultar

\section{\begin{tabular}{l|l|l} 
GRADO TERCERO & GRADO QUINTO & GRADO NOVENO
\end{tabular}}

Resultados de noveno grado en el área de ciencias naturales

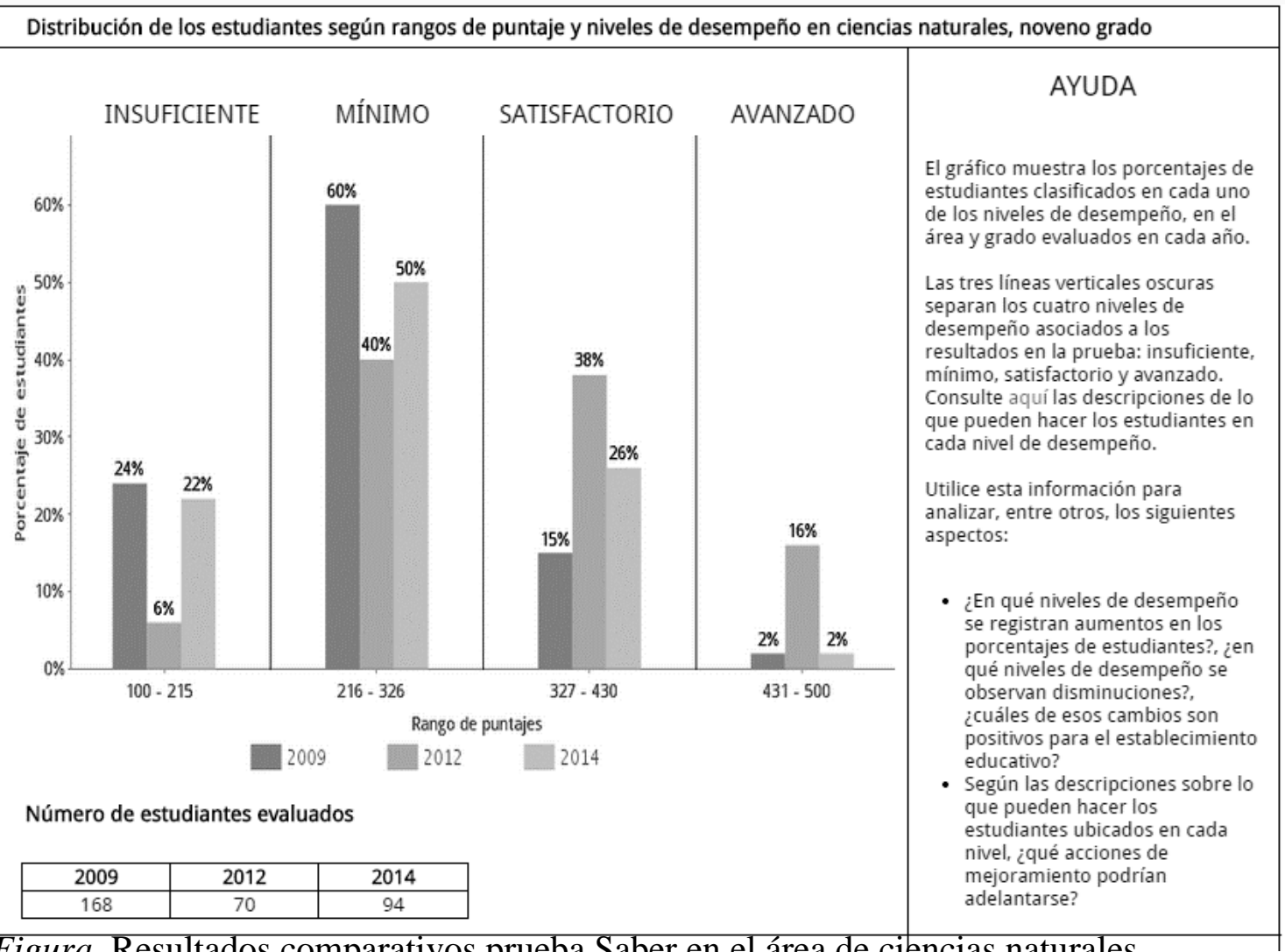

Figura. Resultados comparativos prueba Saber en el área de ciencias naturales (ICFES, 2015). 


\section{Apéndice C: Guía de observación no participante para el grupo experimental (8-1)}

Estudio sobre el análisis del impacto del uso e incorporación de una wiki en el aprendizaje de la Biología en alumnos de nivel secundaria. Esta observación forma parte de una tesis de

maestría del Tecnológico de Monterrey.

Nombre del docente:

No. de sesión observada:

Curso: Fecha:

Hora de Inicio y de Conclusión: Duración:

A. Inicio de la sesión e interacción con el docente

\begin{tabular}{|l|l|}
\hline \multicolumn{1}{|c|}{ Aspectos a observar } & Descripción de las observaciones \\
\hline $\begin{array}{l}\text { 1. El docente establece los objetivos de la } \\
\text { clase. ¿Cuáles fueron ellos? }\end{array}$ & \\
\hline $\begin{array}{l}\text { 2. ¿Al inicio, se destinó un momento para } \\
\text { que los alumnos se familiarizaran con la } \\
\text { wiki? }\end{array}$ & \\
\hline $\begin{array}{l}\text { 3. Describa el inicio de la clase, con base } \\
\text { en las instrucciones respecto de las } \\
\text { actividades cooperativas y de la } \\
\text { interacción a través de la wiki. }\end{array}$ & \\
\hline $\begin{array}{l}\text { 4. ¿La actitud del maestro contribuye a } \\
\text { que los alumnos tuvieran confianza para } \\
\text { acercarse a él y solicitar la aclaración de } \\
\text { dudas? }\end{array}$ & \\
\hline $\begin{array}{l}\text { 5. Especifique la forma cómo se aclaran } \\
\text { las dudas durante el trabajo en la wiki. }\end{array}$ & \\
\hline $\begin{array}{l}\text { 6. Describa la manera en el que el maestro } \\
\text { retroalimenta las actividades desarrolladas } \\
\text { por los estudiantes en la wiki. }\end{array}$ & \\
\hline $\begin{array}{l}\text { 7. Especifique cómo se evalúan las } \\
\text { actividades en la wiki. }\end{array}$ & \\
\hline $\begin{array}{l}\text { 8. ¿Cómo facilita el maestro la resolución } \\
\text { de problemas técnicos en la wiki? }\end{array}$ & \\
\hline
\end{tabular}


B. Interacción de los alumnos con el apoyo tecnológico

\begin{tabular}{|l|l|}
\hline \multicolumn{1}{|c|}{ Aspectos a observar } & Descripción de las observaciones \\
\hline $\begin{array}{l}\text { 1. Especifique las actitudes de agrado o } \\
\text { rechazo, mostradas por los alumnos al usar } \\
\text { la wiki en la clase de Biología. }\end{array}$ & \\
\hline $\begin{array}{l}\text { 2. Detalle los comentarios verbales } \\
\text { efectuados por los alumnos respecto de la } \\
\text { wiki ¿Hubo interés por su uso? }\end{array}$ & \\
\hline $\begin{array}{l}\text { 3. Señale si los alumnos siguieron las } \\
\text { instrucciones del profesor, al interactuar en } \\
\text { la wiki y para realizar las actividades } \\
\text { cooperativas. }\end{array}$ & \\
\hline $\begin{array}{l}\text { 4. ¿Hubo éxito en el desarrollo de las } \\
\text { actividades de clase (individuales y } \\
\text { cooperativas) con el uso de la wiki? }\end{array}$ & \\
\hline $\begin{array}{l}\text { 5. ¿Los alumnos participaron activamente } \\
\text { en la wiki? }\end{array}$ & \\
\hline $\begin{array}{l}\text { 6. ¿Durante las actividades en la wiki, los } \\
\text { alumnos consideraron los conceptos } \\
\text { teóricos de la clase presencial de Biología? }\end{array}$ & \\
\hline $\begin{array}{l}\text { 7. ¿Hubo progreso individual y grupal, con } \\
\text { base en lo que se indicó en las } \\
\text { instrucciones de las actividades? }\end{array}$ & \\
\hline $\begin{array}{l}\text { 8. Describa las principales dificultades que } \\
\text { se presentaron durante la interacción de } \\
\text { los alumnos con la wiki. }\end{array}$ & \\
\hline $\begin{array}{l}\text { 9. ¿Los alumnos interactuaron con } \\
\text { tolerancia y respeto entre ellos? }\end{array}$ & \\
\hline $\begin{array}{l}\text { 10. ¿Destacó el cumplimiento de los } \\
\text { compromisos grupales? }\end{array}$ & \\
\hline
\end{tabular}


C. Cierre de la sesión

\begin{tabular}{|l|l|}
\hline \multicolumn{1}{|c|}{ Aspectos a observar } & Descripción de las observaciones \\
\hline $\begin{array}{l}\text { 1. Detalle si al final de cada sesión, se } \\
\text { resumieron los principales aspectos } \\
\text { abordados en la misma. }\end{array}$ & \\
\hline $\begin{array}{l}\text { 2. Para concluir la sesión, se enfatizaron } \\
\text { las dudas aclaradas durante la misma y que } \\
\text { serán fundamentales para el desarrollo de } \\
\text { la próxima sesión. }\end{array}$ & \\
\hline $\begin{array}{l}\text { 3. Señale si se lograron los objetivos de la } \\
\text { sesión. }\end{array}$ & \\
\hline $\begin{array}{l}\text { 4. Principales logros en el aprendizaje de } \\
\text { la Biología y derivados de esta sesión. }\end{array}$ & \\
\hline $\begin{array}{l}\text { 5. ¿Hubo éxito en la terminación de la } \\
\text { sesión? }\end{array}$ & \\
\hline
\end{tabular}

D. Otras consideraciones de la observación.

Aspectos positivos

Aspectos de mejora: 


\section{Apéndice D: Guía entrevista semiestructurada para el titular del grupo experimental (8-1)}

Esta entrevista forma parte de los estudios de maestría que se realizan en el Tecnológico de Monterrey. Su participación será confidencial. Los resultados de este estudio contribuirán al mejoramiento de los cursos de Biología que se imparten a nivel de secundaria.

Objetivo: conocer la perspectiva de los docentes sobre el impacto del uso e incorporación de una wiki en el aprendizaje de la Biología.

1. ¿Qué utilidad encuentra en la wiki para modificar la enseñanza tradicional de la Biología?

2. ¿Cuáles son los beneficios que genera la incorporación y uso de una wiki en el trabajo cooperativo de la clase de Biología?

3. ¿Cree usted que el trabajo que se desarrolla a través de la wiki refuerza y complementa lo aprendido de forma presencial? Justifique su respuesta.

4. ¿Cuáles son los beneficios principales, derivados del uso de la wiki en el aprendizaje de la Biología?

5. ¿Cuál fue la reacción o actitud de los estudiantes al enfrentarse a esta nueva forma de trabajo con la wiki?

6. ¿Cuáles fueron las dificultades o problemas más comunes que Usted enfrento al usar la wiki como apoyo tecnológico para la enseñanza de la Biología y para dar seguimiento al trabajo cooperativo de sus alumnos?

7. ¿Cuáles fueron las dificultades o problemas más comunes que enfrentaron los estudiantes al usar la wiki? 
8. ¿Se generaron conflictos durante la comunicación o desarrollo de las actividades propuestas en la wiki? ¿Cómo se resolvieron esos conflictos?

9. ¿Cree que un AVA como la wiki debería ser incorporado en el currículo, para la enseñanza de la Biología en todos los grados de secundaria?

10. ¿Considera que la Institución cuenta con la infraestructura apropiada para desarrollar clases virtuales con este tipo de apoyo tecnológico?, ¿cómo la mejoraría?

11. ¿Cuáles son los principales valores y habilidades que se desarrollan a través del uso de la wiki en la clase de Biología?

12. ¿Considera que al utilizar la wiki, los estudiantes tuvieron una participación más activa en la clase de Biología? Justifique su respuesta.

13. ¿Considera que la participación de los equipos de trabajo en el entorno virtual, favorece la construcción del conocimiento de manera interactiva? Detalle sus razones.

14. ¿En su opinión, considera que el uso de la wiki facilita el aprendizaje de la Biología en los alumnos de $8^{\circ}$ grado? Justifique su respuesta.

15. ¿Recomendaría a sus compañeros docentes el uso del AVA en la enseñanza de la Biología y en general, para cualquier otra asignatura de secundaria? Justifique su respuesta.

Profesor entrevistado: Fecha: Día: Mes:

Año: Entrevistó: Sonia Elena Vela Vargas 


\section{Apéndice E: Encuesta para los estudiantes que utilizaron la wiki}

Esta encuesta forma parte de los estudios de maestría que se realizan en el Tecnológico de Monterrey. Tu participación será anónima y confidencial. Los resultados de este estudio solamente contribuirán al mejoramiento de los cursos de Biología que se imparten a nivel de secundaria. Tus respuestas no serán tomadas en cuenta para la evaluación del semestre.

Instrucciones:

Por favor selecciona la opción que mejor represente tu opinión, en cada uno de los siguientes enunciados. No hay respuestas correctas o incorrectas. Por favor contesta con toda honestidad.

\begin{tabular}{|l|l|l|l|l|}
\hline \multicolumn{1}{|c|}{ Ítems } & $\begin{array}{c}\text { 1.Totalmente } \\
\text { de acuerdo }\end{array}$ & 2. De acuerdo & 3.En desacuerdo & $\begin{array}{c}\text { 4.Totalmente } \\
\text { en desacuerdo }\end{array}$ \\
\hline $\begin{array}{l}\text { 1. Es más fácil aprender Biología } \\
\text { con la wiki. }\end{array}$ & & & & \\
\hline $\begin{array}{l}\text { 2. Aprendo más sobre Biología, } \\
\text { al trabajar en equipo con la wiki. }\end{array}$ & & & & \\
\hline $\begin{array}{l}\text { 3. Los contenidos de Biología } \\
\text { presentados en la wiki son } \\
\text { agradables y fáciles de } \\
\text { comprender. }\end{array}$ & & & & \\
\hline $\begin{array}{l}\text { 4. Se consiguen mejores } \\
\text { resultados cuando se trabaja } \\
\text { cooperativamente en las } \\
\text { actividades de Biología. }\end{array}$ & & & & \\
\hline $\begin{array}{l}\text { 5. La comunicación con mis } \\
\text { compañeros mediante la wiki, fue } \\
\text { cordial y respetuosa. }\end{array}$ & & & & \\
\hline $\begin{array}{l}\text { 6. El maestro nos ayudó a } \\
\text { resolver los conflictos que se } \\
\text { presentaron entre los compañeros, } \\
\text { al trabajar en equipo con la wiki. }\end{array}$ & & & & \\
\hline $\begin{array}{l}\text { 7. Las explicaciones del maestro } \\
\text { facilitaron la realización de las } \\
\text { actividades en la wiki. }\end{array}$ & & & & \\
\hline $\begin{array}{l}\text { 8. Al trabajar en la wiki, tengo } \\
\text { mayor interés por desarrollar las } \\
\text { actividades de la clase de } \\
\text { Biología. }\end{array}$ & & & & \\
\hline $\begin{array}{l}\text { 9. Se participa más en la clase de } \\
\text { Biología, cuando se trabaja con la } \\
\text { wiki. }\end{array}$ & & & & \\
\hline $\begin{array}{l}\text { 10. Comprendo de mejor manera } \\
\text { los conceptos de Biología, cuando } \\
\text { los compañeros aportan ideas que }\end{array}$ & & & & \\
\hline
\end{tabular}




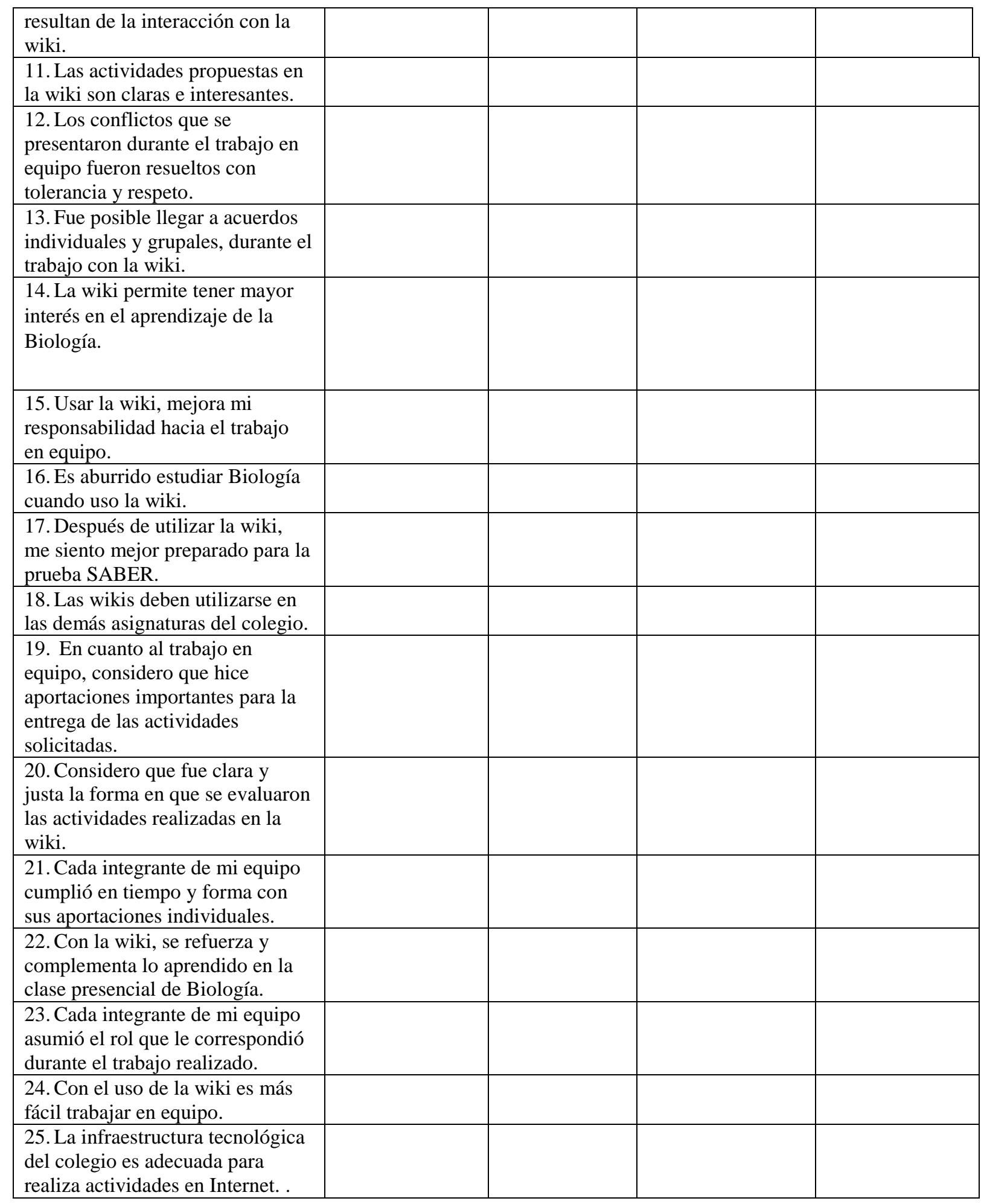




\section{Apéndice F: Preprueba de Biología para los alumnos del octavo grado}

La siguiente prueba forma parte de los estudios de maestría que se realizan en el Tecnológico de Monterrey. Tu participación es muy importante, será anónima y confidencial. Los resultados de este estudio solamente contribuirán al mejoramiento de los cursos de Biología que se imparten a nivel de secundaria. Tus respuestas no serán tomadas en cuenta para la evaluación del periodo.

\section{ÁREA CIENCIAS NATURALES - 1 $^{\mathrm{er}}$ PERÍODO - OCTAVO GRADO}

\section{FECHA:}

GRUPO: 8-

Las siguientes preguntas son de opción múltiple, con una sola respuesta correcta.

Lea con atención, analice las preguntas y conteste en la hoja de respuestas. Seleccione la respuesta correcta en cada pregunta. Recuerde rellenar completamente el óvalo de la opción elegida.

\section{De acuerdo con la siguiente lectura y los esquemas responde las preguntas 1 y 2 .}

La mitosis y la meiosis son mecanismos de división celular que permiten el desarrollo y reproducción de los seres vivos respectivamente. La mitosis se presenta en células somáticas y la meiosis en células sexuales. A continuación se muestran algunos esquemas que representan estos procesos, pero solo dos corresponden a los correctos.

I.

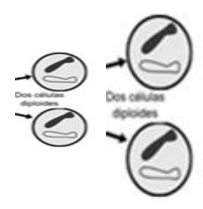

III.

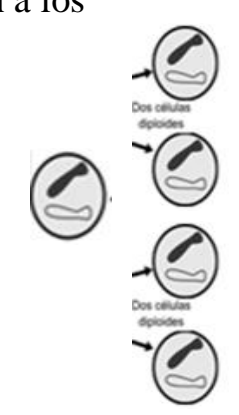

II.

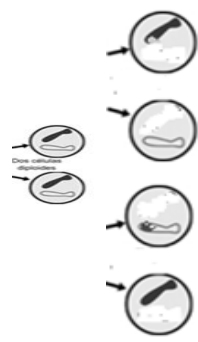

IV.

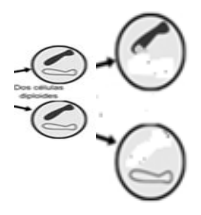

procesos de meiosis y mitosis respectivamente.
a. El esquema I y IV son los adecuados
b. El esquema III y II son los adecuados
c. El esquema II y I son los adecuados
d. El esquema I y II son los adecuados

2. Al finalizar el proceso de la meiosis se obtienen:

a. 2 células hijas que conservan el número de cromosomas de la madre.

b. 2 células hijas que reducen a la mitad el número de cromosomas de la madre.

c. 4 células hijas que conservan el número de cromosomas de la madre.

d. 4 células hijas que reducen a la mitad el número de cromosomas de la madre.

3. El siguiente gráfico muestra la forma como se reproducen las bacterias

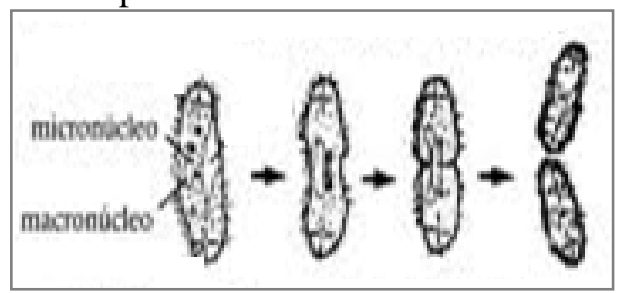


Indica el tipo de reproducción asexual que se representa:
a. Gemación
c. fisión binaria
b. esporulación
d. fragmentación

4. Para reproducirse, una pareja de lombrices se atrae, ponen sus cuerpos juntos, con sus cabezas en direcciones opuestas. El esperma es transferido desde el

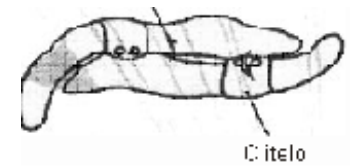
poro masculino a la otra lombriz; ambas quedan fecundadas y luego ponen sus huevos de los que posteriormente saldrán las nuevas lombrices.

De acuerdo con lo anterior, se puede decir que la reproducción de las lombrices es:
a. Asexual
c. Partenogénesis
b. Gemación
d. Sexual

5. Para que una célula pueda realizar la división mitótica es condición fundamental que previamente se dé
a. duplicación del número cromosómico
b. reemplazo de ADN por ARN
c. rompimiento de la membrana
d. reducción del número cromosómico

6. Las técnicas modernas de la biología molecular nos permiten reemplazar el núcleo de un óvulo fecundado por el núcleo de una célula somática de un organismo adulto. Al implantar este óvulo en el útero de una hembra de la especie el resultado más probable será un organismo

a. con características tanto de la hembra como del donante del núcleo b. idéntico al adulto de donde se obtuvo el núcleo implantado

c. muy parecido a la madre que aportó el óvulo modificado

d. con la mitad de la información genética de un adulto normal
7. Algunas bacterias poseen una velocidad de reproducción más alta que otros organismos sencillos, además no se ven afectadas por la concentración de sales. Teniendo en cuenta el anterior enunciado puede inferirse que:

a. Este tipo de bacterias tiene un sistema de reproducción sexual debido a que tienen características diferentes a las de otros organismos.

b. Los otros organismos tienen un sistema de reproducción sexual porque se reproducen rápidamente cuando la concentración de sales es baja.

c. Este tipo de bacterias tiene un sistema de reproducción asexual debido a que la rapidez es una característica propia de este sistema.

d. Los demás organismos tienen un sistema de reproducción asexual debido a que la variabilidad es una característica propia de este sistema.

8. Los procesos, a punto de ocurrir, ilustrados por la figura, corresponden a la:
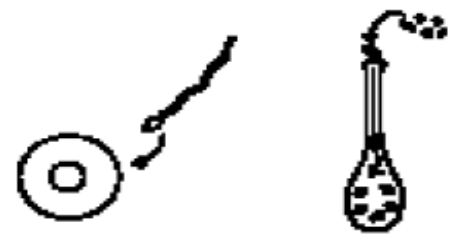
a. polinización
c. hibridación
b. fecundación
d. copulación

9. Identifica la opción correcta:

a. La mitosis es el proceso clave para la reproducción sexual y la meiosis es el proceso clave para la reproducción asexual. b. Las plantas que se reproducen a través de semillas tienen un mecanismo de reproducción asexual.

c. La división que conduce a una célula normal, con un determinado número de cromosomas a otras con la mitad de los mismos se denomina meiosis. 
d. La división que conduce a una célula normal, con un determinado número de cromosomas a otras con igual número de los mismos se denomina mitosis.

10. El tipo de reproducción que se presenta en el siguiente esquema corresponde a:

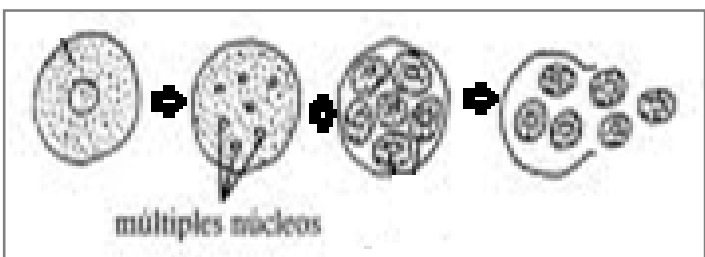

a. Fragmentación b. esporulación

b. Gemación

d. bipartición

11.Se desarrolló un estudio en el que se contó el número de organismos sencillos de tres especies que se desarrollan en un mismo bosque. Las variaciones en el tamaño de la población de las tres especies durante los años 1990-1996 se observan en el gráfico 1. Adicionalmente se muestra una gráfica en la que se observa el comportamiento de las lluvias durante los años de muestreo.

Gráfico 1

Gráfico 2
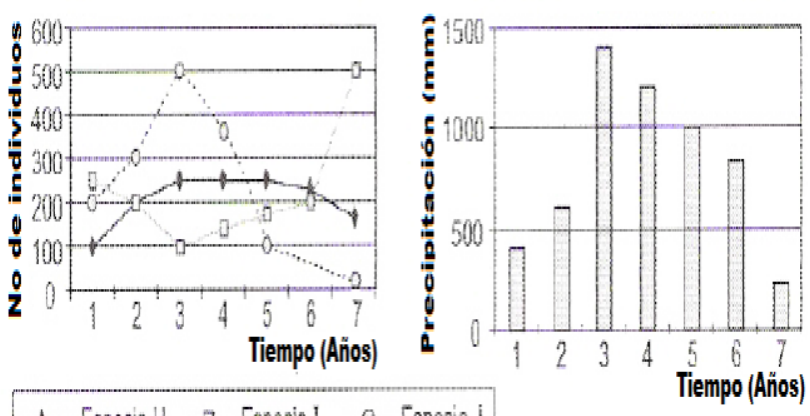

+ Especiet I Espetiel o Especied

A partir de esta información usted podría decir que:

a. Las especies I y $\mathrm{H}$ se reproducen con mayor éxito en las épocas más húmedas b. La especie $\mathrm{J}$ no se reproduce durante las épocas más lluviosas.

c. Las especies $\mathbf{H}$ y $\mathbf{J}$ se reproducen con mayor éxito bajo condiciones muy secas. d. La especie I se reproduce con mayor éxito en épocas secas.

\section{Responda las preguntas 12 y 13 de acuerdo con la siguiente información}

La siguiente gráfica muestra la velocidad de crecimiento de diferentes sistemas o tejidos durante el desarrollo humano.

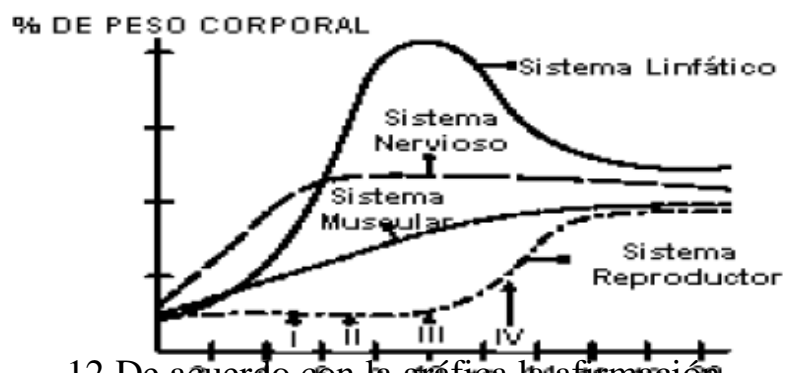

12. De aeuerto cøn la grtáfica hadafirmación correcta es:

a. Menor en el sistema nerviosos que en el tejido muscular entre los 4 y los 6 años.

b. Menor en el sistema linfático entre los 10 y 14 años que en el sistema reproductor entre los 2 y 4 años.

c. Mayor en el sistema reproductor que en el tejido muscular entre los 12 y 16 años. d. Menor en el sistema nervioso que en cualquier otro sistema durante los primeros 5 años de vida.

13.Las células de los testículos en el hombre estarían presentando una mayor cantidad de divisiones meióticas en el punto
a. I b. II
c. III
d. IV

14.El tipo de reproducción asexual en la que un organismo o célula progenitora se divide en dos células hijas iguales y del mismo tamaño
a. Gemación
b. Esporulación
c. Partenogenésis
d. Bipartición

15.El tipo de reproducción propia de muchas plantas, animales y exclusiva del hombre es:
a. Asexual
c. Gemación
b. Fisión
d. Sexual. 


\section{Hoja de respuestas de la preprueba}

NOMBRE:

FECHA:

GRUPO:

Rellena completamente el óvalo con la respuesta correcta según corresponda. Utiliza lápiz de mina negra.

1. $A B C D$

2. $A B C D$

3. $A B C D$

4. $A B(B)$

5. $A B C D$

6. $A B C D$

7. $A B C D$

8. $A B(B)$

9.

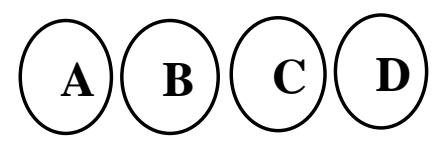

10.
11. $A B C D$

12. $A(B) C D$

13. $A B C D$

14. $A(B)$

15. $A B(B)$ 


\section{Apéndice G: Posprueba de Biología para los alumnos del octavo grado}

La siguiente prueba forma parte de los estudios de maestría que se realizan en el Tecnológico de Monterrey. Tu participación es muy importante, será anónima y confidencial. Los resultados de este estudio solamente contribuirán al mejoramiento de los cursos de Biología que se imparten a nivel de secundaria. Tus respuestas no serán tomadas en cuenta para la evaluación del periodo.

\section{ÁREA CIENCIAS NATURALES - $1^{\mathrm{er}}$ PERÍODO - OCTAVO GRADO}

\section{FECHA:}

GRUPO: 8-

Las siguientes preguntas son de opción múltiple, con una sola respuesta correcta. Lea con atención, analice las preguntas y conteste en la hoja de respuestas. Seleccione la respuesta correcta en cada pregunta. Recuerde rellenar completamente el óvalo de la opción elegida.

\section{De acuerdo con la siguiente lectura y los esquemas responde las preguntas 1 a 3 .}

La mitosis es un mecanismo de división celular que permite el desarrollo y reproducción de los seres vivos respectivamente. La mitosis se presenta en células somáticas. A continuación se muestran algunos esquemas que representan este proceso, pero solo uno es correcto.

III.

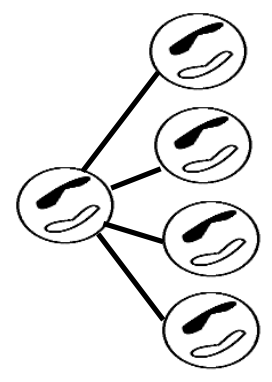

IV.

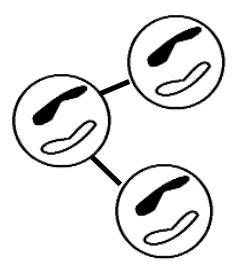

III.

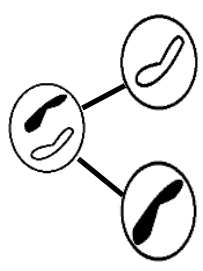

IV.

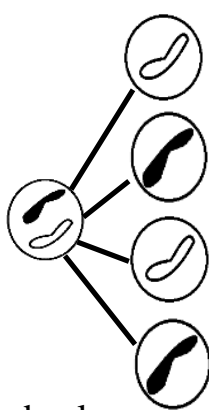

división del núcleo correspondiente a la mitosis.
a. El esquema I es el adecuado.
b. El esquema III es el adecuado.
c. El esquema II es el adecuado.
d. El esquema IV es el adecuado.

2. Al finalizar el proceso de la mitosis se obtienen:

a. 2 células hijas que conservan el número de cromosomas de la madre.

b. 2 células hijas que reducen a la mitad el número de cromosomas de la madre.

c. 4 células hijas que conservan el número de cromosomas de la madre.

d. 4 células hijas que reducen a la mitad el número de cromosomas de la madre.

3. La mitosis es un proceso de división celular que permite a los seres vivos:

a. Reproducirse asexualmente.

b. Procrear hijos diferentes a los padres.

c. Variar la información genética

d. Reproducirse sexualmente.

1. Observa y determina cuál de los esquemas anteriores representa el proceso de 
4. El siguiente gráfico muestra la forma como se reproducen las bacterias

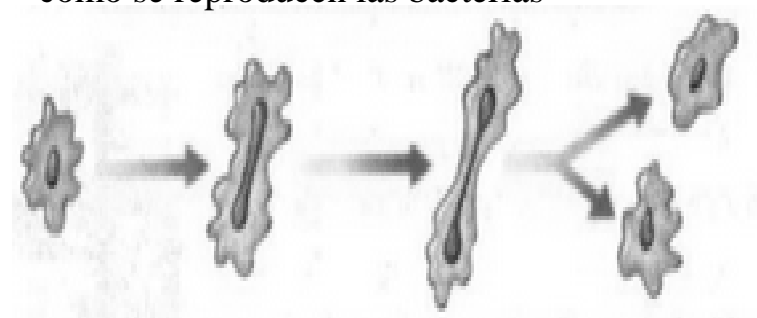

Indica el tipo de reproducción asexual que se representa:
a. Gemación
c. fisión binaria
b. esporulación
d. fragmentación

5. Para reproducirse, dos organismos vivos se atraen, ponen sus cuerpos juntos, con sus cabezas en direcciones opuestas debido a que requieren que sus células germinales o sexuales puedan unirse y completar la información genética.

De acuerdo con lo anterior, se puede decir que la reproducción de estos dos organismos es:
a. Asexual
c. Partenogénesis
b. Gemación
d. Sexual

6. Para que una célula pueda realizar la división mitótica es condición fundamental que previamente se dé
a. La etapa de la citocinesis
b. La etapa de la Interfase
c. Rompimiento de la membrana nuclear
d. Reducción cromosómica

7. Para que los seres vivos perpetúen su especie es necesario que ocurra la función de:
a. Relación.
b. Nutrición
c. Reproducción
d. Evolución

8. Algunas bacterias poseen una velocidad de reproducción más alta que otros organismos sencillos, además no se ven afectadas por la concentración de sales. Teniendo en cuenta el anterior enunciado puede inferirse que:

a. Este tipo de bacterias tiene un sistema de reproducción sexual debido a que tienen características diferentes a las de otros organismos.

b. Los otros organismos tienen un sistema de reproducción sexual porque se reproducen rápidamente cuando la concentración de sales es baja.

c. Este tipo de bacterias tiene un sistema de reproducción asexual debido a que la rapidez es una característica propia de este sistema.

d. Los demás organismos tienen un sistema de reproducción asexual debido a que la variabilidad es una característica propia de este sistema.

9. Los procesos, a punto de ocurrir, ilustrados por la figura, son necesarios para que ocurra la:

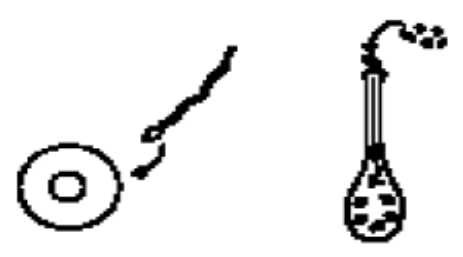
a. fragmentación en invertebrados
b. Reproducción sexual
c. Meiosis en los seres vivos
d. Copulación en los seres vivos

10.Identifica la opción correcta:

a. Las plantas que se reproducen a través de semillas tienen un mecanismo de reproducción asexual.

b. En la reproducción sexual los hijos no son completamente parecidos a sus padres porque hay una combinación de características genéticas.

c. La división que conduce a una célula normal, con un determinado número de 
cromosomas a otras con la misma cantidad de los mismos se denomina meiosis.

d. En la reproducción asexual los hijos son completamente diferentes a sus padres porque no hay una combinación de características genéticas.

11. El tipo de reproducción que se presenta en el siguiente esquema corresponde a:

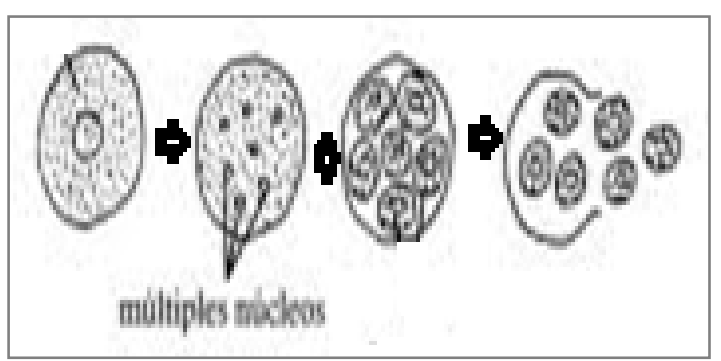

a. Fragmentación

c. esporulación

b. Gemación

d. bipartición

12.Se desarrolló un estudio en el que se contó el número de organismos sencillos de tres especies que se desarrollan en un mismo bosque. Las variaciones en el tamaño de la población de las tres especies durante los años 1990-1996 se observan en el gráfico 1. Adicionalmente se muestra una gráfica en la que se observa el comportamiento de las lluvias durante los años de muestreo.

Gráfico 1
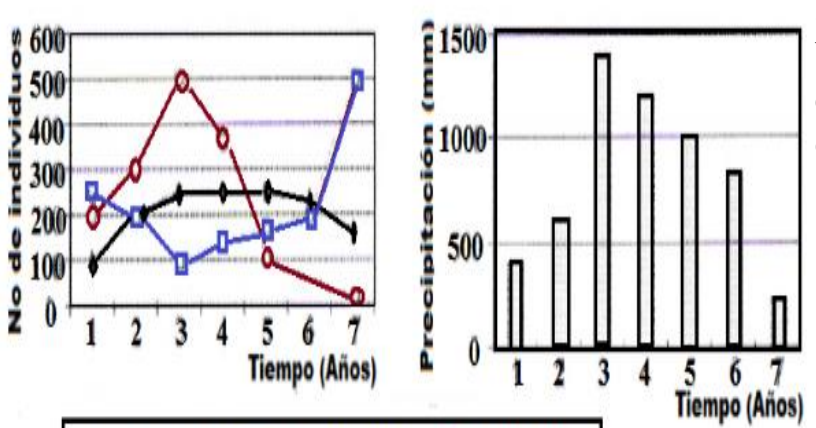

$\triangle$ ESPECIE H 口ESPECIE I OESPECIE J

A partir de esta información usted podría decir que: a. Las especies $\mathrm{I}$ y $\mathrm{H}$ se reproducen con mayor éxito en las épocas más húmedas b. La especie $\mathbf{J}$ no se reproduce durante las épocas más lluviosas.

c. Las especies $\mathrm{H}$ y $\mathbf{J}$ se reproducen con mayor éxito bajo condiciones muy secas. d. La especie I se reproduce con mayor éxito en épocas secas.

13.El tipo de reproducción asexual en la que un organismo o célula progenitora se divide en múltiples células hijas de menor tamaño es
a. Gemación
c. Pluripartición
b. Esporulación
d. Bipartición

14.El tipo de reproducción propia de muchas plantas, animales y exclusiva del hombre es:
a. Asexual
c. Gemación
b. Fisión
d. Sexual.

15.Observe la siguiente imagen.

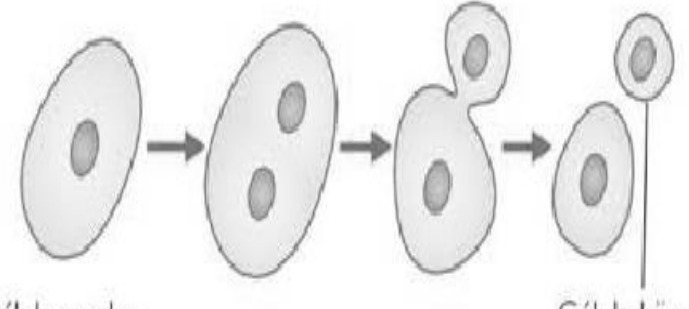

Célula madre

Célula hila

El tipo de reproducción asexual representado en la imagen anterior y que es muy común en unicelulares es:
a. Esporulación
b. Gemación
c. Bipartición
d. Fragmentación 


\section{Hoja de respuestas de la posprueba}

NOMBRE:

FECHA:

GRUPO:

Rellena completamente el óvalo con la respuesta correcta según corresponda. Utiliza lápiz de mina negra.

1. $\mathrm{A} \mathrm{B} \mathrm{C}$

2. $A B C D$

3. $A B(B$

4. $\mathrm{A} B \mathrm{C}$

5. $A B C D$

6. $A B(B)$

7. $A(B) C$

8. $A(B) C$

9. $A(B) C D$

10. $A(B) C$
11. $A B C D$

12. $A B(B)$

13. $A B(B)$

14. $A(B) C$

15. $A B C D$ 


\section{Apéndice H: Actividades cooperativas para realizarse con la wiki}

En este anexo se describen las actividades a realizar con los alumnos de los grupos 8-1 y 8-3 donde se describen tres actividades para fortalecer la competencia de trabajo cooperativo. Asimismo, su elaboración se basó en el objetivo general el cual es conocer el impacto del uso e incorporación de una wiki en el aprendizaje de la Biología en $8^{\circ}$ grado de secundaria.

Área: Ciencias Naturales

Asignatura: Biología Grado: Octavo Grupos: $\underline{8-1 \text { y 8-3 }}$

Colegio/Sede: No. Sesiones: $\underline{3}$

\begin{tabular}{|c|c|c|c|}
\hline Tema 1 & Competencias & Objetivo & Aprendizajes esperados \\
\hline $\begin{array}{l}\text { Función vital } \\
\text { de } \\
\text { reproducción } \\
\text { en los seres } \\
\text { vivos. }\end{array}$ & $\begin{array}{l}\checkmark \text { Comunicar. } \\
\checkmark \text { Trabajo en equipo. } \\
\checkmark \text { Disposición para } \\
\text { aceptar la naturaleza } \\
\text { abierta, parcial y } \\
\text { cambiante del } \\
\text { conocimiento. }\end{array}$ & $\begin{array}{l}\checkmark \text { Reconocer la utilidad del } \\
\text { trabajo cooperativo en el } \\
\text { aprendizaje de las ciencias. } \\
\checkmark \text { Comprender la importancia de } \\
\text { la reproducción para los seres } \\
\text { vivos. }\end{array}$ & $\begin{array}{l}\checkmark \text { Definen y } \\
\text { comprenden el concepto } \\
\text { de reproducción } \\
\text { construido por los } \\
\text { diferentes equipos de } \\
\text { trabajo, a partir de ideas } \\
\text { previas e información } \\
\text { adicional. }\end{array}$ \\
\hline
\end{tabular}

Desarrollo de las sesiones
El profesor explica a los estudiantes acerca de la investigación que pretende realizarse, para la cual es necesario que tengan claro qué es el trabajo cooperativo, sus características y pertinencia para lograr el aprendizaje de algunos conceptos de Biología, como la reproducción. Para ello se hará uso de un video (https://www.youtube.com/watch?v=HrtRcYd36b4) y posteriormente preguntas relativas al trabajo cooperativo. El vídeo se colocará en la wiki (http://aprendamos.cienciasbelisario.wikispaces.net/), con el fin de acercar a los estudiantes al reconocimiento del apoyo tecnológico que se usará en las clases y que deberán manejar para el desarrollo de las actividades. Posteriormente se explicará lo que es una wiki, y cómo participarán en ella. Finalmente se ingresará a una sección de la wiki donde aparecerá la primera actividad alusiva al tema. Los alumnos se integran en equipos de 4 , a quienes se les encomienda la observación de unas imágenes y enlaces a videos localizados en la wiki de trabajo. Después, se les pide responder a unas preguntas y compartirlas a partir del foro de discusión. Deben finalizar escribiendo el concepto de reproducción definido por el equipo con base a la discusión y a información adicional encontrada. Las siguientes son las preguntas detonadoras:

- ¿Qué similitudes notas en las imágenes que se presentan?

- ¿De qué crees que dependan las características de un ser vivo?

- ¿Qué estrategias utilizan los seres vivos para conservar su especie?

- ¿Qué estructuras se requieren?

Posteriormente, los alumnos integrarán sus respuestas en un documento que poco a poco se enriquecerá con el desarrollo de nuevas actividades. Navegador de Internet para la consulta de artículos. Wikispaces (www.wikispaces.com)

Recursos de apoyo El documento permanecerá protegido. 
Área: Ciencias Naturales

Asignatura: Biología Grado: Octavo Grupos: $\underline{8-1 \text { y 8-3 }}$

Colegio/Sede: No. Sesiones: 3

\begin{tabular}{llll}
\hline \multicolumn{1}{c}{ Tema 2 } & \multicolumn{1}{c}{ Competencias } & \multicolumn{1}{c}{ Objetivo } & \multicolumn{1}{c}{ Aprendizajes esperados } \\
\hline Los tipos de & $\checkmark$ Búsqueda y & $\checkmark$ Explicar los tipos de & $\checkmark$ Comparan los tipos de \\
reproducción & selección de & reproducción asexual que se & reproducción asexual para \\
asexual, y su & información & presentan en los seres vivos, & establecer sus diferencias. \\
relación con & $\checkmark$ Negociación y & $\checkmark$ Relacionar el ciclo celular & $\checkmark$ Construyen en la wiki un \\
los procesos & toma de decisiones. & con la reproducción asexual. & documento con la información \\
de división & $\checkmark$ Comunicación & $\checkmark$ Seleccionar, organizar e & tratada. \\
celular. & escrita & interpretar información & $\checkmark$ Expresan ideas de forma \\
& $\checkmark$ Trabajo en equipo. & relevante & crítica y respetuosa. \\
\hline
\end{tabular}

Desarrollo de la sesión Los alumnos continúan en sus equipos de trabajo. Deben buscar información acerca de los tipos de reproducción asexual y los procesos de división celular especialmente la mitosis y deben completar un cuadro comparativo entregado por el profesor y llevarlo a sus respectivos sitios de edición, además deben construir las diferentes etapas de división celular para una célula que contiene 6 cromosomas Posteriormente todos los equipos deben analizar la información y generar comentarios respecto del trabajo realizado por los grupos. Es obligatorio que todos los integrantes de cada equipo participen.

\begin{tabular}{ll}
\hline Recursos de apoyo & $\begin{array}{l}\text { Navegador de Internet para la consulta de artículos. } \\
\text { Wikispaces (www.wikispaces.com) }\end{array}$ \\
\hline Variantes & El documento permanecerá protegido. \\
\hline
\end{tabular}

Área: Ciencias Naturales

Asignatura: Biología Grado: Octavo Grupos: $\underline{\text { 8-1y 8-3 }}$

Colegio/Sede: No. Sesiones: 3

\begin{tabular}{llll}
\multicolumn{1}{c}{ Tema 3 } & Competencias & \multicolumn{1}{c}{ Objetivo } & Aprendizajes esperados \\
\hline Estrategias & $\checkmark$ Gestión de la & $\checkmark$ Construir y comprender argumentos y & $\checkmark$ Construyen en la wiki \\
de & Información. & representaciones que dan razón de los & un documento con \\
reproducción & $\checkmark$ Pensamiento & mecanismos de reproducción utilizados & información relevante y \\
en & crítico y creativo. & por los organismos sencillos. & pertinente sobre la \\
organismos & $\checkmark$ Comunicación & $\checkmark$ Plantear puntos de vista y compartir & reproducción en \\
sencillos. & interpersonal & conocimiento. & organismos sencillos. \\
& $\checkmark$ Trabajo en & $\checkmark$ Reconocer la dimensión social del & $\checkmark$ Expresamos ideas y \\
& equipo. & conocimiento y para asumirla & las defienden.
\end{tabular}

\section{Desarrollo de la sesión}

A cada equipo de trabajo se le entrega un tipo de organismo sencillo y ellos deberán construir la información respecto de las estrategias reproductivas utilizadas por este ser. Deberán continuar en la página destinada para tal fin. Posteriormente deberán compartir el documento construido, leer la información de cada equipo y construir un mapa conceptual que deberán insertar en su correspondiente página. Al finalizar esta actividad cada equipo debe verificar que la información editada en su página sea clara y no contenga errores sintácticos y ortográficos. Para finalizar deben generar tres a cuatro párrafos en la parte final del documento donde se evidencie la utilidad de conocer las estrategias reproductivas de estos organismos en el campo de la alimentación, la salud y la agricultura.

\begin{tabular}{ll}
\hline Recursos de apoyo & $\begin{array}{l}\text { Navegador de Internet para la consulta de artículos. } \\
\text { wikispaces (www.wikispaces.com) }\end{array}$ \\
\hline Variantes & $\begin{array}{l}\text { Una vez terminado el documento se le quitará el atributo de protegido y se hará } \\
\text { público para la consulta de la comunidad escolar. }\end{array}$ \\
\hline
\end{tabular}




\section{Apéndice I: Rúbrica para evaluar el desempeño de los alumnos con la wiki}

\begin{tabular}{|c|c|c|c|c|}
\hline \multirow[t]{2}{*}{ Categorías } & \multicolumn{4}{|c|}{ Escala de calificación } \\
\hline & 4 Superior & 3 Alto & 2 Básico & 1 Bajo \\
\hline $\begin{array}{l}\text { Realización de } \\
\text { actividades en la } \\
\text { wiki }\end{array}$ & $\begin{array}{l}\text { Todas las } \\
\text { actividades } \\
\text { planteadas en la } \\
\text { wiki fueron } \\
\text { plenamente } \\
\text { realizadas con } \\
\text { un trabajo de la } \\
\text { más alta calidad }\end{array}$ & $\begin{array}{l}\text { Todas las } \\
\text { actividades } \\
\text { planteadas en la } \\
\text { wiki fueron } \\
\text { realizadas con un } \\
\text { trabajo de calidad. }\end{array}$ & $\begin{array}{l}\text { Todas las } \\
\text { actividades } \\
\text { planteadas en la } \\
\text { wiki fueron } \\
\text { realizadas sin } \\
\text { embargo algunas } \\
\text { de ellas } \\
\text { necesitaron } \\
\text { reestructuración } \\
\text { para asegurar su } \\
\text { calidad. }\end{array}$ & $\begin{array}{l}\text { No todas las } \\
\text { actividades } \\
\text { planteadas en la } \\
\text { wiki se realizaron } \\
\text { y es evidente que } \\
\text { hubo poco } \\
\text { esfuerzo en el } \\
\text { desarrollo de las } \\
\text { mismas. }\end{array}$ \\
\hline $\begin{array}{l}\text { Aportaciones al } \\
\text { trabajo cooperativo }\end{array}$ & $\begin{array}{l}\text { Siempre } \\
\text { proporciona } \\
\text { ideas útiles a su } \\
\text { grupo y en los } \\
\text { debates } \\
\text { generados en la } \\
\text { wiki, contribuye } \\
\text { constantemente } \\
\text { con ideas claras } \\
\text { y precisas. Se } \\
\text { nota su gran } \\
\text { esfuerzo. }\end{array}$ & $\begin{array}{l}\text { Generalmente } \\
\text { proporciona ideas } \\
\text { útiles a su grupo y } \\
\text { en los debates } \\
\text { generados en la } \\
\text { wiki, contribuye } \\
\text { con ideas claras y } \\
\text { precisas. Se nota } \\
\text { su esfuerzo. }\end{array}$ & $\begin{array}{l}\text { Algunas veces } \\
\text { proporciona ideas } \\
\text { útiles a su grupo y } \\
\text { en los debates } \\
\text { generados en la } \\
\text { wiki, contribuye } \\
\text { con ideas, así no } \\
\text { sean tan claras y } \\
\text { precisas. Hace } \\
\text { solo lo que se le } \\
\text { pide. }\end{array}$ & $\begin{array}{l}\text { Rara vez } \\
\text { proporciona ideas } \\
\text { útiles a su grupo y } \\
\text { en los debates } \\
\text { generados en la } \\
\text { wiki, contribuye } \\
\text { muy poco y en } \\
\text { ocasiones se } \\
\text { rehúsa a } \\
\text { participar. }\end{array}$ \\
\hline Manejo del tiempo & $\begin{array}{l}\text { Muy bien el } \\
\text { manejo de } \\
\text { tiempo durante } \\
\text { el trabajo } \\
\text { cooperativo en } \\
\text { la wiki y se } \\
\text { ajustan } \\
\text { perfectamente a } \\
\text { los tiempos } \\
\text { estipulados para } \\
\text { las entregas } \\
\text { grupales. }\end{array}$ & $\begin{array}{l}\text { El equipo utiliza } \\
\text { bien el tiempo } \\
\text { para el trabajo } \\
\text { cooperativo en la } \\
\text { wiki. A pesar que } \\
\text { alguna de las } \\
\text { contribuciones les } \\
\text { haya tomado un } \\
\text { poco más de } \\
\text { tiempo del } \\
\text { indicado, esto no } \\
\text { afecta los tiempos } \\
\text { estipulados para } \\
\text { las entregas } \\
\text { grupales. }\end{array}$ & $\begin{array}{l}\text { Normalmente son } \\
\text { demorados en sus } \\
\text { contribuciones } \\
\text { para el trabajo } \\
\text { cooperativo en la } \\
\text { wiki; sin embargo } \\
\text { generalmente } \\
\text { alcanzan a } \\
\text { entregar en el } \\
\text { límite de tiempo } \\
\text { estipulado. }\end{array}$ & $\begin{array}{l}\text { Utilizan } \\
\text { inadecuadamente } \\
\text { el tiempo para el } \\
\text { trabajo } \\
\text { cooperativo en la } \\
\text { wiki. Rara vez } \\
\text { hacen sus } \\
\text { contribuciones en } \\
\text { el tiempo } \\
\text { estipulado, esto } \\
\text { afecta las entregas } \\
\text { grupales. }\end{array}$ \\
\hline $\begin{array}{l}\text { Trabajo } \\
\text { cooperativo }\end{array}$ & $\begin{array}{l}\text { Es evidente que } \\
\text { el producto final } \\
\text { es consecuencia } \\
\text { de la unidad y el } \\
\text { esfuerzo mutuo. }\end{array}$ & $\begin{array}{l}\text { El equipo ha } \\
\text { trabajado bien } \\
\text { pero podría haber } \\
\text { utilizado otras } \\
\text { habilidades para } \\
\text { obtener un mejor } \\
\text { resultado. }\end{array}$ & $\begin{array}{l}\text { El equipo tuvo } \\
\text { problemas al } \\
\text { trabajar de } \\
\text { manera conjunta. } \\
\text { Falto mayor } \\
\text { cooperación entre } \\
\text { sus miembros. }\end{array}$ & $\begin{array}{l}\text { El producto final } \\
\text { no es el resultado } \\
\text { del esfuerzo } \\
\text { mutuo. El grupo } \\
\text { no mostró } \\
\text { evidencias de } \\
\text { cooperación. }\end{array}$ \\
\hline
\end{tabular}




\begin{tabular}{|c|c|c|c|c|}
\hline Organización & $\begin{array}{l}\text { La información } \\
\text { está bien } \\
\text { organizada, con } \\
\text { ideas muy } \\
\text { claras, un } \\
\text { lenguaje } \\
\text { apropiado de las } \\
\text { ciencias y una } \\
\text { excelente } \\
\text { construcción de } \\
\text { los párrafos que } \\
\text { presentan } \\
\text { escasos errores } \\
\text { de ortografía y } \\
\text { de gramática. }\end{array}$ & $\begin{array}{l}\text { La información } \\
\text { está organizada } \\
\text { con ideas claras, } \\
\text { lenguaje } \\
\text { apropiado de las } \\
\text { ciencias buena } \\
\text { construcción de } \\
\text { párrafos que } \\
\text { presentan algunos } \\
\text { errores de } \\
\text { ortografía y de } \\
\text { gramática. }\end{array}$ & $\begin{array}{l}\text { La información } \\
\text { está organizada } \\
\text { con algunas ideas } \\
\text { claras, falta el } \\
\text { manejo de un } \\
\text { lenguaje } \\
\text { apropiado de las } \\
\text { ciencias, los } \\
\text { párrafos presentan } \\
\text { varios errores de } \\
\text { ortografía y de } \\
\text { gramática. }\end{array}$ & $\begin{array}{l}\text { La información } \\
\text { no está } \\
\text { organizada con } \\
\text { claridad, le falta } \\
\text { un uso del } \\
\text { lenguaje } \\
\text { apropiado de las } \\
\text { ciencias, los } \\
\text { párrafos presentan } \\
\text { diversidad de } \\
\text { errores de } \\
\text { ortografía y de } \\
\text { gramática. }\end{array}$ \\
\hline $\begin{array}{l}\text { Calidad de la } \\
\text { información }\end{array}$ & $\begin{array}{l}\text { Toda la } \\
\text { información } \\
\text { aportada por los } \\
\text { estudiantes es } \\
\text { pertinente, } \\
\text { muestra } \\
\text { coherencia y } \\
\text { asertividad }\end{array}$ & $\begin{array}{l}\text { La mayor parte de } \\
\text { la información } \\
\text { aportada por los } \\
\text { estudiantes es } \\
\text { pertinente, } \\
\text { muestra } \\
\text { coherencia y } \\
\text { asertividad }\end{array}$ & $\begin{array}{l}\text { Falta mayor } \\
\text { pertinencia en la } \\
\text { información } \\
\text { aportada por los } \\
\text { estudiantes, } \\
\text { muestra } \\
\text { coherencia y } \\
\text { asertividad }\end{array}$ & $\begin{array}{l}\text { La información } \\
\text { aportada por los } \\
\text { estudiantes carece } \\
\text { de pertinencia, } \\
\text { muestra poca } \\
\text { coherencia y } \\
\text { asertividad }\end{array}$ \\
\hline Contenido & $\begin{array}{l}\text { El grupo } \\
\text { demuestra total } \\
\text { comprensión de } \\
\text { los temas } \\
\text { trabajados en la } \\
\text { wiki. }\end{array}$ & $\begin{array}{l}\text { El grupo } \\
\text { demuestra } \\
\text { comprensión de } \\
\text { los temas } \\
\text { trabajados en la } \\
\text { wiki. }\end{array}$ & $\begin{array}{l}\text { El grupo } \\
\text { demuestra } \\
\text { comprensión de } \\
\text { algunos temas } \\
\text { trabajados en la } \\
\text { wiki. }\end{array}$ & $\begin{array}{l}\text { El grupo no } \\
\text { parece } \\
\text { comprender muy } \\
\text { bien los temas } \\
\text { trabajados en la } \\
\text { wiki. }\end{array}$ \\
\hline
\end{tabular}




\section{Apéndice J: Libro de códigos de la encuesta para los alumnos}

\begin{tabular}{|c|c|c|c|c|}
\hline $\begin{array}{c}\text { Variables } \\
\text { del estudio }\end{array}$ & Ítem & Alternativas de respuesta & Códigos & Columnas \\
\hline \multirow{8}{*}{$\begin{array}{c}\text { Uso e } \\
\text { impacto de } \\
\text { una wiki en } \\
\text { el } \\
\text { aprendizaje } \\
\text { de la } \\
\text { Biología }\end{array}$} & $\begin{array}{l}\text { Facilidad en aprendizaje } \\
\text { de Biología con la wiki }\end{array}$ & $\begin{array}{l}\text { - Totalmente de acuerdo } \\
\text { - De acuerdo } \\
\text { - En desacuerdo } \\
\text { - Totalmente en desacuerdo }\end{array}$ & $\begin{array}{l}4 \\
3 \\
2 \\
1\end{array}$ & 1 \\
\hline & $\begin{array}{l}\text { Mayor aprendizaje de } \\
\text { Biología con la wiki }\end{array}$ & $\begin{array}{l}\text { - Totalmente de acuerdo } \\
\text { - De acuerdo } \\
\text { - En desacuerdo } \\
\text { - Totalmente en desacuerdo }\end{array}$ & $\begin{array}{l}4 \\
3 \\
2 \\
1\end{array}$ & 2 \\
\hline & $\begin{array}{l}\text { Contenidos de la wiki } \\
\text { agradables y fáciles de } \\
\text { comprender }\end{array}$ & $\begin{array}{l}\text { - Totalmente de acuerdo } \\
\text { - De acuerdo } \\
\text { - En desacuerdo } \\
\text { - Totalmente en desacuerdo }\end{array}$ & $\begin{array}{l}4 \\
3 \\
2 \\
1\end{array}$ & 3 \\
\hline & $\begin{array}{l}\text { Mejores resultados al } \\
\text { trabajar } \\
\text { cooperativamente }\end{array}$ & $\begin{array}{l}\text { - Totalmente de acuerdo } \\
\text { - De acuerdo } \\
\text { - En desacuerdo } \\
\text { - Totalmente en desacuerdo }\end{array}$ & $\begin{array}{l}4 \\
3 \\
2 \\
1\end{array}$ & 4 \\
\hline & $\begin{array}{l}\text { Comunicación a través } \\
\text { de la wiki de forma } \\
\text { cordial y respetuosa }\end{array}$ & $\begin{array}{l}\text { - Totalmente de acuerdo } \\
\text { - De acuerdo } \\
\text { - En desacuerdo } \\
\text { - Totalmente en desacuerdo }\end{array}$ & $\begin{array}{l}4 \\
3 \\
2 \\
1\end{array}$ & 5 \\
\hline & $\begin{array}{l}\text { Apoyo del maestro para } \\
\text { resolver conflictos en la } \\
\text { wiki }\end{array}$ & $\begin{array}{l}\text { - Totalmente de acuerdo } \\
\text { - De acuerdo } \\
\text { - En desacuerdo } \\
\text { - Totalmente en desacuerdo }\end{array}$ & $\begin{array}{l}4 \\
3 \\
2 \\
1\end{array}$ & 6 \\
\hline & $\begin{array}{l}\text { La guía del maestro } \\
\text { facilita la realización de } \\
\text { actividades en la wiki }\end{array}$ & $\begin{array}{l}\text { - Totalmente de acuerdo } \\
\text { - De acuerdo } \\
\text { - En desacuerdo } \\
\text { - Totalmente en desacuerdo }\end{array}$ & $\begin{array}{l}4 \\
3 \\
2 \\
1\end{array}$ & 7 \\
\hline & $\begin{array}{l}\text { La wiki incrementa el } \\
\text { interés por desarrollar } \\
\text { las actividades de } \\
\text { Biología }\end{array}$ & $\begin{array}{l}\text { - Totalmente de acuerdo } \\
\text { - De acuerdo } \\
\text { - En desacuerdo } \\
\text { - Totalmente en desacuerdo }\end{array}$ & $\begin{array}{l}4 \\
3 \\
2 \\
1\end{array}$ & 8 \\
\hline
\end{tabular}




\begin{tabular}{|c|c|c|c|}
\hline $\begin{array}{l}\text { La wiki genera mayor } \\
\text { participación en clase de } \\
\text { Biología }\end{array}$ & $\begin{array}{l}\text { - Totalmente de acuerdo } \\
\text { - De acuerdo } \\
\text { - En desacuerdo } \\
\text { - Totalmente en desacuerdo }\end{array}$ & $\begin{array}{l}4 \\
3 \\
2 \\
1\end{array}$ & 9 \\
\hline $\begin{array}{l}\text { Mejor comprensión de } \\
\text { conceptos por los } \\
\text { aportes de los } \\
\text { compañeros en la wiki }\end{array}$ & $\begin{array}{l}\text { - Totalmente de acuerdo } \\
\text { - De acuerdo } \\
\text { - En desacuerdo } \\
\text { - Totalmente en desacuerdo }\end{array}$ & $\begin{array}{l}4 \\
3 \\
2 \\
1\end{array}$ & 10 \\
\hline $\begin{array}{l}\text { Actividades en la wiki, } \\
\text { claras e interesantes }\end{array}$ & $\begin{array}{l}\text { - Totalmente de acuerdo } \\
\text { - De acuerdo } \\
\text { - En desacuerdo } \\
\text { - Totalmente en desacuerdo }\end{array}$ & $\begin{array}{l}4 \\
3 \\
2 \\
1\end{array}$ & 11 \\
\hline $\begin{array}{l}\text { Conflictos del trabajo en } \\
\text { equipo resueltos con } \\
\text { tolerancia y respeto }\end{array}$ & $\begin{array}{l}\text { - Totalmente de acuerdo } \\
\text { - De acuerdo } \\
\text { - En desacuerdo } \\
\text { - Totalmente en desacuerdo }\end{array}$ & $\begin{array}{l}4 \\
3 \\
2 \\
1\end{array}$ & 12 \\
\hline $\begin{array}{l}\text { Generación de acuerdos } \\
\text { individuales y grupales } \\
\text { al trabajar en la wiki }\end{array}$ & $\begin{array}{l}\text { - Totalmente de acuerdo } \\
\text { - De acuerdo } \\
\text { - En desacuerdo } \\
\text { - Totalmente en desacuerdo }\end{array}$ & $\begin{array}{l}4 \\
3 \\
2 \\
1\end{array}$ & 13 \\
\hline $\begin{array}{l}\text { La wiki aumento el } \\
\text { interés por aprender } \\
\text { Biología }\end{array}$ & $\begin{array}{l}\text { - Totalmente de acuerdo } \\
\text { - De acuerdo } \\
\text { - En desacuerdo } \\
\text { - Totalmente en desacuerdo }\end{array}$ & $\begin{array}{l}4 \\
3 \\
2 \\
1\end{array}$ & 14 \\
\hline $\begin{array}{l}\text { La wiki mejora la } \\
\text { responsabilidad del } \\
\text { trabajo en equipo }\end{array}$ & $\begin{array}{l}\text { - Totalmente de acuerdo } \\
\text { - De acuerdo } \\
\text { - En desacuerdo } \\
\text { - Totalmente en desacuerdo }\end{array}$ & $\begin{array}{l}4 \\
3 \\
2 \\
1\end{array}$ & 15 \\
\hline $\begin{array}{l}\text { Es aburrido estudiar } \\
\text { Biología cuando uso la } \\
\text { wiki. }\end{array}$ & $\begin{array}{l}\text { - Totalmente de acuerdo } \\
\text { - De acuerdo } \\
\text { - En desacuerdo } \\
\text { - Totalmente en desacuerdo }\end{array}$ & $\begin{array}{l}4 \\
3 \\
2 \\
1\end{array}$ & 16 \\
\hline $\begin{array}{l}\text { Con la wiki me preparo } \\
\text { para la prueba SABER }\end{array}$ & $\begin{array}{l}\text { - Totalmente de acuerdo } \\
\text { - De acuerdo } \\
\text { - En desacuerdo } \\
\text { - Totalmente en desacuerdo }\end{array}$ & $\begin{array}{l}4 \\
3 \\
2 \\
1\end{array}$ & 17 \\
\hline $\begin{array}{l}\text { La wiki debe utilizarse } \\
\text { en otras asignaturas }\end{array}$ & $\begin{array}{l}\text { - Totalmente de acuerdo } \\
\text { - De acuerdo } \\
\text { - En desacuerdo } \\
\text { - Totalmente en desacuerdo }\end{array}$ & $\begin{array}{l}4 \\
3 \\
2 \\
1\end{array}$ & 18 \\
\hline
\end{tabular}




\begin{tabular}{|c|c|c|c|}
\hline $\begin{array}{l}\text { Con la wiki se hacen } \\
\text { aportes importantes } \\
\text { paran las actividades }\end{array}$ & $\begin{array}{l}\text { - Totalmente de acuerdo } \\
\text { - De acuerdo } \\
\text { - En desacuerdo } \\
\text { - Totalmente en desacuerdo }\end{array}$ & $\begin{array}{l}4 \\
3 \\
2 \\
1\end{array}$ & 19 \\
\hline $\begin{array}{l}\text { Las actividades en la } \\
\text { wiki se evalúan } \\
\text { adecuadamente }\end{array}$ & $\begin{array}{l}\text { - Totalmente de acuerdo } \\
\text { - De acuerdo } \\
\text { - En desacuerdo } \\
\text { - Totalmente en desacuerdo }\end{array}$ & $\begin{array}{l}4 \\
3 \\
2 \\
1\end{array}$ & 20 \\
\hline $\begin{array}{l}\text { Se cumple en tiempo y } \\
\text { forma con los aportes }\end{array}$ & $\begin{array}{l}\text { - Totalmente de acuerdo } \\
\text { - De acuerdo } \\
\text { - En desacuerdo } \\
\text { - Totalmente en desacuerdo }\end{array}$ & $\begin{array}{l}4 \\
3 \\
2 \\
1\end{array}$ & 21 \\
\hline $\begin{array}{l}\text { Las clases presenciales } \\
\text { de Biología se refuerzan } \\
\text { y complementan con la } \\
\text { wiki }\end{array}$ & $\begin{array}{l}\text { - Totalmente de acuerdo } \\
\text { - De acuerdo } \\
\text { - En desacuerdo } \\
\text { - Totalmente en desacuerdo }\end{array}$ & $\begin{array}{l}4 \\
3 \\
2 \\
1\end{array}$ & 22 \\
\hline $\begin{array}{l}\text { Cada integrante de mi } \\
\text { equipo asume su rol }\end{array}$ & $\begin{array}{l}\text { - Totalmente de acuerdo } \\
\text { - De acuerdo } \\
\text { - En desacuerdo } \\
\text { - Totalmente en desacuerdo }\end{array}$ & $\begin{array}{l}4 \\
3 \\
2 \\
1\end{array}$ & 23 \\
\hline $\begin{array}{l}\text { La wiki facilita el } \\
\text { trabajo en equipo }\end{array}$ & $\begin{array}{l}\text { - Totalmente de acuerdo } \\
\text { - De acuerdo } \\
\text { - En desacuerdo } \\
\text { - Totalmente en desacuerdo }\end{array}$ & $\begin{array}{l}4 \\
3 \\
2 \\
1\end{array}$ & 24 \\
\hline $\begin{array}{l}\text { Infraestructura } \\
\text { tecnológica del colegio } \\
\text { adecuada }\end{array}$ & $\begin{array}{l}\text { - Totalmente de acuerdo } \\
\text { - De acuerdo } \\
\text { - En desacuerdo } \\
\text { - Totalmente en desacuerdo }\end{array}$ & $\begin{array}{l}4 \\
3 \\
2 \\
1\end{array}$ & 25 \\
\hline
\end{tabular}




\section{Apéndice K: Transcripción de las clases observadas}

\section{Transcripción de la sesión observada No. 1}

Nombre del docente: Niels Horacio Lozano

No. de sesión observada: $\underline{\text { Uno }}$

Grupo: $\underline{8-1}$

Fecha: 12 Febrero 2015

Hora de Inicio y de Conclusión: 7:15 am - 8:50 am Duración: $\underline{\text { 1h } 35 \text { min }}$

A. Inicio de la sesión e interacción con el docente

\begin{tabular}{|c|c|}
\hline Aspectos a observar & Descripción de las observaciones \\
\hline $\begin{array}{l}\text { 1. El docente establece los objetivos de la clase. } \\
\text { ¿Cuáles fueron ellos? }\end{array}$ & $\begin{array}{l}\text { Sí. El docente aclara cuales son los objetivos } \\
\text { de la clase, sin embargo, en esta primera } \\
\text { sesión de clase, el docente no logró que los } \\
\text { estudiantes se hicieran conscientes de lo que } \\
\text { se pretendía. } \\
\text { Los objetivos que el docente propuso fueron: } \\
\checkmark \text { Reconocer la utilidad del trabajo } \\
\text { cooperativo en el aprendizaje de las ciencias. } \\
\checkmark \text { Comprender la importancia de la } \\
\text { reproducción para los seres vivos. }\end{array}$ \\
\hline $\begin{array}{l}\text { 2. ¿Al inicio, se destinó un momento para que los } \\
\text { alumnos se familiarizaran con la wiki? }\end{array}$ & $\begin{array}{l}\text { Una vez el docente aclaró los objetivos, dio } \\
\text { una explicación acerca de lo que es una wiki, } \\
\text { la forma como los alumnos debían acceder a } \\
\text { la wiki creada para el trabajo en Biología. } \\
\text { Posteriormente indicó sobre la organización } \\
\text { de las actividades dentro de la wiki, entregó a } \\
\text { cada estudiante el nombre de usuario y } \\
\text { contraseña, para que los estudiantes } \\
\text { accedieran a la wiki. }\end{array}$ \\
\hline $\begin{array}{l}\text { 3. Describa el inicio de la clase, con base en las } \\
\text { instrucciones respecto de las actividades } \\
\text { cooperativas y de la interacción a través de la wiki. }\end{array}$ & $\begin{array}{l}\text { Una vez aclarados los objetivos el docente } \\
\text { solicitaba a los estudiantes dirigirse a una } \\
\text { página llamada actividad introductoria que se } \\
\text { encontraba dentro de la wiki. Les indicaba la } \\
\text { observación del primer vídeo para responder a } \\
\text { las preguntas efectuadas entorno del mismo. } \\
\text { Aclaró que al trabajar en esta actividad poco a } \\
\text { poco se acercarían a la comprensión de lo que } \\
\text { significa trabajar cooperativamente. Debido a } \\
\text { que hubo problemas con el sonido en los } \\
\text { equipos de cómputo, los estudiantes mostraron } \\
\text { su desagrado y se disiparon. De tal manera } \\
\text { que al solucionar el impase, los estudiantes ya } \\
\text { habían olvidado lo que debían hacer y } \\
\text { comenzaron a preguntar nuevamente sobre la }\end{array}$ \\
\hline
\end{tabular}


4. ¿La actitud del maestro contribuye a que los alumnos tuvieran confianza para acercarse a él y solicitar la aclaración de dudas?

5. Especifique la forma cómo se aclaran las dudas durante el trabajo en la wiki. actividad. El docente les indico leer las instrucciones que se les daba de manera escrita en la página que se les había mencionado. Posteriormente y por efectos del tiempo el docente proyectó en el vídeo beam estas instrucciones y trató de explicar lo que debía hacerse, sin embargo, el tiempo de la clase se agotó y quedó de realizarse la actividad en la siguiente sesión de clase.

Si. La actitud del maestro permite el acercamiento de los estudiantes y la interacción permanente con Él, debido a que en todo momento se muestra atento a los inconvenientes que se presentan y muy cordial para resolver las inquietudes de los estudiantes. Sin embargo, el maestro no logra evitar que algunos estudiantes se molestan cuando se presenta dificultades y no puede atenderles de forma inmediata.

Para la aclaración de dudas durante el trabajo con la wiki, el docente utiliza el video proyector y llama la atención de los alumnos para que todos escuchen y observen las diversas situaciones que se han presentado a diferentes compañeros y que pueden servirles para resolver inconvenientes similares que se les pueda presentar. Además el maestro hace algunas precisiones respecto de las actividades a desarrollar, esto contribuye a dar mayor claridad del trabajo. Para la aclaración de dudas respecto a usuarios y claves de acceso el profesor se dirige directamente a la wiki y desde el administrador organiza los inconvenientes y prueba con los estudiantes el acceso a la wiki.

6. Describa la manera en el que el maestro retroalimenta las actividades desarrolladas por los estudiantes en la wiki.

7. Especifique cómo se evalúan las actividades en la wiki.
En esta sesión de clase, debido a que el avance en las actividades es realmente poco por las dificultades que se han presentado con la señal y los parlantes, de forma general el maestro trata de guiar a los estudiantes para que avancen en la actividad introductoria. Posteriormente da aclaraciones a algunos estudiantes de cómo participar en los foros y les explica que se tendrá en cuenta en este proceso, todo ello lo hace con el video beam. El docente señala a los estudiantes que las actividades desarrolladas en la wiki serán evaluadas a partir de una rúbrica que contempla las aportaciones de los alumnos en cuanto a su desempeño individual y grupal para la realización de las actividades cooperativas, el manejo del tiempo, las actividades desarrolladas en la wiki, el trabajo 


\begin{tabular}{|l|l|}
\hline & $\begin{array}{l}\text { cooperativo, la organización de información, } \\
\text { la calidad de la información, su contenido y } \\
\text { comprensión. }\end{array}$ \\
\hline $\begin{array}{l}\text { 8. ¿Cómo facilita el maestro la resolución de } \\
\text { problemas técnicos en la wiki? }\end{array}$ & $\begin{array}{l}\text { El maestro facilita la resolución de problemas } \\
\text { técnicos en la wiki al escuchar atentamente y } \\
\text { escribir los inconvenientes que se presentaban } \\
\text { y a quien o quienes se le presentaba. Si estos } \\
\text { problemas se relacionan con el ingreso a la } \\
\text { wiki, trataba de cerciorarse que los alumnos } \\
\text { hubiesen colocado bien su nombre de usuario } \\
\text { y contraseña. Normalmente este era el } \\
\text { incidente de mayor ocurrencia. Si era otro tipo } \\
\text { de problemas le solicitaba al estudiante que le } \\
\text { mostrará directamente en el computador lo } \\
\text { que pasaba y analizaba de qué se trataba y } \\
\text { buscaba la forma de resolverlo. }\end{array}$ \\
\hline
\end{tabular}

\section{B. Interacción de los alumnos con el apoyo tecnológico}

\begin{tabular}{|c|c|}
\hline Aspectos a observar & Descripción de las observaciones \\
\hline $\begin{array}{l}\text { 1. Especifique las actitudes de agrado o rechazo, } \\
\text { mostradas por los alumnos al usar la wiki en la } \\
\text { clase de Biología. }\end{array}$ & $\begin{array}{l}\text { En esta sesión de clase, los estudiantes se } \\
\text { mostraron apáticos a utilizar la wiki y } \\
\text { expresaron su molestia al decir que no } \\
\text { entendían para que los colocaban a trabajar en } \\
\text { algo que ellos no conocían. Algunos } \\
\text { estudiantes para demostrar su rechazo no } \\
\text { prestaban atención a la explicación del } \\
\text { docente y sin que el docente se diera cuenta se } \\
\text { distraían con el celular o ingresaban a otras } \\
\text { páginas de Internet. } \\
\text { Las actitudes de rechazo aumentaron cuando } \\
\text { la señal de internet comenzó a tener fallas y } \\
\text { los parlantes de varios equipos no } \\
\text { funcionaron, sumado a que otros equipos } \\
\text { carecían de parlantes y en los portátiles casi } \\
\text { no se escuchaba. }\end{array}$ \\
\hline $\begin{array}{l}\text { 2. Detalle los comentarios verbales efectuados por } \\
\text { los alumnos respecto de la wiki ¿Hubo interés por } \\
\text { su uso? }\end{array}$ & $\begin{array}{l}\text { Antes de iniciar la sesión de clase, los } \\
\text { estudiantes cuando ingresaron al salón de } \\
\text { clase, expresaron comentarios como: que } \\
\text { pereza esa bobada, para qué nos traerán aquí, } \\
\text { más trabajo, es mejor estar en el salón de } \\
\text { clase. A medida que el docente inicio su } \\
\text { explicación acerca de lo que era la wiki, los } \\
\text { estudiantes no expresaron más comentarios } \\
\text { acerca de la wiki, se les veía con expectativa, } \\
\text { posteriormente, en la medida que el docente } \\
\text { les explicó y comenzaron a ingresar a la wiki, } \\
\text { se escuchaba expresiones que reflejaban } \\
\text { inconvenientes para ingresar a la wiki: profe, } \\
\text { ayúdeme que no he podido ver nada; ah, eso }\end{array}$ \\
\hline
\end{tabular}


3. Señale si los alumnos siguieron las instrucciones del profesor, al interactuar en la wiki y para realizar las actividades cooperativas.

4. ¿Hubo éxito en el desarrollo de las actividades de clase (individuales y cooperativas) con el uso de la wiki?

5. ¿Los alumnos participaron activamente en la wiki?

6. ¿Durante las actividades en la wiki, los alumnos consideraron los conceptos teóricos de la clase presencial de Biología?

7. ¿Hubo progreso individual y grupal, con base en lo que se indicó en las instrucciones de las actividades?

8. Describa las principales dificultades que se presentaron durante la interacción de los alumnos con la wiki. no sale nada, mi equipo está malo, se cayó la señal; profe tengo problemas con el ingreso. Profe lo logré, voy a ver si puedo mirar el vídeo. Sin embargo al dañarse la señal de Internet, expresaron que esas salas eran muy malas que no lograban ingresar, que eso tan aburridor.

Se observó que en general los estudiantes tienen inconvenientes para seguir instrucciones, porque ellos se disipan fácilmente. Además el problema de la señal de Internet es un factor que contribuye a esta dispersión. Los estudiantes que tuvieron acceso oportuno al sitio, trataban de explorar toda la wiki y ensayaron escribir en sus foros siempre se mostraban respetuosos con sus compañeros cuando estos tenían dudas. Se notó su agrado y motivación por la información.

En esta sesión de clase no fue exitoso el desarrollo de las actividades cooperativas porque los integrantes de varios equipos tuvieron problemas con el audio y la señal de Internet, esto limitó el tiempo de trabajo. Sin embargo, hubo participación de los estudiantes porque hicieron aportes verbales, una vez el docente presentó de forma general el vídeo y se efectuaron participaciones en los foros muy respetuosas. .

No se logró la participación activa de todos los estudiantes en la wiki debido a los problemas con la señal de Internet, sin embargo los alumnos participaron de forma verbal cuando el docente realizo preguntas que estaban consignadas en la wiki como parte de las actividades y a las cuales no lograron acceder oportunamente los estudiantes debido a las fallas técnicas. Acordaron maestro y estudiantes retomar estas preguntas en la siguiente sesión de clase.

Los alumnos no consideraron conceptos teóricos de la clase presencial de Biología debido a que no pudo avanzarse suficientemente en las actividades debido a los inconvenientes técnicos.

El progreso individual y grupal fue mínimo debido a los inconvenientes técnicos que se presentaron en esta sesión de clase

La principal dificultad que se presentó durante la interacción de los alumnos con la wiki fue técnica, debido a la lentitud en la velocidad de navegación. 


\begin{tabular}{|l|l|}
\hline $\begin{array}{l}\text { 9. ¿Los alumnos interactuaron con tolerancia y } \\
\text { respeto entre ellos? }\end{array}$ & $\begin{array}{l}\text { Se observó una interacción respetuosa entre } \\
\text { alumnos y docentes. En el momento que el } \\
\text { profesor efectuó las preguntas, los estudiantes } \\
\text { que respondieron a ellas, fueron escuchados } \\
\text { atentamente y se generó un momento de } \\
\text { participación. }\end{array}$ \\
\hline $\begin{array}{l}\text { 10. ¿Destacó el cumplimiento de los compromisos } \\
\text { grupales? }\end{array}$ & $\begin{array}{l}\text { No fue posible medir este aspecto debido a los } \\
\text { problemas técnicos presentados, esto no } \\
\text { permitió el avance de las actividades } \\
\text { cooperativas.. }\end{array}$ \\
\hline
\end{tabular}

\section{Cierre de la sesión}

\begin{tabular}{|l|l|}
\hline \multicolumn{1}{|c|}{ Aspectos a observar } & \multicolumn{1}{|c|}{ Descripción de las observaciones } \\
\hline $\begin{array}{l}\text { 1. Detalle si al final de cada sesión, se resumieron } \\
\text { los principales aspectos abordados en la misma. }\end{array}$ & $\begin{array}{l}\text { La sesión de clase no se cerró adecuadamente } \\
\text { porque el docente no logró resumir los } \\
\text { principales aspectos abordados en la clase por } \\
\text { los problemas logísticos que se presentaron } \\
\text { con los parlantes de los computadores y la } \\
\text { señal de internet. Una vez sonó el timbre de } \\
\text { cambio de clase, los estudiantes se dispersaron } \\
\text { completamente e hicieron caso omiso al } \\
\text { intento del docente por resumir los } \\
\text { principales aspectos abordados en la misma. }\end{array}$ \\
\hline $\begin{array}{l}\text { 2. Para concluir la sesión, se enfatizaron las dudas } \\
\text { aclaradas durante la misma y que serán } \\
\text { fundamentales para el desarrollo de la próxima } \\
\text { sesión. }\end{array}$ & $\begin{array}{l}\text { Antes de concluir la sesión de clase, el } \\
\text { docente recordó a los estudiantes tener } \\
\text { presente la forma de acceder a la wiki y de } \\
\text { tener a mano el nombre de usuario y clave } \\
\text { para el ingreso a la wiki en la siguiente sesión. } \\
\text { Invitó a los estudiantes que no tuviesen } \\
\text { posibilidad de acceder a un equipo de } \\
\text { cómputo con Internet a asistir al colegio en } \\
\text { horas contrarias a las de clase y a los que } \\
\text { tuvieran equipo en casa a trabajar desde allí. }\end{array}$ \\
\hline 3. Señale si se lograron los objetivos de la sesión. & $\begin{array}{l}\text { Los objetivos de la clase se lograron } \\
\text { parcialmente, porque los alumnos conocieron } \\
\text { lo que es una wiki y la forma de trabajar en } \\
\text { ella. Sin embargo no realizaron la actividad } \\
\text { introductoria, ni la actividad dirigida al } \\
\text { aprendizaje de aspectos específicos de la } \\
\text { Biología. }\end{array}$ \\
\hline B. Principales logros en el aprendizaje de la & $\begin{array}{l}\text { El principal logro percibido en esta sesión de } \\
\text { clase fue el hecho de que el docente logró dar } \\
\text { inicio a la sensibilización y orientación con } \\
\text { respecto a la metodología del trabajo y } \\
\text { aprendizaje cooperativo con el uso de una } \\
\text { wiki, un apoyo tecnológico totalmente } \\
\text { desconocido para los estudiantes. }\end{array}$ \\
\hline $\begin{array}{l}\text { A pesar de todos los inconvenientes técnicos } \\
\text { como la lentitud del internet, las caídas de la } \\
\text { señal, se observa que el docente logró }\end{array}$ \\
\hline
\end{tabular}




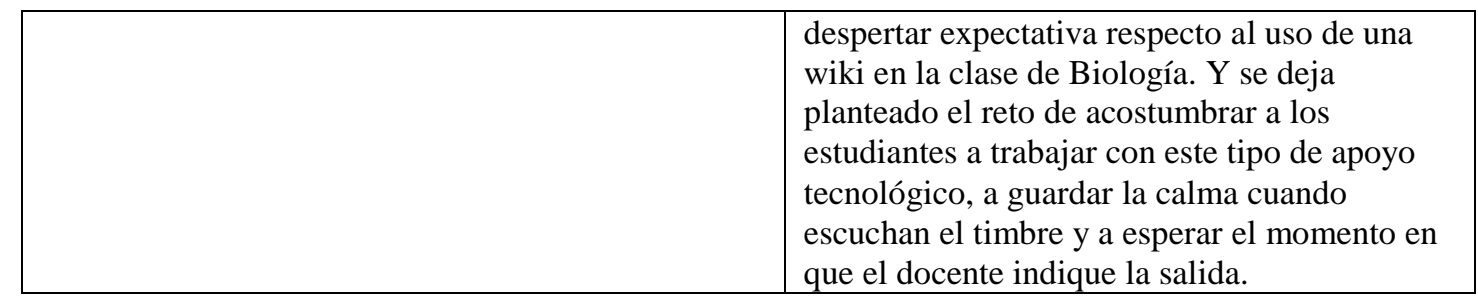

\section{Otras consideraciones de la observación.}

\section{Aspectos positivos}

- Se observó una guía clara de trabajo.

- La acción decidida del maestro por familiarizar a los estudiantes con el apoyo tecnológico y la paciencia reflejada en las diferentes situaciones de rechazo mostradas por los estudiantes.

- Generar expectativa en los estudiantes por el uso de un AVA en un área diferente a la de Informática

\section{Aspectos de mejora:}

Sensibilizar más a los estudiantes, acerca de las habilidades y actitudes que deben desarrollar para la realización de actividades cooperativas.

Buscar la manera de mejorar significativamente la señal de Internet y todo el soporte técnico.

Prever inconvenientes técnicos y ajustar los tiempos en el transcurso de la clase para dar un adecuado cierre de sesión. 


\title{
Transcripción de la sesión observada No. 2
}

\author{
Nombre del docente: Niels Horacio Lozano
}

No. de sesión observada: $\underline{\text { Dos }}$

Grupo: $\underline{8-1}$

Fecha: 17 de Febrero de 2015

Hora de Inicio y de Conclusión: 10:15 am - 11:45 am Duración: 1 h 30 min

A. Inicio de la sesión e interacción con el docente

\begin{tabular}{|c|c|}
\hline Aspectos a observar & Descripción de las observaciones \\
\hline $\begin{array}{l}\text { 1. El docente establece los objetivos de la clase. } \\
\text { ¿Cuáles fueron ellos? }\end{array}$ & $\begin{array}{l}\text { Esta vez el profesor no estableció los } \\
\text { objetivos, ya que esta sesión fue la } \\
\text { continuación de la sesión anterior. } \\
\text { Los objetivos que se habían presentado eran: } \\
\checkmark \text { Reconocer la utilidad del trabajo } \\
\text { cooperativo en el aprendizaje de las ciencias. } \\
\checkmark \text { Comprender la importancia de la } \\
\text { reproducción para los seres vivos. }\end{array}$ \\
\hline $\begin{array}{l}\text { 2. ¿Al inicio, se destinó un momento para que los } \\
\text { alumnos se familiarizaran con la wiki? }\end{array}$ & $\begin{array}{l}\text { Si, en esta sesión de clase el docente destina } \\
\text { un espacio para continuar con la } \\
\text { familiarización de los alumnos con la wiki, ya } \\
\text { que ellos nunca habían manejado este tipo de } \\
\text { apoyos tecnológicos en su clase. El docente } \\
\text { explicó a los alumnos la como debían editar en } \\
\text { la wiki, subir imágenes y videos, así como } \\
\text { crear nuevas páginas y organizar información } \\
\text { dentro del sitio destinado para cada equipo de } \\
\text { trabajo. A medida que los estudiantes ingresan } \\
\text { a la wiki y tratan de avanzar en las actividades } \\
\text { propuestas se percibe su adaptación a trabajar } \\
\text { en la misma. De igual manera, surgen nuevas } \\
\text { dudas respecto a procesos como la edición de } \\
\text { texto en la wiki. Estas inquietudes siempre son } \\
\text { atendidas por el docente. }\end{array}$ \\
\hline $\begin{array}{l}\text { 3. Describa el inicio de la clase, con base en las } \\
\text { instrucciones respecto de las actividades } \\
\text { cooperativas y de la interacción a través de la wiki. }\end{array}$ & $\begin{array}{l}\text { Esta sesión de clase fue una continuación de la } \\
\text { sesión anterior. Por tal razón el docente dio } \\
\text { instrucciones precisas de intentar nuevamente } \\
\text { observar el vídeo. Debido a las constantes } \\
\text { fallas en la señal de Internet, el docente } \\
\text { constantemente orienta a los estudiantes para } \\
\text { que lean y sigan las indicaciones que están } \\
\text { escritas en la wiki. Asimismo, hace } \\
\text { sugerencias para el agrupamiento con otros } \\
\text { compañeros para que puedan escuchar los } \\
\text { vídeos con aquellos equipos que tienen } \\
\text { parlantes en sus computadoras o en los } \\
\text { portátiles. Una vez el docente garantizó que } \\
\text { todos habían escuchado inició una sesión de }\end{array}$ \\
\hline
\end{tabular}


4. ¿La actitud del maestro contribuye a que los alumnos tuvieran confianza para acercarse a él y solicitar la aclaración de dudas?
5. Especifique la forma cómo se aclaran las dudas durante el trabajo en la wiki. preguntas con el fin de sensibilizar a los estudiantes respecto del trabajo cooperativo. Posteriormente el profesor, señaló a los estudiantes escribir sus respuestas en el foro creado para tal fin, de esta manera se generaron las interacciones dentro de los equipos de trabajo. Debido a la dificultad de los estudiantes para participar en el foro, por la inseguridad en el manejo del computador, por dificultad con el Internet y por el temor a equivocarse, el docente debía animar a los jóvenes a escribir en el espacio destinado para el foro.

Si. En esta sesión el maestro pregunta constantemente cómo van en sus actividades y está pendiente de cualquier inconveniente porque ha notado que a ciertos alumnos les cuesta expresar sus dificultades y tratan de pasar inadvertidos.

El docente se acerca hasta los puestos de los alumnos y con mucha amabilidad les aclara las dudas directamente en el computador donde tienen abiertas sus páginas de trabajo.

El docente se acerca al estudiante que tiene la duda y se sienta a su lado y le muestra la forma de resolver el inconveniente planteado. Cuando se repite constantemente una inquietud, solicita al grupo detener lo que estén haciendo y da una explicación de manera general y pregunta si queda aclarada la duda. Si persisten las dudas, se sienta con el equipo, explica nuevamente y solicita a los integrantes del equipo que han comprendido que le expliquen a su compañero.

Posteriormente consulta si ha quedado aclarada la duda.

\section{Describa la manera en el que el maestro} retroalimenta las actividades desarrolladas por los estudiantes en la wiki.

7. Especifique cómo se evalúan las actividades en la wiki.
El docente ingresa a la wiki y observa las participaciones de los estudiantes en los foros desde allí y de manera escrita, alienta a los estudiantes a trabajar y hace una invitación para todos. De acuerdo con lo que escriben los estudiantes va haciendo recomendaciones a los equipos.

Posteriormente, de forma general y verbal nuevamente da indicaciones para que ingresen a sus sitios de trabajo y desarrollen las actividades allí propuestas.

El docente evaluó las aportaciones de los alumnos al trabajo cooperativo, el manejo del tiempo, las actividades desarrolladas en la wiki, el trabajo cooperativo, la organización de información, la calidad de la información, 


\begin{tabular}{|l|l|}
\hline & $\begin{array}{l}\text { su contenido y comprensión. Todo ello a } \\
\text { través de una rúbrica creada para tal fin. }\end{array}$ \\
\hline $\begin{array}{l}\text { 8. ¿Cómo facilita el maestro la resolución de } \\
\text { problemas técnicos en la wiki? }\end{array}$ & $\begin{array}{l}\text { Si persisten casos de dificultad en el ingreso } \\
\text { de algunos estudiantes a la wiki, el docente } \\
\text { hace ajustes en la wiki, cambia el nombre de } \\
\text { usuario del estudiante y la contraseña y } \\
\text { solicita a los estudiantes con problemas que } \\
\text { intenten ingresar nuevamente. } \\
\text { Cuando hay problemas con los equipos, el } \\
\text { docente pide apoyo al profesor de tecnología } \\
\text { y juntos tratan de resolver el inconveniente. } \\
\text { Cuando el problema es de señal se solicita } \\
\text { apoyo a la empresa prestadora del servicio. }\end{array}$ \\
\hline
\end{tabular}

\section{B. Interacción de los alumnos con el apoyo tecnológico}

\begin{tabular}{|c|c|}
\hline Aspectos a observar & Descripción de las observaciones \\
\hline $\begin{array}{l}\text { 1. Especifique las actitudes de agrado o rechazo, } \\
\text { mostradas por los alumnos al usar la wiki en la } \\
\text { clase de Biología. }\end{array}$ & $\begin{array}{l}\text { Se observan diferentes actitudes, la de } \\
\text { estudiantes que continúan apáticos y que } \\
\text { expresan dificultades para manejar los } \\
\text { computadores, otros que expresan estar contentos } \\
\text { porque les parece interesante y novedosos } \\
\text { trabajar con la wiki y también porque salen de la } \\
\text { rutina y del salón de clase y otros que nada les } \\
\text { interesa, les da lo mismo hacer que no hacer } \\
\text { porque dicen que todo les da pereza y que si } \\
\text { aprenden o no, les tiene sin cuidado. } \\
\text { Cuando los estudiantes logran ver el vídeo se } \\
\text { nota su agrado frente a este y se escuchan risas y } \\
\text { se observa el interés de los alumnos que no han } \\
\text { ingresado por observar el vídeo. } \\
\text { Posteriormente, los estudiantes entusiasmados, le } \\
\text { preguntan al docente cómo abrir los foros, para } \\
\text { participar en la resolución de las preguntas. }\end{array}$ \\
\hline $\begin{array}{l}\text { 2. Detalle los comentarios verbales efectuados por } \\
\text { los alumnos respecto de la wiki ¿Hubo interés por } \\
\text { su uso? }\end{array}$ & $\begin{array}{l}\text { Siete estudiantes expresan haber intentado } \\
\text { ingresar desde sus casas, afirman haber entrado a } \\
\text { la wiki pero señalan que les dio temor navegar } \\
\text { porque les faltaba mayor manejo y no recordaron } \\
\text { la forma de acceder a sus sitios de trabajo. } \\
\text { Durante la sesión de clase } 5 \text { estudiantes le } \\
\text { preguntaron al profesor: profe podemos ingresar } \\
\text { a la wiki desde los celulares si tienen Internet? La } \\
\text { respuesta positiva generó la siguiente inquietud } \\
\text { de } 2 \text { alumnos: profe profesor, enséñeme Claro les } \\
\text { dice el profe. Uno de ellos le muestra el celular y } \\
\text { el profe le va indicando. Cuando ambos logran } \\
\text { ver la wiki desde el dispositivo móvil del joven, } \\
\text { le dice uno al otro con gran emoción, hermano } \\
\text { que verraquera. Y se ríen un rato, luego tratan de } \\
\text { continuar desde el celular, pero como la pantalla } \\
\text { es tan pequeña el muchacho decide nuevamente }\end{array}$ \\
\hline
\end{tabular}


3. Señale si los alumnos siguieron las instrucciones del profesor, al interactuar en la wiki y para realizar las actividades cooperativas.
4. ¿Hubo éxito en el desarrollo de las actividades de clase (individuales y cooperativas) con el uso de la wiki? trabajar desde el PC, se percibe más entusiasmo y dedicación, constantemente preguntan cómo van en su trabajo.

Posteriormente, se les ve hacerse señas con otros compañeros y se escuchan comentarios entre ellos, como: Mentiroso venga veo si le funciona la wiki desde su celular y luego carcajadas, cuando les funcionaba o no. Así, poco a poco se nota un cambio de actitud de forma general. En adelante estos jóvenes trabajaron con gran entusiasmo y constantemente participaban en el foro y discutían de forma respetuosa con sus compañeros respecto de las actividades y de la mejor forma de realizarlas. Se decían sus errores y estos eran aceptados con tolerancia.

Los estudiantes siguen las instrucciones cuando el docente es reiterativo con las mismas y cuando las expresa de forma verbal. Cuando el docente los remite a las instrucciones escritas que se encuentran en la wiki, a los estudiantes se les dificulta, o simplemente no les gusta casi leerlas. Ellos expresan no entender y hasta que el profesor no lee y explica, la mayoría no inicia el trabajo. Se percibe que los alumnos presentan dificultades en cuanto a las habilidades lectoescritoras y esto hace complicado el seguimiento de las instrucciones escritas en la wiki y por tanto puede pensarse que esto en parte puede ser la causa del rechazo presentado por algunos de los estudiantes frente al trabajo que se propone en la wiki.

No podría hablarse de éxito. Digamos que hubo avances y participación. Los estudiantes escribieron en el foro y respondieron a las preguntas planteadas en la wiki, se generaron discusiones al interior de algunos grupos que se mostraban muy entusiasmados por contestarle a sus compañeros, siempre se percibió una buena comunicación entre estos alumnos. Debido a las constantes fallas de la señal de Internet nuevamente los equipos de trabajo no alcanzaron a terminar las actividades planteadas, sin embargo se notó interés por varios de los equipos por continuar y algunos estudiantes le expresaron al docente su deseo de trabajar desde la casa.

5. ¿Los alumnos participaron activamente en la wiki? cuando ellos expresan sus opiniones, o las ideas previas que tienen de un concepto en los foros destinados para tal fin. Les gusta leer lo que sus demás compañeros escriben y se sorprenden al poder ver estas opiniones de una manera tan rápida dentro del programa. Responden a lo que dicen sus compañeros de forma respetuosa. 
6. ¿Durante las actividades en la wiki, los alumnos consideraron los conceptos teóricos de la clase presencial de Biología?

7. ¿Hubo progreso individual y grupal, con base en lo que se indicó en las instrucciones de las actividades?

8. Describa las principales dificultades que se presentaron durante la interacción de los alumnos con la wiki.

9. ¿Los alumnos interactuaron con tolerancia y respeto entre ellos?

10. ¿Destacó el cumplimiento de los compromisos grupales?
No sucede lo mismo cuando deben buscar información, organizarla y editarla en sus páginas de trabajo porque requiere mayor compromiso, lo que les toma mayor tiempo de trabajo y mayor esfuerzo. Sin embargo se nota el progreso paulatino en este sentido. Cuando hay alumnos que editan información y esta no es del gusto del resto del grupo se lo hacen saber de forma adecuada y normalmente el alumno que ha escrito acepta las sugerencias de los compañeros.

Se observa que los estudiantes en la medida que van interactuando con la wiki, pese a las dificultades que se presentan con el soporte técnico y las caídas permanentes del internet, muestran sus aproximaciones teóricas y su fundamentación conceptual, así como su interés por el trabajo cooperativo, que empieza a ser más significativo para ellos.

Empiezan a aparecer liderazgos de algunos jóvenes en su intento por superar las dificultades técnicas que se presentan y en su afán de despertar el interés y la motivación por el trabajo cooperativo porque observan que si todos aportan se llegan a mejores y más rápidas resultados

Nuevamente falla el soporte técnico desde el acceso inicial a internet, la rapidez, las caídas del sistema.

Nuevamente los estudiantes se mostraron respetuosos entre ellos y en el momento que el profesor dio las indicaciones respectivas, los estudiantes respondieron; fueron escuchados atentamente y se generó un ambiente de cooperativo y una comunicación fluida y respetuosa.

A pesar de las dificultades que se siguen presentando con el soporte técnico, se logra empezar a resaltar la importancia de los resultados que debe alcanzar colaborativamente el grupo, se logró revisar algunos aspectos conceptuales y de aporte que hizo cada uno de los estudiantes.

\section{Cierre de la sesión}

\begin{tabular}{|l|l|}
\hline \multicolumn{1}{|c|}{ Aspectos a observar } & \multicolumn{1}{|c|}{ Descripción de las observaciones } \\
\hline $\begin{array}{l}\text { 1. Detalle si al final de cada sesión, se resumieron } \\
\text { los principales aspectos abordados en la misma. }\end{array}$ & $\begin{array}{l}\text { La sesión de clase mejoró su cierre con } \\
\text { respecto a la anterior. }\end{array}$ \\
& $\begin{array}{l}\text { Se logra resumir los principales aspectos } \\
\text { abordados en la clase, aunque persisten los } \\
\text { problemas logísticos y técnicos, pero se logró }\end{array}$ \\
\hline
\end{tabular}




\begin{tabular}{|l|l|}
\hline & $\begin{array}{l}\text { un mejor manejo y se redujo su impacto a los } \\
\text { resultados de la clase. } \\
\text { Antes de culminar la sesión el docente } \\
\text { refuerza los compromisos grupales, la } \\
\text { importancia de la participación activa de sus } \\
\text { integrantes y enfatiza en la facilidad de acceso } \\
\text { y de poder interactuar con la plataforma desde } \\
\text { su casa, bien sea para reforzar algunos } \\
\text { conceptos o revisar sus resultados o para } \\
\text { terminar algunas de las actividades pendientes } \\
\text { y la posibilidad de poder interactuar con los } \\
\text { demás compañeros, este es el potencial de la } \\
\text { wiki, extender el salón de clases hasta su casa } \\
\text { o hasta cualquier lugar del mundo. }\end{array}$ \\
\hline $\begin{array}{l}\text { 2. Para concluir la sesión, se enfatizaron las dudas } \\
\text { aclaradas durante la misma y que serán } \\
\text { fundamentales para el desarrollo de la próxima } \\
\text { sesión. }\end{array}$ & $\begin{array}{l}\text { El docente en esta ocasión les recuerda a los } \\
\text { estudiantes tener presente la forma de acceder } \\
\text { a la wiki y de tener a mano el nombre de } \\
\text { usuario y clave para el ingreso a la misma en } \\
\text { la siguiente sesión. } \\
\text { Es mínimo la referencia que se hace en cuanto } \\
\text { a aclarar dudas respecto a las actividades } \\
\text { desarrolladas en la wiki. }\end{array}$ \\
\hline 3. Señale si se lograron los objetivos de la sesión. & $\begin{array}{l}\text { Dado el retraso de la sesión anterior, se } \\
\text { necesitó realizar la actividad introductoria y } \\
\text { la actividad dirigida de los conceptos básicos } \\
\text { de Biología para esta sesión, lo que implicó un } \\
\text { ajuste para lograr los objetivos de esta sesión } \\
\text { correspondiente al concepto de reproducción } \\
\text { Se logra trabajar en los diferentes tipos. }\end{array}$ \\
\hline B. Principales logros en el aprendizaje de la & $\begin{array}{l}\text { Los estudiantes empiezan a trabajar } \\
\text { cooperativamente y van apropiándose de los } \\
\text { conceptos. }\end{array}$ \\
\hline Enología y derivados de esta sesión. & $\begin{array}{l}\text { En el cierre las condiciones tecnológicas } \\
\text { siguen siendo adversas, se logra que los } \\
\text { estudiantes trabajen en las actividades } \\
\text { cooperativas sin embargo éstas implican } \\
\text { mayor responsabilidad y trabajo por parte de } \\
\text { todos. }\end{array}$ \\
\hline
\end{tabular}

\section{Otras consideraciones de la observación.}

\section{Aspectos positivos}

- Los estudiantes lograron avanzar en las actividades cooperativas y acceder mayor tiempo a sus sitios de trabajo, pese a todos los inconvenientes técnicos, en diferentes alumnos se percibe motivación por parte de algunos equipos y mayor participación.

- Se observaron las primeras aportaciones en los foros como inicio al trabajo cooperativo. Algunos estudiantes muestran gran interés en el uso de la wiki. Los estudiantes comienzan a buscar y compartir información que permite iniciar la construcción del concepto de reproducción.

\section{Aspectos de mejora:}

Mejorar significativamente y de manera urgente todo el soporte técnico.

Preparar adecuadamente los momentos y especialmente el cierre. 


\title{
Transcripción de la sesión observada No. 3
}

\author{
Nombre del docente: Niels Horacio Lozano
}

No. de sesión observada: $\underline{\text { Tres }}$

Grupo: $\underline{8-1}$

Fecha: 20 de Febrero de 2015

Hora de Inicio y de Conclusión: 10:15 am - 11:45 am Duración: 1 h 30 min

A. Inicio de la sesión e interacción con el docente

\begin{tabular}{|c|c|}
\hline Aspectos a observar & Descripción de las observaciones \\
\hline $\begin{array}{l}\text { 1. El docente establece los objetivos de la clase. } \\
\text { ¿Cuáles fueron ellos? }\end{array}$ & $\begin{array}{l}\text { Si. El profesor presenta el objetivo de la clase. } \\
\text { Un estudiante solicita aclaración. El docente } \\
\text { le explica y afirma que comprenderá mejor } \\
\text { cuando trabaje las actividades propuestas en la } \\
\text { wiki. Sin embargo se observa como los demás } \\
\text { estudiantes, se distraen en ese momento y } \\
\text { muestran poco interés por los comentarios del } \\
\text { docente. } \\
\text { Estos objetivos fueron: } \\
\checkmark \quad \text { Explicar los tipos de reproducción asexual } \\
\text { que se presentan en los seres vivos. } \\
\checkmark \quad \text { Relacionar el ciclo celular con la } \\
\text { reproducción asexual. } \\
\checkmark \quad \text { Seleccionar, organizar e interpretar } \\
\text { información relevante. }\end{array}$ \\
\hline $\begin{array}{l}\text { 2. ¿Al inicio, se destinó un momento para que los } \\
\text { alumnos se familiarizaran con la wiki? }\end{array}$ & $\begin{array}{l}\text { Se nota mayor familiaridad de los estudiantes } \\
\text { con la wiki. Si bien es cierto que todos no la } \\
\text { manejan completamente, el docente dedica } \\
\text { espacios de tiempo para resolver situaciones } \\
\text { particulares de los alumnos, relacionadas con } \\
\text { el acceso a la wiki por colocar mal el nombre } \\
\text { de usuario o la contraseña, dudas sobre la } \\
\text { forma de editar textos con negrilla o cambio } \\
\text { de color, acceso al grupo, olvido del número } \\
\text { de equipo, entre otros. }\end{array}$ \\
\hline $\begin{array}{l}\text { 3. Describa el inicio de la clase, con base en las } \\
\text { instrucciones respecto de las actividades } \\
\text { cooperativas y de la interacción a través de la wiki. }\end{array}$ & $\begin{array}{l}\text { En esta sesión el docente da nuevas } \\
\text { instrucciones de trabajo porque deben realizar } \\
\text { una nueva actividad dirigida a lograr nuevos } \\
\text { objetivos. Los estudiantes están distraídos y } \\
\text { por tanto se nota una división en cuanto al } \\
\text { seguimiento de las instrucciones. Por tal } \\
\text { razón, el docente debe indicar nuevamente a } \\
\text { qué página deben dirigirse para leer las } \\
\text { actividades a realizar y la forma como deben } \\
\text { hacerlo. Una vez los estudiantes están en la } \\
\text { página, el docente les recuerda que cada } \\
\text { integrante de los equipos deberá escribir con } \\
\text { un color de letra diferente para poder }\end{array}$ \\
\hline
\end{tabular}


4. ¿La actitud del maestro contribuye a que los alumnos tuvieran confianza para acercarse a él y solicitar la aclaración de dudas?

5. Especifique la forma cómo se aclaran las dudas durante el trabajo en la wiki.

6. Describa la manera en el que el maestro retroalimenta las actividades desarrolladas por los estudiantes en la wiki.

\section{Especifique cómo se evalúan las actividades en la wiki.}

8. ¿Cómo facilita el maestro la resolución de problemas técnicos en la wiki? diferenciar los aportes individuales y que posteriormente deben uniformar el color de letra cuando organicen la información de manera grupal y esta sea el resultado del consenso del equipo. Se puede notar que hay dificultad en el seguimiento a las instrucciones escritas. A los alumnos no les gusta leer y buscan que el docente siempre exprese las instrucciones y las explique de forma verbal.

Si. Constantemente el maestro pregunta a los estudiantes acerca de posibles dificultades y de su disposición para resolverlas.

Los estudiantes lo llaman o le hacen preguntas desde sus puestos de trabajo, Se observa que constantemente le consultan y le solicitan aclaraciones

Para los problemas de ingreso a la wiki, analiza directamente con el estudiante cuál es el inconveniente y trata inmediatamente de solucionarlo, si es el caso cambia el nombre de usuario y/o la contraseña.

En cuanto a las dudas en la comprensión de las instrucciones, lee junto con el estudiante y/o equipo hasta que se logre asimilar lo que debe hacer.

Con respecto a la búsqueda de información recomienda sitios web de consulta y recuerda a los alumnos el objetivo que se persigue una vez realizada la actividad, asimismo, comparte consideraciones para organizar la información en la wiki.

A través de los foros en la wiki, o en los sitios de edición, coloca notas y da sugerencias. De manera general aclara las inquietudes expresadas por los alumnos y da indicaciones precisas para resolver una actividad en la que varios estudiantes hayan presentado inquietud. El docente evaluó las aportaciones de los alumnos al trabajo cooperativo, el manejo del tiempo, las actividades desarrolladas en la wiki, el trabajo cooperativo, la organización de información, la calidad de la información, su contenido y comprensión. Todo ello a través de una rúbrica creada para tal fin. El docente solicita apoyo al profesor de tecnología y este a su vez envía practicantes para que le colaboren.

Algunos equipos presentaron fallas internas que el docente y los practicantes no lograron resolver. De tal manera que no fue posible usar estos equipos en las siguientes sesiones. 


\section{B. Interacción de los alumnos con el apoyo tecnológico}

\begin{tabular}{|c|c|}
\hline Aspectos a observar & Descripción de las observaciones \\
\hline $\begin{array}{l}\text { 1. Especifique las actitudes de agrado o rechazo, } \\
\text { mostradas por los alumnos al usar la wiki en la } \\
\text { clase de Biología. }\end{array}$ & $\begin{array}{l}\text { Se nota mayor receptividad y agrado por parte } \\
\text { de los estudiantes y esto también se refleja en } \\
\text { el incremento de las interacciones, que son } \\
\text { más continuas y productivas. Sin embargo aún } \\
\text { se perciben estudiantes sin voluntad de trabajo } \\
\text { Aquellos estudiantes que les gusta trabajar en } \\
\text { la wiki, intentan convencer a sus compañeros } \\
\text { de que es agradable. } \\
\text { El agrado de los estudiantes incrementa } \\
\text { cuando buscan imágenes y vídeos y socializan } \\
\text { con otros lo que encuentran. Asimismo, } \\
\text { cuando observan y comparten información y } \\
\text { la construyen conjuntamente se les percibe } \\
\text { contentos y motivados. }\end{array}$ \\
\hline $\begin{array}{l}\text { 2. Detalle los comentarios verbales efectuados por } \\
\text { los alumnos respecto de la wiki ¿Hubo interés por } \\
\text { su uso? }\end{array}$ & $\begin{array}{l}\text { En esta sesión de clase se observan diferentes } \\
\text { comportamientos y expresiones. Unas como: } \\
\text { Me gusta más las clases con la wiki } \\
\text { ¿Y a usted? La otra niña responde, hay cosas } \\
\text { chéveres, pero en mi equipo hay gente que no } \\
\text { le gusta hacer nada. Y eso me aburre. Yo sola } \\
\text { trabajo. La otra niña le responde, ahh, en mi } \\
\text { equipo también pero yo estoy haciendo lo mío } \\
\text { y mire lo fácil. ¿Usted que ha escrito? ¿Ya } \\
\text { coloco vídeos? La otra niña responde: No. } \\
\text { Casi no he hecho. Mire el que yo subí. Tan } \\
\text { chévere, ¿cómo lo buscó? Hágale, que trabajar } \\
\text { con la wiki es fácil, venga le muestro. } \\
\text { Coloque uno están súper. Ya entendí lo de la } \\
\text { reproducción. Jaaa. Mm y también tengo } \\
\text { ubicado donde habla de los tipos de } \\
\text { reproducción asexual. ¿Verdad? Le dice la } \\
\text { otra niña. Me hubiera gustado trabajar } \\
\text { contigo. La niña le responde, hágale y verá } \\
\text { que es mejor con la wiki. Ahh me aburre el } \\
\text { salón y el profe hable y hable. Aquí uno } \\
\text { mismo busca y hay un poco de cosas } \\
\text { interesantes que el profe no muestra, y si no } \\
\text { entiendo, simple hay sí, le pregunto al profe y } \\
\text { ya. La niña le contesta, es que usted sabe más } \\
\text { de los computadores que yo. } \\
\text { Se observan otros niños juiciosos en sus } \\
\text { actividades y se paran del puesto para } \\
\text { preguntarle a los otros: ¿ya vio lo que yo hice? } \\
\text { Mire a ver si le gusta. El otro le responde, } \\
\text { nooo, esa respuesta del foro que usted hizo no } \\
\text { se entiende nada. Este man nos va hacer } \\
\text { rebajar, creo que deberías leer nuevamente } \\
\text { para saber si escribiste algo mal, sino sabes } \\
\text { cómo corregirlo le podemos preguntar al profe }\end{array}$ \\
\hline
\end{tabular}




\begin{tabular}{|c|c|}
\hline & $\begin{array}{l}\text { cómo hacerlo, es que yo creo que está malo. } \\
\text { El compañero le dice, pues acompáñeme a } \\
\text { decirle al profe. El otro le responde pues } \\
\text { vamos, así todos entendemos y miramos si lo } \\
\text { que hemos hecho nos quedó bien. } \\
\text { Esto muestra que el gran interés que ha } \\
\text { despertado en estos jóvenes el uso de la wiki. } \\
\text { También hay estudiantes más disipados y se } \\
\text { muestran renuentes a realizar sus aportes al } \\
\text { equipo. Que hartera eso, yo no quiero hacer } \\
\text { nada, déjenme que pierda, yo no creo que les } \\
\text { afecte a ustedes. Otros que por no trabajar } \\
\text { constantemente expresan que no saben qué } \\
\text { hacer, el docente les indica y después de unos } \\
\text { minutos insisten en no saber. Sin embargo se } \\
\text { puede apreciar que esconden sus celulares } \\
\text { para dedicarse a otras tareas con ellos. No } \\
\text { prestan atención a las instrucciones y } \\
\text { posteriormente aseguran trabajarán en casa. } \\
\text { Al finalizar la clase, se escucha una voz que } \\
\text { dice: Todas las clases deberían ser así profe. } \\
\text { Puede apreciarse que hay estudiantes y } \\
\text { equipos que muestran interés frente al trabajo } \\
\text { con la wiki, son participativos y tolerantes, } \\
\text { otros que tienen dificultades pero intentan } \\
\text { participar de los foros y siempre se muesran } \\
\text { respetuosos, y aquellos que no hacen } \\
\text { absolutamente nada. No se les ve voluntad de } \\
\text { trabajo y en general siempre están distraídos } \\
\text { con los celulares e intentando chatear en las } \\
\text { redes sociales, solicitando constantemente } \\
\text { permiso para ir al baño, o afirman que les } \\
\text { duele la cabeza, que les duele la mano. Que } \\
\text { les arden los ojos. Algunos de ellos si son } \\
\text { intolerantes y groseros, pero no es la } \\
\text { generalidad del grupo ni de los equipos. }\end{array}$ \\
\hline $\begin{array}{l}\text { 3. Señale si los alumnos siguieron las instrucciones } \\
\text { del profesor, al interactuar en la wiki y para realizar } \\
\text { las actividades cooperativas. }\end{array}$ & $\begin{array}{l}\text { En esta sesión de clase se nota de manera } \\
\text { general una gran disposición de los } \\
\text { estudiantes para trabajar y se observa que la } \\
\text { lectura la lectura y el seguimiento a las } \\
\text { instrucciones escritas. Hay repetidas preguntas } \\
\text { sobre, si lo que ellos entendieron al leer las } \\
\text { instrucciones corresponde a lo que debe } \\
\text { hacerse. El docente debe dar indicaciones para } \\
\text { aclarar las instrucciones. Sin embargo los } \\
\text { estudiantes disipados y con poco interés no } \\
\text { siguen instrucciones y de alguna manera } \\
\text { obstaculizan el trabajo cooperativo de los } \\
\text { equipos donde hacen parte, debido a que no } \\
\text { aportan sus ideas ni participan de las } \\
\text { actividades propuestas. Esto genera desánimo } \\
\text { en los demás integrantes. }\end{array}$ \\
\hline
\end{tabular}




\begin{tabular}{|c|c|}
\hline $\begin{array}{l}\text { 4. ¿Hubo éxito en el desarrollo de las actividades } \\
\text { de clase (individuales y cooperativas) con el uso de } \\
\text { la wiki? }\end{array}$ & $\begin{array}{l}\text { Si bien es cierto se observa una mejoría en el } \\
\text { avance de las actividades, la señal de Internet, } \\
\text { los problemas técnicos y la actitud de algunos } \\
\text { estudiantes no permite el éxito de las } \\
\text { actividades a nivel general. } 5 \text { equipos lograron } \\
\text { culminar completamente la actividad } \\
\text { propuesta, otros estudiantes avanzaron, sin } \\
\text { embargo les quedo faltando completar la } \\
\text { actividad. Otros nuevamente no hicieron nada. }\end{array}$ \\
\hline $\begin{array}{l}\text { 5. ¿Los alumnos participaron activamente en la } \\
\text { wiki? }\end{array}$ & $\begin{array}{l}\text { En general se evidencia más participación de } \\
\text { los estudiantes, más discusiones y avances en } \\
\text { sus actividades. Al leer los escritos que } \\
\text { publican se perciben las construcciones que } \\
\text { hacen grupalmente y las apreciaciones } \\
\text { respecto de lo que hacen los otros equipos y } \\
\text { como podrían mejorarlo, de tal manera que las } \\
\text { participaciones en los foros se enriquecen a } \\
\text { medida que logran manejar y comprender la } \\
\text { información. También persisten, la actitud } \\
\text { desfavorable de algunos estudiantes que no les } \\
\text { permite participar de las actividades, la } \\
\text { deficiencia en la señal de Internet y los } \\
\text { problemas técnicos de ciertos equipos de } \\
\text { cómputo. }\end{array}$ \\
\hline $\begin{array}{l}\text { 6. ¿Durante las actividades en la wiki, los alumnos } \\
\text { consideraron los conceptos teóricos de la clase } \\
\text { presencial de Biología? }\end{array}$ & $\begin{array}{l}\text { Los alumnos refieren los conceptos teóricos } \\
\text { tratados en las clases presenciales y que } \\
\text { refuerzan con las búsquedas de información y } \\
\text { los vídeos compartidos por cada uno de los } \\
\text { integrantes, y de los grupos en general con el } \\
\text { uso de la wiki. }\end{array}$ \\
\hline $\begin{array}{l}\text { 7. ¿Hubo progreso individual y grupal, con base en } \\
\text { lo que se indicó en las instrucciones de las } \\
\text { actividades? }\end{array}$ & $\begin{array}{l}\text { Los progresos individuales superan a los } \\
\text { grupales. La razón es que hay equipos en los } \\
\text { que se dificulta el trabajo porque se presentan } \\
\text { diferencias de orden personal y esto afecta los } \\
\text { progresos grupales. Sin embargo en los grupos } \\
\text { donde se observa que los integrantes han } \\
\text { logrado entenderse, llegar a acuerdos y } \\
\text { cumplir con los compromisos se percibe } \\
\text { progreso constante en las actividades. } \\
\text { También es evidente la actitud positiva y } \\
\text { motivación que reflejan frente a las } \\
\text { actividades y al deseo por culminarlas lo } \\
\text { mejor posible. } \\
\text { Lastimosamente, hay los estudiantes de } \\
\text { excepción que no muestran deseos de } \\
\text { vincularse a la dinámica cooperativa que } \\
\text { necesitan los grupos para progresar. }\end{array}$ \\
\hline $\begin{array}{l}\text { 8. Describa las principales dificultades que se } \\
\text { presentaron durante la interacción de los alumnos } \\
\text { con la wiki. }\end{array}$ & $\begin{array}{l}\text { Las principales dificultades que se presentan } \\
\text { durante la interacción de los alumnos son: los } \\
\text { reiterativos inconvenientes técnicos, el } \\
\text { marcado desinterés e irresponsabilidad de } \\
\text { algunos estudiantes, las dificultades de lectura } \\
\text { y escritura de otros. Esto afecta a los demás }\end{array}$ \\
\hline
\end{tabular}




\begin{tabular}{|c|c|}
\hline & $\begin{array}{l}\text { compañeros e impide el aprendizaje } \\
\text { cooperativo. }\end{array}$ \\
\hline $\begin{array}{l}\text { 9. ¿Los alumnos interactuaron con tolerancia y } \\
\text { respeto entre ellos? }\end{array}$ & $\begin{array}{l}\text { En general los alumnos interactúan con } \\
\text { tolerancia y respeto, sin embargo se presentan } \\
\text { casos en donde los equipos que avanzan en } \\
\text { sus actividades cooperativas, se encuentran } \\
\text { con estudiantes irresponsables, allí se notan } \\
\text { choques y diferencias debidas a que los } \\
\text { integrantes de estos grupos, cuentan con } \\
\text { estudiantes que presentan mayor compromiso } \\
\text { y mejor rendimiento los cuales no aceptan } \\
\text { tener en sus equipos compañeros } \\
\text { desinteresados y con dificultades y que no } \\
\text { quieran reconocerlos y sean apáticos a los } \\
\text { llamados constantes que se les hace para que } \\
\text { mejoren. Hay otros casos en los que los } \\
\text { compañeros que se esfuerzan e intentan hacer } \\
\text { sus aportes, no son valorados y sus aportes } \\
\text { omitidos, lo que genera indisposición. Todo lo } \\
\text { anterior obliga la intervención del docente } \\
\text { quien rápidamente resuelve este tipo de } \\
\text { conflictos. De tal manera que puede afirmarse } \\
\text { que se presentan pocos casos de esta índole. }\end{array}$ \\
\hline $\begin{array}{l}\text { 10. ¿Destacó el cumplimiento de los compromisos } \\
\text { grupales? }\end{array}$ & $\begin{array}{l}\text { En esta instancia se notan grupos armónicos y } \\
\text { con un buen manejo de roles y el liderazgo de } \\
\text { algunos de sus integrantes, pero están también } \\
\text { los estudiantes que no muestran ningún tipo de } \\
\text { interés afectando la actividad en general, se } \\
\text { puede considerar de manera global que gran } \\
\text { parte de los estudiantes participan de los } \\
\text { compromisos grupales como son los foros, las } \\
\text { preguntas, las consultas o investigaciones, la } \\
\text { edición de los textos. }\end{array}$ \\
\hline
\end{tabular}

\section{Cierre de la sesión}

\begin{tabular}{|l|l|}
\hline \multicolumn{1}{|c|}{ Aspectos a observar } & \multicolumn{1}{c|}{ Descripción de las observaciones } \\
\hline $\begin{array}{l}\text { 1. Detalle si al final de cada sesión, se } \\
\text { resumieron los principales aspectos abordados en } \\
\text { la misma. }\end{array}$ & $\begin{array}{l}\text { El docente resaltó el buen trabajo desarrollado } \\
\text { y reconoció a algunos grupos su buen } \\
\text { desempeño e invitó a todos los estudiantes a } \\
\text { participar activamente en la wiki. Hizo } \\
\text { referencia a la importancia de sus aportes y } \\
\text { cooperación para llevar a buen término las } \\
\text { actividades, manifestó que si todos los } \\
\text { integrantes se comprometieran sería más } \\
\text { productivo para los grupos y alcanzarían los } \\
\text { aprendizajes esperados. Detalló los aspectos a } \\
\text { mejorar en las aportaciones hechas en los } \\
\text { foros, hizo sugerencias de cómo mejorar la } \\
\text { manera como han trabajado, hizo }\end{array}$ \\
\hline
\end{tabular}




\begin{tabular}{|c|c|}
\hline & $\begin{array}{l}\text { observaciones a las respuestas leídas y a su } \\
\text { pertinencia. Retomó algunos aportes valiosos } \\
\text { para el desarrollo de las actividades en } \\
\text { general. }\end{array}$ \\
\hline $\begin{array}{l}\text { 2. Para concluir la sesión, se enfatizaron las dudas } \\
\text { aclaradas durante la misma y que serán } \\
\text { fundamentales para el desarrollo de la próxima } \\
\text { sesión. }\end{array}$ & $\begin{array}{l}\text { El docente en esta ocasión además de } \\
\text { recordarles a los estudiantes tener presente la } \\
\text { forma de acceder a la wiki y de tener a mano } \\
\text { el nombre de usuario y clave para el ingreso a } \\
\text { la misma en la siguiente sesión, también los } \\
\text { motiva haciéndoles una invitación a trabajar } \\
\text { desde la casa y enfatiza en la facilidad de } \\
\text { hacerlo por que disponen del tiempo elegido } \\
\text { por ellos mismos, bien sea para reforzar } \\
\text { algunos conceptos o revisar sus resultados o } \\
\text { para terminar algunas de las actividades } \\
\text { pendientes y la posibilidad de poder } \\
\text { interactuar con los demás compañeros, este es } \\
\text { el potencial de la wiki, extender el salón de } \\
\text { clases hasta su casa o hasta cualquier lugar del } \\
\text { mundo. } \\
\text { Se logra dar respuesta y aclaraciones a algunas } \\
\text { de las inquietudes y dudas que los estudiantes } \\
\text { manifiestan en el desarrollo de las actividades. } \\
\text { Resumió los aspectos más relevantes de los } \\
\text { tipos de reproducción asexual y los invitó a } \\
\text { buscar información sobre la división del } \\
\text { núcleo celular. }\end{array}$ \\
\hline 3. Señale si se lograron los objetivos de la sesión. & $\begin{array}{l}\text { Los objetivos cumplidos por algunos de los } \\
\text { grupos fueron: } \\
\checkmark \text { Explicar los tipos de reproducción asexual } \\
\text { que se presentan en los seres vivos. } \\
\checkmark \quad \text { Seleccionar, organizar e interpretar } \\
\text { información relevante. }\end{array}$ \\
\hline $\begin{array}{l}\text { 4. Principales logros en el aprendizaje de la } \\
\text { Biología y derivados de esta sesión. }\end{array}$ & $\begin{array}{l}\text { Los estudiantes desde lo metodológico } \\
\text { desarrollan foros, construyen preguntas que } \\
\text { les permite diferenciar y precisar } \\
\text { características de la reproducción asexual, } \\
\text { consultar e investigar para aportar la } \\
\text { información necesaria para desarrollar las } \\
\text { temáticas expuestas. }\end{array}$ \\
\hline 5. ¿Hubo éxito en la terminación de la sesión? & $\begin{array}{l}\text { Si hay éxito en la terminación de la sesión. Se } \\
\text { consolidan algunos grupos, desde el punto de } \\
\text { vista metodológico, de la apropiación de la } \\
\text { construcción de los conceptos. Desde el } \\
\text { manejo de las actividades algunos estudiantes } \\
\text { juegan un papel interesante como mediadores } \\
\text { e incentivadores de la participación y del } \\
\text { apoyo para que sus compañeros cumplan los } \\
\text { compromisos adquiridos. }\end{array}$ \\
\hline
\end{tabular}




\section{Otras consideraciones de la observación.}

\section{Aspectos positivos}

\begin{tabular}{l}
\hline Algunos grupos se consolidan y definen roles entre sus integrantes. \\
Los estudiantes muestran interés por desarrollar las actividades de la wiki como los foros, la búsqueda \\
de información, no solo textual sino, visual, animada. \\
Se logra mejorar la apropiación conceptual de la reproducción asexual. \\
Se logra afianzar la expectativa y la motivación de los estudiantes. \\
\hline
\end{tabular}

\section{Aspectos de mejora:}

Mejorar significativamente y de manera urgente todo el soporte técnico.

Buscar alternativas de apoyo para los estudiantes con actitudes desfavorables para el aprendizaje cooperativo y propio de la Biología 


\section{Transcripción de la sesión observada No. 4}

Nombre del docente: Niels Horacio Lozano

No. de sesión observada: $\underline{\text { Cuatro }}$

Grupo: $\underline{8-1}$

Fecha: 26 Febrero 2015

Hora de Inicio y de Conclusión: 7:15 am - 8:50 am Duración: 1 h 35 min

A. Inicio de la sesión e interacción con el docente

\begin{tabular}{|c|c|}
\hline Aspectos a observar & Descripción de las observaciones \\
\hline $\begin{array}{l}\text { 1. El docente establece los objetivos de la clase. } \\
\text { ¿Cuáles fueron ellos? }\end{array}$ & $\begin{array}{l}\text { Si, el docente recuerda y aclara el objetivo con } \\
\text { el que han trabajado en las sesiones anteriores } \\
\text { debido al poco avance por las fallas constantes } \\
\text { con la señal de internet. } \\
\text { Estos objetivos fueron: } \\
\checkmark \quad \text { Explicar los tipos de reproducción asexual } \\
\text { que se presentan en los seres vivos. } \\
\checkmark \quad \text { Relacionar el ciclo celular con la } \\
\text { reproducción asexual. } \\
\checkmark \quad \text { Seleccionar, organizar e interpretar } \\
\text { información relevante }\end{array}$ \\
\hline $\begin{array}{l}\text { 2. ¿Al inicio, se destinó un momento para que los } \\
\text { alumnos se familiarizaran con la wiki? }\end{array}$ & $\begin{array}{l}\text { Se destinan momentos para familiarizar a los } \\
\text { estudiantes con situaciones puntuales de } \\
\text { trabajo en la wiki. Por ejemplo al ingresar al } \\
\text { salón de clase, dos estudiantes le comentan al } \\
\text { profesor que los otros dos compañeros de su } \\
\text { equipo les habían comentado que ellos no } \\
\text { participaban porque aún tenían dificultades } \\
\text { para ingresar a la wiki. Nuevamente el docente } \\
\text { destinó un espacio de tiempo para analizar con } \\
\text { ellos esta situación particular. Inmediatamente } \\
\text { les hizo saber a estos estudiantes que les } \\
\text { faltaba mayor compromiso con las actividades } \\
\text { porque ya había pasado tiempo suficiente para } \\
\text { que ellos no tuvieran anotado el nombre de } \\
\text { usuario y contraseña, además de que les } \\
\text { faltaba varias participaciones en el foro donde } \\
\text { ya él les había hecho recomendaciones al } \\
\text { respecto. Su descuido era la razón de no saber } \\
\text { la forma de editar en la wiki y de participar en } \\
\text { los foros. El docente les explicó, sin embargo } \\
\text { llamó su atención respecto de la importancia } \\
\text { de ser responsables y sobre las habilidades } \\
\text { requeridas para el aprendizaje cooperativo. } \\
\text { Se observa que entre compañeros también se } \\
\text { destinan espacios para recordar aspectos } \\
\text { específicos relacionados con la manera de } \\
\text { trabajar en la wiki. }\end{array}$ \\
\hline
\end{tabular}




\begin{tabular}{|c|c|}
\hline $\begin{array}{l}\text { 3. Describa el inicio de la clase, con base en las } \\
\text { instrucciones respecto de las actividades } \\
\text { cooperativas y de la interacción a través de la wiki. }\end{array}$ & $\begin{array}{l}\text { Al inicio de la clase, el docente saludo a los } \\
\text { alumnos, les solicitó su disposición para } \\
\text { trabajar en la wiki, les informó en qué } \\
\text { actividad debían trabajar, les indicó, que las } \\
\text { instrucciones y objetivos de la sesión estaban } \\
\text { claramente descritas en la página y que debían } \\
\text { leerla. Posteriormente, guio a los estudiantes } \\
\text { para que trabajaran de forma cooperativa y } \\
\text { que lo hicieran de manera virtual. Expresó que } \\
\text { tanto las dudas como los acuerdos generados } \\
\text { en el interior de cada equipo debían registrarse } \\
\text { en la página de cada grupo y la información } \\
\text { definitiva acerca del concepto de reproducción } \\
\text { y sus tipos, así como la división celular debía } \\
\text { ser validada por todos los miembros del } \\
\text { equipo. Se presentaron situaciones donde de } \\
\text { forma individualizada los estudiantes } \\
\text { afirmaron no entender las instrucciones, para } \\
\text { lo cual el docente se acercó hasta el puesto de } \\
\text { trabajo y enseñó al estudiante a leer en voz } \\
\text { alta y despacio. Le señalaba en que momento } \\
\text { iniciar y parar la lectura de las instrucciones y } \\
\text { pregunta lo entendido hasta ese momento. De } \\
\text { esta manera guía poco a poco al estudiante } \\
\text { hasta aclarar completamente la instrucción. Se } \\
\text { percibe en los estudiantes dificultades en la } \\
\text { lectura y la escritura, lo que sorprende porque } \\
\text { ya cursan octavo grado. Sin embargo también } \\
\text { se observan unos comportamientos un tanto } \\
\text { complicados por parte de } 10 \text { estudiantes. }\end{array}$ \\
\hline $\begin{array}{l}\text { 4. ¿La actitud del maestro contribuye a que los } \\
\text { alumnos tuvieran confianza para acercarse a él y } \\
\text { solicitar la aclaración de dudas? }\end{array}$ & $\begin{array}{l}\text { Si. El docente se muestra atento y respetuoso } \\
\text { frente a las dudas que exponen los estudiantes, } \\
\text { esto contribuye a que la interacción sea } \\
\text { constante y cada vez se haya participaciones y } \\
\text { discusiones enriquecidas. El profesor es } \\
\text { reiterativo en señalar a los alumnos que no } \\
\text { deben sentir pena o inseguridad para } \\
\text { preguntar, porque todas sus dudas son } \\
\text { importantes y solicita respeto por parte del } \\
\text { grupo para cualquier consulta que se haga por } \\
\text { mínima que parezca. }\end{array}$ \\
\hline $\begin{array}{l}\text { 5. Especifique la forma cómo se aclaran las dudas } \\
\text { durante el trabajo en la wiki. }\end{array}$ & $\begin{array}{l}\text { La forma que utiliza el docente para aclarar } \\
\text { dudas también se ha modificado } \\
\text { progresivamente, al principio fue muy verbal, } \\
\text { posteriormente se notaba más la aclaración } \\
\text { escrita a través de la wiki, en los espacios de } \\
\text { trabajo de cada equipo. }\end{array}$ \\
\hline $\begin{array}{l}\text { 6. Describa la manera en el que el maestro } \\
\text { retroalimenta las actividades desarrolladas por los } \\
\text { estudiantes en la wiki. }\end{array}$ & $\begin{array}{l}\text { En esta sesión de clase, los equipos presentan } \\
\text { un avance diferente; las retroalimentaciones se } \\
\text { hacen de acuerdo a las necesidades de cada } \\
\text { equipo y de cada uno de sus integrantes. De } \\
\text { esta manera el docente se sienta con los }\end{array}$ \\
\hline
\end{tabular}




\begin{tabular}{|l|l|}
\hline & $\begin{array}{l}\text { jóvenes que le solicitan y retroalimenta sus } \\
\text { trabajos de acuerdo con las inquietudes. } \\
\text { Por otra parte, coloca notas a los equipos que } \\
\text { no muestran avances y habla con ellos para } \\
\text { tratar de indagar lo que sucede. }\end{array}$ \\
\hline $\begin{array}{l}\text { 7. Especifique cómo se evalúan las actividades en } \\
\text { la wiki. }\end{array}$ & $\begin{array}{l}\text { El docente lee las aportaciones de los alumnos } \\
\text { para el desarrollo de las actividades } \\
\text { cooperativas, las retroalimenta y } \\
\text { constantemente les dice a los estudiantes no } \\
\text { olvidar la guía que ofrece la rúbrica de } \\
\text { evaluación, donde se abordan aspectos como, } \\
\text { el manejo del tiempo, las actividades } \\
\text { desarrolladas en la wiki, el trabajo } \\
\text { cooperativo, la organización de información, } \\
\text { la calidad de la información, su contenido y } \\
\text { comprensión. Todo ello lo tiene en cuenta el } \\
\text { docente al momento de evaluar el trabajo que } \\
\text { se realiza en la wiki.. }\end{array}$ \\
\hline $\begin{array}{l}\text { El docente invitó a los estudiantes a asistir a } \\
\text { problemas técnicos en la wiki? }\end{array}$ & $\begin{array}{l}\text { las salas en jornada contraria a la de clases } \\
\text { para tratar de mejorar el tema de la velocidad. } \\
\text { Esto en razón a que la señal de Internet que } \\
\text { llegaba a la sala donde se trabajaba con los } \\
\text { estudiantes dependía de otra sala, de tal } \\
\text { manera que si en esta sala madre se hacía uso } \\
\text { del Internet, en la sala donde se encontraban } \\
\text { los estudiantes de octavo grado la señal se } \\
\text { volvía aún más lenta y en este sentido no } \\
\text { había nada que hacer. Sin embargo es } \\
\text { pertinente señalar que este inconveniente se } \\
\text { presentó durante todo el tiempo que se trabajó } \\
\text { en la wiki. } \\
\text { Sin embargo solo } 5 \text { alumnos utilizaron esta } \\
\text { alternativa. }\end{array}$ \\
\hline
\end{tabular}

\section{B. Interacción de los alumnos con el apoyo tecnológico}

\begin{tabular}{|c|c|}
\hline Aspectos a observar & Descripción de las observaciones \\
\hline $\begin{array}{l}\text { 1. Especifique las actitudes de agrado o rechazo, } \\
\text { mostradas por los alumnos al usar la wiki en la } \\
\text { clase de Biología. }\end{array}$ & $\begin{array}{l}\text { Nuevamente, se identifican tanto actitudes de } \\
\text { agrado como actitudes de rechazo. } \\
\text { Es pertinente señalar que fue una constante el } \\
\text { hecho que a los estudiantes les gustara ir a la } \\
\text { sala de cómputo a buscar información, ver } \\
\text { vídeos, elegir imágenes para alimentar su } \\
\text { página. Sin embargo se les hacía más } \\
\text { complicado, organizar la información, editarla } \\
\text { adecuadamente, llegar a consensos, esforzarse } \\
\text { por construir los textos con sus propias ideas } \\
\text { de acuerdo con lo que ellos comprendían En } \\
\text { esta última situación es en la que se notan las } \\
\text { actitudes negativas y. como ya se indicó }\end{array}$ \\
\hline
\end{tabular}




\begin{tabular}{|c|c|}
\hline & $\begin{array}{l}\text { anteriormente se perciben problemas de } \\
\text { lectura y escritura, esto hace que los alumnos } \\
\text { en ocasiones se desmotiven. }\end{array}$ \\
\hline $\begin{array}{l}\text { 2. Detalle los comentarios verbales efectuados por } \\
\text { los alumnos respecto de la wiki ¿Hubo interés por } \\
\text { su uso? }\end{array}$ & $\begin{array}{l}\text { En esta sesión se nota mayor concentración de } \\
\text { los alumnos en sus tareas, expresiones como, } \\
\text { ya casi acabo, nos está quedando bien chévere } \\
\text { nuestra página, ¿Ya vio el vídeo que } \\
\text { publicamos? Reunamos para definir el } \\
\text { concepto que va a dejar el grupo. } \\
\text { Profe hay un estudiante que no quiso trabajar, } \\
\text { no le rogamos más, por culpa de él se nos va a } \\
\text { tirar la nota. Tan maluco cuando en el equipo } \\
\text { hay gente irresponsable. } \\
\text { ¿Profe la otra semana volvemos? ¡No...i ¿por } \\
\text { qué?.. Sí ya estábamos en la juega, ya le } \\
\text { cogimos el tiro y ahora que nos gusta, } \\
\text { entendemos, está chévere nos devolvemos pal } \\
\text { salón, que pereza. } \\
\text { Gracias a Dios se acabó eso, yo la pierdo pero } \\
\text { no me importa, nada de sistemas me gusta, lo } \\
\text { detesto todo, lo único bueno de estudiar es } \\
\text { charlar. } \\
\text { Particularmente en esta sesión de clase se } \\
\text { puede observar el notable incremento de las } \\
\text { discusiones, el número de jóvenes que } \\
\text { constantemente preguntaban, que mostraban al } \\
\text { docente lo que trabajaban y le solicitaban que } \\
\text { les retroalimentara sus respuestas para saber si } \\
\text { les quedaba, se veía a los estudiantes muy } \\
\text { dispuestos. Se puede predecir que un } 80 \% \text { de } \\
\text { los alumnos expresaban aspectos positivos de } \\
\text { la wiki. }\end{array}$ \\
\hline $\begin{array}{l}\text { 3. Señale si los alumnos siguieron las instrucciones } \\
\text { del profesor, al interactuar en la wiki y para realizar } \\
\text { las actividades cooperativas. }\end{array}$ & $\begin{array}{l}\text { Nuevamente para esta sesión de clase se } \\
\text { observan diferencias. Es notorio el } \\
\text { seguimiento por parte de los estudiantes de las } \\
\text { instrucciones y su avance en las actividades, } \\
\text { se les ve más comprometidos con las mismas } \\
\text { y son más receptivos con las instrucciones. } \\
\text { Sin embargo algunos de ellos no muestran } \\
\text { seguridad por las instrucciones escritas y } \\
\text { corroboran con el docente si lo que ellos } \\
\text { piensan que deben hacer, es lo correcto. El } \\
\text { docente siempre explica verbalmente las } \\
\text { instrucciones escritas. Estos estudiantes } \\
\text { navegan mejor en sus sitios de trabajo, } \\
\text { aunque a veces olvidan ciertos aspectos } \\
\text { específicos como la forma de crear un vínculo } \\
\text { o cambiar el nombre de una página, subir } \\
\text { imágenes o vídeos. } \\
\text { Una minoría presta poca atención a las } \\
\text { instrucciones y constantemente interrumpen a }\end{array}$ \\
\hline
\end{tabular}


4. ¿Hubo éxito en el desarrollo de las actividades de clase (individuales y cooperativas) con el uso de la wiki?

5. ¿Los alumnos participaron activamente en la wiki?

6. ¿Durante las actividades en la wiki, los alumnos consideraron los conceptos teóricos de la clase presencial de Biología?

7. ¿Hubo progreso individual y grupal, con base en lo que se indicó en las instrucciones de las actividades?

8. Describa las principales dificultades que se presentaron durante la interacción de los alumnos con la wiki.

9. ¿Los alumnos interactuaron con tolerancia y respeto entre ellos? sus compañeros para preguntar lo que se debe hacer, debido a que no están atentos. Y a pesar que sus compañeros dan indicaciones finalmente no trabajan de ninguna forma y no hacen ningún tipo de aporte en las páginas donde deben editar la información que investigan.

Aproximadamente 8 equipos lograron completar cabalmente las actividades, sin embargo no se puede asegurar que estén correctamente realizadas, porque el tiempo no es suficiente para que el docente logre revisar las mismas. Esto en razón a que siguen presentándose problemas con la señal de Internet, la baja velocidad y por momentos la pérdida completa de la señal.

No es claro, si el manejo conceptual que muestran los jóvenes fue el resultado de sus conceptos previos teóricos de la actividad presencial o corresponden más bien a los resultados de la interacción con la nueva herramienta wiki.

Se observa que son pocos los jóvenes que muestran avances significativos desde el aspecto conceptual y esto se encuentra afectado por las dificultades técnicas.

Los estudiantes no consideraron los conceptos teóricos de la clase de Biología, se basaron en sus búsquedas personales y en lo que construyen a nivel grupal. Se percibe una evolución en el manejo conceptual que aparentemente se debe al incremento de las interacciones con sus iguales y a las discusiones que se generan en torno a las actividades y temáticas trabajadas.

En esta instancia es notable el progreso individual y grupal de gran parte de los estudiantes. Se notan grupos armónicos con claridad en el manejo de roles y el liderazgo de algunos de sus integrantes y equipos que no tienen mayores progresos así como estudiantes que no muestran ningún tipo de interés afectando la actividad en general.

Desafortunadamente todas las fallas técnicas descritas no se superaron y afectaron considerablemente tanto la motivación como la producción académica de los muchachos.

Normalmente los estudiantes establecen interacciones respetuosas y tolerantes. Se nota un ambiente mucho más cooperativo, se conservan los aspectos positivos y negativos ya mencionados, pero si vale la pena resaltar 


\begin{tabular}{|l|l|}
\hline & $\begin{array}{l}\text { la buena disposición de trabajo de los } \\
\text { estudiantes a nivel general }\end{array}$ \\
\hline $\begin{array}{l}\text { 10. ¿Destacó el cumplimiento de los compromisos } \\
\text { grupales? }\end{array}$ & $\begin{array}{l}\text { De forma general los estudiantes participar en } \\
\text { los compromisos grupales como son los foros, } \\
\text { las preguntas, las consultas o investigaciones, } \\
\text { la edición de los textos, en su afán por cumplir } \\
\text { las actividades establecidas, podríamos decir } \\
\text { que en algunos grupos un estudiante no } \\
\text { cumplía con las tareas propuestas en el grupo. } \\
\text { Es bueno exaltar que algunos estudiantes } \\
\text { hacen trabajo extracurricular, es decir, fuera } \\
\text { del aula de clase en horarios distintos con el } \\
\text { fin de completar las actividades } \\
\text { correspondientes. }\end{array}$ \\
\hline
\end{tabular}

\section{Cierre de la sesión}

\begin{tabular}{|c|c|}
\hline Aspectos a observar & Descripción de las observaciones \\
\hline $\begin{array}{l}\text { 1. Detalle si al final de cada sesión, se } \\
\text { resumieron los principales aspectos abordados } \\
\text { en la misma. }\end{array}$ & $\begin{array}{l}\text { En el cierre el docente resume los aspectos } \\
\text { relevantes que a su juicio fueron tratados. } \\
\text { Confirma que esa era la última sesión con la } \\
\text { wiki. Entonces se escuchan comentarios muy } \\
\text { interesantes que hacen referencia al deseo } \\
\text { porque estas actividades tengan continuidad. } \\
\text { Expresiones como "profe, que pesar" "tanto } \\
\text { que nos quejamos al principio y vea lo } \\
\text { chévere que estábamos trabajando" y } \\
\text { expresiones de rechazo de volver a la clase } \\
\text { tradicional "que pereza volver al salón", hacen } \\
\text { notar la motivación que les produjo a muchos } \\
\text { de los estudiantes trabajar con la wiki, se } \\
\text { advirtió mucho más compromiso de los } \\
\text { alumnos, una respuesta positiva al trabajo } \\
\text { cooperativo, más participación en los foros, } \\
\text { más interés por indagar, más actitud de } \\
\text { asombro a la información consultada y el } \\
\text { valor agregado que esto les da y el deseo de } \\
\text { compartirlo con otros compañeros. }\end{array}$ \\
\hline $\begin{array}{l}\text { 2. Para concluir la sesión, se enfatizaron las dudas } \\
\text { aclaradas durante la misma y que serán } \\
\text { fundamentales para el desarrollo de la próxima } \\
\text { sesión. }\end{array}$ & $\begin{array}{l}\text { En esta sesión se observa que el docente hace } \\
\text { énfasis en las dudas aclaradas, en las tareas y } \\
\text { compromisos pendientes ya que esta es la } \\
\text { última sesión. El profesor recuerda los } \\
\text { aspectos técnicos de acceso a la wiki, por otro } \\
\text { lado se refiere concretamente a aspectos } \\
\text { propios del conocimiento de los temas } \\
\text { tratados en cuanto al mejoramiento de las } \\
\text { preguntas, las observaciones en cuanto a los } \\
\text { errores cometidos por algunos compañeros, la } \\
\text { necesidad de reforzar algunos conceptos en } \\
\text { los que se denota poco manejo. }\end{array}$ \\
\hline
\end{tabular}




\begin{tabular}{|l|l|}
\hline 3. Señale si se lograron los objetivos de la sesión. & $\begin{array}{l}\text { Se continúa con los objetivos de las } \\
\text { actividades correspondientes a la reproducción } \\
\text { asexual y se inicia con los de la reproducción } \\
\text { sexual, en algunos grupos es evidente el logro } \\
\text { de estos objetivos, pero otros muestran } \\
\text { retrasos considerables. }\end{array}$ \\
\hline $\begin{array}{l}\text { 4. Principales logros en el aprendizaje de la } \\
\text { Biología y derivados de esta sesión. }\end{array}$ & $\begin{array}{l}\text { Los estudiantes muestran competencias con } \\
\text { respecto a la comparación y clasificación de } \\
\text { los diferentes tipos de reproducción asexual e } \\
\text { inician la construcción del concepto referente } \\
\text { a la reproducción respecto a la reproducción } \\
\text { sexual de forma cooperativa. }\end{array}$ \\
\hline 5. ¿Hubo éxito en la terminación de la sesión? & $\begin{array}{l}\text { En cuanto a la terminación de la sesión puede } \\
\text { notarse que hay apropiación por parte de } \\
\text { algunos de los grupos con referencia a la } \\
\text { reproducción asexual, mediados por los foros, } \\
\text { por la formulación de preguntas, construcción } \\
\text { de conceptos y valoración de los diferentes } \\
\text { aportes que hacen sus compañeros en el } \\
\text { trabajo cooperativo, además la clasificación de } \\
\text { información, desarrollo de competencias de } \\
\text { comparación y se nota al cierre final de la } \\
\text { actividad el impacto positivo que le ha dado } \\
\text { esta herramienta y a la angustia por la no } \\
\text { continuidad de la propuesta y el poder seguir } \\
\text { contando con alternativas y ambientes de } \\
\text { enseñanza diferentes a los del aula de clase } \\
\text { tradicional. }\end{array}$ \\
\hline
\end{tabular}

D. Otras consideraciones de la observación.

\section{Aspectos positivos}

Los estudiantes progresivamente aprenden de forma cooperativa y resaltan lo adecuado que resulta en las clases de Biología porque consideran que se les facilita la comprensión del concepto que se ha trabajado, siempre y cuando el grupo sea integrado por compañeros responsables.

Se observa que en general los estudiantes consideran la wiki como una buena alternativa de enseñanza de las clases de Biología. A pesar de que algunos afirman sería mejor si el internet fuera más rápido. Se observan cambios evidentes en la forma como se comunican, avances y responsabilidad en los comentarios que se generan de manera virtual y se percibe el progreso paulatino de algunas competencias como el discernimiento, la búsqueda y selección de información, la negociación y toma de decisiones y la comunicación escrita.

\section{Aspectos de mejora:}

Mejorar significativamente y de manera urgente todo el soporte técnico. Ofrecer alternativas a los estudiantes con problemas de lectura y escritura Buscar apoyo para resolver las situaciones complejas que se presentan con las actitudes extremadamente negativas de algunos estudiantes. 


\title{
Apéndice L: Transcripción de la entrevista con el titular del grupo experimental
}

\author{
El objetivo de la entrevista fue el conocer la perspectiva del docente sobre el impacto \\ del uso e incorporación de una wiki en el aprendizaje de la Biología.
}

\section{Marzo 4 de 2015}

1. ¿Qué utilidad encuentra en la wiki para modificar la enseñanza tradicional de la Biología?

Respuesta: a nivel personal yo veo muy interesante el trabajo en la wiki porque en ella se incorpora la parte dinámica, la parte de videos, la parte de los conceptos y permite mayor interacción con el docente y entre los estudiantes y también con la misma fuente digamos de consulta, además ehh, como esta wiki está incorporada a un manejo de un trabajo en equipo con actividades cooperativas va a permitir también intercambiar ideas y conceptos mm digamos previos que ellos tienen, o ideas previas, ayudarse, esto facilita el aprendizaje y les va a permitir avanzar o que los estudiantes evolucionen en la construcción del conocimiento. Esto hace que sea diferente al trabajo de tablero y marcador que rutinariamente manejamos, otorga mayor protagonismo y cierta autonomía a los estudiantes, autonomía que considero en un principio debe ser guiada por el docente, sin embargo pienso que hay que ser muy cuidadosos también de la forma como sea concebida la wiki, porque de no contemplar ciertas estrategias pedagógicas que dinamicen el trabajo en ella podría caerse nuevamente en el tradicionalismo. De hecho los maestros debemos manejar estos apoyos tecnológicos, pero estos deben estar mediados en el currículo para lograr el cumplimiento de las competencias definidas para cada período y curso.

Con la wiki se comparte conocimiento e información de manera diferente y rápida y esto es de gran agrado para aquellos estudiantes para quienes quizá es mucho más fácil que solamente texto. Pienso que debido a que algunos estudiantes interactúan constantemente, logran construir conjuntamente páginas llamativas y presentar ideas que captan el interés de otros, las interacciones mejoran, se incrementan, además de que así, poco a poco van tomando protagonismo y esto les ayuda a alcanzar las metas, mejorar sus conocimientos y a disfrutar compartirlo. Van dejando se ser tan egoístas en algunos aspectos y un poco más conscientes de que no se trata de que regalen las tareas a los otros, sino que les expliquen o indiquen como han logrado sus avances. 
Otra cosa que es interesantes es leer las opiniones y pensamiento que va desarrollando el estudiante o que no ha logrado y que se refleja en los foros, esto de alguna manera orienta al docente a que analice mejor a sus estudiantes y pueda canalizar sus dificultades para tratar de cambiar constantemente sus métodos para lograr que el estudiante aprenda. Claro esto no es tan fácil, máxime en salones con tantos estudiantes con problemáticas sociales complejas y diversas.

2. ¿Cuáles son los beneficios que genera la incorporación y uso de una wiki en el trabajo cooperativo de la clase de Biología?

Respuesta: bueno, como lo dije antes, vemos que con la wiki se genera trabajo cooperativo, esto permite que los estudiantes aporten lo que en su momento ellos creen, pero también de acuerdo a lo que ellos van trabajando allí, a la información que investigan, que leen y organizan de acuerdo al desarrollo de los trabajos en la wiki, ellos van puliendo sus conceptos, entre todos se ayudan y tratan mutuamente de aclararse dudas, así, ellos van formando y reformulando las ideas que ellos tienen para construir un concepto un poco más aproximado a lo científico porque pueden discutir en cualquier momento con sus compañeros y docente, tienen la disponibilidad de buscar esta información en el momento que consideren conveniente y tienen la oportunidad de leer lo que sus otros compañeros van realizando, lo que los anima también a participar y todo estos insumos les permite interactuar de mejor manera y generar discusiones más enriquecedoras en sus equipos de trabajo. Así los integrantes de cada equipo se ayudan mutuamente, se evalúan, respetan los aportes de todos y tratan de mejorar sus producciones. Claro está, cuando hay responsabilidad y entendimiento entre los grupos de trabajo. Esto permite una evolución en las ideas, en el concepto y ya después pueden hablar en términos científicos en la misma terminología de la Biología para la comprensión de sus ideas y su posterior socialización con el docente y con el grupo en general. Lo anterior, siempre y cuando los alumnos comprendan y tengan presente la dinámica del trabajo cooperativo. Así, no solo los estudiantes pueden expresar sus ideas, sino que también están son tenidas en cuenta o refutadas de forma respetuosa, los estudiantes aprenden a comunicarse sin pelear y a entender que no todo lo que escriben y piensan es correcto o aceptado por sus compañeros. Por otra parte, digamos que si un estudiante no tiene la voluntad de trabajar, de estudiar y buscar información y la responsabilidad para hacerlo, resulta muy complicado generar ese trabajo cooperativo y esto puede 
llegar a generar un desánimo en los equipos de trabajo, al observar que sus compañeros no aportan, ni editan nada, como sucedió con algunos alumnos en nuestro caso particular. Por más guías e intentos de los compañeros y el docente la parte volitiva juega un papel primordial, así como las habilidades lecto escritoras que los estudiantes deben manejar, resultan muy importantes para trabajar en la wiki. La wiki estimula las actividades cooperativas, de alguna manera hace que recobre importancia el papel activo que deben tener los estudiantes, los motiva a participar pero los alumnos deben aprender también a reconocer las habilidades de sus compañeros para no entrar en conflicto, así como acostumbrarse a trabajar con cualquier compañero, y a reconocer mutuamente cuál es la mejor forma de trabajar juntos, de tal suerte que cumplan responsablemente con los requerimientos de cada actividad. Mmmm, también pienso que de pronto al realizar las actividades cooperativamente hay aspectos que manejan los estudiantes que a veces dificultan como tal, el trabajo que se planteaba a través de la wiki. Por ejemplo sus discrepancias en pensamiento o por amistades o hasta familiares hacían que ellos rechazaran trabajar con uno u otro compañero y esto complicaba el manejo de las actividades. Cuando en los grupos no se presentan tantas diferencias y logran empatía entre sus integrantes, digamos que la wiki les posibilita trabajar cuando ellos así lo quieren o pueden tanto de forma presencial como virtual, se apoyan mutuamente en las actividades cooperativas, tienen definidos claramente sus roles y los hacen cumplir, se nota una interacción más frecuente y productiva, comparten no solo conocimientos sino que aprenden y socializan experiencias personales, que los sensibiliza y les ayuda a ser más amigables y respetuosos entre ellos. Además se veía que se preocupaban un poco más por escribir adecuadamente. Se daban cuenta fácilmente cuál compañero no hacía aportes y entre ellos mismos se juzgaban, con eso, algunos estudiantes aprendieron a aceptar con respeto lo que se decían, aunque a veces no les guste mucho escuchar o leer las opiniones de sus compañeros cuando estas no son muy positivas.

Por otro lado pienso que el aprendizaje cooperativo no se logra de un momento para otro, el tiempo ayuda a que los grupos se vayan ajustando y sus integrantes digamos aprendan a conocerse, a reconocerse, y así las interacciones y producciones cada vez sean mejores.

Yo lo veo muy interesante. 
3. ¿Cree usted que el trabajo que se desarrolla a través de la wiki refuerza y complementa lo aprendido de forma presencial? Justifique su respuesta.

Respuesta: si, el trabajo que se desarrolla a través de la wiki permite reforzar y complementar lo aprendido presencialmente porque no se trata solamente de una fuente de información que es el docente y el concepto que el emite sino que permite al estudiante interactuar con diferentes fuentes y de diferente forma, ya no solo sincrónicamente sino también asincrónicamente, no solo verbal, sino escrito y toda esa información adquirida poder digamos relacionarla y contrastarla para tener una idea más clara del concepto que se pueda trabajar. Igualmente el estudiante tiene la oportunidad de analizar lo que sus compañeros hacen en la wiki y compararlo con lo que ellos hicieron, esto les ayuda a mejorar si así lo quieren.

4. ¿Cuáles son los beneficios principales, derivados del uso de la wiki en el aprendizaje de la Biología?

Respuesta: bueno, particularmente creo que la wiki es una herramienta que sirve de apoyo tanto al docente como al estudiante en el proceso educativo porque el docente tiene una forma diferente de presentar los contenidos, y de proponer diversas actividades y de incentivarlos a consultar otras fuentes de información, puede generar interacciones con el estudiante mientras que el estudiante tiene una forma diferente de comunicarse tanto con sus compañeros como con su profesor. Otro de los beneficios que podría hacer que los estudiantes ehh, cuando se encuentran ellos digamos un equipo sólido como tal, ehh pueden entre ellos mismos aportar ideas y esas ideas entre ellos mismos también van diciendo que tan cerca o que tan lejos están del concepto, también permite interactuar con la realidad, y ahora que digamos estamos con la parte tecnológica, y que a ellos les encanta, entonces agiliza eso y los acerca en parte a este mundo de la tecnología y les muestra la utilidad de usar esto en lo académico en cuanto a construcción del conocimiento y al interactuar con diferentes estudiantes en cualquier momento y forma. Asimismo pueden ser leídos por otros, acceder a lo que otros hacen y compartir criterios y esto les puede ayudar a ser más activos, reflexivos en cuanto a lo que aprenden y puede llevarlos a querer mejorar. Creo además que con esto pueden llegar a desarrollar habilidades que tienen que ver con el pensamiento crítico y les puede facilitar la búsqueda de apoyo cuando no comprenda algo. Por último se convierte en una alternativa para los padres que no están de acuerdo en que sus hijos deban ir a las casas de los 
compañeros a hacer tareas, sin embargo en este caso hay que trabajar más en la concientización tanto de padres como de hijos para que no haya inconvenientes futuros.

5. ¿Cuál fue la reacción o actitud de los estudiantes al enfrentarse a esta nueva forma de trabajo con la wiki?

Respuesta: bueno, varias actitudes, podemos hablar de unas positivas que yo las veo, es que cuando al estudiante se le dice que vamos a trabajar en el computador le gusta, él quiere hacerlo, cuando el estudiante uno le dice que puede interactuar o visitar páginas correspondientes a la temática, pues también se motiva a veces ven videos que de pronto quieren compartir con la otra persona, en el momento que ellos ven sus aportes también les gusta y mostrarle a los compañeros las cosas buenas que ellos han realizado, también el hecho que ellos puedan descargar estas aplicaciones a sus teléfonos celulares lo ven increíble y se ve el ánimo por participar en los foros con sus compañeros pero desde sus dispositivos, en esos aspectos es muy bueno, pero hay otros aspectos en cuanto a que no funcione bien digamos el sistema o se caiga la línea la parte de Internet entonces eso sería un poco negativo en cuanto al desarrollo del proceso y también digamos las condiciones que se deben tener en cuanto a la sala de internet que de pronto como en nuestro caso no tiene buen aire, entonces ellos se sienten un poco incómodos por el calor porque están allí y esto genera actitudes de rechazo frente al apoyo. Otra cuestión es cuando no tienen la posibilidad de acceder a un equipo de cómputo e internet entonces ellos se sienten en desventaja con sus compañeros y rechazan este tipo de trabajos con la wiki. Igualmente cuando las actividades cooperativas deben realizarlas con compañeros que a ellos no les gustan, eso se vuelve traumático y a veces hay conflictos. En ese sentido hay mucho por mejorar.

6. ¿Cuáles fueron las dificultades o problemas más comunes que usted enfrento al usar la wiki como apoyo tecnológico para la enseñanza de la Biología y para dar seguimiento al trabajo cooperativo de sus alumnos?

Respuesta: las dificultades que enfrente al usar la wiki fue en un principio el manejo de la herramienta y el seguimiento al trabajo que los estudiantes desarrollan en ella, requiere de tiempo, y de habilidades, el poder organizar la información y tratar de que sea atractiva para los estudiantes, el manejo de volúmenes de participaciones. Mejor dicho, el maestro tiene que manejar bien la herramienta y saber que 
habilidades busca realmente que sus estudiantes desarrollen a partir de la wiki para que guíe adecuadamente y en el tiempo preciso las participaciones a los estudiantes, y les ayude a que aterricen las ideas que expresan en los foros y le den forma y sentido a lo que construyen de forma grupal. También que los alumnos no estaban acostumbrados a esa clase de recursos audiovisuales y que de pronto en un primer momento todo se les dificulta. Y ellos quieren que instantáneamente todo se resuelva. A esto se le suma las incomodidades del aula de sistemas asignada para este trabajo, hace que los estudiantes les dé pereza ingresar en la wiki, participar en los foros, además, porque es un lugar completamente cerrado con techo de Zinc y no tienen aire, bueno, la velocidad que se maneja es muy baja y los computadores que nosotros tenemos allí, requieren actualización, entonces los estudiantes se desmotivan, mientras aparece la página, mientras rueda el video, entonces es un distractor bastante fuerte, que de cierta manera contribuye a que los estudiantes pierdan el interés por la clase y la interacción con el profesor.

7. ¿Cuáles fueron las dificultades o problemas más comunes que enfrentaron los estudiantes al usar la wiki?

Respuesta: bueno, las dificultades o problemas más comunes que enfrentaron los estudiantes al usar la wiki fue que al principio, para que los estudiantes ingresaran en la wiki pues había que asignarles un nombre de usuario, ellos con ese código pues tenían que ingresar y al hacerlo en muchos casos los estudiantes no lo lograban y decían, profe no, no me abre, profe no esto y lo otro. Y pues al hablar con el ingeniero de acá al respecto, el me comentaba que la velocidad era mínima, muy lenta la llegada de la señal, entonces para que la página se descargue había que esperar y después de tanta espera, a veces, pues como quien dice los sacaba del sistema, entonces eso que hablábamos ahorita se convirtió en una de las grandes dificultades que hace que el proceso de trabajo se vea como un poco frenado y no fluye como bien lo programado. Además hay estudiantes que tienen dificultades con las habilidades tecnológicas y lecto escritoras y estas son necesarias para el trabajo en la wiki. Como nosotros conocemos hay diferentes estudiantes de pronto unos un poco más concentrados un poco más distraídos, los aspectos o dificultades que mencioné anteriormente contribuye a que los estudiantes que son como distraídos se 
disipen y pierdan el interés sobre el trabajo que nosotros debemos realizar con ellos y hagan que los más juiciosos también comiencen a desmotivarse.

Como de alguna manera lo mencioné anteriormente, debido a que los estudiantes no están acostumbrados a manejar estas herramientas, el acostumbrarse a que deben saber su nombre de usuario y contraseña fue una dificultad frecuente, así como la forma de escribirlo. Esto entorpeció las interacciones entre los compañeros y hasta conmigo, mejor dicho con el docente.

El poder ingresar a sus páginas de trabajo en equipo y el aprender a editar, subir imágenes, vídeos, cambiar el formato de la letra, participar en el foro pertinente, todo esto, en un principio se les hizo difícil pero poco a poco esto cambió. Otro aspecto muy relevante es la desmotivación que les causa que sus compañeros no hagan los aportes, o que si los hacen sean inadecuados o fuera de tiempo o que simplemente no participen en nada. En este sentido considero como docente que debo planear más espacios de reflexión con los grupos para que juntos resolvamos este tipo de inconvenientes, y si es el caso retirar de la dinámica de grupos a aquellos alumnos que no obstaculizan el proceso de aprendizaje cooperativo y para quienes uno debe tener listo un nuevo plan de trabajo que les ayude a inmiscuirse en su propio aprendizaje. Además generar el espacio para que los alumnos también capitalicen y celebren lo bueno ellos que hacen y los logros obtenidos.

8. ¿Se generaron conflictos durante la comunicación o desarrollo de las actividades propuestas en la wiki? ¿Cómo se resolvieron esos conflictos?

Respuesta: bueno, se generaron algunos conflictos durante la comunicación y en el desarrollo de las actividades propuestas en la wiki porque no todos los estudiantes de un mismo equipo lograron ingresar al mismo tiempo a trabajar en dichas actividades, entonces ellos se acusaban de que no ingresaban por pereza. Claro está, que esto se había convertido en la excusa perfecta para no trabajar, pero les demostré que esto no era cierto y les indiqué que simplemente debían asumir una actitud más responsable y honesta. También detecté que en ocasiones la dificultad en el ingreso y en el desarrollo de las actividades no era producto de la pereza o irresponsabilidad sino que había alumnos que tenían pocas destrezas para el manejo de equipos de cómputo y dificultades en la búsqueda de información y esto hacía que los compañeros se sintieran disgustados porque perderían tiempo si tenían que explicarles. Este tipo de 
conflictos se resolvían fácilmente porque se explicaba que la dinámica del cooperativismo es precisamente superar esas dificultades como equipo y garantizar que todos se ayudaran mutuamente y definieran roles y tareas adecuadas para cada integrante. Y en este sentido se les guía bastante.

Otro es en el manejo correspondiente al sistema como tal que ya lo mencionamos por la baja velocidad que tenemos aquí y lo otro que se puede enfatizar es que hay unos estudiantes que no forman como tal equipo de trabajo, no tienen buena comunicación como entre ellos, entonces por lo tanto al crearse el grupo y que ellos estén en ese grupo, pues van a trabajar pero no de una forma armónica, constructiva para ellos, sino que cada uno da su aporte pero ese aporte a veces no cumple ni con la forma ni el tiempo establecido, y no hay como la empatía para dialogar al respecto, así que a veces no es tenido en cuenta y esto ocasiona inconvenientes al interior de los grupos. Por otro lado, es necesario que los aportes de cada integrante sean analizados por todos y estos generen la interacción necesaria para que lleguen a acuerdos y tomen decisiones de conjunto de grupo y puedan en su mismo momento compartirlos. De allí, que aquellos casos de estudiantes que no tienen ningún compromiso por su aprendizaje y poco les interesa realizar una actividad académica, debido en ocasiones a dificultades personales y sociales, incrementan los desacuerdos al interior de los grupos y las actividades cooperativas se ven afectadas por estas discusiones que se presentan. A veces pienso que la institución debe analizar el componente social y afectivo de muchos de los estudiantes porque esto es un factor difícil de manejar y que genera obstáculos en los procesos de enseñanza aprendizaje con o sin apoyos tecnológicos.

Cuando uno como docente observa que el alumno no está aportando le envía un mensaje en el foro o se le llama y se habla con el alumno y con su grupo, sin embargo en muchas ocasiones el estudiante no tiene la voluntad o convicción de trabajar. Y expresan no interesarles hacer nada. Es complicado resolver estas situaciones que requieren de otros manejos. De todas formas se les indica a los grupos que estas actitudes no influirán en sus notas porque se salen de su manejo.

9. ¿Cree que un AVA como la wiki debería ser incorporado en el currículo, para la enseñanza de la Biología en todos los grados de secundaria?

Respuesta: una wiki debería ser incorporada en el currículo para la enseñanza de Biología no solo desde secundaria sino desde la primaria ya que efectivamente en primaria es donde se debe enmarcar 
básicamente el estudio y el desarrollo del pensamiento científico y crítico y allí puede iniciarse la sensibilización del manejo y el buen uso de la Internet y de la comprensión de saber que existen diversidad de herramientas que los pueden ayudar en su proceso de aprendizaje. Desde mi posición, creo que es posible y deberíamos estar trabajando en ello. Mnnnn, pero es indispensable para ello cambiar primero la dinámica Institucional, los directivos deben convencerse de que hay que hacerlo y destinar los recursos requeridos para ello, pero a su vez también los docentes debemos estar en disposición de ser capacitados y dedicar tiempo para implementar lo aprendido. De esta manera podemos lograr que sea cotidiano tanto para docentes como para estudiantes usar diferentes programas y herramientas educativas que medien los procesos de enseñanza aprendizaje. Creo que sería un aporte muy significativo y bueno y prudente digamos la incorporación de esta wiki porque sirve de apoyo para el docente en su planeación y en su organización de las clases y eso también ayuda en la parte digamos de la didáctica porque el estudiante ya no va a estar encasillado solo en lo tradicional en un puesto solo oyendo al docente o leyendo solamente allí sino que el mismo a través de la wiki va hacer participativo en la construcción de su conocimiento. Y dado que el conocimiento evoluciona y se adquiere de diferentes formas e implica diferentes disciplinas pues me parece que si deben estudiarse las mejores maneras de organizar en primera instancia el currículo para que sea considerado dentro de este, y mmm, pues así también involucrar y educar a los docentes en este sentido para que poco a poco se logren cambios significativos. Claro, reitero, con el compromiso directivo y estatal que esto requiere.

10. ¿Considera que la Institución cuenta con la infraestructura apropiada para desarrollar clases virtuales con este tipo de apoyo tecnológico?, ¿cómo la mejoraría?

Respuesta: desafortunadamente en la institución no hay suficientes recursos físicos ni tecnológicos para llevar a cabo clase con este tipo de apoyos tecnológicos. En nuestra institución no estamos digamos a la vanguardia, los computadores que pueden ser usados por otras áreas son muy viejos. No hay una logística apropiada de uso para los equipos relativamente modernos. Actualmente han llegado también unas tabletas pero no hay una red Wi-Fi robusta que logre abarcar a todo el colegio y que garantice el buen funcionamiento de estos aparatos. Tampoco han sido entregados oficialmente, así que no pueden usarse. Además de la falta de claridad sobre las responsabilidades de su uso, de tal manera que se 
descarga toda la responsabilidad al docente por los daños, lo que conlleva a que se opte por no usar lo poco que hay. En cuanto a la parte digamos del ambiente como tal, la sala destinada para clases diferentes de informática es relativamente pequeña para el número de estudiantes y carece de aire acondicionado, esto hace que los estudiantes a partir de ciertas horas no quieran estar alli porque se siente sofocados, esto no ayuda a que ellos se concentren a trabajar. Aquí lo ideal sería potencializar los recursos existentes, bajo la consideración que no solo el área de tecnología es el que puede hacer uso de estos instrumentos, esto con el fin de acercar desde las escuelas y desde diferentes áreas a los estudiantes a ese mundo virtual. Y que lo conozcan y lo trabajen para beneficiar la adquisición y construcción de conocimiento y no solo de esparcimiento, como es el uso normal que ellos le dan. También puede ayudar que los docentes se formen en este sentido así se crea mayor necesidad y se dan más ideas de mejoramiento.

11. ¿Cuáles son los principales valores y habilidades que se desarrollan a través del uso de la wiki en la clase de Biología?

Respuesta: los principales valores que considero se desarrollan a través del uso de la wiki, es la responsabilidad enfocada tanto en el buen uso de esas ayudas tecnológicas como en el cumplimiento de los compromisos que se adquieren en todo el proceso de realización de las actividades. Otro valor que pienso se desarrollan es el respeto a las ideas, a las formas de ser y de trabajar que tienen los diferentes integrantes de un equipo y del salón en general. También se fortalece la honestidad porque no se trata de copiar sino de producir, claro esto no se desarrolla inmediatamente pero poco a poco sus comportamientos hacen notar progresos en este sentido. Los estudiantes también son más cordiales en el trato con sus compañeros, aunque claro, también no falta el estudiante que se vuelve grosero por el incumplimiento de otro. Desde el punto de vista de las habilidades, mmm, creo que se desarrollan, de hacer bien las cosas unas habilidades tecnológicas, para poder manejar el apoyo de forma adecuada y rápida, también se desarrollan habilidades lingüisticas y sociales porque para poder interactuar adecuadamente con otros y participar es necesario tenerlas. Ehh, también veo que se mejora paulatinamente la búsqueda, organización y análisis de la información sobre Biología en este caso específico sobre reproducción. 
12. ¿Considera que al utilizar la wiki, los estudiantes tuvieron una participación más activa en la clase de Biología? Justifique su respuesta.

Respuesta :con el uso de la wiki la participación es activa a nivel individual, pero a nivel grupal varía, hay participación siempre y cuando se presente un buen ambiente entre los integrantes del grupo, digámoslo, allí, se suele presentar que intenten estar cooperando ellos, pero si se presentan conflictos o diferencias en lo personal, y el ambiente de trabajo ya no es de familiaridad, de que la van bien digámoslo así, con ese término, entonces la participación se ve afectada, algunos intentarán trabajar, pero la motivación, el interés y disposición para participar se va a ir un poquito para abajo porque eh por ejemplo al escribir ellos no van a, a opinar sobre lo que el compañero realiza, no se apoyan ni ayudan a construir o a mejorar lo que el otro está haciendo, entonces yo pienso que nosotros aparte de hacer uso de la wiki debemos también hacer unos planes de apoyo o programas donde al estudiante lo formemos para trabajar cooperativamente en grupo y que este grupo sea un grupo de apoyo para los que lo conforman y poder avanzar entre ellos y que no se limite solamente a estar en ese grupo sino que los alumnos puedan cambiar de grupo en cualquier momento sin que esto sea traumática, entonces tenemos que digamos pasar esas barreras. Una vez superadas pienso que la participación en las clases de Biología se ve favorecida por el uso de la wiki y en la medida que haya más participación, hay más interacción, se incrementan las posibilidades de que se aclaren dudas se consigan mejores desempeños porque unos ayudan a los otros y se comprometen con su propio aprendizaje, hay autogestión y con ello más garantías de aprender Biología de manera conjunta y los estudiantes sientan que se les facilita aprender Biología, ven la adquisición y construcción de conocimiento de una forma sencilla y agradable. 13. ¿Considera que la participación de los equipos de trabajo en el entorno virtual, favorece la construcción del conocimiento de manera interactiva? Detalle sus razones.

Respuesta: si, considero que la participación de los equipos de trabajo en el entorno virtual favorece la construcción del conocimiento, porque como lo he expresado con anterioridad en mis intervenciones, pienso que el hecho de que los equipos y sus integrantes aprendan a apoyarse mutuamente y a interactuar y compartir sus ideas y elaboraciones de manera responsable y crítica, les ayuda positivamente para la construcción del conocimiento. Esto sí, teniendo o considerando el manejo de unas condiciones 
apropiadas para que la construcción pueda lograrse. Pienso que para los grupos actuales de trabajo se puede dificultar ya que aún, los estudiantes manejan unos conceptos un poco equivocados del trabajo y aprendizaje cooperativo, algunos estudiantes son muy individualistas, otros muy tranquilos, otros creen que trabajar cooperativamente es esperar a que el piloso haga todo y los otros copien porque así les va mejor. De tal manera que al estar muy arraigadas estas ideas considero que cada uno optaría por un beneficio propio y en ese caso se haría necesario trabajar fuertemente en sensibilizar para el trabajo cooperativo y que los docentes de manera conjunta promuevan las actividades cooperativas, con ello se puede favorecer el desarrollo de los aprendizajes que ayuden a lograr la construcción conjunta del conocimiento de forma virtual.

14. ¿En su opinión, considera que el uso de la wiki facilita el aprendizaje de la Biología en los alumnos de $8^{\circ}$ grado? Justifique su respuesta.

Respuesta: Sí, digamos que el aporte de la wiki es significativo siempre y cuando pues como todo se reúnan las condiciones para trabajar con ella, pero como tal, diseñar la wiki nos facilita la organización de actividades para desarrollar con los estudiantes porque la wiki va a servir como de una guía, de una una guía de apoyo al docente pero un poco más interactiva donde el estudiante puede estar eh actuando con sus compañeros, actuando con la fuente y actuando con el conocimiento y a la vez con el docente entonces todo esta parte de interacción entre otros aspectos hace que que ehh circule conocimiento y sea un poco más dinámico y no tan estático como cuando se está de pronto sentado en un solo puesto. Con la wiki los docentes pueden generar vínculos que lleven a los estudiantes a sitios como Eduteka, las bibliotecas virtuales, laboratorios virtuales, juegos, sopas de letras, en fin, se le puede ofrecer muchas opciones a los estudiantes para que estudien y aprendan, cuando nosotros podemos dar opciones y cuando al muchacho accede a estas opciones se le guía, se les motiva, esto ayuda a que él se interese más y se interese más por la asignatura, por lo que está viendo y se interese más por hacer el trabajo y en grupo todavía más cuando ellos están construyendo algo para ellos mismos, entonces esto contribuye enormemente al aprendizaje de la Biología. Por otro lado el uso de las rúbricas de evaluación es un aspecto muy importante que no se utilizado en la institución, y que las veo como instrumentos de seguimiento a favor del estudiante que tiene la posibilidad de conocer de antemano como va a ser 
valorado, los aspectos relevantes que deberá tener en cuenta al momento de desarrollar las actividades, aprenderá a reconocer la importancia de sus aportaciones y del trabajo cooperativo que se desarrolle en los equipos así como de los aprendizajes que se espera debe alcanzar. Además, el estudiante adquiere herramientas o habilidades que ayudan a mejorar sus desempeños académicos, yo lo vería o lo veo desde ese punto.

Por otro lado con la wiki se facilita el trabajo cooperativo y por tanto el aprendizaje cooperativo lo cual es sumamente provechoso para que aprendan Biología, además hay algo muy interesante y es cuando digamos por motivos digamos de distancias u otro motivo no se pueden encontrar, pero tienen la posibilidad de acceder en el mismo horario, juntos pueden leer de Biología, aclararse dudas, compartir conocimientos, que se pongan de acuerdo ellos para poder interactuar allí es bueno, aunque, eso eh requiere de una disciplina de los estudiantes y los padres de familia que nos apoyen bien en ese aspecto que ellos van a trabajar en eso, porque a veces los padres de familia ven que el estudiante esta muchas horas en internet pero no conocen que realmente está haciendo un trabajo, entonces tendríamos que digamos en ese sentido ponernos de acuerdo todos para ah que vaya funcionando ese aspecto porque si no pues ahí nos vemos un poco limitados por que el estudiante puede decir que el papá o la mamá le dijo que no trabajara. Digamos el hecho de que eh no se vea pero si se ven, o sea no están físicamente pero si están interactuando en el sistema virtual es bueno, porque de alguna manera se le está dado la posibilidad de aprender en horarios diferentes de la clase, de pedir apoyo, de mostrar avances en diferentes momentos. Los estudiantes aprendan que no solamente entre ellos se interactúa virtualmente si no que se puede interactuar virtualmente con otros estudiantes, de otros colegios, de otros municipios, inclusive de otros países siempre y cuando guardando digamos las condiciones de seguridad que debe tener, eso también ayuda a que los muchachos despierten ese interés por conocer nuevas ideas. Todo ello es benéfico en los procesos de aprendizaje de la Biología de los estudiantes.

15. ¿Recomendaría a sus compañeros docentes el uso del AVA en la enseñanza de la Biología y en general, para cualquier otra asignatura de secundaria? Justifique su respuesta.

Respuesta: bueno, yo si recomendaría a mis compañeros el, el, este, este tipo de AVA como la wiki siempre que hayan los recursos físicos por parte de la Institución educativa y que se capaciten a los 
docentes y la institución entienda que implementar estrategias pedagógicas que tengan en cuenta este tipo de apoyos tecnológicos no es una tarea que se logra de la noche a la mañana así como la aceptación gradual de los estudiantes a trabajar con ellos

Es interesante que nosotros como docentes sepamos manejar diferentes apoyos tecnológico eso nos ayuda a soltarnos un poquito de manejar todo el tiempo solo el lenguaje del texto, y ya dejemos que entre la parte de la tecnología, que nos permite igualmente enriquecer nuestros conocimientos y estrategias didácticas, porque también tenemos oportunidad de interactuar con otros compañeros en otros momentos, de otros lugares e instituciones compartir lo que hacemos y enriquecernos pedagógicamente, con eso también mejoramos las interacciones con nuestros estudiantes. 


\section{Apéndice M: Evidencias fotográficas del trabajo de campo}

Evidencias fotográficas de las clases observadas
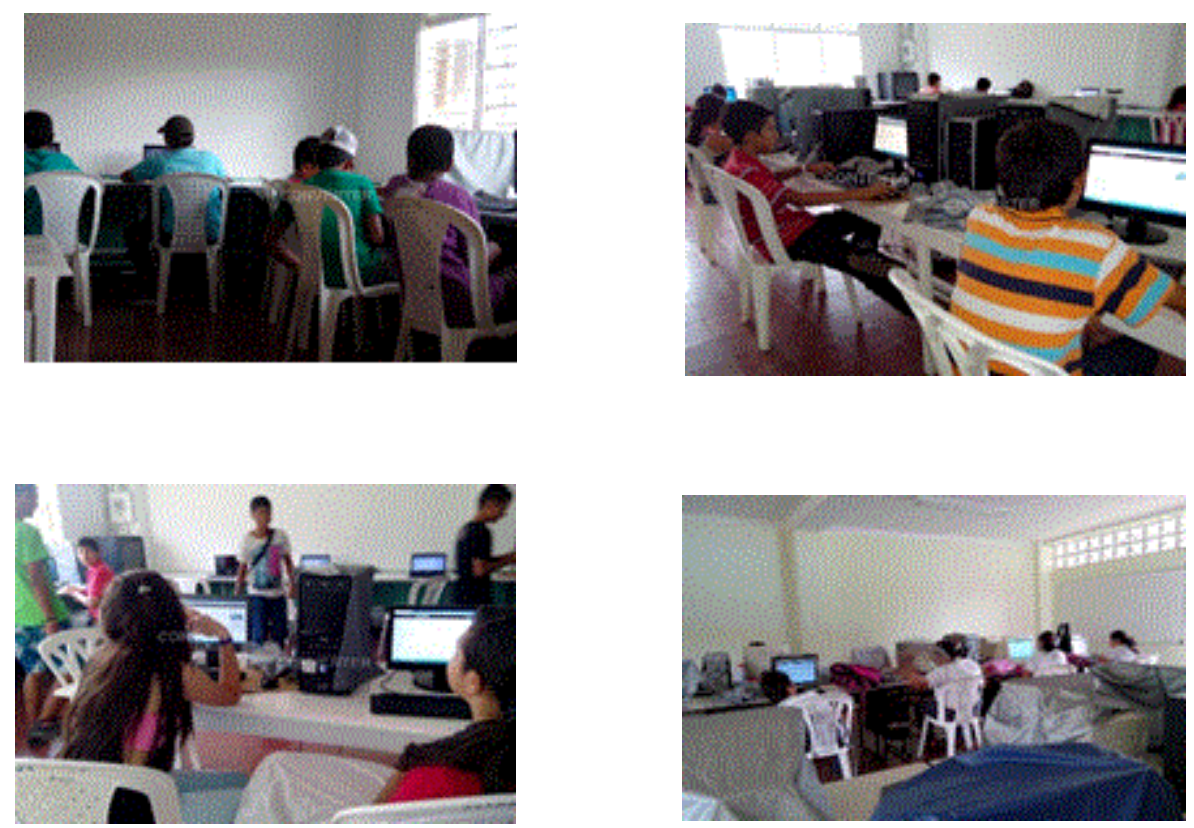

Evidencia fotográfica de la entrevista al maestro titular del grupo experimental

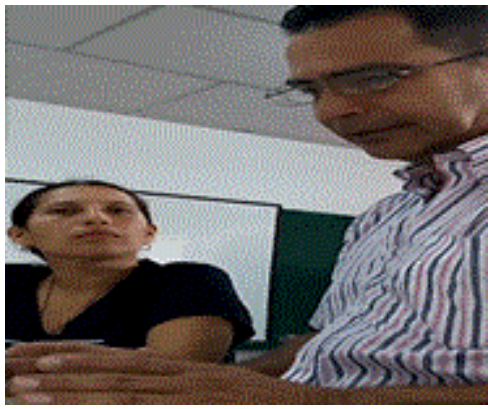


Evidencias fotográficas de la preprueba aplicada a los alumnos
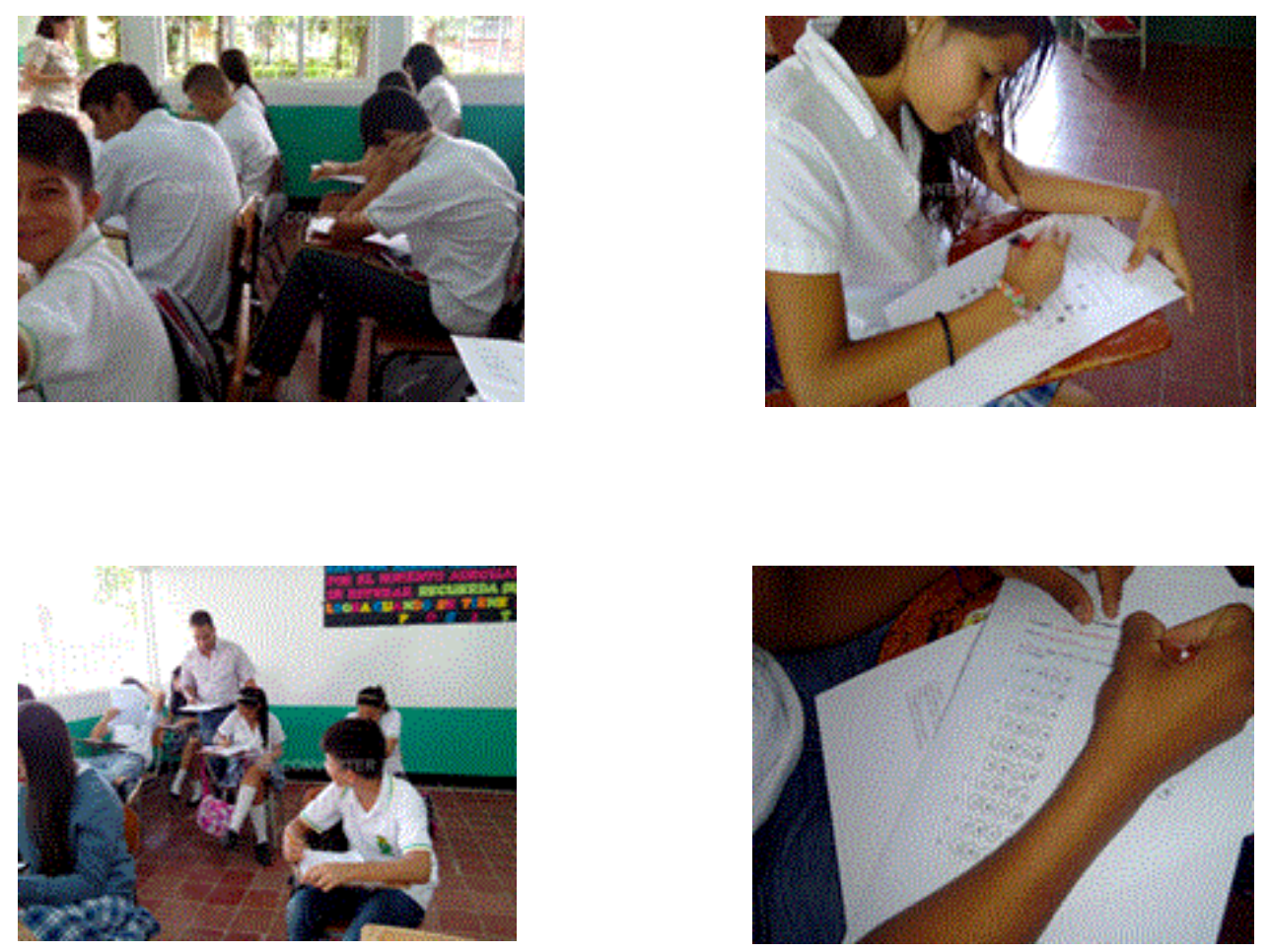
Evidencias fotográficas de la posprueba aplicada a los alumnos
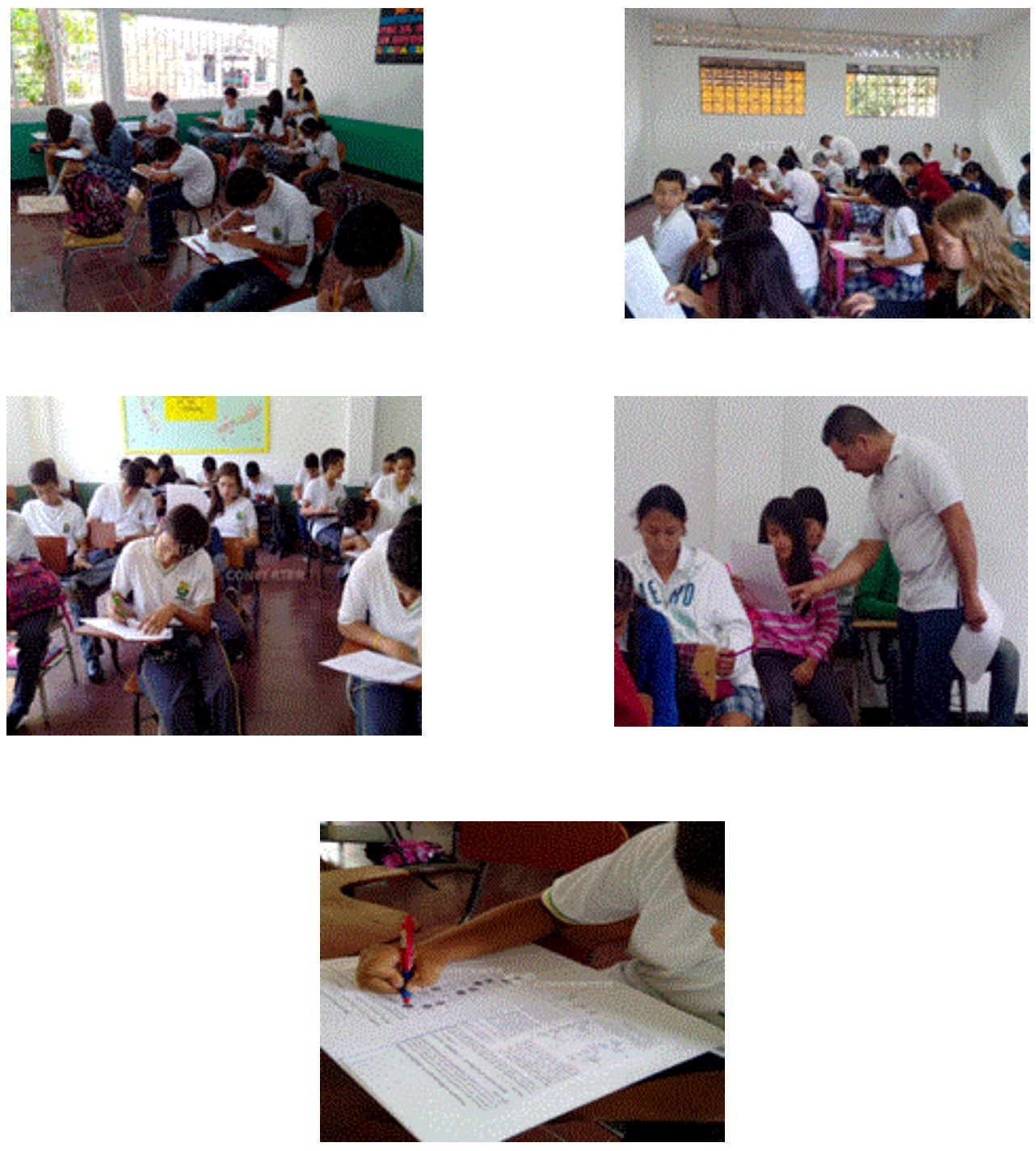
Evidencias fotográficas correspondientes a la encuesta aplicada al grupo experimental
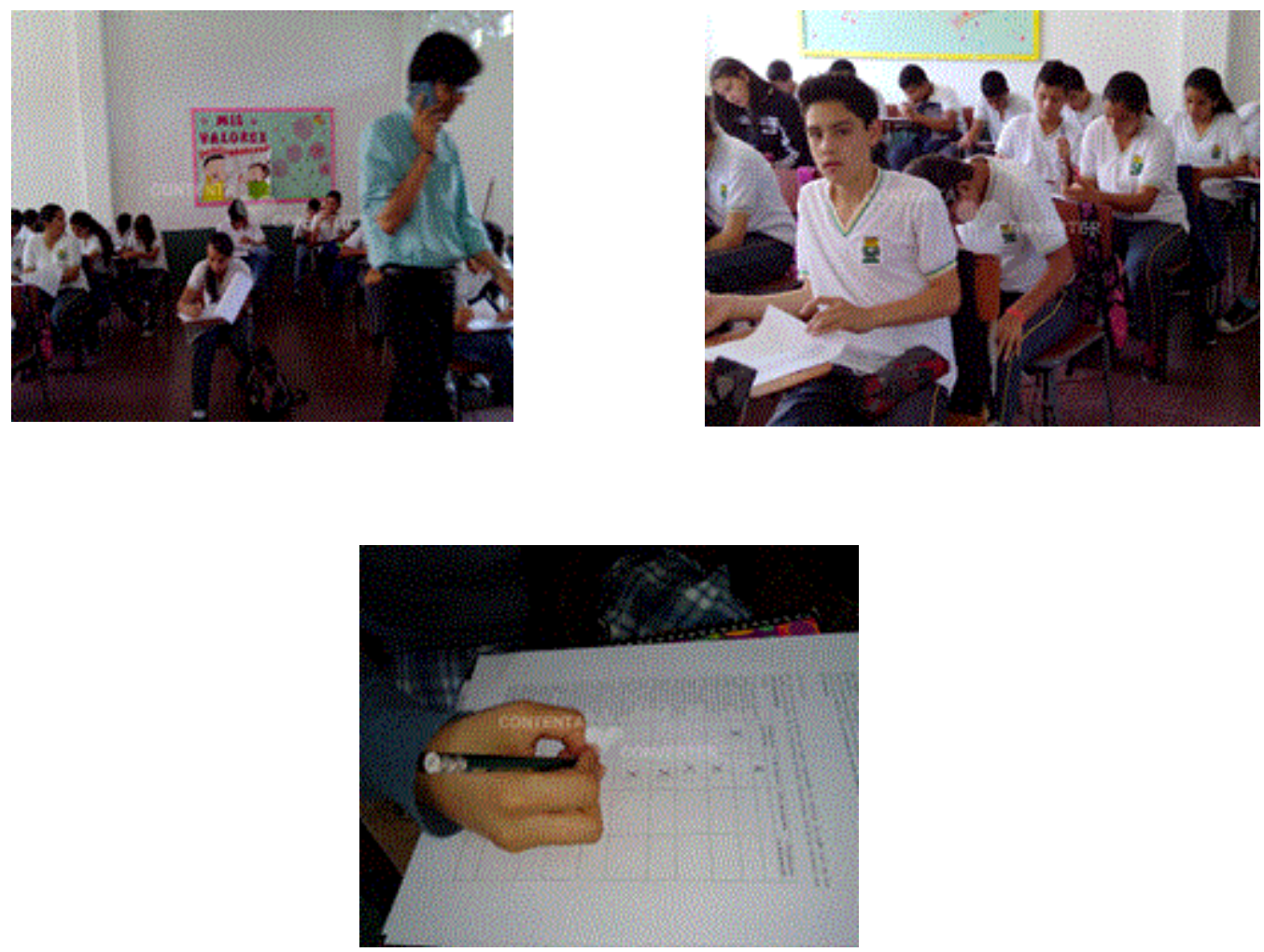


\section{Apéndice N: Datos aclaratorios de los resultados de la encuesta}

\begin{tabular}{|c|c|c|c|c|c|c|c|}
\hline $\begin{array}{c}\text { Ítems (frases } \\
\text { representativas) }\end{array}$ & $\begin{array}{l}\text { Alternativas } \\
\text { de respuesta }\end{array}$ & Media & Mediana & Moda & Rango & Varianza & $\begin{array}{c}\text { Desviación } \\
\text { estándar }\end{array}$ \\
\hline \multirow{4}{*}{$\begin{array}{l}\text { 1. Facilidad en } \\
\text { aprendizaje de } \\
\text { Biología con la } \\
\text { wiki }\end{array}$} & $\begin{array}{l}\text { 1.Totalmente } \\
\text { en desacuerdo }\end{array}$ & \multirow{4}{*}{3} & \multirow{4}{*}{4} & \multirow{4}{*}{4} & \multirow{4}{*}{3} & \multirow{4}{*}{0.9} & \multirow{4}{*}{0.9} \\
\hline & $\begin{array}{l}\text { 2. En } \\
\text { desacuerdo }\end{array}$ & & & & & & \\
\hline & 3. De acuerdo & & & & & & \\
\hline & $\begin{array}{l}\text { 4.Totalmente } \\
\text { de acuerdo }\end{array}$ & & & & & & \\
\hline \multirow{4}{*}{$\begin{array}{l}\text { 2.Mayor } \\
\text { aprendizaje de } \\
\text { Biología con la } \\
\text { wiki }\end{array}$} & $\begin{array}{l}\text { 1.Totalmente } \\
\text { en desacuerdo }\end{array}$ & \multirow{4}{*}{3} & \multirow{4}{*}{3} & \multirow{4}{*}{4} & \multirow{4}{*}{3} & \multirow{4}{*}{0.6} & \multirow{4}{*}{0.8} \\
\hline & $\begin{array}{l}\text { 2. En } \\
\text { desacuerdo }\end{array}$ & & & & & & \\
\hline & 3. De acuerdo & & & & & & \\
\hline & $\begin{array}{l}\text { 4. Totalmente } \\
\text { de acuerdo }\end{array}$ & & & & & & \\
\hline \multirow{4}{*}{$\begin{array}{l}\text { 3. Contenidos de la } \\
\text { wiki agradables y } \\
\text { fáciles de } \\
\text { comprender }\end{array}$} & $\begin{array}{l}\text { 1.Totalmente } \\
\text { en desacuerdo }\end{array}$ & \multirow{4}{*}{3} & \multirow{4}{*}{3} & \multirow{4}{*}{4} & \multirow{4}{*}{2} & \multirow{4}{*}{0.5} & \multirow{4}{*}{0.7} \\
\hline & $\begin{array}{l}\text { 2.En } \\
\text { desacuerdo }\end{array}$ & & & & & & \\
\hline & 3. De acuerdo & & & & & & \\
\hline & $\begin{array}{l}\text { 4.Totalmente } \\
\text { de acuerdo }\end{array}$ & & & & & & \\
\hline \multirow{4}{*}{$\begin{array}{l}\text { 4. Mejores } \\
\text { resultados al } \\
\text { trabajar } \\
\text { cooperativamente. }\end{array}$} & $\begin{array}{l}\text { 1.Totalmente } \\
\text { en desacuerdo }\end{array}$ & \multirow{4}{*}{3} & \multirow{4}{*}{3} & \multirow{4}{*}{4} & \multirow{4}{*}{2} & \multirow{4}{*}{0.5} & \multirow{4}{*}{0.7} \\
\hline & $\begin{array}{l}\text { 2.En } \\
\text { desacuerdo } \\
\end{array}$ & & & & & & \\
\hline & 3. De acuerdo & & & & & & \\
\hline & $\begin{array}{l}\text { 4. Totalmente } \\
\text { de acuerdo }\end{array}$ & & & & & & \\
\hline \multirow{4}{*}{$\begin{array}{l}\text { 5. Comunicación a } \\
\text { través de la wiki de } \\
\text { forma cordial y } \\
\text { respetuosa }\end{array}$} & $\begin{array}{l}\text { 1.Totalmente } \\
\text { en desacuerdo }\end{array}$ & \multirow{4}{*}{3} & \multirow{4}{*}{3} & \multirow{4}{*}{3} & \multirow{4}{*}{2} & & \\
\hline & $\begin{array}{l}\text { 2.En } \\
\text { desacuerdo }\end{array}$ & & & & & 0.4 & 0.6 \\
\hline & 3. De acuerdo & & & & & & \\
\hline & $\begin{array}{l}\text { 4.Totalmente } \\
\text { de acuerdo }\end{array}$ & & & & & & \\
\hline & $\begin{array}{l}\text { 1.Totalmente } \\
\text { en desacuerdo }\end{array}$ & & & & & & \\
\hline $\begin{array}{l}\text { 6. Mejores } \\
\text { resultados al }\end{array}$ & $\begin{array}{l}\text { 2.En } \\
\text { desacuerdo }\end{array}$ & 3 & 4 & 4 & 3 & 0.7 & 0.8 \\
\hline trabajar & 3. De acuerdo & & & & & & \\
\hline & $\begin{array}{l}\text { 4.Totalmente } \\
\text { de acuerdo }\end{array}$ & & & & & & \\
\hline
\end{tabular}


Continuación del Apéndice $N$

\begin{tabular}{|c|c|c|c|c|c|c|c|}
\hline Ítems & $\begin{array}{l}\text { Alternativas } \\
\text { de respuesta }\end{array}$ & Media & Mediana & Moda & Rango & Varianza & $\begin{array}{c}\text { Desviació } \\
\text { n } \\
\text { estándar }\end{array}$ \\
\hline \multirow{4}{*}{$\begin{array}{l}\text { 7. La guía del } \\
\text { maestro facilita } \\
\text { realizar las } \\
\text { actividades en } \\
\text { la wiki. }\end{array}$} & $\begin{array}{l}\text { 1.Totalmente } \\
\text { en desacuerdo }\end{array}$ & \multirow{4}{*}{3} & \multirow{4}{*}{3} & \multirow{4}{*}{4} & \multirow{4}{*}{3} & \multirow{4}{*}{0.7} & \multirow{4}{*}{0.8} \\
\hline & $\begin{array}{l}\text { 2.En } \\
\text { desacuerdo }\end{array}$ & & & & & & \\
\hline & 3. De acuerdo & & & & & & \\
\hline & $\begin{array}{l}\text { 4.Totalmente } \\
\text { de acuerdo }\end{array}$ & & & & & & \\
\hline \multirow{4}{*}{$\begin{array}{l}\text { 8. La wiki } \\
\text { incrementa el } \\
\text { interés por } \\
\text { desarrollar las } \\
\text { actividades de } \\
\text { Biología. }\end{array}$} & $\begin{array}{l}\text { 1.Totalmente } \\
\text { en desacuerdo }\end{array}$ & \multirow{4}{*}{3} & \multirow{4}{*}{3} & \multirow{4}{*}{4} & \multirow{4}{*}{3} & \multirow{4}{*}{0.7} & \multirow{4}{*}{0.8} \\
\hline & $\begin{array}{l}\text { 2.En } \\
\text { desacuerdo }\end{array}$ & & & & & & \\
\hline & 3. De acuerdo & & & & & & \\
\hline & $\begin{array}{l}\text { 4.Totalmente } \\
\text { de acuerdo }\end{array}$ & & & & & & \\
\hline \multirow{3}{*}{$\begin{array}{l}\text { 9. La wiki } \\
\text { genera mayor } \\
\text { participación } \\
\text { en clase de } \\
\text { Biología. }\end{array}$} & $\begin{array}{l}\text { 1.Totalmente } \\
\text { en desacuerdo }\end{array}$ & \multirow{3}{*}{3} & \multirow{3}{*}{3} & \multirow{3}{*}{4} & \multirow{3}{*}{3} & \multirow{3}{*}{0.7} & \multirow{3}{*}{0.8} \\
\hline & $\begin{array}{l}\begin{array}{l}\text { 2.En } \\
\text { desacuerdo }\end{array} \\
\text { 3. De acuerdo }\end{array}$ & & & & & & \\
\hline & $\begin{array}{l}\text { 4.Totalmente } \\
\text { de acuerdo }\end{array}$ & & & & & & \\
\hline \multirow{3}{*}{$\begin{array}{l}\text { 10. Mejor } \\
\text { comprensión de } \\
\text { conceptos } \\
\text { gracias a los } \\
\text { aportes de los } \\
\text { compañeros en } \\
\text { la wiki. }\end{array}$} & $\begin{array}{l}\text { 1.Totalmente } \\
\text { en desacuerdo } \\
2 . \text { En } \\
\text { desacuerdo } \\
\end{array}$ & \multirow[t]{3}{*}{3} & \multirow[t]{3}{*}{4} & \multirow[t]{3}{*}{4} & \multirow[t]{3}{*}{3} & \multirow[t]{3}{*}{0.5} & \multirow[t]{3}{*}{0.7} \\
\hline & 3. De acuerdo & & & & & & \\
\hline & $\begin{array}{l}\text { 4.Totalmente } \\
\text { de acuerdo }\end{array}$ & & & & & & \\
\hline \multirow{4}{*}{$\begin{array}{l}\text { 11. Actividades } \\
\text { en la wiki, } \\
\text { claras e } \\
\text { interesantes. }\end{array}$} & $\begin{array}{l}\text { 1.Totalmente } \\
\text { en desacuerdo }\end{array}$ & \multirow{4}{*}{3} & \multirow{4}{*}{4} & \multirow{4}{*}{4} & \multirow{4}{*}{3} & \multirow{4}{*}{0.8} & \\
\hline & $\begin{array}{l}\text { 2.En } \\
\text { desacuerdo }\end{array}$ & & & & & & 0.9 \\
\hline & 3. De acuerdo & & & & & & \\
\hline & $\begin{array}{l}\text { 4.Totalmente } \\
\text { de acuerdo }\end{array}$ & & & & & & \\
\hline 12. Conflictos & $\begin{array}{l}\text { 1.Totalmente } \\
\text { en desacuerdo }\end{array}$ & & & & & & \\
\hline $\begin{array}{l}\text { del trabajo en } \\
\text { equipo }\end{array}$ & $\begin{array}{l}\text { 2.En } \\
\text { desacuerdo }\end{array}$ & 3 & 3 & 4 & 3 & 0.5 & 0.7 \\
\hline resueltos con & 3. De acuerdo & & & & & & \\
\hline $\begin{array}{l}\text { tolerancia y } \\
\text { respeto. }\end{array}$ & $\begin{array}{l}\text { 4.Totalmente } \\
\text { de acuerdo }\end{array}$ & & & & & & \\
\hline
\end{tabular}


Continuación del Apéndice $N$

\begin{tabular}{|c|c|c|c|c|c|c|c|}
\hline Ítems & $\begin{array}{l}\text { Alternativas } \\
\text { de respuesta }\end{array}$ & Media & Mediana & Moda & Rango & Varianza & $\begin{array}{c}\text { Desviación } \\
\text { estándar }\end{array}$ \\
\hline \multirow{4}{*}{$\begin{array}{l}\text { 13. Generación } \\
\text { de acuerdos } \\
\text { individuales y } \\
\text { grupales al } \\
\text { trabajar en la } \\
\text { wiki. }\end{array}$} & $\begin{array}{l}\text { 1.Totalmente } \\
\text { en desacuerdo }\end{array}$ & \multirow{4}{*}{3} & \multirow{4}{*}{3} & \multirow{4}{*}{3} & \multirow{4}{*}{3} & \multirow{4}{*}{$0 .}$. & \multirow{4}{*}{0.9} \\
\hline & $\begin{array}{l}\text { 2.En } \\
\text { desacuerdo }\end{array}$ & & & & & & \\
\hline & 3. De acuerdo & & & & & & \\
\hline & $\begin{array}{l}\text { 4.Totalmente } \\
\text { de acuerdo }\end{array}$ & & & & & & \\
\hline \multirow{4}{*}{$\begin{array}{l}\text { 14. La wiki } \\
\text { aumento el } \\
\text { interés por } \\
\text { aprender } \\
\text { Biología }\end{array}$} & $\begin{array}{l}\text { 1.Totalmente } \\
\text { en desacuerdo }\end{array}$ & \multirow{4}{*}{3} & \multirow{4}{*}{3} & \multirow{4}{*}{4} & \multirow{4}{*}{3} & \multirow{4}{*}{0.8} & \multirow{4}{*}{0.9} \\
\hline & $\begin{array}{l}\text { 2.En } \\
\text { desacuerdo }\end{array}$ & & & & & & \\
\hline & 3. De acuerdo & & & & & & \\
\hline & $\begin{array}{l}\text { 4. Totalmente } \\
\text { de acuerdo }\end{array}$ & & & & & & \\
\hline \multirow{4}{*}{$\begin{array}{l}\text { 15. La wiki } \\
\text { mejora la } \\
\text { responsabilidad } \\
\text { del trabajo en } \\
\text { equipo }\end{array}$} & $\begin{array}{l}\text { 1.Totalmente } \\
\text { en desacuerdo }\end{array}$ & \multirow{4}{*}{3} & \multirow{4}{*}{3} & \multirow{4}{*}{3} & \multirow{4}{*}{3} & \multirow{4}{*}{1.1} & \multirow{4}{*}{1.0} \\
\hline & $\begin{array}{l}\text { 2.En } \\
\text { desacuerdo }\end{array}$ & & & & & & \\
\hline & 3. De acuerdo & & & & & & \\
\hline & $\begin{array}{l}\text { 4. Totalmente } \\
\text { de acuerdo }\end{array}$ & & & & & & \\
\hline \multirow{4}{*}{$\begin{array}{l}\text { 16. Es aburrido } \\
\text { estudiar } \\
\text { Biología } \\
\text { cuando uso la } \\
\text { wiki. }\end{array}$} & $\begin{array}{l}\text { 1. Totalmente } \\
\text { en desacuerdo }\end{array}$ & \multirow{4}{*}{1.6} & \multirow{4}{*}{1} & \multirow{4}{*}{1} & \multirow{4}{*}{3} & \multirow{4}{*}{0.7} & \multirow{4}{*}{0.8} \\
\hline & $\begin{array}{l}\text { 2.En } \\
\text { desacuerdo }\end{array}$ & & & & & & \\
\hline & 3. De acuerdo & & & & & & \\
\hline & $\begin{array}{l}\text { 4.Totalmente } \\
\text { de acuerdo }\end{array}$ & & & & & & \\
\hline \multirow{4}{*}{$\begin{array}{l}\text { 17. Con la wiki } \\
\text { me preparo } \\
\text { para la prueba } \\
\text { SABER. }\end{array}$} & $\begin{array}{l}\text { 1.Totalmente } \\
\text { en desacuerdo }\end{array}$ & \multirow{4}{*}{2.7} & \multirow{4}{*}{3} & \multirow{4}{*}{3} & \multirow{4}{*}{3} & & \\
\hline & $\begin{array}{l}\text { 2.En } \\
\text { desacuerdo }\end{array}$ & & & & & 0.8 & 0.8 \\
\hline & 3. De acuerdo & & & & & & \\
\hline & $\begin{array}{l}\text { 4.Totalmente } \\
\text { de acuerdo }\end{array}$ & & & & & & \\
\hline & $\begin{array}{l}\text { 1.Totalmente } \\
\text { en desacuerdo }\end{array}$ & & & & & & \\
\hline $\begin{array}{l}\text { 18. La wiki } \\
\text { debe utilizarse }\end{array}$ & $\begin{array}{l}\text { 2.En } \\
\text { desacuerdo }\end{array}$ & 3 & 3 & 4 & 3 & 1 & 1 \\
\hline en otras & 3. De acuerdo & & & & & & \\
\hline & $\begin{array}{l}\text { 4.Totalmente } \\
\text { de acuerdo }\end{array}$ & & & & & & \\
\hline
\end{tabular}


Continuación del Apéndice $N$

\begin{tabular}{|c|c|c|c|c|c|c|c|}
\hline Ítems & $\begin{array}{l}\text { Alternativas } \\
\text { de respuesta }\end{array}$ & Media & Mediana & Moda & Rango & Varianza & $\begin{array}{c}\text { Desviación } \\
\text { estándar }\end{array}$ \\
\hline \multirow{4}{*}{$\begin{array}{l}\text { 19. Con la wiki } \\
\text { se hacen } \\
\text { aportes } \\
\text { importantes } \\
\text { paran las } \\
\text { actividades }\end{array}$} & $\begin{array}{l}\text { 1.Totalmente } \\
\text { en desacuerdo }\end{array}$ & \multirow{4}{*}{3} & \multirow{4}{*}{3} & \multirow{4}{*}{3} & \multirow{4}{*}{2} & \multirow{4}{*}{0.4} & \multirow{4}{*}{0.6} \\
\hline & $\begin{array}{l}\text { 2.En } \\
\text { desacuerdo }\end{array}$ & & & & & & \\
\hline & 3. De acuerdo & & & & & & \\
\hline & $\begin{array}{l}\text { 4. Totalmente } \\
\text { de acuerdo }\end{array}$ & & & & & & \\
\hline \multirow{4}{*}{$\begin{array}{l}20 . \text { Las } \\
\text { actividades en } \\
\text { la wiki se } \\
\text { evalúan } \\
\text { adecuadamente }\end{array}$} & $\begin{array}{l}\text { 1.Totalmente } \\
\text { en desacuerdo }\end{array}$ & \multirow{4}{*}{3} & \multirow{4}{*}{3} & \multirow{4}{*}{3} & \multirow{4}{*}{2} & \multirow{4}{*}{0,3} & \multirow{4}{*}{0,6} \\
\hline & $\begin{array}{l}\text { 2.En } \\
\text { desacuerdo }\end{array}$ & & & & & & \\
\hline & 3. De acuerdo & & & & & & \\
\hline & $\begin{array}{l}\text { 4.Totalmente } \\
\text { de acuerdo }\end{array}$ & & & & & & \\
\hline \multirow{4}{*}{$\begin{array}{l}\text { 21. Se cumple } \\
\text { en tiempo y } \\
\text { forma con los } \\
\text { aportes. }\end{array}$} & $\begin{array}{l}\text { 1.Totalmente } \\
\text { en desacuerdo }\end{array}$ & \multirow{4}{*}{2,6} & \multirow{4}{*}{3} & \multirow{4}{*}{2} & \multirow{4}{*}{3} & \multirow{4}{*}{0,9} & \multirow{4}{*}{0,9} \\
\hline & $\begin{array}{l}\text { 2.En } \\
\text { desacuerdo }\end{array}$ & & & & & & \\
\hline & 3. De acuerdo & & & & & & \\
\hline & $\begin{array}{l}\text { 4.Totalmente } \\
\text { de acuerdo }\end{array}$ & & & & & & \\
\hline \multirow{4}{*}{$\begin{array}{l}\text { 22. Las clases } \\
\text { presenciales de } \\
\text { Biología se } \\
\text { refuerzan y } \\
\text { complementan } \\
\text { con la wiki. }\end{array}$} & $\begin{array}{l}\text { 1.Totalmente } \\
\text { en desacuerdo }\end{array}$ & \multirow{4}{*}{3} & \multirow{4}{*}{3} & \multirow{4}{*}{3} & \multirow{4}{*}{3} & \multirow{4}{*}{0.7} & \multirow{4}{*}{0.8} \\
\hline & $\begin{array}{l}\text { 2.En } \\
\text { desacuerdo }\end{array}$ & & & & & & \\
\hline & 3. De acuerdo & & & & & & \\
\hline & $\begin{array}{l}\text { 4.Totalmente } \\
\text { de acuerdo }\end{array}$ & & & & & & \\
\hline \multirow{4}{*}{$\begin{array}{l}\text { 23. Cada } \\
\text { integrante de } \\
\text { mi equipo } \\
\text { asume su rol. }\end{array}$} & $\begin{array}{l}\text { 1.Totalmente } \\
\text { en desacuerdo }\end{array}$ & \multirow{4}{*}{2.8} & \multirow{4}{*}{3} & \multirow{4}{*}{4} & \multirow{4}{*}{3} & & \\
\hline & $\begin{array}{l}\text { 2.En } \\
\text { desacuerdo }\end{array}$ & & & & & 1.1 & 1 \\
\hline & 3. De acuerdo & & & & & & \\
\hline & $\begin{array}{l}\text { 4.Totalmente } \\
\text { de acuerdo }\end{array}$ & & & & & & \\
\hline & $\begin{array}{l}\text { 1.Totalmente } \\
\text { en desacuerdo }\end{array}$ & & & & & & \\
\hline $\begin{array}{l}\text { 24. La wiki } \\
\text { facilita el }\end{array}$ & $\begin{array}{l}\text { 2.En } \\
\text { desacuerdo }\end{array}$ & 3 & 3 & 4 & 3 & 0.7 & 0.8 \\
\hline trabajo en & 3. De acuerdo & & & & & & \\
\hline equipo. & $\begin{array}{l}\text { 4.Totalmente } \\
\text { de acuerdo }\end{array}$ & & & & & & \\
\hline
\end{tabular}


Continuación del Apéndice $N$

\begin{tabular}{|c|c|c|c|c|c|c|c|}
\hline Ítems & $\begin{array}{l}\text { Alternativas } \\
\text { de respuesta }\end{array}$ & Media & Mediana & Moda & Rango & Varianza & $\begin{array}{c}\text { Desviación } \\
\text { estándar }\end{array}$ \\
\hline \multirow{4}{*}{$\begin{array}{l}\text { 25. Recursos e } \\
\text { infraestructura } \\
\text { escolar para } \\
\text { usar la wiki. }\end{array}$} & $\begin{array}{l}\text { 1.Totalmente } \\
\text { en desacuerdo }\end{array}$ & \multirow{4}{*}{2} & \multirow{4}{*}{2} & \multirow{4}{*}{2} & \multirow{4}{*}{3} & \multirow{4}{*}{0.6} & \multirow{4}{*}{0.8} \\
\hline & $\begin{array}{l}\text { 2.En } \\
\text { desacuerdo }\end{array}$ & & & & & & \\
\hline & 3. De acuerdo & & & & & & \\
\hline & $\begin{array}{l}\text { 4.Totalmente } \\
\text { de acuerdo }\end{array}$ & & & & & & \\
\hline
\end{tabular}

Como se observó en los resultados anteriores, de las 25 preguntas realizadas a los estudiantes, 21 preguntas presentaron una media de 3 lo que demostró en forma general, que, existió una actitud positiva y favorable por parte de los estudiantes del grupo experimental hacia el uso e incorporación de la wiki. Esta situación fue similar para la moda y la mediana. Sumado a esto, las puntuaciones tuvieron desviaciones relativamente pequeñas respecto a la media, lo que indicó que no hubo una notable dispersión de los datos, lo que reafirmó el buen resultado antes expresado. 


\section{Apéndice O: Datos aclaratorios de los resultados de la preprueba}

Tabla

Distribución de frecuencias de los puntajes de la preprueba en grupo experimental (8-1)

\begin{tabular}{ccccc}
\hline Puntaje obtenido & frecuencia & $\begin{array}{c}\text { frecuencia } \\
\text { acumulada }\end{array}$ & \% de frecuencias & $\begin{array}{c}\text { \% de frecuencias } \\
\text { acumuladas }\end{array}$ \\
\hline 4 & 2 & 2 & $4.9 \%$ & $4.9 \%$ \\
6 & 6 & 8 & $14.6 \%$ & $19.5 \%$ \\
8 & 10 & 18 & $24.40 \%$ & $43.9 \%$ \\
10 & 5 & 23 & $12.20 \%$ & $56.1 \%$ \\
12 & 11 & 34 & $26.82 \%$ & $82.92 \%$ \\
14 & 5 & 39 & $12.20 \%$ & $95.12 \%$ \\
20 & 1 & 40 & $2.44 \%$ & $97.56 \%$ \\
\hline
\end{tabular}

Tabla

Distribución de frecuencias de los puntajes de la preprueba en el grupo de control (8-2)

\begin{tabular}{ccccc}
\hline Puntaje obtenido & frecuencia & $\begin{array}{c}\text { frecuencia } \\
\text { acumulada }\end{array}$ & \% de frecuencias & $\begin{array}{c}\text { \% de frecuencias } \\
\text { acumuladas }\end{array}$ \\
\hline 4 & 8 & 8 & $21.1 \%$ & $21.1 \%$ \\
6 & 6 & 14 & $15.8 \%$ & $36.9 \%$ \\
8 & 3 & 17 & $7.9 \%$ & $44.8 \%$ \\
10 & 6 & 23 & $15.8 \%$ & $60.6 \%$ \\
12 & 7 & 30 & $18.4 \%$ & $79.0 \%$ \\
14 & 4 & 34 & $10.5 \%$ & $89.5 \%$ \\
18 & 2 & 36 & $5.3 \%$ & $94.8 \%$ \\
20 & 1 & 37 & $2.6 \%$ & $97.4 \%$ \\
& 1 & 38 & $2.6 \%$ & $100 \%$ \\
\hline
\end{tabular}




\section{Apéndice P: Datos aclaratorios de los resultados de la posprueba}

Tabla

Distribución de frecuencias de los puntajes de la posprueba en el grupo experimental (8-1)

\begin{tabular}{ccccc}
\hline Puntaje obtenido & $\begin{array}{c}\text { frecuencias } \\
\text { absolutas }\end{array}$ & $\begin{array}{c}\text { frecuencia } \\
\text { acumulada }\end{array}$ & \% de frecuencias & $\begin{array}{c}\text { \% de frecuencias } \\
\text { acumuladas }\end{array}$ \\
\hline 8 & 5 & 5 & $12.2 \%$ & $12.2 \%$ \\
10 & 6 & 11 & $14.6 \%$ & $26.8 \%$ \\
12 & 6 & 17 & $14.6 \%$ & $41.4 \%$ \\
14 & 5 & 22 & $12.2 \%$ & $53.6 \%$ \\
16 & 1 & 23 & $2.45 \%$ & $56.05 \%$ \\
18 & 8 & 31 & $19.5 \%$ & $75.55 \%$ \\
20 & 5 & 36 & $12.2 \%$ & $87.75 \%$ \\
22 & 2 & 38 & $4.9 \%$ & $92.65 \%$ \\
24 & 1 & 39 & $2.45 \%$ & $95.1 \%$ \\
26 & 1 & 40 & $2.45 \%$ & $97.55 \%$ \\
28 & 1 & 41 & $2.45 \%$ & $100 \%$ \\
\hline
\end{tabular}

Tabla

Distribución de frecuencias de los puntajes de la posprueba en el grupo de control (8-2)

\begin{tabular}{ccccc}
\hline Puntaje obtenido & frecuencia & $\begin{array}{c}\text { frecuencia } \\
\text { acumulada }\end{array}$ & \% de frecuencias & $\begin{array}{c}\text { \% de frecuencias } \\
\text { acumuladas }\end{array}$ \\
\hline 6 & 3 & 3 & $7.9 \%$ & $7.9 \%$ \\
8 & 5 & 8 & $13.15 \%$ & $21.05 \%$ \\
10 & 10 & 18 & $26.3 \%$ & $47.35 \%$ \\
12 & 5 & 23 & $13.15 \%$ & $60.05 \%$ \\
14 & 2 & 25 & $5.3 \%$ & $65.8 \%$ \\
16 & 5 & 30 & $13.1 \%$ & $78.9 \%$ \\
18 & 2 & 32 & $5.3 \%$ & $84.2 \%$ \\
20 & 4 & 36 & $10.5 \%$ & $94.7 \%$ \\
22 & 2 & 38 & $5.3 \%$ & $100 \%$ \\
\hline
\end{tabular}

Tabla

Resultados comparativos de las pruebas escritas en el grupo experimental y de control

\begin{tabular}{lcccc}
\hline Medidas estadísticas & \multicolumn{2}{c}{$\begin{array}{c}\text { Grupo experimental } \\
\text { (41 estudiantes) }\end{array}$} & \multicolumn{2}{c}{$\begin{array}{c}\text { Grupo de control } \\
\text { (38 estudiantes) }\end{array}$} \\
\hline & Preprueba & Posprueba & Preprueba & Posprueba \\
Media & 9.951 & 15.561 & 9.526 & 12.789 \\
Desviación Estándar & 3.507 & 5.450 & 4.397 & 4.709 \\
Calificación Mínima & 4 & 8 & 4 & 6 \\
Calificación Máxima & 20 & 28 & 20 & 22 \\
Rango & 16 & 20 & 16 & 16 \\
Mediana & 10 & 14 & 10 & 12 \\
Moda & 8 & 18 & 4 & 10 \\
Varianza & 12.298 & 29.702 & 19.337 & 22.170 \\
Asimetría & 0.65 & 0.30 & 0.38 & 0.49 \\
\hline
\end{tabular}




\section{Apéndice Q: Datos aclaratorios de los resultados de la prueba $t$}

Las diferencias del rendimiento académico del GE, antes de la intervención con la wiki (preprueba) y después de su intervención (posprueba) derivaron de la prueba $t$, que permitió evaluar y comparar este desempeño a partir de las medias respectivas. Por lo tanto, para probar la hipótesis fue necesario hallar los grados de libertad, mediante la fórmula: $g l=n l+n l-2$ y determinar si el valor de $t$ era significativo, es decir, hallar los valores críticos de $t$ (tabla de distritución $t$ de student, según Hernández et al. 2010) en un nivel de significancia de 0.05. Este valor fue asumido con el fin de tener el mínimo error y un valor significativo de los resultados, por cuanto indica que existe una probabilidad del $95 \%$ de que los promedios de las dos pruebas difieran entre sí (debido al tratamiento) y un 5\% de posibilidad de error, o de que la diferencia de promedios no sea significativa o importante (Hernández et al. 2010). Consecuentemente, para el cálculo del valor de $t$ se obtuvieron los siguientes resultados:

Tabla

Resultados de la prueba t aplicada al grupo experimental antes y después del apoyo tecnológico

\begin{tabular}{lcc}
\hline & $\begin{array}{c}\text { Grupo experimental } \\
\text { Posprueba }\end{array}$ & $\begin{array}{c}\text { Grupo experimental } \\
\text { Preprueba }\end{array}$ \\
\hline Media & 15.56151221 & 9.95175609 \\
Varianza & 29.70260976 & 12.2982439 \\
Observaciones & 41 & 41 \\
Diferencia hipotética de las medias & 0 & \\
Grados de libertad & 70 & \\
Estadístico $t$ & 5.162027284 & \\
$\mathrm{P}(\mathrm{T}<=\mathrm{t})$ una cola & $1.09359 \mathrm{E}-06$ & \\
Valor crítico de $t$ (una cola) & 1.666914479 & \\
$\mathrm{P}(\mathrm{T}<=\mathrm{t})$ dos colas & $2.18718 \mathrm{E}-06$ & \\
Valor crítico de $t$ (dos colas) & 1.994437112 & \\
\hline
\end{tabular}


De acuerdo con lo anteriormente presentado, el valor calculado de $t$ fue 5.162027284 y resultó superior al valor crítico en un nivel de confianza de 0.05 $(5.162027284>1.994437112)$ por lo tanto, la hipótesis de investigación (Hi), relativa a que el uso e incorporación de una wiki facilita el aprendizaje de la Biología, en los alumnos de octavo grado fue aceptada y por tal razón se rechaza la hipótesis nula (Ho). Esto significa que a los estudiantes que utilizaron la wiki, se les facilitó el aprendizaje de la Biología. 


\section{Apéndice R: Evidencias de los contenidos en la wiki}

\section{Página de Bienvenida:}

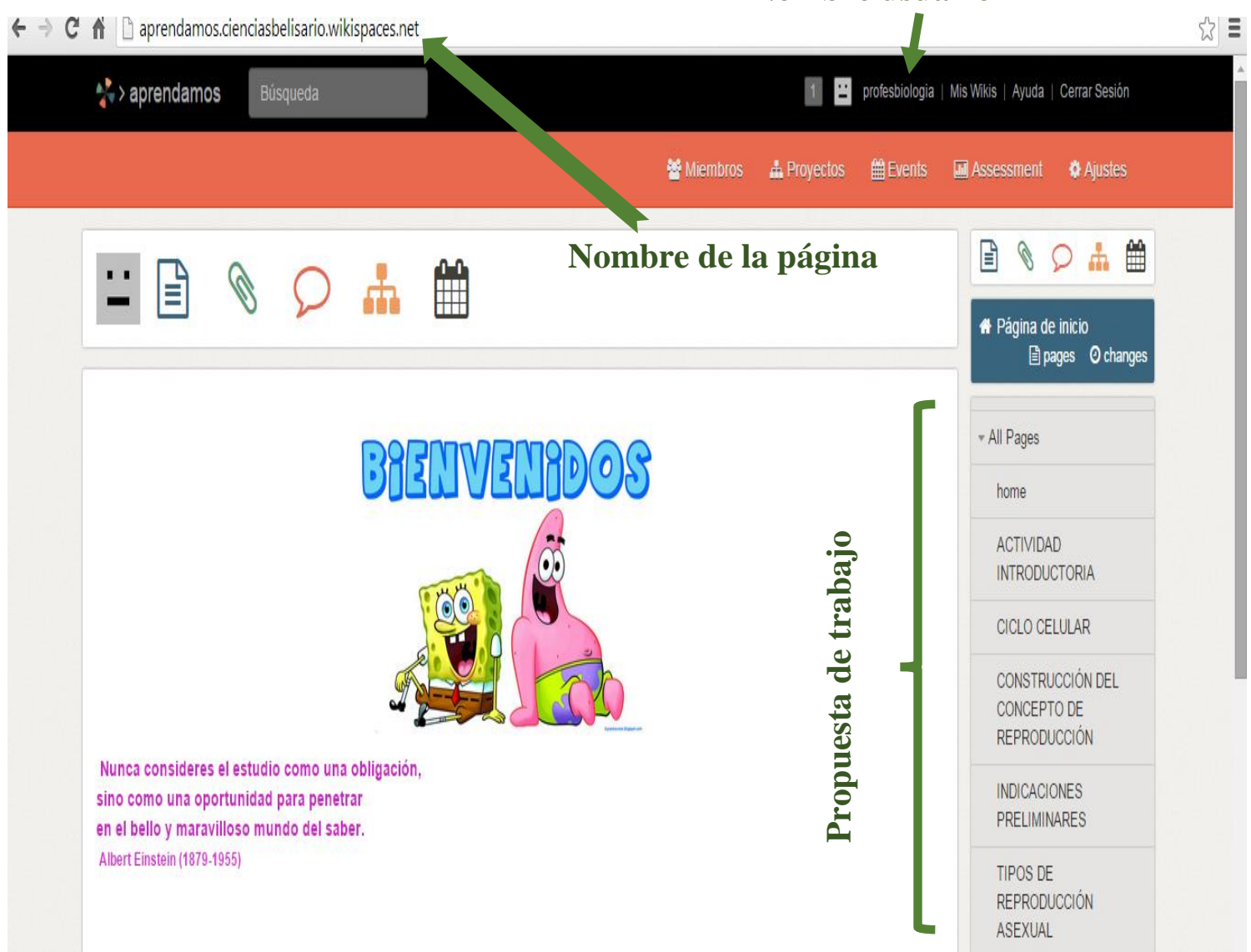

\section{ESTE ES TU SALÓN O AULA VIRTUAL}

Aquí compartirás una experiencia de enseñanza - aprendizaje a través de este apoyo tecnológico conocido con el nombre de WIKI.

Asistan a sus clases con una mente abierta y positiva, esto les ayudará a motivarse para trabajar de forma comprometida por su mejoramiento personal, les permitirá aprovechar cada actividad propuesta, investigar, participar y sobre todo construir y compartir conocimientos de forma cooperativa con sus compañeros, con el respeto y responsabilidad característicos de personas que se educan.

Es fácil y agradable. Para ingresar a cada actividad deben observar el menú que esta a su derecha dar clic en All Pages, luego pulsar en el proyecto, página o tema que deseen consultar, alli encontrarán las indicaciones de cada una de las luego pulsar en el proyecto, pagir

actividades de forna general.

Tambien es impotante que recuerden que cada uno de ustedes tendrá un equipo de trabajo que ha sido escogido de forma aleatoria, de esta manera cada grupo tendrá un espacio especifico en el cual deberán desarrollar las actividades propuestas en las diferentes sesiones de clase. 


\section{Página de indicaciones para la realización de actividades cooperativas:}

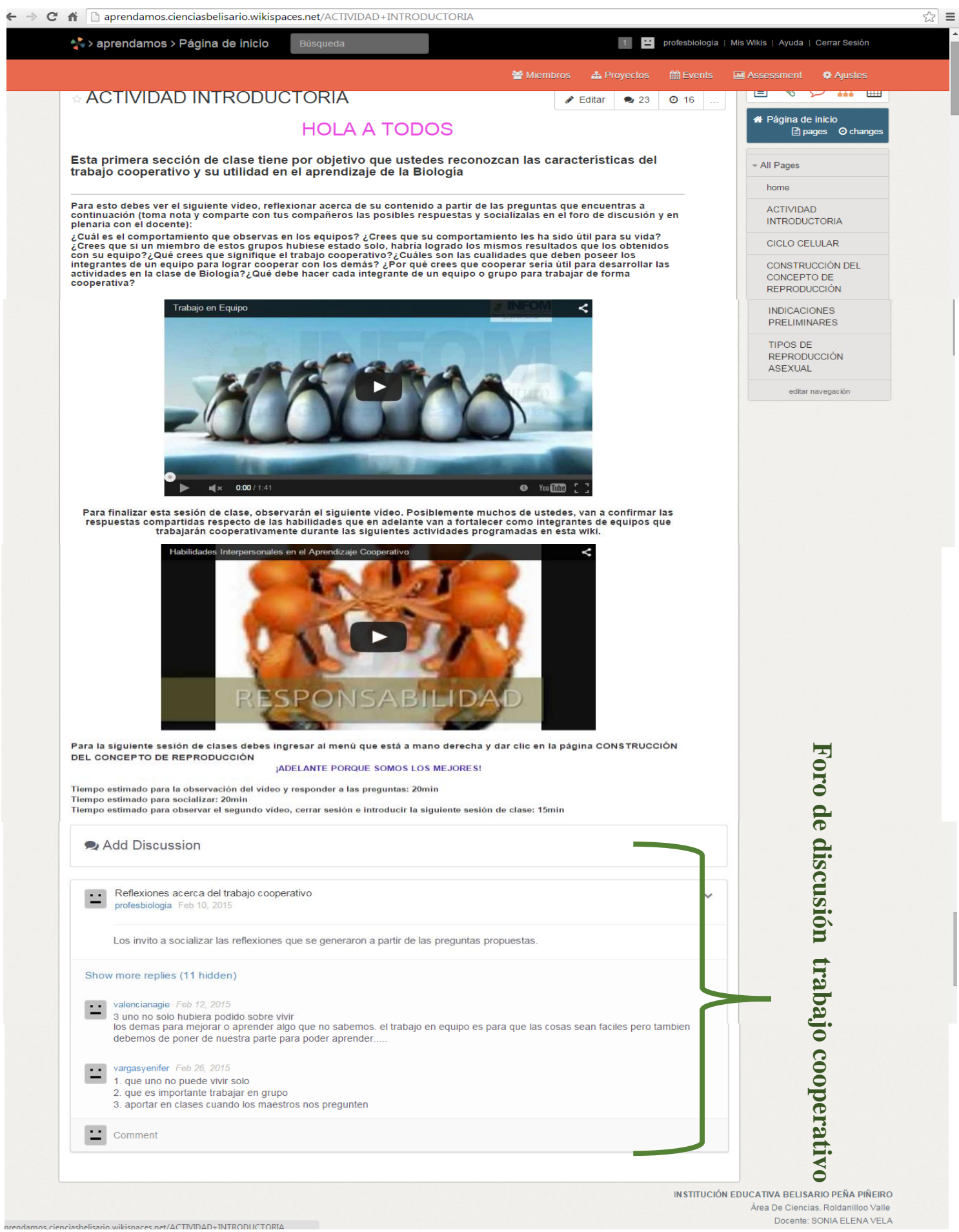




\section{Trabajo desarrollado por los estudiantes en la wiki:}

Los diferentes colores de letra indican las aportaciones de cada integrante, Al final de la página se encuentra un aporte en letra negra, este indica el consenso grupal.

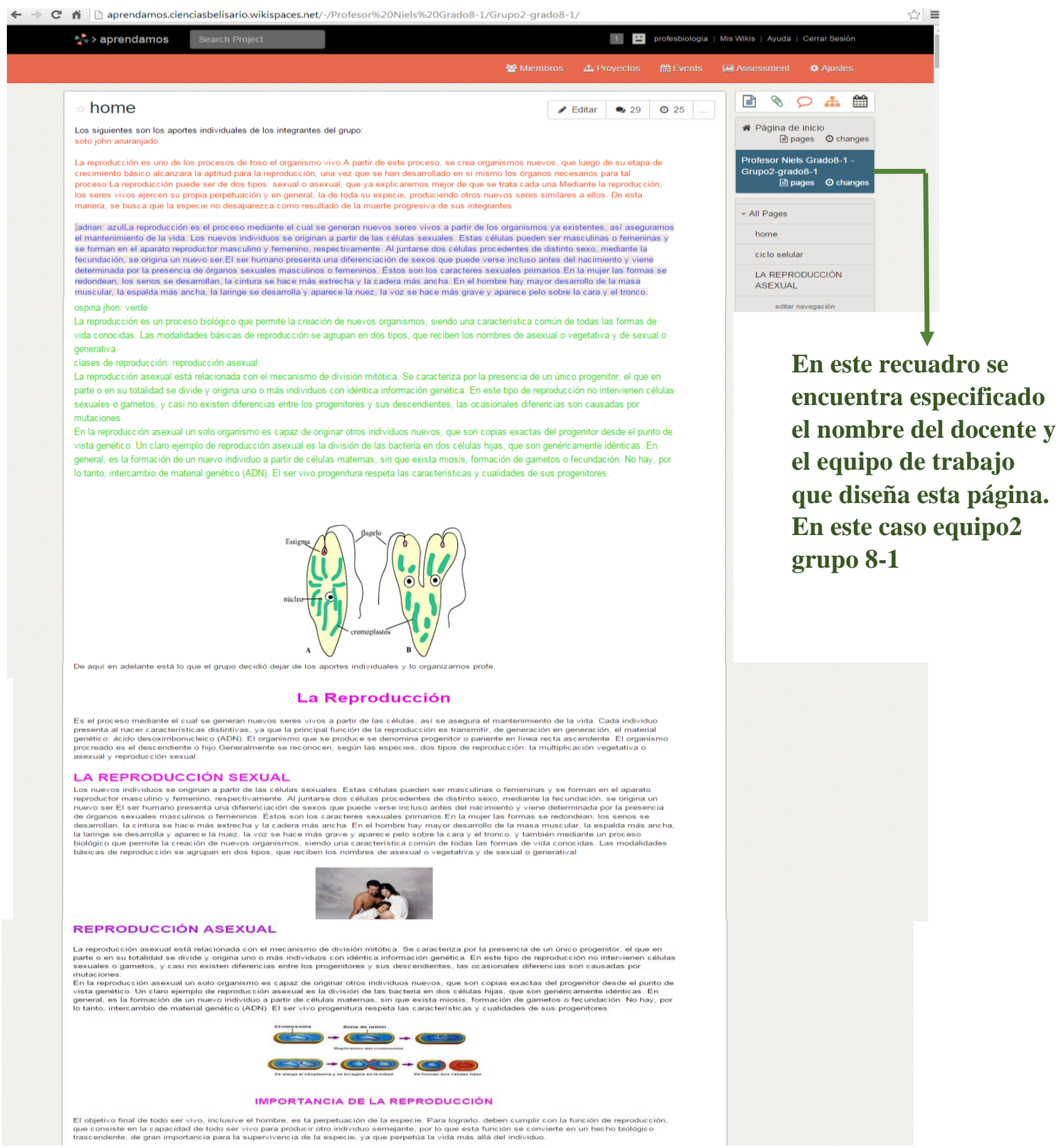




\section{Aportaciones de un equipo en su foro de discusión:}

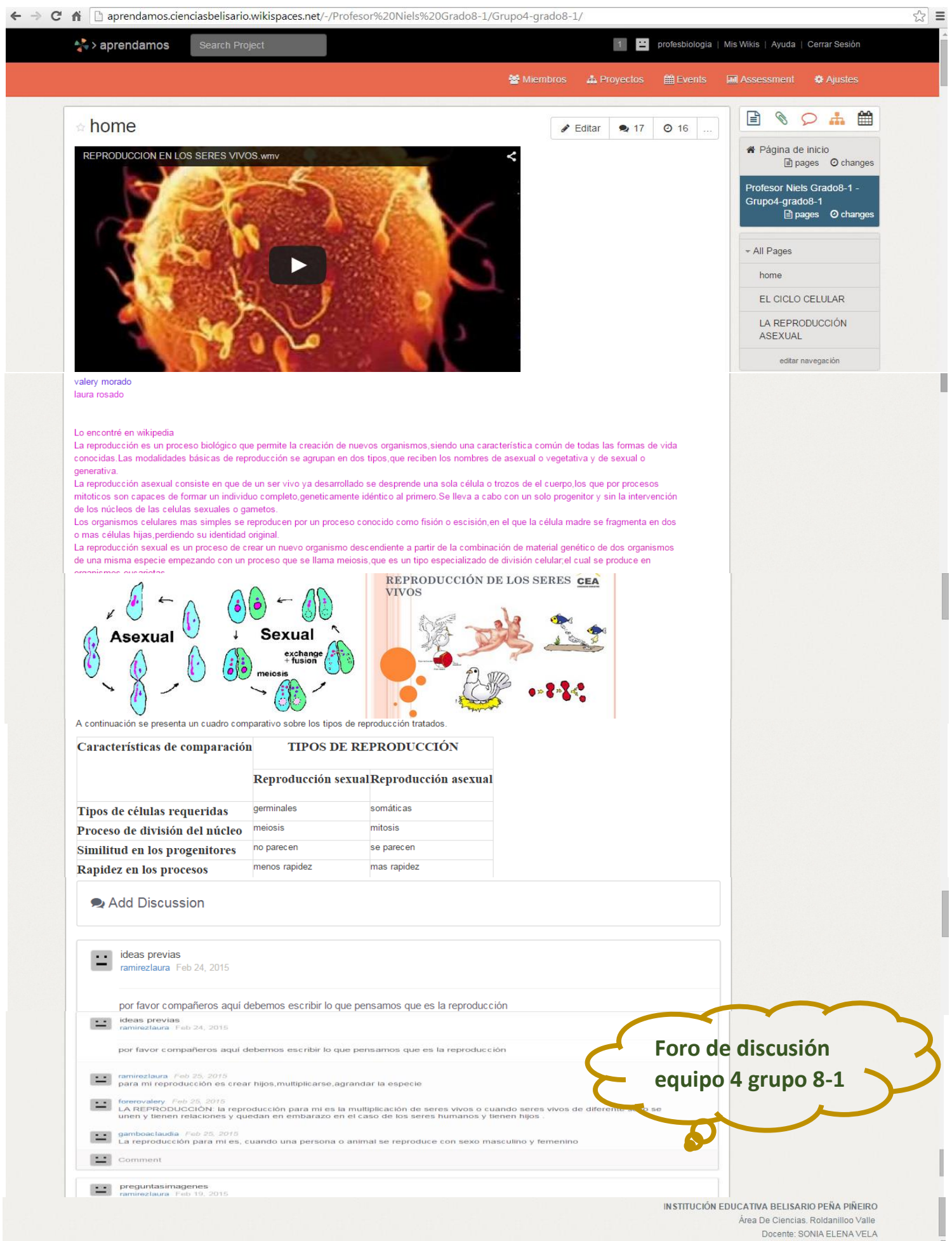




\section{Currículum vitae}

\section{Ing. Sonia Elena Vela Vargas \\ soelvela@gmail.com}

Originaria del Municipio de Roldanillo, en el Departamento del Valle del Cauca, Colombia, Sonia Elena Vela realizó estudios profesionales en Ingeniería, obteniendo el título de Ingeniera Química por la Universidad del Valle de la Ciudad de Cali. La investigación intitulada: Impacto del uso e incorporación de una wiki en el aprendizaje de la Biología, es la que presenta en este documento para aspirar al grado de Maestría en Tecnología Educativa, por parte del Tecnológico de Monterrey.

Su experiencia de trabajo ha girado alrededor del campo de la docencia a nivel de secundaria, específicamente en el área de ciencias naturales, desde hace 10 años. Asimismo, se ha desempeñado como coordinadora del programa de Ingeniería Industrial en una sede de la Universidad Antonio Nariño ubicada en Roldanillo, también como investigadora en Sucromiles S.A., empresa productora de químicos ubicada en Palmira, Valle del Cauca.

Actualmente funge como docente de ciencias naturales en la Institución Educativa Belisario Peña Piñeiro. Ha impartido las cátedras de: Biología, Química y Física, brinda asesoría a estudiantes en general. Tiene una especialización en Administración de Empresas y un diplomado en el programa de Formación pedagógica para la cualificación docente. Ha demostrado interés por actualizar y adquirir mayores conocimientos respecto a la integración de las tecnologías en la práctica pedagógica. En un futuro desea participar en programas de formación doctoral en la enseñanza de las ciencias naturales. 